\section{Pacific Northwest}

National Laboratory

Operated by Battelle for the

U.S. Department of Energy

\title{
Results of Large Scale Testing on Effects of Anti-Foam Agent on Gas Retention and Release
}

C. W. Stewart
C. E. Guzman-Leong
S. T. Arm
M. G. Butcher
E. C. Golovich
L. K. Jagoda
W. R. Park
R. W. Slaugh
Y-F. Su
C. Wend

\author{
L. A. Mahoney \\ J. M. Alzheimer \\ J. A. Bailey \\ S. K. Cooley \\ D. E. Hurley \\ C. D. Johnson \\ L. D. Reid \\ H. D. Smith \\ B. E. Wells \\ S. T. Yokuda
}

December 2007

Prepared for the U.S. Department of Energy under Contract DE-AC05-76RL01830 


\title{
DISCLAIMER
}

This report was prepared as an account of work sponsored by an agency of the United States Government. Neither the United States Government nor any agency thereof, nor Battelle Memorial Institute, nor any of their employees, makes any warranty, express or implied, or assumes any legal liability or responsibility for the accuracy, completeness, or usefulness of any information, apparatus, product, or process disclosed, or represents that its use would not infringe privately owned rights. Reference herein to any specific commercial product, process, or service by trade name, trademark, manufacturer, or otherwise does not necessarily constitute or imply its endorsement, recommendation, or favoring by the United states Government or any agency thereof, or Battelle Memorial Institute. The views and opinions of authors expressed herein do not necessarily state or reflect those of the United States Government or any agency thereof.

\author{
PACIFIC NORTHWEST NATIONAL LABORATORY \\ operated by \\ BATTELLE \\ for the \\ UNITED STATES DEPARTMENT OF ENERGY \\ under Contract DE-AC05-76RL01830
}

Printed in the United States of America

\author{
Available to DOE and DOE contractors from the \\ Office of Scientific and Technical Information, \\ P.O. Box 62, Oak Ridge, TN 37831-0062; \\ ph: (865) 576-8401 \\ fax: (865) 576-5728 \\ email: reports@adonis.osti.gov
}

Available to the public from the National Technical Information Service, U.S. Department of Commerce, 5285 Port Royal Rd., Springfield, VA 22161

ph: (800) 553-6847

fax: (703) 605-6900

email: orders@ntis.fedworld.gov

online ordering: http://www.ntis.gov/ordering.htm

This document was printed on recycled paper. 
PNNL-17170

WTP-RPT-156 Rev. 0

\section{Results of Large-Scale Testing on Effects of Anti-Foam Agent on Gas Retention and Release}

\author{
C. W. Stewart \\ C. E. Guzman-Leong \\ S. T. Arm \\ M. G. Butcher \\ E. C. Golovich \\ L. K. Jagoda \\ W. R. Park \\ R. W. Slaugh \\ $\mathrm{Y}-\mathrm{F} \mathrm{Su}$ \\ C. Wend \\ December 2007
}

Test Specification

Test Plan

Test Exceptions

R\&T Focus Area

Test Scoping Statement
L. A. Mahoney
J. M. Alzheimer
J. A. Bailey
S. K. Cooley
D. E. Hurley
C. D. Johnson
L. D. Reid
H. D. Smith
B.E. Wells
S.T. Yokuda

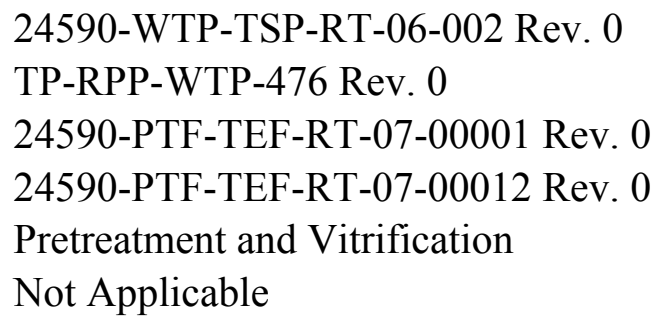

Not Applicable

Prepared for

the U.S. Department of Energy

under Contract DE-AC05-76RL01830

Pacific Northwest National Laboratory

Richland, Washington 99352 


\section{Completeness of Testing}

This report describes the results of work and testing specified by Test Specification 24590-WTP-TSP-RT-06-0002, Rev. 0 and Test Plan TP-RPP-WTP-476, Rev. 0. The work and any associated testing followed the quality assurance requirements outlined in the Test Specification/Plan. The descriptions provided in this test report are an accurate account of both the conduct of the work and the data collected. Test plan results are reported. Also reported are any unusual or anomalous occurrences that are different from expected results. The test results and this report have been reviewed and verified.

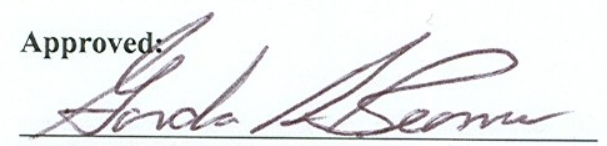

Gordon H. Beeman, Manager RPP-WTP Support Project

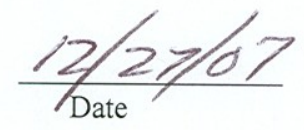




\section{Testing Summary}

The U.S. Department of Energy (DOE) Office of River Protection's Waste Treatment and Immobilization Plant (WTP) will process and treat radioactive waste stored in tanks at the Hanford Site. The waste treatment process in the pretreatment facility will mix both Newtonian and non-Newtonian slurries in large process tanks. Process vessels mixing non-Newtonian slurries will use pulse jet mixers (PJMs), air sparging, and recirculation pumps. An anti-foam agent (AFA) will be added to the process streams to prevent surface foaming but may also increase gas holdup and retention within the slurry.

Some gas retention tests that were carried out in nonprototypic systems-bubble columns and impeller-mixed vessels - indicated trends that posed process and flammable-gas concerns (Russell et al. 2005, Stewart et al. 2006). Both types of nonprototypic results indicated that the presence of AFA in a chemical simulant of Hanford Tank 241-AZ-101 high-level waste (HLW) might increase gas retention by a factor of 10 or more over that in clay without AFA, the simulant on which WTP design studies were based (see Section 1.2). In addition, the increase over clay holdup was greater at lower simulant yield stress, implying that the 30-Pa simulant results, which had been used for WTP design, might not bound gas retention.

The work described in this report addresses gas retention and release in simulants with AFA through prototypic testing and analytical studies. This test program was established to determine whether the AFA has as strong an effect in a large-scale prototypic mixing system as it did in the small-scale nonprototypic tests. Gas holdup and release tests were conducted in a 1/4-scale replica of the lag storage vessel operated in the Pacific Northwest National Laboratory (PNNL) Applied Process Engineering Laboratory using a kaolin/bentonite clay and an AZ-101 chemical simulant with non-Newtonian rheological properties representative of actual waste slurries. Additional tests were performed in a smallscale mixing vessel in the PNNL Physical Sciences Building using liquids and slurries representing major components of typical WTP waste streams to address the fact that simulants delivered to the WTP will come from other tanks in addition to 241-AZ-101. Analytical studies were directed at discovering how the effect of AFA might depend on gas composition, and a model was developed for predicting the effect of AFA on gas retention and release in the WTP, including the effects of mass transfer to the sparge air.

The prototypic gas retention and release tests performed in this test program indicate that gas holdup with AZ-101 simulant with AFA is higher than it is in clay, but not to the extent that initially raised WTP design concerns. In addition, the trend to a higher increase in holdup with decreasing simulant yield stress was not seen in the prototypic system.

The work at PNNL was part of a larger program that included tests conducted at Savannah River National Laboratory (SRNL) that is being reported separately. SRNL conducted gas holdup tests in a small-scale mixing vessel using the AZ-101 high-level waste (HLW) chemical simulant to investigate the effects of different AFAs, their components, and of adding noble metals. Full-scale, single-sparger mass transfer tests were also conducted at SRNL in water and AZ-101 HLW simulant to provide data for PNNL's WTP gas retention and release modeling. PNNL objectives for this project are summarized in Table S.1, and test results and recommendations are summarized in the following paragraphs. 


\section{Objectives}

Table S.1 summarizes the objectives and results of this testing.

Table S.1. Summary of Test Objectives and Results

\begin{tabular}{|c|c|c|}
\hline Test Objective & \begin{tabular}{|c|} 
Objective \\
Met?
\end{tabular} & Discussion \\
\hline \begin{tabular}{|l} 
Evaluate the theoretical \\
basis for the potential effect \\
of gas composition on gas \\
retention on Hanford waste \\
materials
\end{tabular} & Yes & $\begin{array}{l}\text { As discussed in Section } 4 \text { of this report, a literature investigation was con- } \\
\text { ducted on the effect of gas physical properties on the following processes: } \\
\text { - Bubble formation from single and multiple orifices } \\
\text { - Bubble breakup } \\
\text { - Bubble coalescence. } \\
\text { Overall, the literature indicates that the gas density (which is proportional to } \\
\text { molecular weight) may have a weak effect on these processes. At the same } \\
\text { time, retained gas bubble composition may not differ significantly from air } \\
\text { as a result of air sparging, so there is little opportunity for gas composition to } \\
\text { affect bubble holdup or release. However, gas density is the primary } \\
\text { property affecting bubble size and behavior. In general, higher gas densities } \\
\text { produce smaller bubbles, and smaller bubbles are attributed to higher gas } \\
\text { retention, hence, a high density gas would increase gas retention and release. }\end{array}$ \\
\hline \begin{tabular}{|l} 
Determine the relationship \\
between gas volume \\
fraction and superficial \\
velocity with a $1 / 4$-scale \\
PJM-sparger mixing system \\
in water, clay, and waste \\
simulants with and without \\
AFA over a range of yield \\
stresses.
\end{tabular} & Yes & $\begin{array}{l}\text { The results of 1/4-scale lag storage (QSLS) testing are presented in } \\
\text { Section 5.4. Gas retention and release tests were conducted in water with } \\
\text { and without AFA, clay without AFA, and AZ-101 HLW simulant with AFA. } \\
\text { Tests used clay and AZ-101 simulants at yield stresses of } 3,13 \text {, and } 30 \mathrm{~Pa} \\
\text { over a range of superficial velocities of gas generation of } 0.025 \text { to } 0.1 \mathrm{~mm} / \mathrm{s} \text {. } \\
\text { The steady-state retained gas volume fraction in clay was similar to that of } \\
\text { previous } 1 / 4-\text { and } 1 / 2 \text {-scale lag storage (HSLS) tests in clay. The data } \\
\text { showed that the combination of AFA and AZ-101 chemical simulant does } \\
\text { not increase gas retention in a prototypic mixing system over clay simulant } \\
\text { as much as had been implied by previous studies conducted in a small-scale } \\
\text { impeller-mixed vessel. In addition, the increase in gas holdup for AZ-101 } \\
\text { simulant with AFA (compared with clay) was greater for } 30 \text {-Pa simulant } \\
\text { than for 13-Pa simulant, removing concerns that the relative holdup would } \\
\text { show an increase with decreasing yield stress. Gas retention due to in situ } \\
\text { generation was higher at 30-Pa yield stress than at } 13 \text { or } 3 \text { Pa, though sparger } \\
\text { holdup was higher at } 3 \text { Pa. } \\
\text { (Per Test Exception } 24590 \text {-PTF-TEF-RT-07-00001 Rev. 0, tests were not } \\
\text { performed in waste simulants without AFA or an alternative AFA, nor were } \\
\text { post-design-basis event (DBE) operations demonstrated.) }\end{array}$ \\
\hline \begin{tabular}{|l|} 
Evaluate and test the gas \\
retention and release \\
characteristics of waste \\
simulants made by modi- \\
fying the baseline AZ-101 \\
recipe; perform tests using \\
these materials with and \\
without AFA to determine \\
how compositional \\
variations of the waste \\
interact with AFA and alter \\
the gas retention/release \\
behavior of the system.
\end{tabular} & Yes & 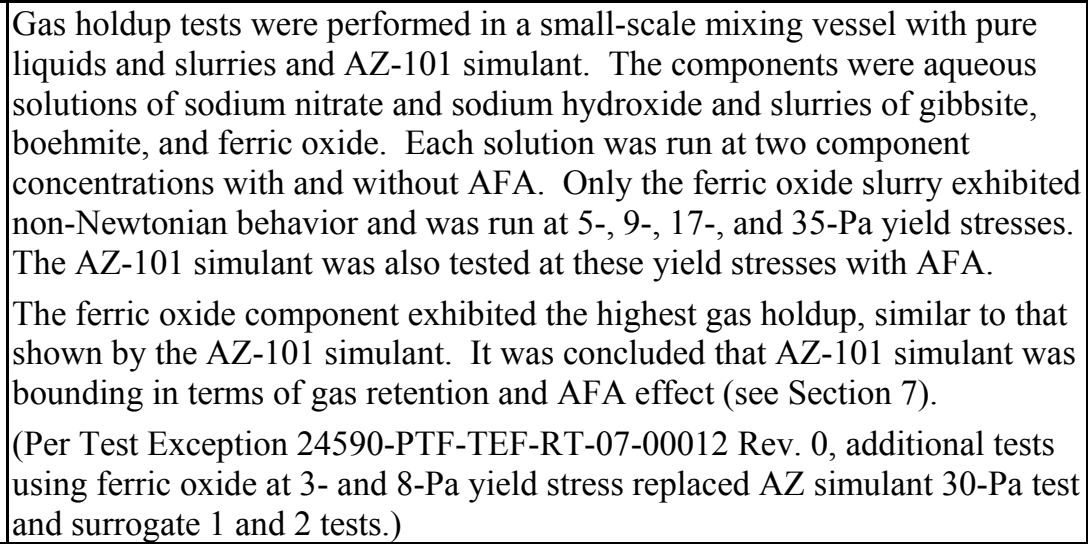 \\
\hline
\end{tabular}


Table S.1 (contd)

\begin{tabular}{||l|c|l||}
\hline \multicolumn{1}{|c||}{ Test Objective } & $\begin{array}{c}\text { Objective } \\
\text { Met? }\end{array}$ & \multicolumn{1}{|c||}{ Discussion } \\
\hline $\begin{array}{l}\text { Develop revised gas } \\
\text { retention/release model to } \\
\text { predict plant-scale opera- } \\
\text { tions for WTP based on } \\
\text { data from testing conducted } \\
\text { in tasks at PNNL and } \\
\text { SRNL and information } \\
\text { developed from other WTP }\end{array}$ & Yes & $\begin{array}{l}\text { A model was developed based on the results of this work, mass transfer tests } \\
\text { at SRNL, and prior 1/4- and 1/2-scale tests to predict gas retention and } \\
\text { release in the WTP vessels, including the effect of mass transfer to sparge air } \\
\text { testing programs. }\end{array}$ \\
\hline
\end{tabular}

\section{Test Exceptions}

A summary description of the test exceptions applied to these tests is shown in Table S.2.

Table S.2. Test Exceptions ${ }^{(a)}$

\begin{tabular}{|l|l||}
\hline \multicolumn{1}{|c|}{ Test Exceptions } & \multicolumn{1}{|c|}{ Description of Test Exceptions } \\
\hline Rev. 0 & $\begin{array}{l}\text { This test exception modified the Test Plan as follows: } \\
\text { 1) Deleted QSLS tests in AZ-101 HLW simulant without AFA because foaming } \\
\text { observed in small-scale tests would make it impossible to determine the bulk gas } \\
\text { volume fraction from surface level. } \\
\text { 2) Deleted QSLS tests with alternative AFA and the post-DBE demonstration } \\
\text { because QSLS testing in 30- and 13-Pa AZ-101 simulant preliminary test data } \\
\text { indicated that gas holdup was less than or equal to that in the baseline in the 1/4- } \\
\text { and 1/2-scale clay tests. Thus, there is no need to test an alternative AFA, and } \\
\text { post-DBE operations are not an issue. } \\
\text { 3) Added a repeat of the QSLS tests of 3-Pa AZ-101 simulant, using available } \\
\text { AZ simulant at PNNL, to verify the dominance of sparger gas holdup behavior } \\
\text { over hydrogen-peroxide-induced gas holdup. } \\
\text { There is no impact on test objectives. }\end{array}$ \\
\hline $\begin{array}{l}\text { Replaced surrogate tests 1 and 2 with tests using ferric oxide simulant having } \\
\text { nominally 3- and 8-Pa yield stresses to complete the suite of tests on this material } \\
\text { and show that the baseline AZ-101 recipe is the bounding simulant for gas } \\
\text { retention/release. The AZ-101 waste simulant test with 30-Pa yield stress was } \\
\text { deleted and replaced with two AZ simulant tests having 3- and 8-Pa yield stresses } \\
\text { to better understand the trend of gas holdup at lower yield stress. } \\
\text { There is no impact to test objectives. }\end{array}$ \\
\hline $\begin{array}{l}\text { 24590-PTF-TEF-RT-07-00012 } \\
\text { Test Plan. The test results section in includes testing approaches and procedures and test configurations; the modeling } \\
\text { included. }\end{array}$
\end{tabular}

\section{Results and Performance Against Success Criteria}

The R\&T success criteria are discussed in Table S.3. 
Table S.3. Success Criteria

\begin{tabular}{|c|c|}
\hline Success Criteria & How Testing Did or Did Not Meet Success Criteria \\
\hline $\begin{array}{l}\text { Identify and evaluate the potential effect of } \\
\text { gas composition on gas retention and } \\
\text { release behavior. }\end{array}$ & $\begin{array}{l}\text { As discussed in Section } 4.4 \text {, gas density is the primary property } \\
\text { affecting bubble size and behavior. However, gas density does not } \\
\text { appear to influence bubble coalescence. In general, higher gas } \\
\text { densities produce smaller bubbles, and smaller bubbles result in } \\
\text { higher gas retention. This indicates that a high density gas would } \\
\text { increase gas retention and release. }\end{array}$ \\
\hline \multirow[t]{2}{*}{$\begin{array}{l}\text { Provide sufficient data to describe the gas } \\
\text { volume fraction as a function of superficial } \\
\text { velocity in a } 1 / 4 \text {-scale lag storage vessel in } \\
\text { water, clay, and waste simulant with and } \\
\text { without AFA for the range of conditions } \\
\text { defined in the Test Plan. }\end{array}$} & $\begin{array}{l}\text { As defined in Tables } 9,10 \text { and } 11 \text { of the Test Plan, enough data were } \\
\text { collected during QSLS testing using water with and without AFA } \\
\text { and AZ simulant with AFA and kaolin/bentonite clay without AFA } \\
\text { at varying rheologies }(\sim 4-, \sim 13-, \text { and } \sim 33-P a \text { Bingham yield stress }) \\
\text { and superficial velocities }(0.025,0.050 \text {, and } 0.1 \mathrm{~mm} / \mathrm{s}) \text {. }\end{array}$ \\
\hline & $\begin{array}{l}\text { Per Test Exception 24590-PTF-TEF-RT-07-00001 Rev. 0, AZ } \\
\text { simulant without AFA, post-DBE, and alternative AFA tests were } \\
\text { not completed. }\end{array}$ \\
\hline $\begin{array}{l}\text { Demonstrate gas retention/release behavior } \\
\text { during simulated post-DBE operation. }\end{array}$ & $\begin{array}{l}\text { As identified in Table S-2., Test Exception } 24590-\mathrm{PTF}-\mathrm{TEF}-\mathrm{RT}-07- \\
00001 \text { Rev. } 0 \text { deleted the post-DBE test. Success criteria for this } \\
\text { task are no longer applicable. }\end{array}$ \\
\hline $\begin{array}{l}\text { Identify waste components and/or specific } \\
\text { tank wastes that may have higher gas } \\
\text { retention than AZ-101 (that is, "bounding } \\
\text { simulant") and provide a bounding simulant } \\
\text { recipe. Provide enough data to compare gas } \\
\text { retention in the bounding simulant to that of } \\
\text { AZ-101 simulant with and without AFA. }\end{array}$ & $\begin{array}{l}\text { No waste components or specific tank wastes were identified that } \\
\text { exhibit higher gas retention than the baseline AZ-101 waste recipe. } \\
\text { The major components in AZ-101 waste investigated were sodium } \\
\text { hydroxide, sodium nitrate, gibbsite, boehmite, and ferric oxide. Thus } \\
\text { the baseline recipe for AZ-101 is the bounding waste recipe for } \\
\text { AZ-101 tank waste, and no new bounding simulant recipe was } \\
\text { required. (Per Test Exception } 24590 \text {-PTF-TEF-RT-07-00012 Rev. } 0 \text {, } \\
\text { additional tests using ferric oxide at 3- and 8-Pa yield stress replaced } \\
\text { AZ simulant 30-Pa test and surrogate } 1 \text { and } 2 \text { tests.) }\end{array}$ \\
\hline $\begin{array}{l}\text { Apply the revised gas retention/release } \\
\text { model to predict the results of these tests } \\
\text { and flammable gas concentrations for plant- } \\
\text { scale operations of the WTP using } \\
\text { previously developed information (for WTP } \\
\text { Project and Hanford tank farms) and the } \\
\text { results of this testing. }\end{array}$ & $\begin{array}{l}\text { The model matched observed HSLS and QSLS measurements at } \\
\text { steady-state conditions. Compared with HSLS cyclic operations } \\
\text { tests, it tended to overestimate cycle maximum gas fraction. It } \\
\text { underestimated the cycle minimum gas fraction when mass transfer } \\
\text { was turned off and tended to overestimate when mass transfer was } \\
\text { turned on. Model performance could be improved by refitting model } \\
\text { parameters to HSLS data consistent with current assumptions about } \\
\text { the power-law relation between retained gas bubble rise velocity and } \\
\text { retained gas fraction. The refitting would need to include the effect } \\
\text { of mass transfer as well as gas generation in producing retained gas } \\
\text { volume. In addition, the assumption that retained gas bubbles are in } \\
\text { equilibrium with dissolved gases in the surrounding liquid should be } \\
\text { confirmed. Finally, the model implementation should be changed to } \\
\text { make it more computationally efficient, allowing smaller timesteps } \\
\text { to be used in solving equations and permitting the accuracy of the } \\
\text { results to be refined. }\end{array}$ \\
\hline
\end{tabular}

\section{Quality Requirements}

PNNL implements the WTP quality requirements by performing work in accordance with the River Protection Project - Waste Treatment Plant Support Program Quality Assurance Plan (RPP-WTP-QA001). Work is performed to the quality requirements of NQA-1-1989 Part I, Basic and Supplementary Requirements; NQA-2a-1990 Part 2.7; and DOE/RW-0333P Rev. 13, Quality Assurance Requirements and Descriptions. Although the test specification, 24590-WTP-TSP-RT-06-002 Rev 0, Large Scale Testing for Effects of Anti-Foam Agent on Gas Retention/Release, does not impose DOE/RW-0333P 
Rev. 13 because this work is not high-level waste-impacting, it is acceptable to exceed QA expectations. These quality requirements are implemented through the River Protection Project - Waste Treatment Plant Support Program Quality Assurance Manual (RPP-WTP-QA-003).

The WTP Support Program addresses internal verification and validation activities by conducting an independent technical review of the final data report in accordance with procedure QA-RPP-WTP-604, Independent Technical Review. The review of this test report verifies that the documented results are traceable, that inferences and conclusions are soundly based, complete, and correct; and the reported work satisfies the test plan objectives. Refer to Section 2, Quality Assurance, for more information on the quality assurance requirements imposed on the AFA project.

\section{Research and Technology Test Conditions}

A series of tests was performed in a QSLS vessel (eight PJMs and seven spargers) to determine the effect of AFA on gas retention and release in kaolin/bentonite clay and AZ-101 HLW simulant over a range of Bingham model yield stresses (see Table S.4). Hydrogen peroxide was injected into the slurry and decomposed, generating oxygen gas to simulate the flammable gas mixtures produced in radioactive liquid waste. Specific test runs, conditions, and recorded data were provided in the test plan that was reviewed and approved by WTP management.

Table S.4. R\&T Test Conditions

\begin{tabular}{|l|l||}
\hline \multicolumn{1}{|c|}{ R\&T Test Conditions } & Were Test Conditions Followed? \\
\hline $\begin{array}{l}\text { Gas retention and release tests will begin with a period of } \\
\text { continuous sparger-PJM operation without gas generation to } \\
\text { measure the holdup of sparger bubbles. This will be followed } \\
\text { by a series of steady retention tests with stepped increases in } \\
\text { the gas generation rate (that is, the rate of hydrogen peroxide } \\
\text { injection). After the last retention test, hydrogen peroxide } \\
\text { injection and the mixing system will be shut down to allow the } \\
\text { remaining hydrogen peroxide to decompose and build up a } \\
\text { volume of retained gas (hold time on the order of 1 hour in a } \\
\text { 1/4-scale vessel). The PJMs and spargers will then be turned } \\
\text { on for a gas release test. }\end{array}$ & \\
\hline
\end{tabular}

\section{Simulant Use}

A visualization test was conducted with water, and two simulants were used in these gas retention and release tests. A kaolin/bentonite simulant similar to that used in previous QSLS- and HSLS tests was selected to provide data that could be compared with previous test results. A chemical simulant of pretreated sludge from Tank 241-AZ-101 (AZ-101) was also tested to compare gas retention in clay and in a sludge whose composition was similar to that of an actual Hanford tank waste (refer to Section 3). This chemical simulant was prepared by a method that resembled the conditions under which actual waste was formed (hydroxide precipitation and dehydration at boiling temperature), and its rheological properties and chemical properties, as mentioned in Section 3, have been validated against those of actual AZ-101 sludge (Eibling et al. 2003). 
Rheological measurements(a) made on actual waste slurry have indicated the WTP non-Newtonian waste stream can be represented by a Bingham plastic rheology model, which is represented by

$$
\tau=\mu_{B} \dot{\gamma}+\tau_{0} \quad \text { for } \tau>\tau_{0}
$$

where

$\tau=$ shear stress

$\mu_{\mathrm{B}}=$ Bingham consistency factor; in some past work, this property has been referred to as $\kappa$.

$\dot{\gamma}=$ shear rate or strain rate

$\tau_{0}=$ Bingham yield stress, the assumed minimum stress required to initiate fluid movement as determined by a flow curve obtained by fitting rheological data using a Bingham plastic rheological model; in some past work, this property has been referred to as $\tau_{\mathrm{y}}$.

The non-Newtonian waste stream upper-bound rheological values of $\tau_{0}=30 \mathrm{~Pa}$ and $\mu_{\mathrm{B}}=30 \mathrm{cP}$ were identified based on limited data from actual waste slurries that can be represented by a Bingham plastic rheology model (Poloski et al. 2004). Simulant dilutions with yield stresses of approximately 30, 13, and $3 \mathrm{~Pa}$ were used in the current tests.

Gas retention tests with actual waste are not planned, nor are they within the scope of the current efforts due to the difficulty of obtaining and working with actual waste samples. The absence of data from actual waste implies some uncertainty regarding the applicability of test results. Should new or extended insight into actual waste properties become available, careful comparison with the properties of simulants used in the current tests is recommended, and the potential effects on PJM performance should be investigated.

\section{Summary of Test Results}

The series of gas retention and release tests was conducted in a QSLS mixing vessel using a representative AZ-101 simulant and kaolin/bentonite clay at 3-, 13-, and 30-Pa Bingham yield stress to address the concern that AFA may have as strong an effect in a large-scale prototypic mixing system as it did in previous small-scale tests and mixing vessels (see Section 1.2). Each test nominally consisted of three sets of hydrogen peroxide injections followed by an undisturbed gas holdup and release test. The hydrogen peroxide injection set included 2-hr-long injections at $\sim 33, \sim 65$, and $\sim 130 \mathrm{~mL} / \mathrm{min}$. These rates corresponded to superficial gas velocities (volumetric gas generation rate divided by slurry surface area) of $\sim 0.025, \sim 0.05$, and $\sim 0.1 \mathrm{~mm} / \mathrm{s}$, respectively. The gas volume fractions produced by generated gas and sparge air were distinguished from each other by using data from periods when the spargers were shut down. Both types of gas volume fraction were calculated independently from both level data and pressure-difference data, which gave consistent trends and results. Water visualization tests were also conducted to determine the effect of increasing AFA concentrations on sparger bubble behavior.

To address the concern that simulants delivered to the WTP will come from tanks other than AZ-101, tests were also conducted to determine a bounding AZ-101 simulant recipe for gas holdup. High and low concentrations of pure sodium nitrate, sodium hydroxide, boehmite, gibbsite, and ferric oxide with and

(a) The development and selection of non-Newtonian waste simulants for use in WTP PJM testing are summarized in Poloski et al. (2004). 
without AFA were tested over a range of gas injection rates in a small-scale mixing vessel. These pure components were selected from the most prevalent constituents in Hanford tank wastes. From the results of these tests mixtures, the pure components showing the highest holdup were tested and compared with the AZ-101 simulant with AFA.

The following is an overview of the AFA project test results:

- The prototypic gas retention and release tests performed in this program indicate that gas holdup in AZ-101 simulant with AFA is higher than that in clay over a range of yield stresses, but not to the extent that initially raised WTP design concerns. The factor $F_{w}$ is defined as the ratio of holdup in AZ-101 simulant with AFA to that in clay simulant at the same gas generation superficial velocity. The $F_{w}$ observed in these prototypic tests is 8 or less, compared with a maximum factor of 20 found in previous tests in smaller nonprototypic systems.

- $F_{w}$ was found to be about the same in 13-Pa simulant as in 30-Pa simulant, whereas in smaller nonprototypic systems $F_{w}$ was observed to increase with decreasing yield stress. Concerns raised by previous studies regarding $F_{w}$ of up to 20 at the low gas generation rates of plant operations and the potential for even higher $F_{w}$ at low yield stress have not been borne out by current prototypic tests.

- The QSLS gas retention and release test results support the scaling principles applied to the lag storage and HLW feed blending vessels for predicting WTP full-scale plant operations.

- Steady-state holdup of generated gas decreases with decreasing yield stress based on the results of tests in 30- and 13-Pa yield stress simulants. Sparger holdup in the 3-Pa AZ simulant with AFA was as high as 9 vol\%, making it difficult to measure the relatively small holdup from gas generation. There was no evidence that the generated gas holdup was greater in 3-Pa than in 13-Pa simulant either for clay without AFA or for AZ-101 simulant with AFA.

- Gas holdup is not sensitive to mixing system configuration or scale within the range of PJM and sparger hybrid configurations and scales of lag storage test stands that have been used at PNNL.

- The bounding simulant tests determined the baseline AZ-101 simulant recipe to be bounding for AZ-101 tank waste in terms of gas retention.

The remainder of this Summary describes the water visualization, gas retention, gas release, and bounding simulant test results, as well as the plant predictive model outcomes.

\section{Water Tests}

The purpose of the water visualization tests was to qualitatively describe the effects of increasing AFA concentration on sparger holdup, bubble size, and behavior (refer to Section 5.4.1). Bubble behavior was recorded without AFA and at AFA concentrations of 10-, 30-, 100-, and 350 ppm (10-, 30-, $100-$, and $350 \mathrm{mg} / \mathrm{L}$ ). The effect of AFA on bubble behavior was most dramatic at the $10-\mathrm{mg} / \mathrm{L}$ concentration, with more gradual changes at higher concentrations. The effect of AFA appears to be mainly a dramatic increase in the number of small bubbles. However, the behavior (e.g., size, formation frequency, breakup, and coalescence) of the largest bubbles and bubble swarms appears to be relatively little affected by AFA. In addition, the volume of the increased small bubble population was low. The sparger holdup remained fairly constant at $1.6 \pm 0.8 \mathrm{vol} \%$ throughout all of the AFA concentrations. Though the sparger tube tips are near the PJM nozzle outlet, the PJM jet seemed only to cause a large- 
scale circulation of smaller bubbles in the lower portion of the tank. The additional turbulence of the jet did not appear to cause additional sparge bubble breakup. Sparge bubble breakup in the tank is attributed to the bubble interaction in the sparger "region of bubbles."

\section{Gas Retention Tests}

Within the uncertainty of the data, \pm 1 standard deviation of the mean gas volume fraction, the current QSLS data in clay simulant matches the previous HSLS (Bontha et al. 2005) and QSLS (Russell et al. 2005) results. The consistency with earlier tests is remarkable because of the variety of test conditions and operating modes. Not only did the simulant depth (H/D), PJM nozzle velocity, and stroke vary, but a different PJM configuration and secondary mixing system were also used. Nevertheless, data from all these variant tests gave consistent results and trends. Gas holdup is apparently not sensitive to system configuration or operating conditions. Because of this consistency, the relationships between volume fraction of in situ generated gas and the gas generation superficial velocity determined in clay and AZ simulants for the QSLS provide appropriate scaling bases for the lag storage vessel (see Section 5.4.2).

The gas holdup in 13-Pa clay follows approximately the same trend as the 30-Pa clay tests, though it falls off more rapidly as the gas generation superficial velocity decreases and is about half that in the $30-\mathrm{Pa}$ clay at $0.1 \mathrm{~mm} / \mathrm{s}$. The gas holdup in 3-Pa clay was barely detectable and probably lower than that observed at $13 \mathrm{~Pa}$.

The tests in 30-Pa AZ-101 simulant with AFA generated a gas volume fraction of about $1.8 \%$ at the $0.1 \mathrm{~mm} / \mathrm{s}$ gas generation superficial velocity (refer to Section 5.4.3). At $0.1 \mathrm{~mm} / \mathrm{s}$, the gas holdup in 13-Pa AZ-101 simulant with AFA was lower than in the 30-Pa AZ-101 simulant with AFA by a factor of 3 to 4 and lower than 30-Pa clay by about 3. The gas holdup in the 13-Pa AZ simulant with AFA falls off more rapidly as the superficial velocity decreases than the 30-Pa AZ simulant with AFA. Like the data for 3-Pa clay simulant, the holdup data for 3-Pa AZ-101 simulant with AFA were more uncertain than the error bars indicated due to the small gas generation holdup; the uncertainty in the 3-Pa AZ-101 simulant with AFA was further increased by a large and variable sparge gas holdup. The 3-Pa holdup of generated gas was similar to that at $13-\mathrm{Pa}$ and significantly lower than at $30-\mathrm{Pa}$. Though tested three times, the 3-Pa AZ simulant with AFA continued to produce doubtful data because of interference by sparger holdup.

\section{Gas Release Tests}

PJM operation was shut off and spargers set to idle flow after a 2-hour hydrogen peroxide injection at the highest flow rate for gas release tests (refer to Section 5.4.4). The unreacted hydrogen peroxide left in the simulant would then decompose and generate gas that remained trapped in the simulant because there was no mixing. After the tank simulant level stopped increasing, indicating all the hydrogen peroxide had decomposed, PJM and sparger operating was resumed to release the trapped gas, resulting in a transient decrease in gas volume fraction over time. Analysis of the gas release transient is based on the assumption that the superficial velocity of the retained gas rising through the simulant, $U_{G s}$, is related to the bulk volume fraction of retained gas by a power function of the form $\alpha_{G}=r_{1} U_{G s}^{r_{2}}$, the same as for the gas holdup tests (Stewart et al. 2006). (a)

(a) For reference, in past work there was no need to distinguish between sparge gas holdup and retained gas holdup, so the bulk volume fraction of retained gas was referred to simply as $\alpha$ and the superficial velocity as $U_{s}$. 
Gas releases in both clay and AZ-101 simulant with AFA were relatively rapid and complete, consistent with previous test results. A large fraction of the gas was released within 5 minutes, and the releases were essentially complete within 10 to 15 minutes. The gas release transients are most closely represented by holdup parameters in clay simulant. The 13-Pa clay releases gas more rapidly than $30-\mathrm{Pa}$ clay, but both simulants release essentially all the retained gas in less than 10 minutes. The gas releases in AZ-101 simulant with AFA are similar to those in clay, and gas release is faster in AZ simulant than in clay; however, the holdup parameters for 13-Pa AZ simulant predict a faster release than the release data, while those from holdup tests in $30-\mathrm{Pa} \mathrm{AZ}$ simulant show a slower release.

\section{Bounding Simulant Tests}

Bounding tests used different concentrations of sodium nitrate, sodium hydroxide, boehmite, gibbsite, and ferric oxide with and without AFA (refer to Section 7). These pure components were selected by examining the AZ-101 waste composition and selecting the most prevalent constituents. Gas holdup increased with increasing solids concentration in Newtonian slurries, and this trend prevailed to a lesser degree upon addition of AFA. In non-Newtonian slurries of ferric oxide, gas holdup increased with decreasing Bingham yield stress, but the holdup was higher than in the Newtonian fluids studied. The AFA effect further increased gas holdup in ferric oxide. The magnitude of the AFA effect increased with decreasing Bingham yield stress. Gas retention in simulated AZ-101 waste slurries correlated well with that in ferric oxide for the same Bingham yield stress. Consequently, within the components tested in this bounding simulant study, the baseline recipe for AZ-101 waste bounded AZ-101 tank waste because ferric oxide is the major constituent of the waste. These tests also suggest that testing major components is sufficient for simulant characterization.

\section{Modeling}

A model was developed to provide a technical basis for predicting flammable gas retention and mass transfer in WTP vessels with AFA added. The model developed and implemented for this study was shown to be capable of matching observed HSLS and QSLS measurements at steady-state conditions when mass transfer from sparge bubbles was zeroed. Modeling of mode cycling (turning PJMs off and on, switching spargers between full and idle flow rates) was less successful. Results for both steady-state and cyclic operations could be improved by refitting HSLS cyclic operation data using the assumption that the retained bubble rise velocity is a power-law function of the retained bubble gas fraction. It would also be possible to reduce conservatism for off-normal operating cycles by assuming that the retained gas bubble rise velocity is non-zero even when mixing is turned off.

The net effect of mass transfer was to increase predicted retained gas volume fractions in the fullscale lag storage vessel. However, mass transfer also decreased the hydrogen concentration predicted in the vessel headspace after an instantaneous release of retained gas. The model predicted that, in the fullscale lag-storage system containing 30-Pa AZ-101 chemical simulant with AFA, mass transfer would increase the maximum retained gas fraction from $0.05 \mathrm{vol} \%$ to $3.7 \mathrm{vol} \%$ for the normal operating cycle, but that little of this increased volume would be hydrogen. The maximum headspace hydrogen concentration predicted to be produced in the case of an instantaneous release was reduced by a factor of at least three by mass transfer; the value was $2660 \mathrm{ppm} \mathrm{H}_{2}$ in the case of zero mass transfer. Similar trends were predicted for the post-DBE cycle, but in this case the predicted maximum headspace concentration without mass transfer was $5500 \mathrm{ppm}$. 
The trends of these results seem reasonable, but it should be recognized that they depend on three basic assumptions:

- The double-counting of mass transfer effects referred to above does not lead to an underestimation of the retained hydrogen inventory.

- Mass transfer between the sparge bubbles and the dissolved gas is as rapid in the lag-storage vessel as in the SRNL bubble column.

- The dissolved gases are in equilibrium with the gases in the retained gas bubbles; i.e., the mass transfer for the retained gas bubbles is essentially instantaneous.

Finally, the model implementation in Excel ${ }^{\mathrm{TM}}$ was not computationally efficient. The relatively large timesteps, 0.04 hour, used to solve the ordinary differential equations only allowed the maxima and minima of retained gas fraction and headspace hydrogen concentration to be predicted within an accuracy of $9 \%$. A more efficient implementation is needed to obtain complete convergence and increase the accuracy of predictions by using smaller timesteps.

\section{Discrepancies and Follow-on Tests}

As stated in the previous section, sparger holdup in the 3-Pa AZ simulant with AFA was higher than 30- and 13-Pa AZ simulants and probably dominated the hydrogen peroxide injection-induced gas generation. By contrast, the sparger holdup seen in the 3-Pa clay simulant without AFA was too low to detect. The causes of this behavior have not been determined but may be the combination of the increased turbulence in the lower yield stress fluid and AFA properties increasing bubble breakup. An increase in slurry volume due to sparger holdup of about 9 vol\% could cause a tank capacity issue, which can be avoided by controlling the volume of waste in the tanks. The high sparger holdup is not a flammable gas concern because it consists largely of air; however, it may be an operational problem in limiting batch volumes. To optimize tank capacity at the WTP, further tests designed to explain the cause of high sparger holdup could be conducted to test whether varying plant operating conditions (PJM and sparger operation, etc.) increase or decrease sparger holdup in low yield stress AZ simulant.

Gas retention and release tests performed to date have been evaluated in the context of their relationship to the waste in Tank 241-AZ-101. Though bounding with respect to gas retention (based on the results of the bounding simulant tests), waste from this tank does not represent WTP operations over the wide range of compositions expected from the tank farms. In addition to composition, process history could be significant because the AZ-101 chemical simulant used in these tests foamed, while that used in 2006 tests at SRNL did not foam despite being produced with the same recipe using methods as similar as possible given the difference in the batch size. Given the variety of simulant properties the WTP will see, the uncertainties and tolerances in processing actual radioactive waste, and the possibility of new or extended insight into actual waste properties becoming available, careful comparison with the properties of simulants used in the current tests is recommended, and the potential effects on PJM performance should be investigated to assist WTP operation. Additional AZ-101 waste component testing can also be conducted to confirm that the baseline $\mathrm{AZ}$ waste recipe is still bounding for AZ-101 tank waste. 


\section{References}

Bontha JR, CW Stewart, DE Kurath, PA Meyer, ST Arm, CE Guzman-Leong, MS Fountain, M Friedrich, SA Hartley, LK Jagoda, CD Johnson, KS Koschik, DL Lessor, F Nigl, RL Russell, GL Smith, W Yantasee, and ST Yokuda. 2005. Technical Basis for Predicting Mixing and Flammable Gas Behavior in the Ultrafiltration Feed Process and High-Level Waste Lag Storage Vessels with NonNewtonian Slurries. WTP-RPT-132 (PNWD-3676), Battelle - Pacific Northwest Division, Richland, Washington.

Eibling RE, RF Schumacher, and EK Hansen. 2003. Development of Simulants to Support Mixing Tests for High Level Waste and Low Activity Waste. SRT-RPP-2003-00098 Rev. 0, Westinghouse Savannah River Company, Aiken, South Carolina.

Guzman-Leong CE, CW Stewart, JM Alzheimer, LA Mahoney, ST Arm and LK Jagoda. March 2007. Test Plan for Large -Scale Testing for Effects of Anti-Foaming Agent on Gas Retention and Release. TP-RPP-WTP-476 Rev. 0, Battelle - Pacific Northwest Division, Richland, Washington.

Poloski AP, PA Meyer, LK Jagoda, and PR Hrma. 2004. Non-Newtonian Slurry Simulant Development and Selection for Pulse Jet Mixer Testing. PNNL-3495 (WTP-RPT-111 Rev 0), Battelle - Pacific Northwest Division, Richland, Washington.

Russell RL, SD Rassat, ST Arm, MS Fountain, BK Hatchell, CW Stewart, CD Johnson, PA Meyer, and CE Guzman-Leong. 2005. Final Report: Gas Retention and Release in Hybrid Pulse Jet-Mixed Tanks Containing non-Newtonian Waste Simulants. PNWD-3552 (WTP-RPT-114 Rev. 1), Battelle - Pacific Northwest Division, Richland, Washington.

Stewart CW, PA Meyer, MS Fountain, CE Guzman-Leong, SA Hartley-McBride, JL Huckaby and BE Wells. 2006. Effect of Anti-Foam Agent on Gas Retention and Release Behavior in Simulated High Level Waste. WTP-RPT-147 (PNWD-3786), Battelle - Pacific Northwest Division, Richland, Washington. 



\section{Acknowledgments}

Anti-foam agent task leaders sincerely thank all staff members who supported the AFA project. In particular, we want to thank all the test crew members who worked unpredictable, long, and odd-hour shifts during the entire summer in the Applied Process Engineering Laboratory (APEL). The AFA tests would not have been a success without the following testing personnel, Rich Hallen, Rosanne Aaberg, Joan Young, Lynette Jagoda, Beric Wells, Jeffrey Bailey, Walter Park, James Alzheimer, Carl Baker, Bryan Broocks, Wesley Johnson, William Buchmiller, Elizabeth Golovich, David Hurley, Naveen Karri, Maria Luna, Eric Mast, Keith Peterson, Siva Pilli, Amy Qiao, Larry Reid, Aaron Richter, Brian Riley, Donald Rinehart, Deborah Sklarew, Ryan Slaugh, Wayne Wilcox, Lirong Zhong, and Mac Zumhoff. In addition, we commend the extraordinary efforts of the data analysis team for their tenacity and dedication to the numerous data files that were analyzed, reviewed, and packaged. Data analysis members and technical reviewers include Lenna Mahoney, Beric Wells, Siva Pilli, Lirong Zhong, Amy Qiao, Maria Luna, Ellen Baer, and Dave Rector.

The authors also want to thank Lubov Lavrentiev, Kay Hass, and Karen Mercer for their outstanding administrative support; Sheila Bennett for her valuable editorial support; Chrissy Charron for project

office support; Al Garcia, Lorena Ruiz, and Kevin Nelson for procurement support; and Kirsten Meier for her guidance on quality assurance matters. 



\section{Contents}

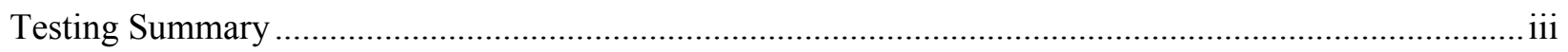

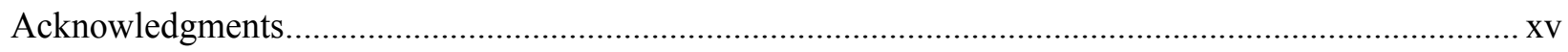

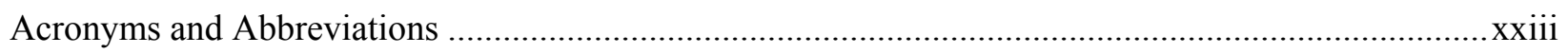

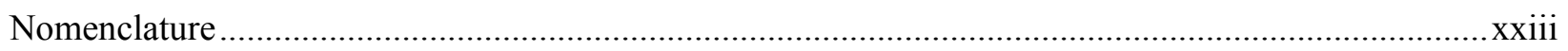

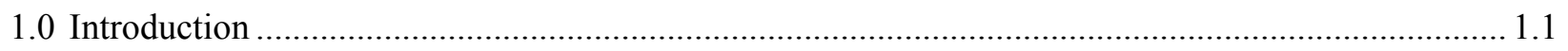

$1.1 \quad$ WTP Gas Retention and Release Testing Overview ...................................................... 1.1

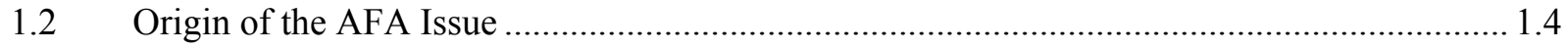

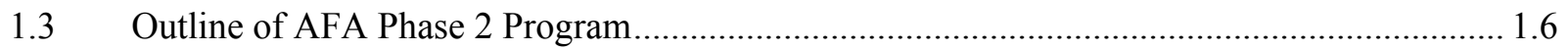

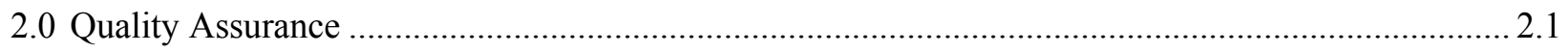

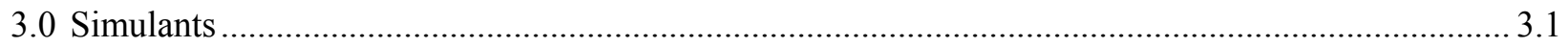

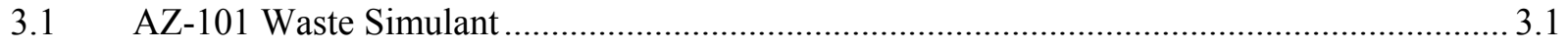

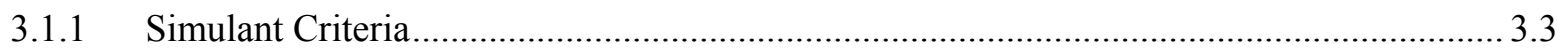

3.1.2 Produced Simulant Batches and Confirmatory Analyses ............................................... 3.4

3.1.3 Comparison of Properties Between Batches................................................................... 3.5

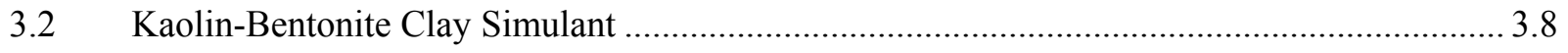

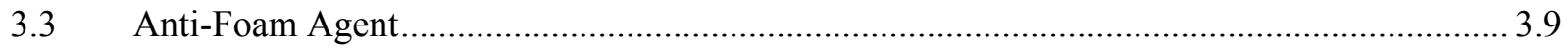

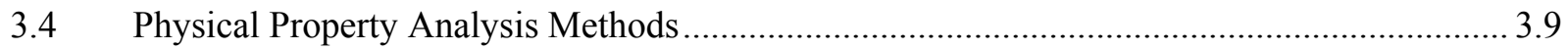

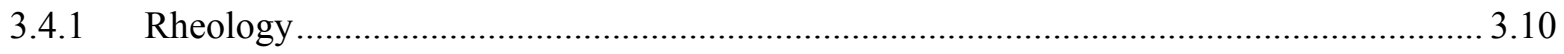

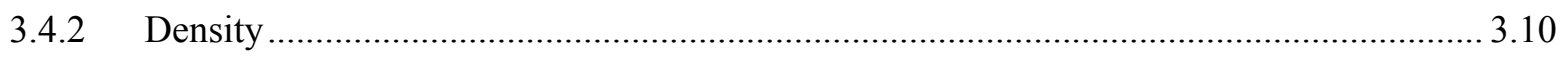

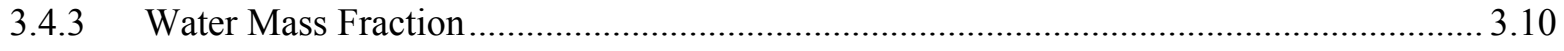

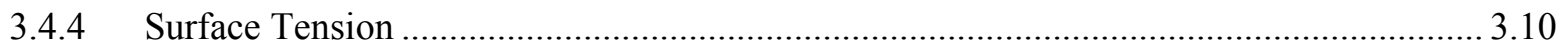

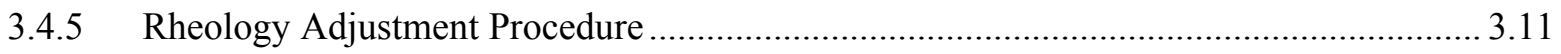

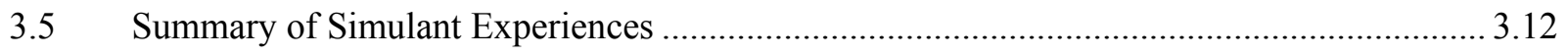

4.0 Effect of Gas Physical Properties on Bubble Characteristics........................................................ 4.1

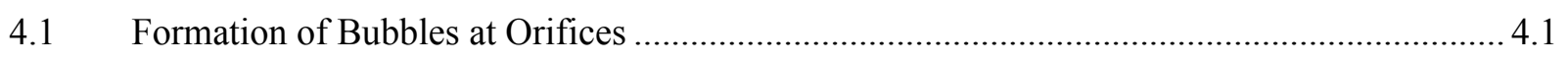

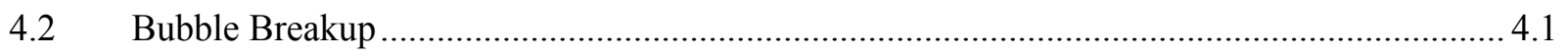

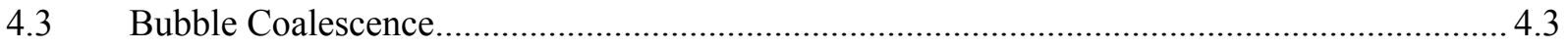

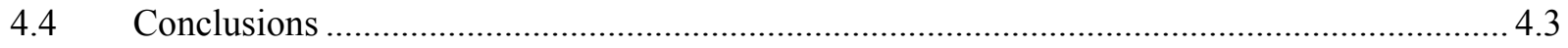


5.0 Testing in the 1/4-Scale Lag Storage Vessel ............................................................................. 5.1

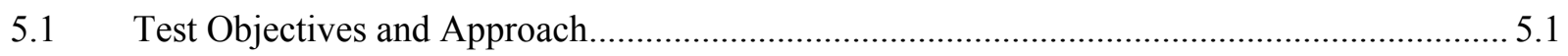

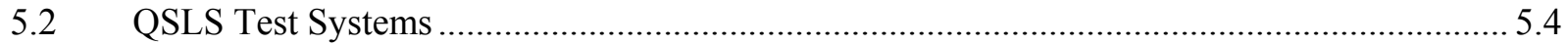

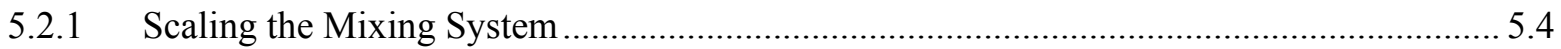

5.2.2 Description of the QSLS Vessel and Internals ............................................................... 5.7

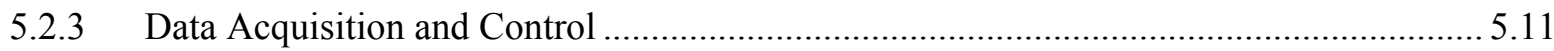

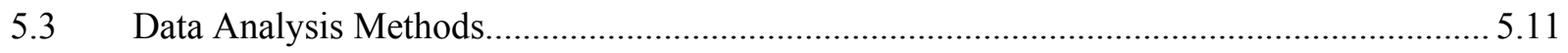

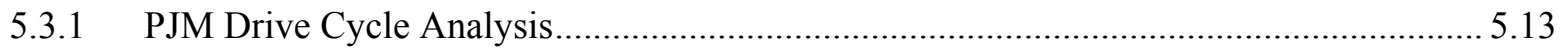

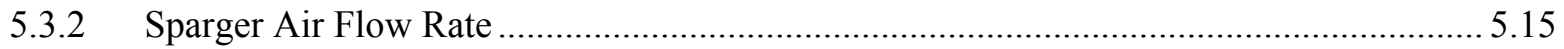

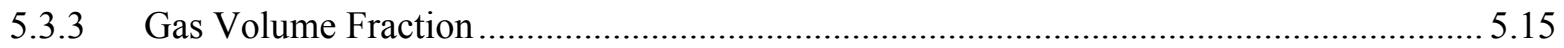

5.3.4 Determining Steady-State Values ............................................................................. 5.16

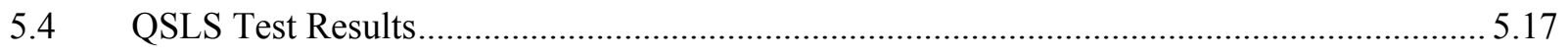

5.4.1 Visualization of AFA Effects in Water.......................................................................... 5.19

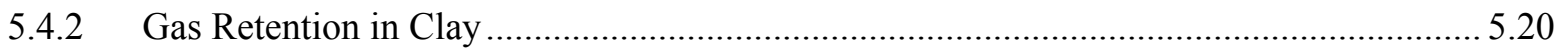

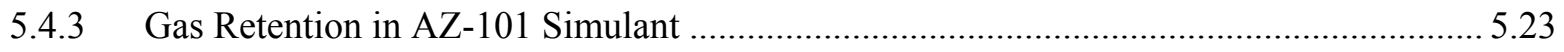

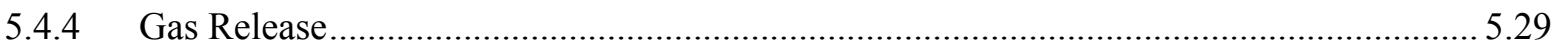

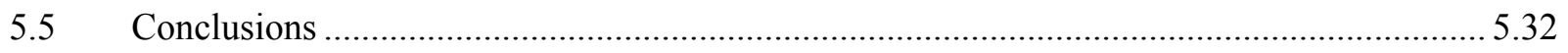

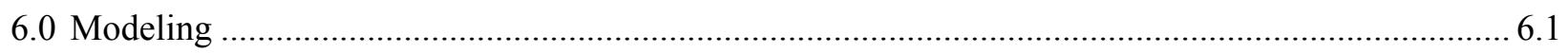

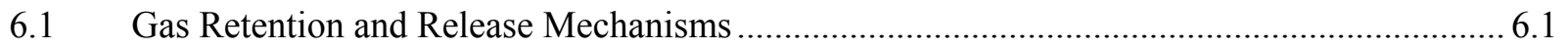

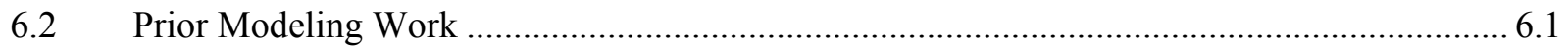

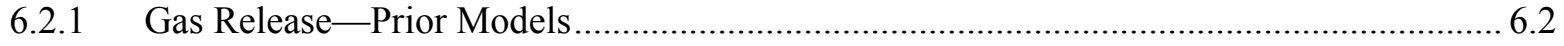

6.2.2 Gas Accumulation_Prior Models...................................................................................... 6.4

6.3 A New Model for Gas Retention and Release.................................................................. 6.5

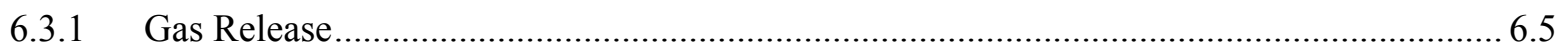

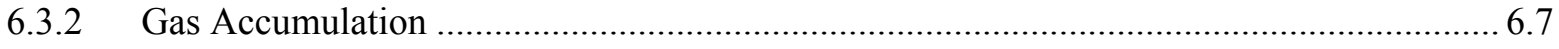

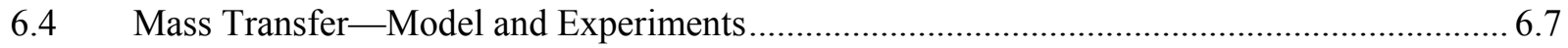

6.4.1 SRNL Sparged Column Test Apparatus and Methods ...................................................... 6.8

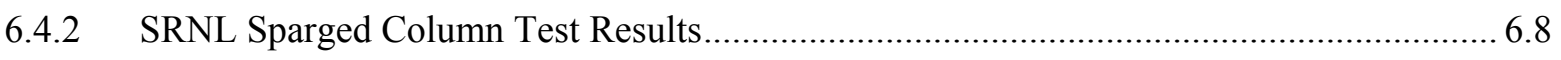

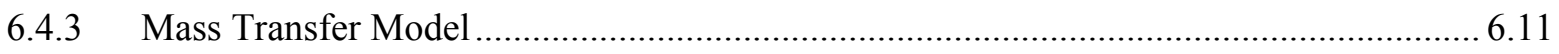

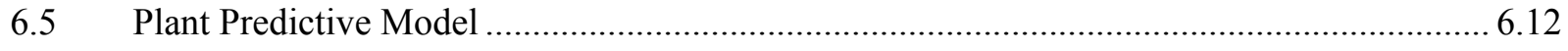

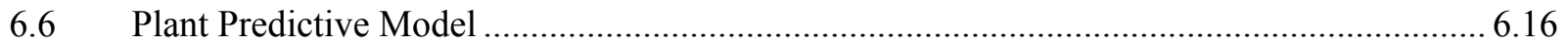

6.6.1 Comparison of Model Output to 2007 QSLS Data............................................................ 6.16 
6.6.2 Comparison of Model Output and HSLS Data ............................................................... 6.18

6.6.3 Prediction of Retained Gas Holdup and Composition in the FSLS ................................ 6.22

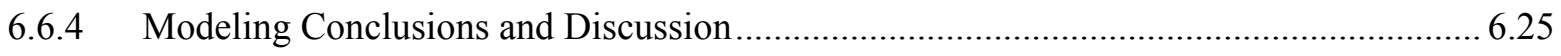

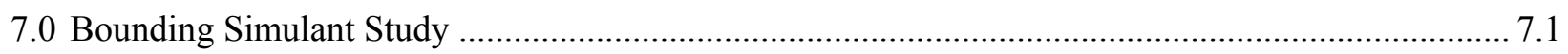

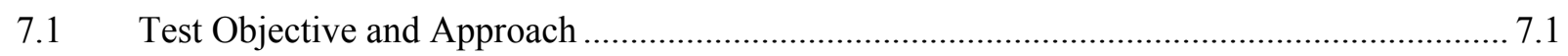

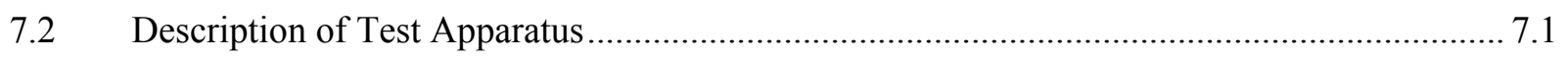

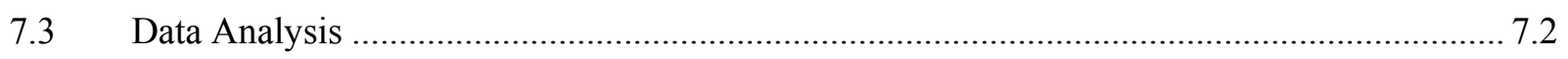

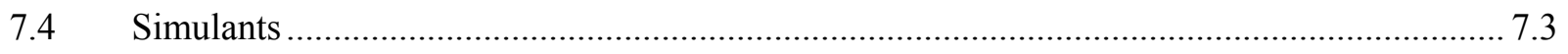

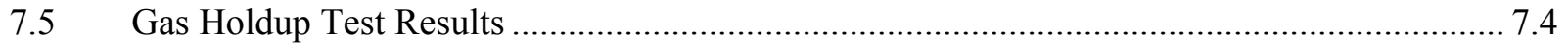

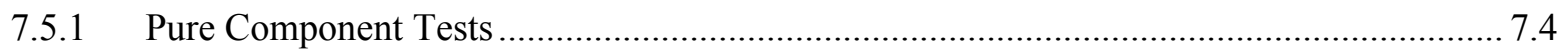

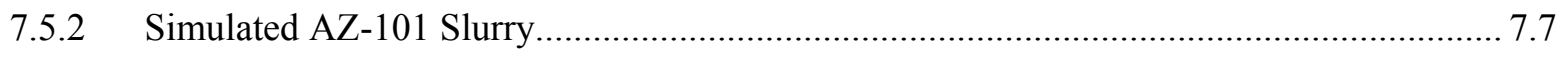

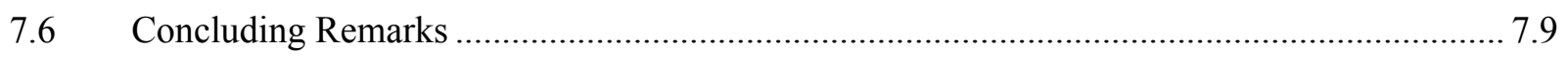

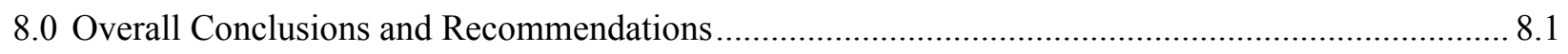

8.1 Effect of AFA on Gas Retention and Release ............................................................... 8.1

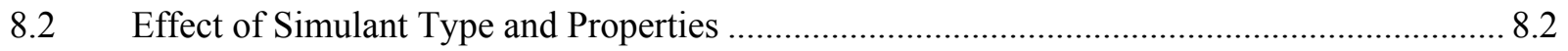

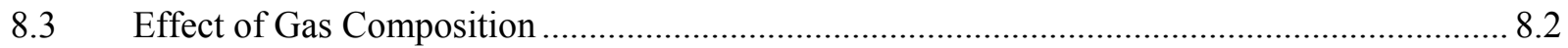

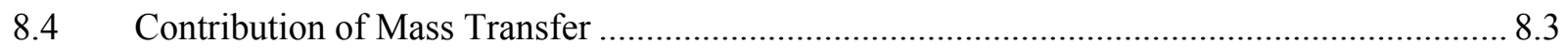

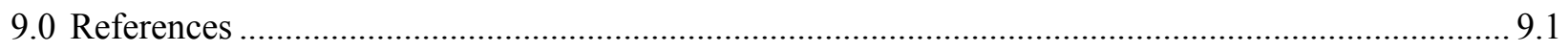

Appendix A - Tank Volume and PJM/Tank Fluid Surface Areas as a Function of the

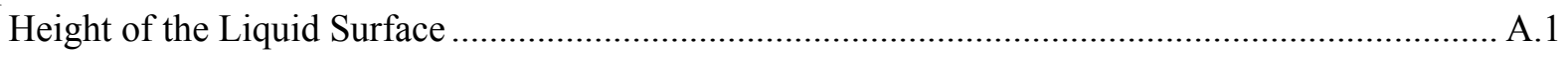

Appendix B - QSLS Data Analysis Methodology …......................................................................1

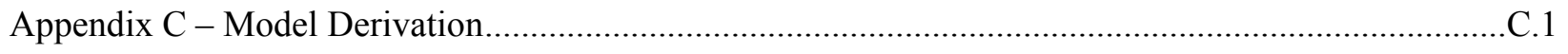

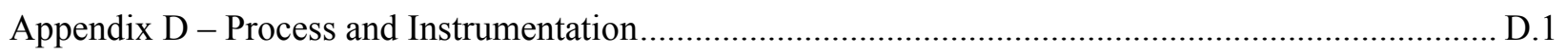

Appendix E - Details of Statistical Analyses ................................................................................... 


\section{Figures}

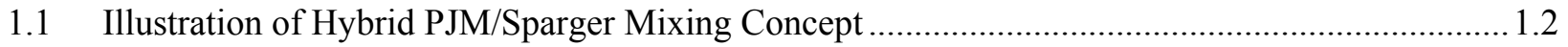

3.1 Waste Slurry Simulant Being Actively Stirred and Showing Desired Simulant Color at SRNL ....3.4

3.2 Yield Stress as a Function of Weight Percent Total Solids for AZ-101 Simulants Produced by Optima as Reported at PNNL and SRNL …........................................................ 3.7

5.1 Example of Data from QSLS Tests in 13-Pa AZ-101 Simulant..................................................5.2

5.2 Summary of Previous Gas Retention Test Results ....................................................................

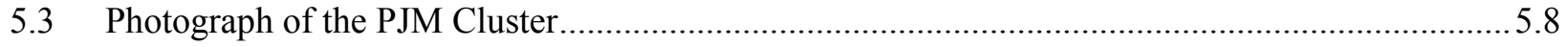

5.4 QSLS Vessel with PJM Cluster and Sparge Tubes ...................................................................5.9

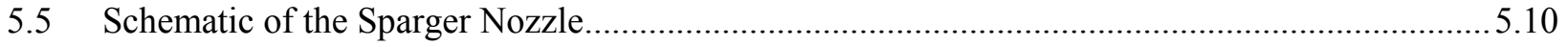

5.6 PJM Drive Cycle Illustration Showing Equilibrium Period .......................................................5.12

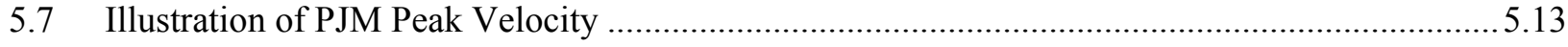

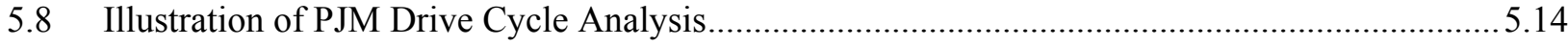

5.9 Video Camera Position for Water Tests ............................................................................... 5.19

5.10 Surface Tension of AZ-101 Simulant Liquid Fraction Versus AFA Concentration ....................5.20

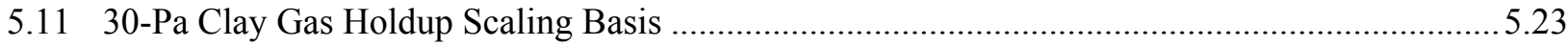

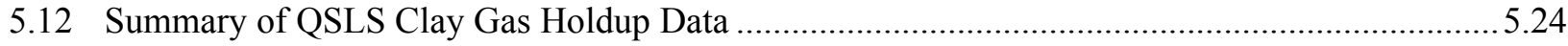

5.13 Summary of AZ-101 HLW Simulant Gas Holdup Data ...........................................................2.26

5.14 Summary of AZ-101 HLW Simulant Gas Holdup Data ........................................................5.26

5.15 Comparison of Gas Holdup in 13 Pa Clay and AZ-101 HLW Waste Simulant...........................5.27

5.16 Gas Volume Fraction Versus Time: 3 Pa AZ Simulant Test.......................................................5.29

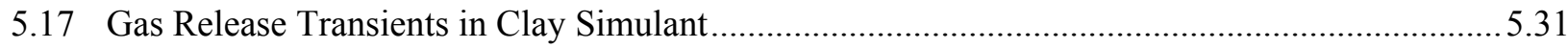

5.18 Gas Release Transients in AZ-101 HLW Simulant ....................................................................5.31

5.19 Sparger Holdup Release Transients in 3-Pa AZ HLW Simulant ..............................................5.32

5.20 Schematic of Bubble Breakup by a Rotating Agitator .............................................................5.33

6.1 Volumetric Mass Transfer Coefficients in the SRNL Sparged Column .......................................6.9

6.2 Gas Holdup in the SRNL Sparged Column, Measured Using $\triangle \mathrm{P}$............................................6.10

6.3 Gas Holdup in the SRNL Sparged Column, Measured Using Level .........................................6.10

6.4 Predicted Holdup and Headspace $\mathrm{H}_{2}$ for FSLS Normal Operations ............................................23

6.5 Predicted Holdup and Headspace $\mathrm{H}_{2}$ for FSLS Post-DBE Operations ....................................... 6.24

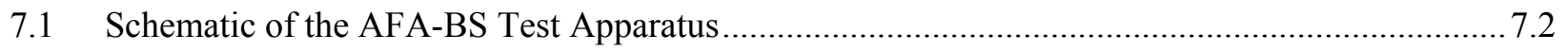

7.2 Oxygen Holdup in Sodium Nitrate Solutions......................................................................... 7.5

7.3 Oxygen Holdup in Sodium Hydroxide Solutions .................................................................... 7.5

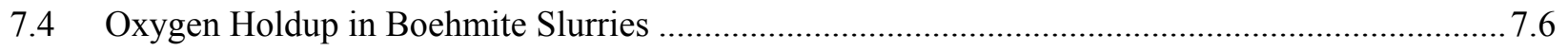




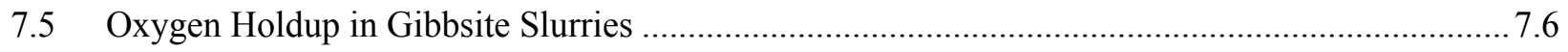

7.6 Effect of AFA on Oxygen Holdup in Ferric Oxide Slurries......................................................... 7.7

7.7 Effect of Yield Stress on Oxygen Holdup in Ferric Oxide Slurries .......................................... 7.8

7.8 Comparison of Oxygen Holdup in Ferric Oxide and Simulated AZ-101 Slurries .........................7.8

\section{Tables}

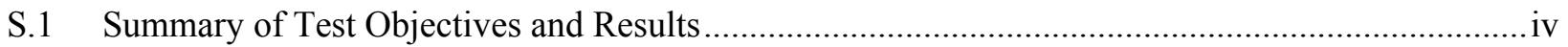

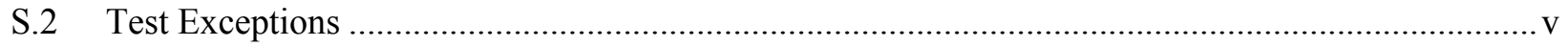

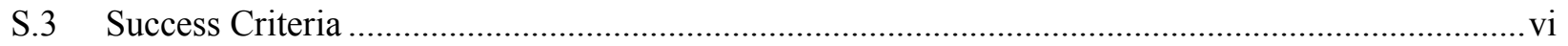

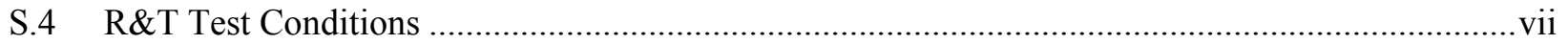

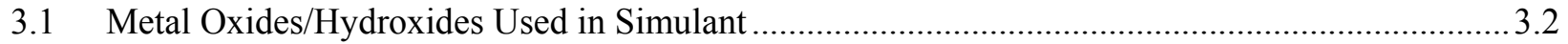

3.2 Chemicals for Producing the HLW Precipitated Hydroxide Feed Simulant .................................. 3.2

3.3 Chemicals for Producing the Cesium Ion Exchange Concentrate Simulant .................................3.3

3.4 Fe-Scaled Simulant Data for Slurry in Analyzed Batches 1, 2, and 3 ........................................ 3.6

3.5 Significant Simulant Properties for PJM Performance and Goal Values .......................................3.8

$5.1 \quad$ Scaled PJM Parameters for Lag Storage Vessels .........................................................................

5.2 Scaled Sparger Parameters for Lag Storage Vessels ..................................................................5.7

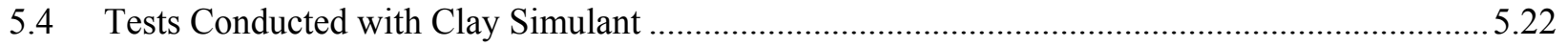

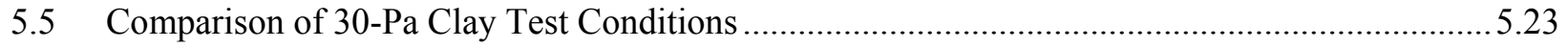

5.6 Tests Conducted with AZ-101 HLW Simulant with AFA ….....................................................25

5.7 Comparison of $F_{w}$ Values for QSLS-07 and SRNL Test Stands .............................................5.27

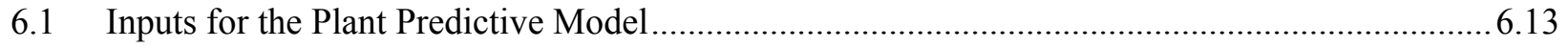

6.2 System Parameters for Lag Storage Systems ....................................................................... 6.13

6.3 Slurry-Related Parameters for QSLS and HSLS Tests and a FSLS Case ................................. 6.14

6.4 Comparison of Measurement and Model Predictions for 2007 QSLS ........................................ 6.17

6.5 Comparison of Measurement and Model Predictions for HSLS-1 ................................................20

6.6 Comparison of Measurement and Model Predictions for HSLS-2 and -3 ...............................6.21

7.1 Physical Properties of Pure Newtonian Solutions and Slurries ................................................... 7.3

7.2 Physical Properties of non-Newtonian Slurries with AFA ......................................................... 7.4

7.3 Average Gas Holdups Relative to Water for Studied Materials .................................................. 7.9 



\section{Acronyms and Abbreviations}

$\begin{array}{ll}\text { acfm } & \text { actual cubic feet per minute } \\ \text { ADM } & \text { axial-dispersion model } \\ \text { AFA } & \text { anti-foam agent } \\ \text { AFAGUI } & \text { AFA graphical user interface } \\ \text { APEL } & \text { Applied Process Engineering Laboratory } \\ \text { CFD } & \text { computational fluid dynamics } \\ \text { CSTRM } & \text { continuous stirred-tank reactor model } \\ \text { DACS } & \text { data acquisition and control system } \\ \text { DBE } & \text { design basis event } \\ \text { DOE } & \text { U.S. Department of Energy } \\ \text { FPC } & \text { FieldPoint computer } \\ \text { FSLS } & \text { full-scale lag storage } \\ \text { HSLS } & \text { half-scale lag storage } \\ \text { JPP } & \text { jet pump pair } \\ \text { ODE } & \text { ordinary differential equation } \\ \text { PJM } & \text { pulse jet mixer } \\ \text { PNNL } & \text { Pacific Northwest National Laboratory } \\ \text { QSLS } & \text { quarter-scale lag storage } \\ \text { ROB } & \text { region of bubbles } \\ \text { scfm } & \text { standard cubic feet per minute } \\ \text { SRNL } & \text { Savannah River National Laboratory } \\ \text { TWINS } & \text { Tank Waste Information Network System } \\ \text { WTP } & \text { Waste Treatment Plant } \\ \text { ZOI } & \text { zone influence } \\ & \end{array}$

\section{Nomenclature}

$\alpha$

$\alpha_{A}$

$\alpha_{b}$

$\alpha_{\mathrm{G}}$

$\alpha_{G s s}$

$\alpha_{G}(t)$

$\alpha_{\text {Gmax }}$ volume fraction of gas (not distinguishing between retained and sparge gas) sparge gas volume fraction gas volume fraction of in situ slurry at baseline conditions; approximately zero holdup (retained) gas volume fraction in bubbly slurry retained gas volume fraction at dynamic steady state retained gas volume fraction as a function of time maximum retained gas volume fraction 


\begin{tabular}{|c|c|}
\hline$\alpha_{\mathrm{Gmin}}$ & minimum retained gas volume fraction \\
\hline$\alpha_{0}$ & initial gas volume fraction (volume of gas/(total slurry + gas volume)) \\
\hline$b_{1}$ & slope estimate obtained from the simple linear regression \\
\hline$\beta_{1}$ & slope according to the null hypothesis \\
\hline$\Delta \mathrm{P}_{\mathrm{b}}$ & baseline pressure differential between upper and lower transducers $(\mathrm{Pa})$ \\
\hline$\Delta \mathrm{P}$ & pressure differential at time $\mathrm{t}(\mathrm{Pa})$ \\
\hline$\mu_{\mathrm{B}}$ & Bingham consistency factor $(\mathrm{Pa}-\mathrm{s})$ \\
\hline$\rho$ & density $\left(\mathrm{kg} / \mathrm{m}^{3}\right)$ \\
\hline$\rho_{b}$ & gasless density of slurry for sample taken at baseline conditions $\left(\mathrm{kg} / \mathrm{m}^{3}\right)$ \\
\hline$\rho_{H}$ & density of peroxide solution $\left(\mathrm{kg} / \mathrm{m}^{3}\right)$ \\
\hline$\rho_{s}$ & average density of total solid in slurry $\left(\mathrm{kg} / \mathrm{m}^{3}\right)$ \\
\hline$\rho_{w}$ & density of water $\left(\mathrm{kg} / \mathrm{m}^{3}\right)$ \\
\hline$\tau$ & Bingham yield stress or shear strength $(\mathrm{Pa})$ of the slurry \\
\hline$\tau_{\mathrm{s}}$ & shear strength $(\mathrm{Pa})$ of the slurry \\
\hline$\tau_{0}$ & Bingham model yield stress $(\mathrm{Pa})$ \\
\hline$\phi$ & solid volume fraction in slurry \\
\hline$\omega$ & water mass fraction in gasless slurry at time $\mathrm{t}$ \\
\hline$\omega_{b}$ & water mass fraction in gasless slurry for sample taken at baseline conditions \\
\hline$\omega_{H}$ & $\mathrm{H}_{2} \mathrm{O}_{2}$ mass fraction in peroxide solution \\
\hline$\omega_{\mathrm{s}}$ & total solids mass fraction \\
\hline a & specific interfacial area of each bubble $\left(\mathrm{m}^{-1}\right)$ \\
\hline$a_{v}$ & area of all bubbles per volume of slurry $\left(\mathrm{m}^{-1}\right)$ \\
\hline A & surface area of slurry $\left(\mathrm{m}^{2}\right)$ \\
\hline$A_{n}$ & area of a PJM nozzle $\left(\mathrm{m}^{2}\right)$ \\
\hline $\mathrm{A}_{\mathrm{pt}}$ & internal area of the cylindrical section of a pulse tube $\left(\mathrm{m}^{2}\right)$ \\
\hline $\mathrm{A}_{\mathrm{t}}$ & area of the cylindrical portion of a pulse tube $\left(\mathrm{m}^{2}\right)$ \\
\hline$A_{t}$ & surface area of the slurry in the tank $\left(\mathrm{m}^{2}\right)$ \\
\hline $\mathrm{C}_{\mathrm{Di}}$ & molar concentration of dissolved gas $i\left(\mathrm{~mol} / \mathrm{m}^{3}\right)$ \\
\hline$C_{D i}^{*}$ & saturated molar concentration of dissolved gas $i\left(\mathrm{~mol} / \mathrm{m}^{3}\right)$ \\
\hline $\mathrm{dH}_{\mathrm{p} t} / \mathrm{dt}$ & rate of change of simulant level in the pulse tubes \\
\hline $\mathrm{D}_{\mathrm{ROB}}$ & diameter of the ROB (inches) at the surface \\
\hline $\mathrm{D}_{\text {ZOI }}$ & diameter of ZOI (inches) at the surface \\
\hline $\mathrm{f}_{\mathrm{w}}$ & mass fraction of water in peroxide solution, including water produced by reaction \\
\hline$F_{W}$ & $\begin{array}{l}\text { waste factor (ratio of retained gas holdup in AZ-101 simulant with AFA to that in } \\
\text { clay simulant without AFA) }\end{array}$ \\
\hline $\mathrm{F}_{\mathrm{e}}$ & unitless adjustment factor for water evaporation rate \\
\hline $\mathrm{F}_{\mathrm{V}, \mathrm{g}}$ & volume/level relation determined by measurement (per Appendix A) \\
\hline
\end{tabular}




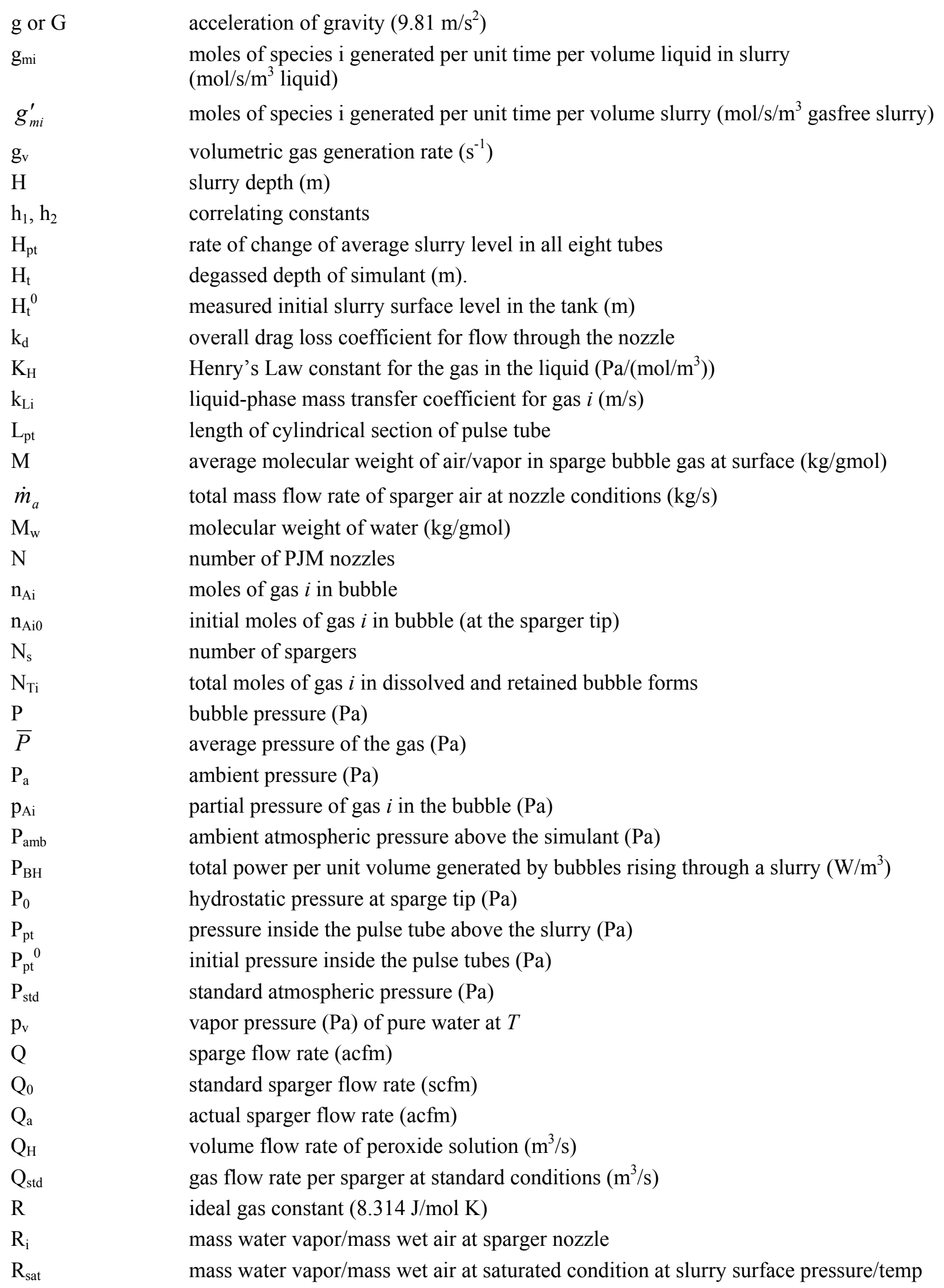




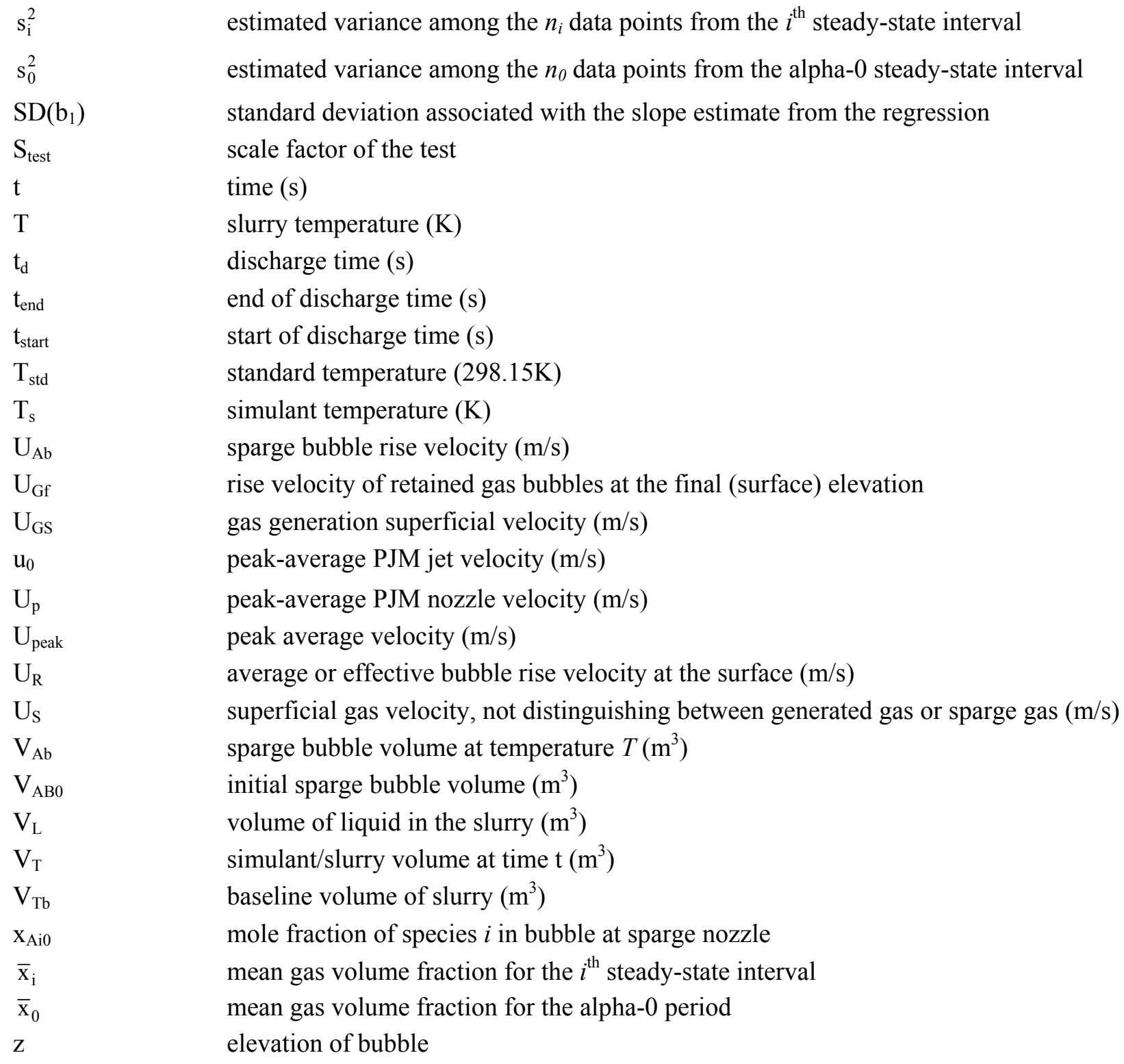

estimated variance among the $n_{i}$ data points from the $i^{\text {th }}$ steady-state interval estimated variance among the $n_{0}$ data points from the alpha- 0 steady-state interval standard deviation associated with the slope estimate from the regression scale factor of the test time (s) slurry temperature $(\mathrm{K})$ discharge time (s) end of discharge time (s) start of discharge time (s) standard temperature $(298.15 \mathrm{~K})$ simulant temperature $(\mathrm{K})$ sparge bubble rise velocity $(\mathrm{m} / \mathrm{s})$ rise velocity of retained gas bubbles at the final (surface) elevation gas generation superficial velocity $(\mathrm{m} / \mathrm{s})$ peak-average PJM jet velocity $(\mathrm{m} / \mathrm{s})$ peak-average PJM nozzle velocity $(\mathrm{m} / \mathrm{s})$ peak average velocity $(\mathrm{m} / \mathrm{s})$ average or effective bubble rise velocity at the surface $(\mathrm{m} / \mathrm{s})$ superficial gas velocity, not distinguishing between generated gas or sparge gas $(\mathrm{m} / \mathrm{s})$ sparge bubble volume at temperature $T\left(\mathrm{~m}^{3}\right)$ initial sparge bubble volume $\left(\mathrm{m}^{3}\right)$ volume of liquid in the slurry $\left(\mathrm{m}^{3}\right)$ simulant/slurry volume at time $\mathrm{t}\left(\mathrm{m}^{3}\right)$ baseline volume of slurry $\left(\mathrm{m}^{3}\right)$ mole fraction of species $i$ in bubble at sparge nozzle mean gas volume fraction for the $i^{\text {th }}$ steady-state interval mean gas volume fraction for the alpha- 0 period elevation of bubble 


\subsection{Introduction}

This report describes the results of a test program conducted at Pacific Northwest National Laboratory (PNNL) and Savannah River National Laboratory (SRNL) to evaluate holdup and release of gas bubbles generated in waste simulants with an anti-foam agent (AFA) in accordance with Test Specification 24590-WTP-TSP-RT-06-002 Rev. 0, Large Scale Testing for Effects of Anti-Foam Agent on Gas Retention/Release. Previous testing in small-scale bubble columns and mixing vessels indicated that adding AFA increased bulk gas retention by more than a factor of 10. This raised the concern that, if gas retention in the Hanford Waste Treatment and Immobilization Plant (WTP) process vessels was increased by a similar factor, flammable gas safety limits might be exceeded during reduced vessel mixing after a design basis power loss event (DBE). This would require modifications to the WTP [additional air compressors to support more frequent pulse jet mixer (PJM) and sparger operation], revisions in the flammable gas safety basis, or qualification of an acceptable alternative AFA.

This test program was undertaken to determine whether AFA has as strong an effect in a large-scale prototypic mixing system as it did in the small-scale tests, and, if it does, to help provide a technical basis for modifying the design and operating strategies to mitigate potential adverse effects. In addition to the large-scale gas retention and release testing, the program included a survey of the mechanisms by which AFA can affect gas retention, large-scale tests to quantify the mitigating effect of mass transfer of dissolved gases to sparged air bubbles, small-scale tests to evaluate the effect of simulant composition on gas retention, small-scale tests to find alternative AFAs, and development of improved models to predict gas retention and release in full-scale WTP process vessels.

This section provides the background for this test program. Section 1.1 summarizes the development of PJM mixing theory and the associated gas retention and release theory. Section 1.2 describes previous tests that revealed the effect of AFA on gas retention and release, and Section 1.3 summarizes the tasks in the AFA Phase 2 program and how they are interrelated.

\subsection{WTP Gas Retention and Release Testing Overview}

The WTP is being designed and built to pretreat and vitrify a large portion of the waste in Hanford's 177 underground waste storage tanks. Some of the WTP process streams consist of waste slurries that contain relatively high concentrations of undissolved solids that are expected to exhibit non-Newtonian rheological behavior.

Based on rheological measurements of pretreated tank waste samples, the Bingham yield stress model, using yield stress $\tau_{0}$ and consistency factor $\mu_{B}$, (a) best represents non-Newtonian waste streams (Poloski et al. 2004). When not under shear, this kind of material is an immobile solid-liquid matrix that deforms like a solid under applied stress; it also exhibits shear strength, $\tau_{s}$, and the stress that must be exceeded before it begins to flow. These complex fluids must be mixed sufficiently to satisfy process requirements and to prevent hazardous volumes of flammable gases generated by radioactivity and chemical reactions from building up in the settled solids.

(a) In some past work, the symbols $\tau_{y}$ and $k$ were used instead of $\tau_{0}$ and $\mu_{B}$. 
The primary method of mixing in most vessels in the pretreatment facility is the PJM because it has no moving parts that require maintenance. A PJM consists of a large vertical pulse tube with an air pressure/vacuum source connected to the top and a nozzle attached to the base that exits near the tank bottom. PJMs operate by first applying a vacuum to fill the pulse tube with slurry, then applying pressure to expel the slurry through the nozzles at high velocity. The duration of the PJM drive cycle at full scale is $\sim 230$ seconds, with a jet drive period of 30 seconds. The total volume of the pulse tube assembly is about $10 \%$ of the total tank volume.

Because PJMs had not been used in non-Newtonian slurries, an integrated scaled testing program was required to provide a technical basis for the WTP vessels expected to contain them (Meyer et al. 2005). This program resulted in a scaling theory for pulse jet mixing of non-Newtonian fluids (Bamberger et al. 2005) based on the concept of intermittent mixing within the PJM "cavern," a region near the PJM nozzles where the yielded slurry experiences turbulent flow. The cavern is bounded by immobile, solidified slurry.

To ensure mixing of the region above the PJM cavern, air spargers were added. The combined system of PJMs plus spargers is the "hybrid" mixing system. The full-scale air-sparging systems consist of 15 to 36 pipes, 2 inches in diameter, which exit near the tank bottom. Through each flows 7 to 25 acfm of air, producing large bubbles several inches to $\sim 1 \mathrm{ft}$ in diameter. Sparge action produces a high-speed upwelling region of bubbles (ROB) surrounded by a slow downward flow in the wider zone of influence (ZOI). Correlations were developed from testing results at nearly full scale to relate the ROB and ZOI diameters to the sparging air flow rate (Poloski et al. 2005). Adequate mixing is ensured if sparge tubes are arranged so there is adequate overlap of the individual sparging-induced mixing regions. The hybrid mixing system concept is illustrated in Figure 1.1.

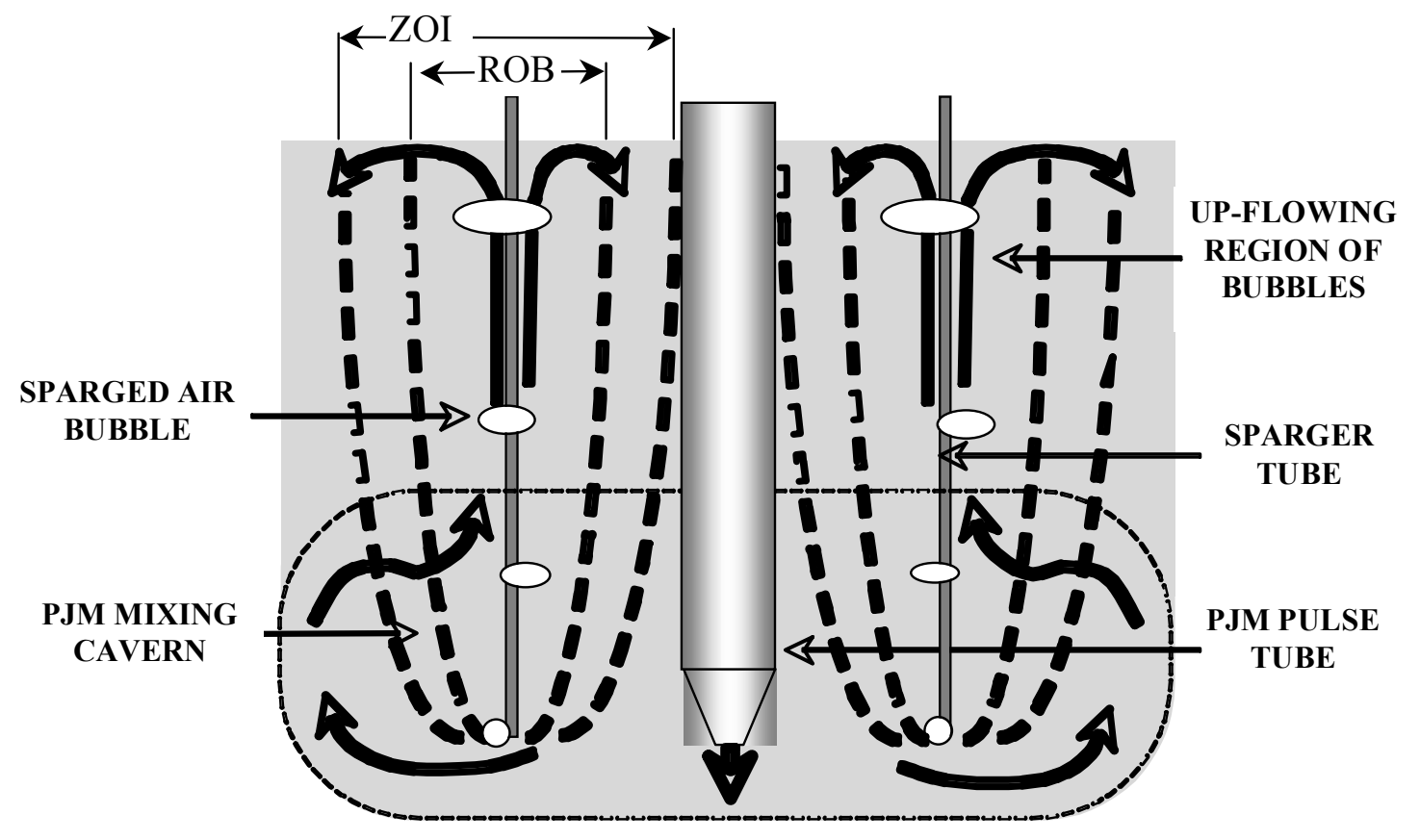

Figure 1.1. Illustration of Hybrid PJM/Sparger Mixing Concept 
In fluids without yield stress, gas bubbles of all sizes rise continuously and are retained only in the sense that they exist within the fluid during their transit time to the surface. In materials with yield stress, bubbles can rise only if their buoyant force exceeds the force exerted by the limiting stress in the material. The bounding yield stress for slurry in the WTP is $30 \mathrm{~Pa}$, which will retain bubbles up to about $5 \mathrm{~mm}$ in diameter (Stewart et al. 1996). Therefore, the bubbles generated in situ that are retained when the WTP mixing system is not operating are small and spherical or slightly ellipsoidal.

These small bubbles are distributed relatively uniformly throughout the slurry during mixing and remain so when mixing stops. A material with a uniform bubble distribution can retain large volumes of gas. During static holding periods before gas release tests using hydrogen peroxide decomposition to generate gas, gas volume fractions up to 0.1 were measured (Russell et al. 2005). A clay simulant with a shear strength of $30 \mathrm{~Pa}$ exhibited maximum gas volume fractions up to 0.4 (Gauglitz et al. 1996).

Data from gas retention and release tests to date show that the small retained bubbles rise predictably through the non-Newtonian slurry while it is being sheared or mixed by PJMs, air sparging, or a rotary mixing vane (Russell et al. 2005, Bontha et al. 2005, Poloski et al. 2005, Stewart et al. 2006). In steadystate mixing, the volume fraction, $\alpha_{\mathrm{G}}$, ${ }^{(a)}$ of these bubbles in transit is proportional to the generated gas superficial velocity (volumetric gas generation rate divided by surface area) raised to approximately the $1 / 3$ power (Stewart et al. 2006). This is similar to trends observed in large industrial mixing vessels (e.g., Smith 2006).

The air sparge system is designed to produce air bubbles that are large enough to mobilize and mix the slurry without any other mixing system. Design airflow rates suggest that the diameter of the sparged air bubbles will be on the order of several inches, based on the bubble size correlation recommended by Chhabra (1993) for non-Newtonian fluids. This is consistent with visual observations of bubble frequency and surface disturbance in half-scale tests in clay with a 30- to 35-Pa yield stress. Bubbles of this size are retained only in the sense that they are present in the slurry as they rise rapidly through it. They do not recirculate to any significant extent. The measured gas volume fraction of these large bubbles in transit is very low, $\sim 0.005$ (Bontha et al. 2005, Poloski et al. 2005).

Gas is released from the slurry by the simple mechanism of bubbles rising through the slurry to the surface, where they eventually burst and release their gas. ${ }^{(b)}$ The large sparged air bubbles rise rapidly from the moment they are formed at the sparge tube exit. The small in situ generated bubbles can rise only when the surrounding slurry is mobilized by shearing forces from an independent source; in this case, PJM jets and large sparged air bubbles. In both cases, because mass conservation dictates that the average vertical velocity of the non-gas portion of the slurry is zero, the gas release rate is determined only by the relative rise speed of the bubbles relative to the slurry. The complexity and intensity of the slurry circulation is immaterial.

Mixing is neither uniform nor continuous in the WTP. The PJM jets mix the slurry for about 30 seconds every few minutes depending on the vessel. Spargers may not operate continuously and the

(a) In past work there was no need to distinguish between sparge gas holdup and retained gas holdup, so the bulk volume fraction of retained gas was referred to simply as $\alpha$.

(b) The details of the bursting process are immaterial to gas release. Once a bubble reaches the surface, it has left the bulk fluid and ceases to be of interest. Production and control of surface foam is a separate issue. 
intensity of mixing varies over the volume. However, an effective bubble rise speed can be used to characterize the overall gas release performance of a specific mixing system. Gas retention and release scaling theory in a non-Newtonian slurry assumes that gas exists as discrete bubbles that rise through the slurry in a mixed (i.e., mobilized and flowing) region but are fixed when mixing ceases. Under the simplest assumption, that the bubble rise speed does not depend on the holdup, the volume fraction of generated gas, $\alpha_{\mathrm{G}}(\mathrm{t})$, is determined by the following expression (Russell et al. 2005):

$$
\alpha_{G}(t)=\alpha_{G 0} e^{-\frac{U_{G f}}{H} t}+g_{v} \frac{H}{U_{G f}}\left(1-e^{-\frac{U_{G f}}{H} t}\right)
$$

where

$\alpha_{\mathrm{G} 0}=$ initial generated gas volume fraction (volume of gas/(total slurry + gas volume))

$\mathrm{U}_{\mathrm{Gf}}=$ effective generated gas bubble rise velocity at the surface $(\mathrm{m} / \mathrm{s})$ (in past work, this has been referred to as $U_{R}$ )

$\mathrm{H}$ = effective slurry depth (m), equal to the total slurry volume divided by the vessel cross-sectional area at the surface

$\mathrm{g}_{\mathrm{v}}=$ volumetric gas generation rate $(1 / \mathrm{s})$, (volume of gas generated/unit volume of slurry/unit time).

The effect of mixing on gas retention and release is defined by the time constant $\mathrm{H} / \mathrm{U}_{\mathrm{Gf}}$, where the bubble release velocity $U_{\mathrm{Gf}}$ includes the combined effects of intermittency and nonuniformity. The higher the bubble rise speed or the lower the slurry depth, the faster gas is released and the lower the retained gas volume fraction is. If mixing continues for a long time, Eq. (1.1) reduces to a steady-state form:

$$
\alpha_{G s s}=g_{v} \frac{H}{U_{G f}}
$$

The product, $\mathrm{g}_{\mathrm{v}} \mathrm{H}$, is the superficial velocity of gas generation, $\mathrm{U}_{\mathrm{Gs}}$, which is the measure of the volumetric rate of gas volume flow per unit area.

Gas accumulates during periods when the mixing system is not operating and the unsheared slurry acts as a solid, and thus $\mathrm{U}_{\mathrm{Gf}}$ is zero. In this condition, Eq. (1.1) reduces to

$$
\alpha_{G}(t)=\alpha_{G 0}+g_{v} t
$$

In cyclic operation, a repeating quasi-steady cycle occurs where the maximum gas volume fraction, $\alpha_{\mathrm{Gmax}}$, at the end of the unmixed period is described by Eq. (1.3) and $\alpha_{\mathrm{G} 0}$ is set to the minimum gas volume fraction, $\alpha_{\mathrm{Gmin}}$. This minimum gas volume fraction occurs at the end of a mixing period and is defined by Eq. (1.1), with $\alpha_{\mathrm{G} 0}$ set to $\alpha_{\mathrm{Gmax}}$ from the preceding reduced mixing period. If the mixing period lasts for several time constants, $\tau=\mathrm{H} / \mathrm{U}_{\mathrm{Gf}}$, then $\alpha_{\mathrm{Gmin}}$ can be approximated by Eq. (1.2).

\subsection{Origin of the AFA Issue}

The mixing as well as other waste pretreatment processes such as evaporative concentration in the WTP tend to create foam. This is a common operational problem, and adding an AFA was recommended 
to control foam buildup in evaporators used to concentrate tank waste at Hanford and at the Savannah River Site. Bechtel National, Inc. has likewise chosen an AFA additive for waste streams in the WTP to prevent foaming (Baich et al. 2003). It is a surface-active agent consisting mostly of the polymers polydimethylsiloxane ${ }^{(a)}$ and polypropylene glycol.(b)

In 2004, tests were conducted in a bubble column to investigate gas holdup as a function of gas composition and waste rheology in water, a mixture of kaolin clay and bentonite clay, and a chemical representative of pretreated high-level waste (HLW) from Tank AZ-101 (Russell et al. 2005). The AZ-101 simulant developed by Eibling et al. (2003) is chemically similar to radioactive waste in Tank AZ-101 and is referred to in this document as "AZ simulant" or "AZ-101." The chosen AFA was added to both the clay and the AZ-101 simulants. The results of the bubble column tests indicated that the presence of AFA in AZ-101 simulant might increase retained gas volume by a factor of up to 10 compared to tests in clay or AZ-101 simulant without AFA. These data, however, were controversial because 1) the bubbles representing the retained gas also provided the mixing, and 2) the bubbles were generated at a ceramic diffuser at the base of the column, a process that might be much more strongly affected by AFA than the process of generating bubbles in situ.

A method was later developed to scale up the results of half-scale gas retention and release tests to predict gas volume fractions in the WTP using Eq. (1.1). The scale-up process modified the parameter $\mathrm{U}_{\mathrm{Gf}} / \mathrm{H}$ derived from the half-scale test data to account for differences in physical scale, rheological properties, gas generation rate, and fluid type between test and plant conditions (Bontha et al. 2005).

The largest source of uncertainty in the scale-up process is the difference between the behavior of the clay simulant used in the test and the radioactive waste slurry containing AFA in the plant. Past work expressed this difference in terms of a waste factor, $F_{W}>1$, the ratio of the bubble rise speed in clay simulant to that in waste with AFA under the same conditions. (c) Ignoring the second-order effects, the resulting scale-up expression was

$$
\left(\frac{U_{G f}}{H}\right)_{\text {plant }}=\left(\frac{U_{G f}}{H}\right)_{\text {test }} \frac{S_{\text {test }}}{F_{W}}
$$

where $\mathrm{S}_{\text {test }}$ is the scale factor of the test (e.g., 0.5 for the half-scale test), and the $F_{W}$ factor is defined by

$$
F_{W}=\frac{U_{G f-c l a y}}{U_{G f-\text { waste }+A F A}}=\frac{\alpha_{G, \text { waste }+A F A}}{\alpha_{G, \text { clay }}}
$$

where $\mathrm{U}_{\text {Gf-clay }}$ and $\mathrm{U}_{\mathrm{Gf}-\mathrm{waste}+\mathrm{AFA}}$ are the release velocities of retained gas bubbles for clay simulant and waste plus AFA, respectively, and $\alpha_{\mathrm{G}-\text { clay }}$ and $\alpha_{\mathrm{G}-\text { waste }+\mathrm{AFA}}$ are the retained gas volume fractions for the same slurries.

(a) The polymer $\left(\mathrm{CH}_{3}\right)_{3} \mathrm{SiO}\left[\mathrm{SiO}\left(\mathrm{CH}_{3}\right)_{2}\right]_{\mathrm{n}} \mathrm{Si}\left(\mathrm{CH}_{3}\right)_{3}$ is a common silicone oil.

(b) The hydrocarbon polymer $\mathrm{C}_{3} \mathrm{H}_{8} \mathrm{O}_{2}$ is a relatively hydrophilic part of the AFA mixture.

(c) Because the gas volume fraction is inversely proportional to the bubble rise speed via Eq. (1.2), the ratio may also be expressed as the ratio of the gas volume in waste with AFA to that in clay simulant. 
When the half-scale tests were analyzed, the only data available to quantify the effect of AFA were the results from the bubble column tests. To express both the measurement uncertainty and the doubts about the applicability of the bubble column data, the value of $F_{W}$ was assigned a uniform distribution between 1.0 and 10, which led to a large uncertainty in the scale-up calculation.

The concerns about the applicability and high uncertainty of the bubble column data eventually led to a test program at SRNL to quantify the effect of AFA more precisely. The tests were performed in the existing SRNL 1/9-scale 4PJM test stand(a) with the four PJMs replaced with mixing vanes. Tests were conducted in the modified small-scale test stand from March to June 2006 (Stewart et al. 2006) in water, clay, and AZ simulant with and without AFA. The results of this testing confirmed that the presence of AFA greatly increased gas retention and that the increase was greater at lower yield stress. More significantly, the ratio of gas retention in AZ simulant with AFA to that in clay without AFA was a factor of as much as 15 in the tested range of gas generation rates.

Concerns similar to those raised about the bubble column suggested that the AFA results from Stewart et al. (2006) could not be applied directly to predict WTP operations. Though the mixing system was made independent from the bubble source, its action was unlike that of the PJM-sparger hybrid system planned for the WTP. This difference apparently caused the trends of retained gas volume fraction versus gas superficial velocity (i.e., volumetric gas generation rate divided by the slurry surface area) in the small-scale mixing vessel to diverge from the data trend resulting from previous tests in larger vessels with prototypic mixing systems.

A similar series of tests in a larger-scale prototype PJM/hybrid-mixed vessel using clay, AZ simulant (or similar chemical simulant), and AZ simulant with AFA over a range of yield stress and gas generation rates was recommended to provide this basis. The more complete data set was intended to provide a scaling basis for the chemical simulant that would replace the $F_{w}$ method.

\subsection{Outline of AFA Phase 2 Program}

The results of the SRNL tests raised the issue of flammable gas retention and release during the postDBE period, where PJMs and spargers must be operated intermittently because of the reduced availability of their air supply. Gas bubbles in non-Newtonian materials are essentially immobile when the mixing system is not operating, so the rate of gas retention is equal to the generation rate up to a limit dictated by the shear strength of the material. This static condition is unaffected by the AFA. During mixing periods, however, the AFA could further slow bubble rise and decrease the rate at which gas bubbles are released. Thus, post-DBE operation may require more frequent and longer periods of mixing with PJMs and spargers than originally assumed in WTP design calculations to meet the flammable gas safety criterion. For post-DBE operation, this criterion dictates that retained gas volume be maintained below that which would raise the flammable gas concentration in the vessel headspace to the lower flammability limit if all the gas were released instantaneously.

(a) This test stand is 1/9-scale compared to the large-scale 4-PJM test in the PNNL 336 Building test facility. Based on vessel diameter, it is actually close to $1 / 17$-scale with respect to the full-scale WTP lag storage vessel. The remainder of the report refers to this test vessel as the "SRNL mixing vessel." 
Depending on how much the gas release rate is actually reduced in full-scale systems with AFA added, the plant air supply may not be adequate for the baseline safety strategy. Preliminary scoping calculations performed by WTP Engineering using Eq. (1.1) indicated that the peak retained gas volume was maintained within the safety limits for $F_{W}<10$, but the available air supply would be inadequate to provide sufficient mixing for $F_{W}>10$. Potential alternative strategies to remediate a possible air supply deficit include:

- Providing additional air capacity to support the required mixing schedule or reducing batch volumes to reduce the mixing requirement

- Revising the safety strategy (for example, determining a bounding finite rate of gas release based on accumulated data instead of assuming instantaneous release or crediting the stripping effect of air sparging in reducing the flammable gas concentration in the retained gas) to allow higher retained flammable gas volumes

- Identifying or developing an alternative AFA that reduces surface foaming to acceptable levels in WTP systems without increasing bulk gas retention.

There are several other issues related to the basic problem of AFA effects on gas retention and release and to the available remedial actions in case these effects prove severe. First, the actual mechanisms causing AFA to increase bulk gas retention are not known. This makes firm predictions of AFA effects more difficult and compromises any technical basis developed by testing. Second, all gas retention and release tests thus far have been evaluated in the context of their relationship to the waste in Tank AZ-101. However, waste from this tank is not typical of other wastes, which likely have different and possibly more severe gas retention characteristics.

The AFA Phase 2 project consists of the following seven specific tasks performed by PNNL and SRNL:

Task 1: $\quad$ Define a baseline simulant for Envelope B/D waste from Hanford Tank 241-AZ-101 to use in QSLS vessel with PJM-sparger mixing system (SRNL).

Task 2: Evaluate the theoretical basis for the potential effect of gas composition on gas retention on Hanford waste materials (PNNL).

Task 3: Determine the relationship between gas volume fraction and superficial velocity (that is, gas generation rate) with 1/4-scale PJM-sparger mixing system in water, clay, and waste simulants with and without AFA over a range of shear strengths. In addition, demonstrate gas retention/release behavior in wastes with AFA during the intermittent mixing required to represent post-DBE operations of the WTP (PNNL).

Task 4: Determine mass transfer coefficients for transfer of dissolved slurry gas to sparger air bubbles in simulated waste materials with and without AFA (SRNL).

Task 5: Evaluate and test alternative AFA products and formulations. Recommend a product and/or provide a formulation for a new AFA that does not exhibit deleterious gas retention/release behavior when added to the "bounding waste simulant" defined next (SRNL).

Task 6: Evaluate and test the gas retention/release characteristics of waste simulants made by modifying the baseline AZ-101 recipe. Perform tests using these materials with and without AFA to determine how compositional variations of the waste interact with AFA and alter the gas retention/release behavior of the system (PNNL). 
Task 7: Develop a revised gas retention and release model to predict plant-scale operations for the WTP based on information from testing conducted in the tasks above at PNNL, tasks being performed at SRNL, and information developed from other WTP Project testing programs (PNNL).

This report provides literature summaries, test data results, and gas retention and release model results as specified in the PNNL tasks (SRNL task outcomes are not included). The report describes quality assurance requirements (Section 2) and simulants used in the AFA test series (Section 3). Section 4 describes the effects of gas physical properties on bubble behavior, and Section 5 describes the 1/4-scale test objectives, test stand, and results. Gas retention and release model input parameters and results are presented in Section 6, while Section 7 describes the bounding simulant test results. Section 8 provides overall test results for the 1/4-scale test stand. Cited references are listed in Section 9, and the appendixes contain supporting information. 


\subsection{Quality Assurance}

PNNL is operated by Battelle for DOE. PNNL has a Quality Assurance (QA) program that is based on the requirements as defined in DOE Order 414.1C, Quality Assurance, and 10 CFR 830, Energy/Nuclear Safety Management, Subpart A, Quality Assurance Requirements. PNNL has chosen to implement the requirements of DOE Order 414.1C and 10 CFR 830 Subpart A by integrating them into its management systems and daily operating processes. The procedures necessary to implement the requirements are documented through the Laboratory's Standards-Based Management System.

PNNL implements the RPP-WTP quality requirements by performing work in accordance with the River Protection Project - Waste Treatment Plant Support Program Quality Assurance Plan (RPP-WTPQA-001). Work is performed to the quality requirements of NQA-1-1989 Part I, Basic and Supplementary Requirements, NQA-2a-1990, Part 2.7, and DOE/RW-0333P Rev. 13, Quality Assurance Requirements and Descriptions. Although the test specification, 24590-WTP-TSP-RT-06-002 Rev. 0, Large Scale Testing for Effects of Anti-Foam Agent on Gas Retention/Release, does not impose DOE/RW-033P Rev. 13-because this work is not high-level waste impacting, it is acceptable to exceed QA expectations. These quality requirements are implemented through the RPP-WTP Quality Assurance Manual (RPP-WTP-QA-003).

Experiments that are not method-specific shall be performed in accordance with procedures QA-RPPWTP-1101, "Scientific Investigations," and QA-RPP-WTP-1201, "Calibration Control System," ensuring that sufficient data are taken with properly calibrated measuring and test equipment to obtain quality results (Test Plan).

A log of test activities, data file lists, data sheets, and hand-written notes were maintained in an RPPWTP project-appropriate laboratory record book (LRB). Training and briefings were assigned and documented in accordance with procedure QA-RPP-WTP-201, "Indoctrination and Training." Test instructions were generated according to procedure QA-RPP-WTP-1105, "Test Instructions." Hand calculations were independently checked and verified by an independent technical reviewer according to QA-RPP-WTP-301, "Hand Calculations." Samples were controlled and identified according to QA-RPPWTP-801, "Sample Control"; analytical processes were performed in accordance with requirements in RPP-WTP's statement of work (RPP-WTP-QA-005).

Data from the tests performed and associated observations were recorded in an RPP-WTP projectappropriate LRB or on datasheets associated with a test instruction in accordance with QA-RPP-WTP1705, "Data Entries for Project Records." LRB use and reviews were also conducted following the requirements in QA-RPP-WTP-1705. 


\subsection{Simulants}

The current gas retention and release tests required two different simulants whose non-Newtonian rheological properties varied by dilution with water. Because past 1/4- and 1/2-scale tests had used kaolin/bentonite clay mixtures as physical simulants of Hanford tank wastes, these same simulants were used to compare present and past test results. A nonradioactive chemical simulant of pretreated Hanford tank waste was also required. A simulant of pretreated HLW from Tank AZ-101 was chosen based on its use in previous tests and the determination that its chemical and rheological properties were similar to those of an actual AZ-101 sludge sample (Eibling et al. 2003). This section discusses the chemical simulant (Section 3.1), the clay simulant (Section 3.2), and the AFA (Section 3.3).

\subsection{AZ-101 Waste Simulant}

The physical properties of AZ-101 HLW simulant depend on the insoluble solids loading and thermal processing of the simulant. Therefore, it was important that each batch of simulant be prepared by the same method using the same reagents as much as possible to keep the differences between batches to a minimum.

The composition of the AZ-101 simulant (Eibling et al. 2003, Appendix F) was derived from a combination of AZ-101 waste, based on the characterization of a sample of actual AZ-101 sludge, with a portion of cesium ion exchange concentrate from the return of radioactive cesium from the sludge supernatant to the HLW. The simulant includes all the measured species that are not radioactive or substitutes a nonradioactive surrogate for a radioactive one where appropriate.

Table 3.1 lists specific size-constrained metal oxides that were part of the portion of the simulant that represented AZ-101 waste alone. Table 3.2 lists the remaining chemicals included in the AZ-101 portion of the simulant. The chemicals used for preparing the simulated cesium ion exchange concentrate, which was the remaining component of the AZ-101 simulant, are given in Table 3.3.

The production of the AZ-101 simulant, as originally carried out at SRNL, used reagent-grade chemicals and specific oxides/hydroxides of known particle sizes. After hydrous $\mathrm{MnO}_{2}$ was generated by reacting manganous nitrate, $\mathrm{Mn}\left(\mathrm{NO}_{3}\right)_{2}$, with potassium permanganate, $\mathrm{KMnO}_{4}$, alkaline-earth and transition-metal nitrates were added to the solution. For this particular simulant, the noble metals $\mathrm{Rh}$ and $\mathrm{Ru}$ were omitted from the SRNL recipe. Enough sodium hydroxide (not shown in the tables) was added to increase the $\mathrm{pH}$ to 10 , precipitating metal oxides and hydroxides in the same way as in the original tank waste. A sodium carbonate solution $\left(400 \mathrm{~mL}\right.$ of $\left.0.6 \mathrm{M} \mathrm{Na}_{2} \mathrm{CO}_{3}\right)$ was then mixed in to convert slightly soluble hydroxides to more insoluble carbonates. The resulting slurry was washed to remove excess sodium, nitrate, and carbonate ions, the size-constrained reagents in Table 3.1, were added. The sludge was concentrated to an initial target insoluble solids concentration by boiling at $101^{\circ}$ to $103^{\circ} \mathrm{C}$. Soluble potassium and sodium salts and boric acid (the reagents listed at the end of Table 3.2) were added with a small portion of the simulated cesium ion exchange concentrate described in Table 3.3. The simulant was further concentrated by removing water through sparging rather than boiling. More details can be found in Eibling et al. (2003, Appendix F). 
Table 3.1. Metal Oxides/Hydroxides Used in Simulant

\begin{tabular}{|l|l||}
\hline \multicolumn{1}{|c|}{ Material } & \multicolumn{1}{c|}{ Product Name } \\
\hline Aluminum Oxide, $99.5 \%$ & Fine powder $(98$ vol $\%<27 \mu \mathrm{m})$ \\
\hline Silica, $\mathrm{SiO} 2$ & Silicon(IV) oxide, $99.5 \%-400$ mesh \\
\hline Tin (IV) Oxide & Tin (IV) oxide, $99.9 \%-325$ mesh \\
\hline Titanium Dioxide & Titanium(IV) oxide, powder, $<5$ micron, $99.9+\%$ \\
\hline
\end{tabular}

Table 3.2. Chemicals for Producing the HLW Precipitated Hydroxide Feed Simulant

\begin{tabular}{|c|c|c|}
\hline \multicolumn{3}{|c|}{ FLW Precipitated Hydroxide Feed Simulant } \\
\hline Compounds & Formula & $\begin{array}{c}\text { Mass } \\
(\mathrm{g})\end{array}$ \\
\hline Potassium Permanganate & $\mathrm{KMnO}_{4}$ & 1.913 \\
\hline Manganese Nitrate Solution, $50 \mathrm{wt} \%$ & $\mathrm{Mn}\left(\mathrm{NO}_{3}\right)_{2}$ & 6.500 \\
\hline Ferric Nitrate & $\mathrm{Fe}\left(\mathrm{NO}_{3}\right)_{3} \cdot 9 \mathrm{H}_{2} \mathrm{O}$ & 453.860 \\
\hline Nickel Nitrate & $\mathrm{Ni}\left(\mathrm{NO}_{3}\right)_{2} \cdot 6 \mathrm{H}_{2} \mathrm{O}$ & 15.348 \\
\hline Zirconyl Nitrate & $\mathrm{ZrO}\left(\mathrm{NO}_{3}\right)_{2} \bullet \times \mathrm{H}_{2} \mathrm{O}, \mathrm{X} \sim 6$ & 75.012 \\
\hline Cerium Nitrate & $\mathrm{Ce}\left(\mathrm{NO}_{3}\right)_{3} \cdot 6 \mathrm{H}_{2} \mathrm{O}$ & 5.034 \\
\hline Lanthanum Nitrate & $\mathrm{La}\left(\mathrm{NO}_{3}\right)_{3} \cdot 6 \mathrm{H}_{2} \mathrm{O}$ & 5.612 \\
\hline Neodymium Nitrate & $\mathrm{Nd}\left(\mathrm{NO}_{3}\right)_{3} \cdot 6 \mathrm{H}_{2} \mathrm{O}$ & 4.042 \\
\hline Barium Nitrate & $\mathrm{Ba}\left(\mathrm{NO}_{3}\right)_{2}$ & 0.891 \\
\hline Calcium Nitrate & $\mathrm{Ca}\left(\mathrm{NO}_{3}\right)_{2} \bullet 4 \mathrm{H}_{2} \mathrm{O}$ & 13.708 \\
\hline Cadmium Nitrate & $\mathrm{Cd}\left(\mathrm{NO}_{3}\right)_{2} \bullet 4 \mathrm{H}_{2} \mathrm{O}$ & 12.335 \\
\hline Chromium Nitrate & $\mathrm{Cr}\left(\mathrm{NO}_{3}\right)_{3} \cdot 9 \mathrm{H}_{2} \mathrm{O}$ & 5.450 \\
\hline Cobalt Nitrate & $\mathrm{Co}\left(\mathrm{NO}_{3}\right)_{2} \cdot 6 \mathrm{H}_{2} \mathrm{O}$ & 0.195 \\
\hline Cupric Nitrate & $\mathrm{Cu}\left(\mathrm{NO}_{3}\right)_{2} \cdot 2.5 \mathrm{H}_{2} \mathrm{O}$ & 0.662 \\
\hline Magnesium Nitrate & $\mathrm{Mg}\left(\mathrm{NO}_{3}\right)_{2} \cdot 6 \mathrm{H}_{2} \mathrm{O}$ & 5.036 \\
\hline Lead Nitrate & $\mathrm{Pb}\left(\mathrm{NO}_{3}\right)_{2}$ & 0.856 \\
\hline Strontium Nitrate & $\mathrm{Sr}\left(\mathrm{NO}_{3}\right)_{2}$ & 2.554 \\
\hline Zinc Nitrate & $\mathrm{Zn}\left(\mathrm{NO}_{3}\right)_{2} \cdot 6 \mathrm{H}_{2} \mathrm{O}$ & 0.391 \\
\hline Silver Nitrate & $\mathrm{AgNO}_{3}$ & 0.004 \\
\hline Potassium Nitrate & $\mathrm{KNO}_{3}$ & 1.560 \\
\hline Potassium Molybdate & $\mathrm{K}_{2} \mathrm{MoO}_{4}$ & 0.051 \\
\hline Boric Acid & $\mathrm{H}_{3} \mathrm{BO}_{3}$ & 0.088 \\
\hline Sodium Chloride & $\mathrm{NaCl}$ & 0.196 \\
\hline Sodium Fluoride & $\mathrm{NaF}$ & 0.146 \\
\hline Sodium Sulfate & $\mathrm{Na}_{2} \mathrm{SO}_{4}$ & 0.604 \\
\hline Sodium Phosphate & $\mathrm{Na}_{3} \mathrm{PO}_{4} \bullet 12 \mathrm{H}_{2} \mathrm{O}$ & 9.370 \\
\hline Sodium Hydroxide & $\mathrm{NaOH}$ & 6.430 \\
\hline Sodium Carbonate & $\mathrm{Na}_{2} \mathrm{CO}_{3}$ & 6.680 \\
\hline Sodium Nitrite & $\mathrm{NaNO}_{2}$ & 1.170 \\
\hline
\end{tabular}


Table 3.3. Chemicals for Producing the Cesium Ion Exchange Concentrate Simulant

\begin{tabular}{|c|c|c|}
\hline \multicolumn{3}{|c|}{ Cesium Ion Exchange Concentrate Simulant } \\
\hline Compounds & Formula & Mass (grams) \\
\hline Water & $\mathrm{H}_{2} \mathrm{O}$ & 200 \\
\hline Aluminum Nitrate & $\mathrm{Al}\left(\mathrm{NO}_{3}\right)_{3} \cdot 9 \mathrm{H}_{2} \mathrm{O}$ & 8.19 \\
\hline Sodium Borate & $\mathrm{Na}_{2} \mathrm{~B}_{4} \mathrm{O}_{7} \cdot 10 \mathrm{H}_{2} \mathrm{O}$ & 23.39 \\
\hline Cadmium Nitrate & $\mathrm{Cd}\left(\mathrm{NO}_{3}\right)_{2} \bullet 4 \mathrm{H}_{2} \mathrm{O}$ & 0.404 \\
\hline Calcium Nitrate & $\mathrm{Ca}\left(\mathrm{NO}_{3}\right) 2 \cdot 4 \mathrm{H}_{2} \mathrm{O}$ & 13.72 \\
\hline Cesium Nitrate & $\mathrm{CsNO}_{3}$ & 1.60 \\
\hline Copper Nitrate & $\mathrm{Cu}\left(\mathrm{NO}_{3}\right)_{2} \cdot 2.5 \mathrm{H}_{2} \mathrm{O}$ & 0.54 \\
\hline Ferric Nitrate & $\mathrm{Fe}\left(\mathrm{NO}_{3}\right)_{3} \cdot 9 \mathrm{H}_{2} \mathrm{O}$ & 3.41 \\
\hline Lead Nitrate & $\mathrm{Pb}(\mathrm{NO} 3)_{2}$ & 0.471 \\
\hline Nickel Nitrate & $\mathrm{Ni}\left(\mathrm{NO}_{3}\right)_{2} \bullet 6 \mathrm{H}_{2} \mathrm{O}$ & 0.438 \\
\hline Potassium Nitrate & $\mathrm{KNO}_{3}$ & 13.943 \\
\hline Sodium Chloride & $\mathrm{NaCl}$ & 2.77 \\
\hline Sodium Sulfate & $\mathrm{Na}_{2} \mathrm{SO}_{4}$ & 12.33 \\
\hline Oxalic Acid & $\mathrm{HO}_{2} \mathrm{CCO}_{2} \mathrm{H} \cdot 2 \mathrm{H}_{2} \mathrm{O}$ & 9.65 \\
\hline Nitric Acid & $\mathrm{HNO} 3,70 \mathrm{wt} \%$ & 434.49 \\
\hline Sodium Meta-Silicate & $\mathrm{Na}_{2} \mathrm{SiO}_{3} \cdot 9 \mathrm{H}_{2} \mathrm{O}$ & 0.52 \\
\hline Sodium Chromate & $\mathrm{Na}_{2} \mathrm{CrO}_{4}$ & 4.957 \\
\hline Sodium Nitrate & $\mathrm{NaNO}_{3}$ & 206.21 \\
\hline Water & $\mathrm{H}_{2} \mathrm{O}$ & 379.25 \\
\hline
\end{tabular}

Figure 3.1 shows the properly prepared simulant in terms of color and fluidity. The slurry color is an important indicator of slurry "aging," which was observed to convert amorphous dark-colored $\mathrm{Fe}(\mathrm{OH})_{3}$ to red-brown $\mathrm{Fe}_{2} \mathrm{O}_{3}$. This dehydration of the iron compound is accelerated by the higher temperature characteristic of boiling.

\subsubsection{Simulant Criteria}

The chief criterion for the simulant was that its composition should be in accord with that implied by the procedure developed by SRNL and summarized above. Many of the salts used in the simulant included waters of hydration; the specific form proposed is shown in Tables 3.2 and 3.3. When the specified reagents were unavailable, it was acceptable for other degrees of hydration or a solution of the compound to be used. The water additions shown in Tables 3.2 and 3.3 were adjusted to account for the water in the solution of the compound.

In addition to meeting chemical composition targets, the vendor needed to meet criteria for weight percent total solids and aging. The weight percent total solids criterion was a value between 26.37 and 27 (wt\%) (corresponding to a density of approximately $1.25 \mathrm{~g} / \mathrm{cc}$, although density was not used as the determining criterion). The $\mathrm{wt} \%$ total solids are correlated with the rheological properties of the waste slurry simulant, and the above value was selected based on the desired properties and on rheological 


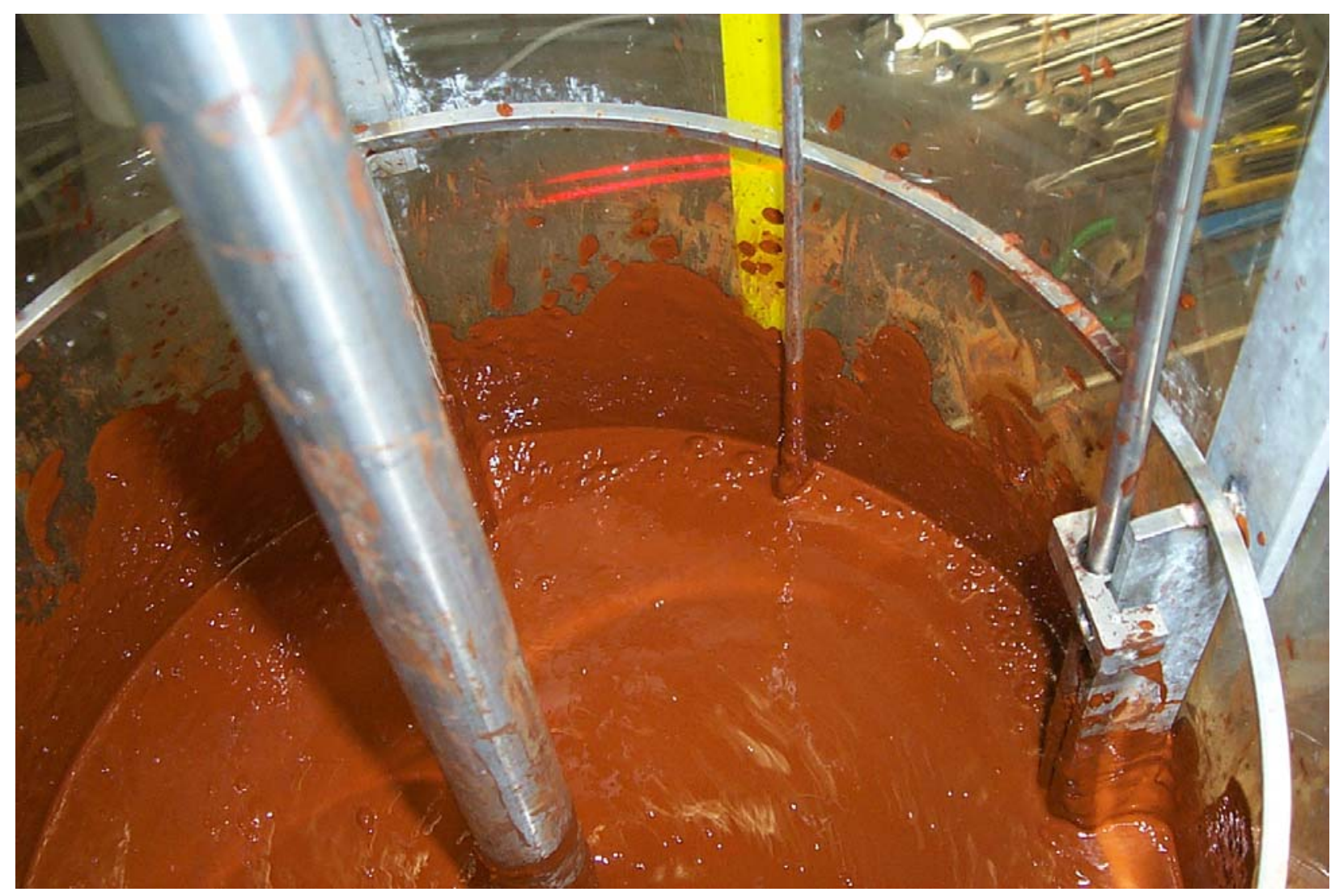

Figure 3.1. Waste Slurry Simulant Being Actively Stirred and Showing Desired Simulant Color at SRNL

measurements of previous batches of this recipe. The rheological behavior is also related to the type of undissolved solids present, which is affected by aging of the undissolved solids, during which the solidphase compounds present and possibly their size distribution are modified by time at boiling temperature.

\subsubsection{Produced Simulant Batches and Confirmatory Analyses}

The vendor, Optima Chemical Co., produced more than 11,000 L of the AZ-101 simulant in several batches. Because a higher solids concentration was required than had been produced by the original procedure, it was agreed that the final concentration step would be carried out by boiling rather than room-temperature sparged evaporation.

Two problem areas were encountered. The first had to do with washing excess nitrate out of the precipitated transition metal hydroxide solids. These solids were produced by coprecipitating the metal hydroxides from a mixed nitrate solution using sodium hydroxide, a process that mimics the way they were originally produced in the Hanford waste tanks. The resultant slurry needed to be washed to remove the sodium nitrate to match the actual AZ-101 HLW. The effluent was apparently incorrectly sampled for the initial batch, underestimating the nitrate content. Subsequent analyses showed that the initial batch had unacceptably high nitrate content. The sampling problem was solved for later batches. 
The second problem area was related to total boiling time and the resulting concentration of the slurry required to achieve the target solids concentration and slurry color. The initial batch was inadvertently over-concentrated; a sample sent to PNNL had a shear strength of over $200 \mathrm{~Pa}$. Slurries of this kind, once concentrated to this extent, do not return to their original properties when rediluted. Hence this initial batch (referred to as batch 1) was rejected as not being representative of a physical simulant. It was not used in any of the gas retention and release or mass transfer tests carried out by PNNL and SRNL.

Subsequent discussions between PNNL, SRNL, and Optima, plus a consultation between SRNL and Optima at PNNL's request, resulted in an adjusted procedure that caused nitrate levels in the finished simulant to be brought into line with the target values. In parallel, the boiling time and slurry concentration activities were adjusted to increase the boiling time while controlling the concentration more closely, preventing the overshoot that occurred with the initial batch.

Table 3.4 summarizes the chemical analyses performed on the slurry in the batches of AZ-101 simulant produced by the vendor and analyzed at PNNL by inductively coupled plasma/atomic emission spectrometry (ICP-AES), ion chromatography (IC), and total organic/inorganic carbons. The composition of the liquid phase in the slurry was not analyzed. The target values in the table are taken from Eibling et al. (2003, Table 44) and are based on analyses of the AZ-101 simulant produced in small batches at SRNL. For the comparisons made in Table 3.4, iron, which is present in the greatest amount, is used to scale all of the analytical data to the same basis. The $\mu \mathrm{g} / \mathrm{g}$ values reported in the table have all been scaled to the same iron concentration, which is a surrogate for total solids concentration. On the assumption that the iron measurement precision is high and the iron reagent was batched accurately, little additional uncertainty has been added by this scaling operation.

In most cases, batches 2 and 3 analyte concentrations are in reasonable agreement with what was expected from the small-batch results described by Eibling et al. (2003). The notable exception is $\mathrm{Zr}$, whose measured concentration is much lower. This low concentration appears to have been a measurement artifact caused by difficulty in dissolving Zr-containing solids in the simulant, in preparation for ICP analysis. To confirm this conclusion, a sample from an intermediate point in the production of batch 2 , before the precipitation of hydroxides, was analyzed. This sample gave an Fe-scaled Zr concentration that was roughly $10 \%$ greater than the expected value, indicating the requisite $\mathrm{Zr}$ was present.

Only batch 2 was used in the QSLS studies. Batch 3, though prepared, was not used because the number of QSLS tests performed was decreased from the original plan. Batch 2 was observed to foam in 2007 SRNL tests, although the original simulant prepared by Eibling et al. (2003) in smaller batches had not foamed. It was not understood what change in preparation method produced the change in simulant behavior.

\subsubsection{Comparison of Properties Between Batches}

Once the initial difficulties were addressed, the vendor was asked to prepare each simulant batch the same way so that the weight percent solids and slurry viscosity and shear strength were the same from batch to batch. The vendor was to accomplish this by boiling down the simulant to give a slurry of about $27 \mathrm{wt} \%$ total solids. This slurry could then be diluted to obtain the lower weight percent total solids that was needed for the test program. 
Table 3.4. Fe-Scaled Simulant Data for Slurry in Analyzed Batches 1,2 , and $3^{(\text {a) }}$

\begin{tabular}{|c|c|c|c|c|}
\hline Chemical & $\begin{array}{c}\text { Eibling et al. } \\
\text { simulant scaled } \\
(\mu \mathrm{g} / \mathrm{g})\end{array}$ & $\begin{array}{c}\text { Batch } 3 \\
\text { scaled } \\
(\mu \mathrm{g} / \mathrm{g}) \\
\end{array}$ & $\begin{array}{c}{\text { Batch } 2^{(\mathbf{b})}}^{\text {scaled }} \\
(\mu \mathrm{g} / \mathrm{g}) \\
\end{array}$ & $\begin{array}{c}\text { Batch } 1 \\
\text { scaled } \\
(\mu \mathrm{g} / \mathrm{g}) \\
\end{array}$ \\
\hline $\mathrm{Al}$ & 86659 & 117693 & 113000 & 81749 \\
\hline $\mathrm{Ba}$ & 1657 & 1638 & 1612 & 1484 \\
\hline B & 3573 & - $^{(\mathrm{c})}$ & - $^{(\mathrm{c})}$ & 314 \\
\hline $\mathrm{Cd}$ & 11265 & 14540 & 13943 & 13161 \\
\hline $\mathrm{C}_{2} \mathrm{O}_{4}$ & 186 & 310 & 325 & 633 \\
\hline $\mathrm{Ca}$ & 8158 & 7765 & 7102 & 9018 \\
\hline $\mathrm{Ce}$ & 3444 & - $^{\text {(c) }}$ & - $^{\text {(c) }}$ & 2453 \\
\hline $\mathrm{Cl}$ & 443 & 880 & 848 & 1267 \\
\hline $\mathrm{Co}$ & 150 & - $^{\text {(c) }}$ & - (c) & 82 \\
\hline $\mathrm{CO}_{3}$ & $\mathrm{NR}^{(\mathrm{d})}$ & $\mathrm{NM}^{(\mathrm{d})}$ & 42375 & 25201 \\
\hline $\mathrm{Cr}$ & 2344 & 2131 & 2334 & 2750 \\
\hline $\mathrm{Cu}$ & 609 & 756 & 508 & 494 \\
\hline $\mathrm{F}$ & 172 & 216 & 310 & 284 \\
\hline $\mathrm{Fe}$ & 202384 & \multicolumn{3}{|c|}{ same value - was the scaling basis } \\
\hline $\mathrm{K}$ & 3172 & $-^{(\mathrm{c})}$ & - (c) $^{(1)}$ & 4038 \\
\hline $\mathrm{La}$ & 3755 & 4611 & 4996 & 4816 \\
\hline $\mathrm{Mg}$ & 1554 & 1658 & 1278 & 2543 \\
\hline $\mathrm{Mn}$ & 5438 & 5723 & 5810 & 5474 \\
\hline Mo & $\mathrm{NR}^{(\mathrm{d})}$ & 146 & 218 & 138 \\
\hline $\mathrm{Na}$ & 42212 & - $^{(\mathrm{c})}$ & - $^{\text {(c) }}$ & 61020 \\
\hline $\mathrm{Nd}$ & 3108 & 3579 & 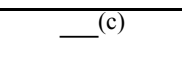 & 2737 \\
\hline $\mathrm{Ni}$ & 9970 & 10030 & 9470 & 9497 \\
\hline $\mathrm{NO}_{2}$ & 4623 & 4554 & 3971 & 6745 \\
\hline $\mathrm{NO}_{3}$ & 48686 & 57817 & 58643 & 90723 \\
\hline $\mathrm{Pb}$ & $\mathrm{NR}^{(\mathrm{d})}$ & 1840 & 1496 & 1690 \\
\hline $\mathrm{P}$ & 2564 & 3215 & 2716 & 3141 \\
\hline $\mathrm{PO}_{4}$ & 627 & 694 & 425 & 311 \\
\hline$S$ & $\mathrm{NR}^{(\mathrm{d})}$ & - $^{(\mathrm{c})}$ & - $^{\text {(c) }}$ & 7478 \\
\hline $\mathrm{Si}$ & 15794 & 15571 & 15541 & 18246 \\
\hline $\mathrm{Sn}$ & 1554 & 3883 & 4648 & 3619 \\
\hline $\mathrm{SO}_{4}$ & 1997 & 2884 & 2699 & 6491 \\
\hline $\mathrm{Sr}$ & $\mathrm{NR}^{(\mathrm{d})}$ & 3130 & 3371 & 3084 \\
\hline $\mathrm{Ti}$ & 341 & 224 & 257 & 248 \\
\hline TOC & $\mathrm{NR}^{(\mathrm{d})}$ & $\mathrm{NM}^{(\mathrm{d})}$ & 327 & 239 \\
\hline $\mathrm{Zn}$ & 337 & 506 & 523 & 292 \\
\hline $\mathrm{Zr}$ & 61505 & 9221 & 10661 & 27863 \\
\hline
\end{tabular}

(a) Concentrations in italics were below the quantitation limit; error can be $>15 \%$.

(b) Only batch 2 was used in the QSLS tests.

(c) Blank cells indicate concentrations below the lower detection limit for the analyte.

(d) NM indicates analyte was not measured; NR indicates not reported. 
To compare the results from PNNL and SRNL, a similar rheological analysis procedure was adopted. Rheograms were analyzed from $50-1000 \mathrm{~s}^{-1}$ by fitting to the Bingham equation, and only the down curve (e.g., decreasing shear rate) yield stress data were reported for comparison. Despite an agreed-upon rheological procedure, PNNL and SRNL have different rheometers. The differences between the two instruments can create a small variation in the yield stress results obtained. The method used to determine the weight percent total solids was also different. PNNL used a standard oven method of drying the samples in 24-hour increments at $105^{\circ} \mathrm{C}$ until a steady mass was achieved. SRNL used a Mettler-Toledo moisture analyzer to determine weight percent total solids.

PNNL and SRNL each received batch samples from Optima for analysis. Figure 3.2 shows yield stress as a function of weight percent total solids from PNNL and SRNL for Optima simulant batches 1 and 2. This plot shows PNNL results for an aged batch 1 sample. Originally, the batch 1 sample was not analyzed according to the above description. The samples were analyzed again after approximately seven weeks of aging. PNNL received two samples from batch 2; after the first sample (\#128075) was analyzed, Optima was asked to dilute and remix the simulant before sending another sample (\#128751). A dilution curve was not completed for batch 3 by PNNL because the decision had already been made to proceed with batch 2. Data from pretreated HLW sludge samples (AZ101, AZ102 and C104) are shown as reference with $1 \%$ error bars on the $\mathrm{x}$-axis and $30 \%$ error bars on the $\mathrm{y}$-axis.

The data SRNL obtained for batch 1 and 2 samples show consistency between them. It was found that aging has a significant effect on measured yield stress and $\mathrm{wt}_{\mathrm{t}} \%$ total solids. Comparison of PNNL results of aged batch 1 samples with SRNL batch 1 data or PNNL batch 2 data would not yield a fair

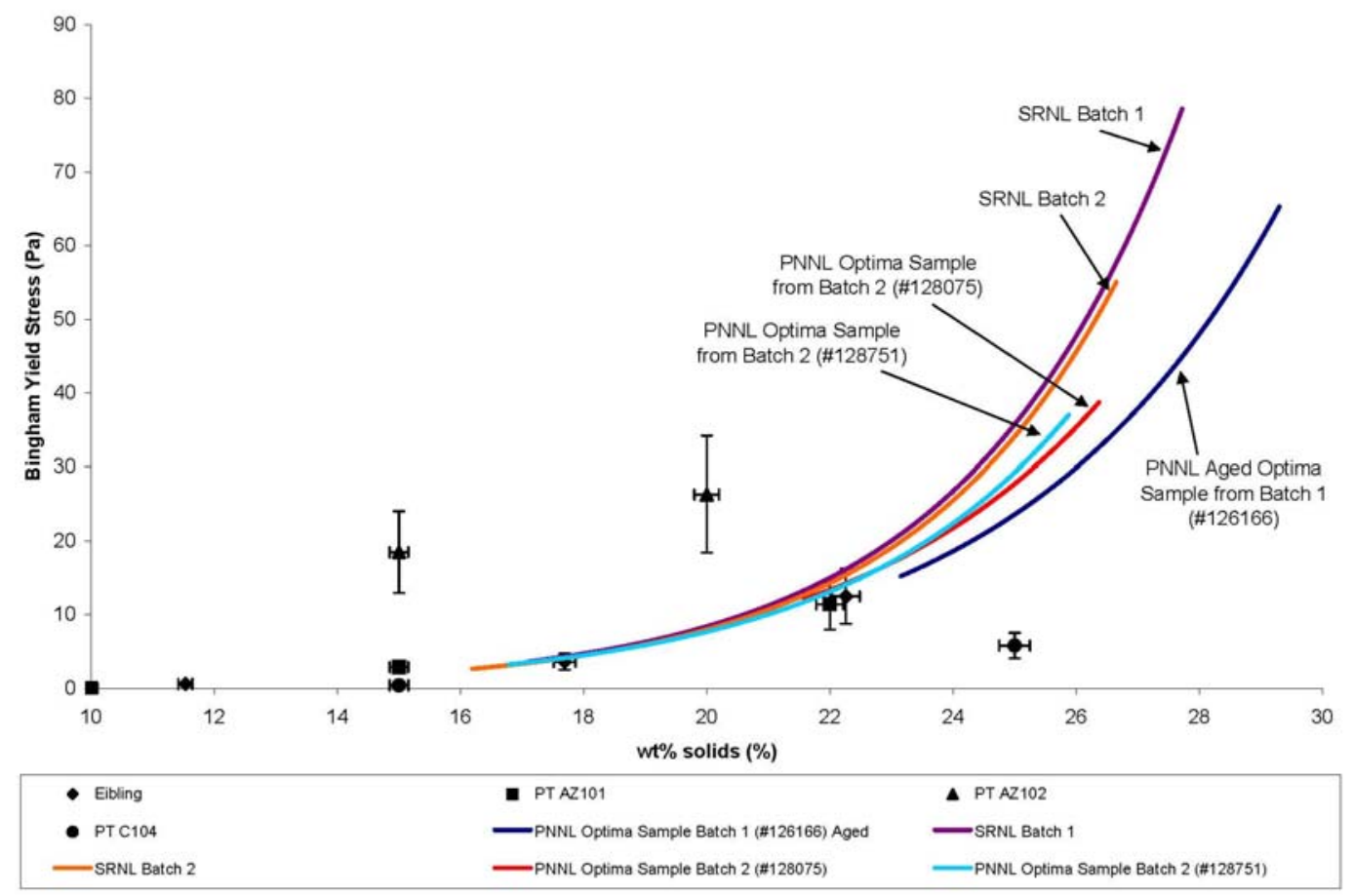

Figure 3.2. Yield Stress as a Function of Weight Percent Total Solids for AZ-101 Simulants Produced by Optima as Reported at PNNL and SRNL 
comparison. The results obtained by PNNL for both batch 2 samples shows consistency within the two samples. A comparison of PNNL data with SRNL data from batch 2 at a yield stress of 30 Pa shows a shift in $\mathrm{wt} \%$ total solids by approximately $1 \%$, which is within experimental error. Additional properties such as surface tension, density, and/or particle size distribution were neither determined nor used for comparison of the received Optima batches.

\subsection{Kaolin-Bentonite Clay Simulant}

As part of the design effort for the WTP, samples of actual Hanford tank waste were taken and processed through laboratory-scale unit operations. Samples were characterized at many points during this testing. Rheological and physical properties were part of this characterization. From this work rheological parameters were defined and simulants developed for larger-scale PJM testing (Poloski 2004).

The rheological parameters identified that are significant to the performance of a PJM mixing vessel were density, Bingham consistency, Bingham yield stress, and shear strength (Poloski et al. 2004). The Bingham plastic model was determined to be the most conservative of the curve fits for design estimation and therefore was the method of choice for further testing. For AFA testing, all evaluations were to be done from fully developed steady-state mixing conditions, so shear strength was not a critical parameter.

Table 3.5. Significant Simulant Properties for PJM Performance and Goal Values

\begin{tabular}{||l|c||}
\hline \multicolumn{1}{|c||}{ Property } & Goal Values \\
\hline Density & $1.2 \mathrm{~g} / \mathrm{mL}$ \\
\hline Bingham Consistency & $30 \mathrm{cP}$ \\
\hline Bingham Yield Stress & $30 \mathrm{~Pa}$ \\
\hline Shear Strength & $80 \mathrm{~Pa}$ \\
\hline
\end{tabular}

Because testing took place in relatively large amounts of 100 to 10,000 gallons, the original PJM simulants needed to be nonhazardous. Loading, unloading, and sampling of the simulant presented many opportunities for personnel exposure, and working in personal protective equipment for several hours during a test would have added undesirable complications to the initial PJM testing. For this reason, clay was used for most of the scale testing originally done. While the AFA work was also being done with a chemical simulant (AZ-101), it was determined that clay testing should also be done so that data could be compared directly with previous testing.

Rassat et al. (2003) developed a simulant for Hanford tank retrieval studies based on clay suspensions that are readily available because they are used in industry. The clay exhibits a shear-thinning pseudoplastic flow. This simulant was a mixture of $80 \%$ kaolin (EPK Feldspar pulverized) and 20\% bentonite (WYO-Ben Big Horn CH-200) powder mixed to various solids concentrations in process water. This recipe produced a simulant with Bingham plastic properties near the goal of 30-Pa yield stress and 30-cP consistency. These properties usually occurred at a solids loading in the $20-30 \mathrm{wt} \%$ range. 
Poloski et al. (2004) refined this recipe for PJM testing. The AFA clay simulant used this 80/20 kaolin/bentonite ratio for the base simulant recipe and adjusted rheology by varying solids concentration.

- Yield stress was a primary control variable for the clay testing. The simulant targets for AFA testing were 30,13 , and $3 \pm 3 \mathrm{~Pa}$.

- Consistency was a secondary consideration, reported but not controlled.

- Density was reported but not controlled.

Because AFA testing required large quantities of clay simulant, preparation was subcontracted to a chemical manufacturer. When scaling a recipe up from laboratory to production scale, complex preparation procedures and variations in stock material of the dry clay mixtures often led to large deviances from target simulant properties. Aging effects also caused variations in the rheological properties from those measured immediately after mixing. When this occurred, rheology would need to be adjusted in the AFA testing tank by adding water or dry clay as needed. Over the course of testing, biological growth might have changed rheological properties; that possibility needed to be minimized as much as possible. Therefore, a biocide was included in the clay simulant make-up recipe.

Aging (hydration of the base material) had a significant effect on clay rheology; thus, time was required after initial make-up and concentration adjustments for the rheology to stabilize. Testing took place over several weeks, and during each test, the simulant was exposed to shear forces that could have degraded the simulant and changed its rheological properties. Thus, rheological testing was done at the start and finish of every test, and samples were pulled during testing at opportunistic points. Rheology adjustments were made if the simulant was determined to be out of specification.

\subsection{Anti-Foam Agent (AFA)}

The AFA testing used Dow Corning® Q2-3183A AFA at a level of $350 \mathrm{ppm}(350 \mathrm{mg} / \mathrm{L})$ in both clay (80\% kaolin-20\% bentonite) and AZ-101 simulant, which is a liquid with a specific gravity of 1.0 at $25^{\circ} \mathrm{C}$, a viscosity of $2800 \mathrm{cSt}$ (centistokes), and a boiling point $>100^{\circ} \mathrm{C}$. It contains octylphenoxypolyethoxy-ethanol, polyether polyol, and silica treated by a "trade secret" process and is reportedly a stable chemical.

Dow Corning Q2-3183A AFA is flammable, with a flash point of $>100^{\circ} \mathrm{C}$. Hazardous decomposition products such as those from burning include carbon oxides, traces of incompletely burned carbon compounds, silicon dioxide, and formaldehyde. The principal inhalation hazard appears to be silica. The "as received" material is not considered a hazardous waste. For further information on hazards, cleanup, and environmental restrictions, see the material safety data sheet (Dow Corning 2004).

\subsection{Physical Property Analysis Methods}

Physical property measurements were made according to the Guidelines for Performing Chemical, Physical, and Rheological Properties Measurements (Smith and Prindiville 2002). 


\subsubsection{Rheology}

During this testing, yield stress measurements were made with a TA Instruments AR2000 rheometer. This instrument contains an electronically controlled induction motor with an air bearing support for the rotation parts. The air bearing allows a virtually friction-free application of torque. The instrument also contains low inertia optical encoders for high-resolution measurements of angular displacement (strain) and speed (shear rate) over wide ranges, which allows the delicate material structure to be characterized.

Measurements were made using a stainless-steel concentric cylinder. The concentric cylinder system uses a Peltier temperature control that can provide a temperature range of $-20^{\circ}$ to $150^{\circ} \mathrm{C}$. For these tests, all rheological measurements were made at $25^{\circ} \mathrm{C}$.

Yield stress measurements were made by linearly increasing the shear rate from 0 to $1000 \mathrm{~s}^{-1}$ over five minutes. The shear rate was then held at $1000 \mathrm{~s}^{-1}$ for one minute, followed by a linear decrease in shear rate from 1000 to $0 \mathrm{~s}^{-1}$ over five minutes. Each measurement was made in triplicate. The up and down curves were fit to both the Bingham and Herschel-Bulkley models from 50 to $1000 \mathrm{~s}^{-1}$. Only results from the Bingham fit of the down curve were reported.

\subsubsection{Density}

The process used to measure the density of the simulant, which is mass/volume, is to transfer a sample into a preweighed (using a calibrated analytical balance, sensitivity based on sample size and data needs), labeled pycnometer flask of known volume, reweigh the flask and determine the sample mass by difference, and calculate the density by dividing the sample mass by the sample volume.

\subsubsection{Water Mass Fraction}

The process used for determining the $\mathrm{wt} \%$ total solids was to transfer the sample into a preweighed, labeled crucible or vial and calculate mass of sample by difference. The sample was then air dried until enough free liquid had evaporated to prevent spatter during over-drying. The sample was then placed in a $105^{\circ} \pm 5^{\circ} \mathrm{C}$ drying oven or furnace for approximately 24 hours, after which it was placed in a desiccator to cool to room temperature. The cool dried sample was then reweighed. The mass of the sample would normally be measured to $\pm 0.02 \mathrm{~g}$ or better. The $\mathrm{wt} \%$ total solids was calculated as the residual mass divided by the initial sample mass multiplied by $100 \%$.

\subsubsection{Surface Tension}

A Krüss K-12 tensiometer was used to make surface tension measurements on the simulants. The measurements were made using the Wilhelmy plate method, which is based on a force measurement. The measuring device is a vertically hung platinum plate with known geometry. The lower edge of the plate is brought into contact with the liquid surface by raising the sample vessel. This is known as the zero position. The lower edge of the plate touches the liquid and is pulled into the liquid by the surface tension. The plate is then lifted to its zero position. The surface tension of the liquid is calculated from the measured force (Eq. (3.8): 


$$
\sigma=\frac{P_{w}}{l_{w} \bullet \cos \Theta}
$$

where

$\sigma=$ surface tension

$\mathrm{P}_{\mathrm{w}}=$ measured (Wilhelmy) force

$1_{\mathrm{w}}=$ wetted length

$\Theta=$ contact angle between the tangent at the wetting line and the plate surface.

To keep the measurements consistent, sample vessels were filled to $2 / 3$ total capacity. The stainless steel measurement plate was rinsed with deionized water, flamed, and cooled to room temperature before each measurement. To avoid contamination between samples, sample vessels were rinsed with water, followed by a rinse with ethanol, rinsed again with deionized water, and air dried. No soaps or paper products were used to wash or dry the sample vessels. The surface tension of deionized water was used at the beginning and end of a course of measurements to verify that the glassware was clean and the instrument was working properly. At $21^{\circ} \mathrm{C}$, the surface tension value should be $72.8 \pm 0.3 \mathrm{dynes} / \mathrm{cm}$.

The instrument was set up to record multiple measurements over a 60 -second period. Values were recorded approximately every 6 seconds. The measurements would end at 60 seconds or when the last five values were the same. The recorded surface tension value was the average of the last five measurements.

\subsubsection{Rheology Adjustment Procedure}

An initial sample was taken after the AFA testing tank was loaded with testing material and mixed for at least 8 hours. There were three sample locations within the tank, and samples were taken from each of them. Rheograms for each sample were obtained following the approved procedures.

Weight percent total solids measurements were also obtained based on procedures. If the rheograms were consistent, indicating the tank was homogeneous, but the rheology was not in the desired target range, a larger sample was obtained, a set of dilutions performed, and rheograms run on the diluted samples.

In Excel, plots were made of the yield stress values for the Bingham down fits from $50-1000 \mathrm{~L} / \mathrm{s}$ as a function of percent dilution and curve fit. Based on these data, calculations were made to determine what dilution was needed to attain the desired rheology. Another sample was adjusted to match this value and tested to ensure the desired rheology was attained. Then calculations were made to determine how much water needed to be added to the testing vessel to achieve this same result.

The tank should be allowed to equilibrate for at least 4-8 hours and the rheology be retested before starting a testing sequence. If the rheology was not in the target range it as adjusted. 


\subsection{Summary of Simulant Experiences}

The performance of the clay simulants was similar to that seen in previous PJM testing. The weight percent solids was the dominating factor influencing rheology; however, variations in the dry clay component batches and aging effects made this parameter vary from batch to batch to maintain the target rheology.

AZ-101 simulant was also strongly dependent on solids concentration. However, due to the chemical complexities of this simulant slurry, solids concentration and rheology needed to be adjusted by adding water and testing several times.

Sampling the simulants was not a trivial process during testing. The high non-sheared yield stress of some of the simulants caused the lines to plug often. Thus, scale up of simulants from small batches tested in the lab to large testing volumes of the simulants presented unique challenges for each simulant. 


\subsection{Effect of Gas Physical Properties on Bubble Characteristics}

The WTP must deal with hydrogen and other gases generated by radiolytic and thermolytic processes in the radioactive waste slurries. Gas retention and release may be tested with just one less-hazardous gas if the effects of gas physical properties on bubble behavior are identified.

This section describes the results from a literature investigation on the effect of gas physical properties on bubble behavior. Bubble behavior is considered in the following terms.

- Bubble formation from single and multiple orifices

- Bubble breakup

- Bubble coalescence.

The investigation was conducted with reference to no specific application. For the WTP, this means the results from tests employing either prototypic or non-prototypic mixing and gas injection systems can be analyzed with reference to this investigation.

\subsection{Formation of Bubbles at Orifices}

The published literature on the formation of bubbles at single and multiple orifices was reviewed by Kulkarni and Joshi (2005). The gas density is the most important gas physical property affecting bubble formation and can be varied either through the pressure or molecular weight. However, the surface tension force is dominant in determining bubble size for low gas density and low gas flow rates. For large orifices, detachment becomes faster as gas density increases and the bubble diameter decreases. In addition, there is a greater tendency for necking as gas density increases, which also leads to smaller bubbles. Most models for the sizes of bubbles from single orifices include the gas density with reference to the liquid-gas density difference. Therefore, there is no significant effect of gas density in using these models. There is no reported significant difference in the effect of gas density on the sizes of bubbles formed at orifices in Newtonian and non-Newtonian fluids.

Little information on the effect of gas density on the sizes of bubbles formed at multiple orifices was found. However, it was noted that gas momentum is too small to cause any gas density effect on the sizes of bubbles formed on porous plates. One model presented by Kulkarni and Joshi (2005) based on a Rayleigh-Taylor stability analysis shows bubble volume proportional to $\rho_{\mathrm{g}}^{0.192}$. Therefore, for bubbles formed at the same orifice, the ratio of volumes of hydrogen to oxygen is 1.7 , and the ratio of the bubble diameters is 1.2 .

\subsection{Bubble Breakup}

The effect of gas density on bubble breakup was investigated by Wilkinson et al. (1993). They found that the bubble breakup fraction increased with increasing gas density and that the effect of gas density increased with increasing gas density and bubble diameter. They postulated that the gas motion within 
the bubble and the resulting difference in velocity between the gas and liquid can cause pressure on the bubble interface. These pressure forces lead to Rayleigh-Taylor instabilities on the bubble surface that can result in bubble breakup. In water, the densities of hydrogen, helium, and air were considered too low for the differences in gas density to have an effect. This result confirms that previously found by Akita (1973), who observed no effect of gas density on gas holdup in bubble columns for air, carbon dioxide, oxygen and helium in water. They did not study bubble breakup in non-Newtonian fluids. Wilkinson and Dierendonck (1990) also observed that the homogeneous flow regime (characterized by small bubbles of narrow size distribution) remained stable over increasingly broader gas velocity ranges with increasing gas density in bubble columns. Persistence of the homogeneous flow regime leads to higher gas holdup than if the column had transitioned to the "churn-turbulent" regime.

The results of that work - the holdup increasing with gas density-are consistent with those of Russell et al. (2005) and Arm et al. (2007), who investigated hydrogen, air, oxygen, and argon holdup in Newtonian solutions and non-Newtonian slurries of kaolin-bentonite clay and simulated AZ-101 waste. The effect of gas density was most pronounced in the non-Newtonian slurries; gas holdup generally increased with increasing gas molecular weight. A notable exception was hydrogen, which appeared to be an anomaly, particularly in the simulated AZ-101 waste where it generated the highest holdup.

Hikita et al. (1980) also investigated the effect of gas physical properties in bubble columns. They studied the gases air, hydrogen, carbon dioxide, methane and hydrogen/nitrogen mixtures in water and found holdup increased with increasing gas density as well as with gas viscosity. Gas holdup was correlated in the form $\alpha \propto \rho_{g}{ }^{0.062} \mu_{g}{ }^{0.107}$. Thus for their system, air holdup was $\sim 27 \%$ higher than hydrogen holdup. Approximately $6 \%$ of the increase was apparently due to the higher viscosity of air. This was the only correlation identified that included a physical property other than gas density, but the effect of viscosity appears minor.

Larachi et al. (1994) also confirmed that the effect of increasing gas density is to decrease bubble size and increase holdup. They studied helium, nitrogen, argon and carbon dioxide holdup in water and ethylene glycol in a gas-liquid upflow fixed bed reactor column packed with non-porous polypropylene extrudates. Gas holdup was found to be independent of gas viscosity but increased with increasing density.

More recently, Macchi et al. (2003) studied the effect of gas density on the hydrodynamics of coarseparticle, three-phase fluidized beds. The solid phase was represented by borosilicate glass beads, while a $55 \mathrm{wt} \%$ aqueous glycerol solution formed the liquid phase. The authors studied the holdup of air, helium, carbon dioxide, and sulfur hexafluoride and again found holdup increasing with increasing gas density. They also confirmed that the velocity for transitioning from homogeneous to churn-turbulent flow regimes increased with increasing gas density. That these effects are manifested in the bulk fluid was concluded when plugging $65 \%$ of the 1 -mm-diameter distributor orifices led to an insignificant effect on holdup. The effect of gas density appeared independent of the solids concentration.

Krishna et al. (1994) examined the work of others as well as their own, investigating helium, air, argon, and sulfur hexafluoride holdup in water in bubble columns to develop a theoretical basis for the effect of gas density. Bubble swarm velocity data showed that the Richardson-Zaki exponent increases with decreasing gas density and stabilized the bubbly flow regime. They also observed that large bubble holdup in the churn-turbulent flow regime is virtually independent of gas and liquid phase properties. 
A numerical simulation of bubble column flows by Chen et al. (2005) also shows that increasing gas density increases holdup and stabilizes the bubbly flow regime. These authors performed a KelvinHelmholtz stability analysis to derive an equation for the drag force acting on a bubble, which is proportional to the gas density raised to 0.25 power.

Little work appears to have been done to investigate the effect of gas density on bubble breakup in agitated vessels. Laakkonen et al. (2007) modeled bubble size distributions in agitated vessels and derived an error function describing the breakup frequency. According to this correlation, breakup frequency increases with increasing gas density, which is consistent with the experimental observations described above. A generalized model for bubble breakup in turbulent dispersions was developed by Luo and Svendsen (1996). These authors reviewed a number of models, one of which shows the breakup rate as proportional to the dispersed phase density raised to the 0.3 power. However, the authors' own model, which was based on classical turbulence theory, included no dispersed phase physical property effects.

\subsection{Bubble Coalescence}

There appears to have been little work to investigate the effect of gas physical properties on bubble coalescence. Chaudhari and Hofmann (1994), for example, seem to suggest that there was little effect of gas physical properties on bubble coalescence. Tse et al. (2003) describe how secondary bubbles (approximately an order of magnitude smaller than the primary bubbles) may be formed during bubble coalescence. They observed very small bubbles being formed as disturbance waves travel the length of a bubble post coalescence, which results in its unstable elongation. These waves, akin to Rayleigh instabilities, pinch off small bubbles. The authors postulate that the rate of secondary bubble formation increases with decreasing gas to liquid viscosity ratio. Therefore, there will be an increasing tendency for small bubbles to be formed and the holdup to increase as the gas viscosity decreases. This phenomenon will counteract the effect of gas density because gas viscosity is proportional to the gas molecular weight.

\subsection{Conclusions}

In summary, the major gas physical property affecting bubble behavior is density, either through gas pressure or molecular weight. The size of bubbles formed at orifices appears to decrease with increasing gas density in both Newtonian and non-Newtonian fluids. In Newtonian fluids, bubble breakup increases with increasing gas density, though there appears to be little significant difference for hydrogen and air. The published work on gas holdup in bubble columns of non-Newtonian slurries has also shown that bubble size decreases with increasing gas density. Indeed, the effect of gas density appears more pronounced in non-Newtonian fluids. Gas density appears to have no significant effect on bubble coalescence. Thus, increasing gas density decreases bubble size in general, though the qualitative effects are fluid-specific. The effect of gas viscosity on holdup appears minor compared with the effect of density. 


\subsection{Testing in the 1/4-Scale Lag Storage Vessel}

The gas retention and release tests conducted in the QSLS prototype test stand are presented in this section. The QSLS is an 8-PJM, 7-sparger hybrid mixing system using hydrogen peroxide decomposition to simulate the in situ gas generation occurring in the WTP lag storage vessel. (a) The gas volume fraction is calculated from the measured simulant surface level and hydrostatic pressure difference. The overall approach, test stand equipment, data analysis methods, tests results, and conclusions are described.

Section 5.1 describes the overall test approach, and Section 5.2 describes the major test systems and components. Section 5.3 summarizes the data analysis methods, Section 5.4 presents the test results, and Section 5.5 gives the conclusions derived from these results.

\subsection{Test Objectives and Approach}

The original objective of these tests was to determine the effect of AFA on gas retention and release behavior in AZ-101 HLW simulant using a prototypic WTP mixing system. However, tests conducted concurrently at SRNL rapidly demonstrated that the AZ-101 simulant foamed in the absence of AFA so no tests of AZ-101 simulant alone could be run. The tests that were conducted allow a comparison of AZ-101 simulant with AFA to the clay simulant used in all previous 1/4- and 1/2-scale lag storage tests, making it possible to determine a scaling basis for the AZ simulant in the lag storage mixing system.

Gas retention is characterized primarily by the steady-state gas volume fraction resulting from the applied gas generation rate expressed as the superficial gas velocity. Gas release tests where mixing starts with an initially static retained gas volume provide the time required for the slurry to return to a steadystate level. These gas holdup and release tests supply the information necessary to scale the results up to plant conditions. (Refer to Section 5.2.1 for a discussion of the scaling parameters.)

The decomposition of hydrogen peroxide into oxygen and water simulates the in situ gas bubble generation that occurs in radioactive waste slurries in the WTP. In situ gas generation is required to avoid the complication and potential bias of mechanical bubble generation (e.g., orifices, porous diffusers, mixing vanes). Hydrogen peroxide decomposition is minimally intrusive and precisely controllable, though care must be taken to inject the hydrogen peroxide solution only into well-mixed regions. It is the only method of truly in situ gas generation that is practical in large-scale tests. ${ }^{(b)}$

Estimates of maximum hydrogen generation rates in the WTP process vessels $(\mathrm{c})$ indicate a gas generation superficial velocity of $\sim 0.0004 \mathrm{~mm} / \mathrm{s}$ in the lag storage vessels and $\sim 0.002 \mathrm{~mm} / \mathrm{s}$ in the ultrafiltration process (UFP) vessel. Scaled tests must use higher gas generation rates to produce a

(a) This system represents HLW lag storage vessel HLP-27A/B at 1:4.29 scale and blend vessel HLP-28 at 1:4.54.

(b) Other in situ gas generation methods that have been used in small test volumes include carbon dioxide production by yeast metabolizing sugar, ammonia bubble nucleation by depressurization, and water radiolysis by intense gamma irradiation.

(c) Derived from WTP calc. sheet 24590-WTP-M4C-V11T-00004 Rev. C, assuming the gas is $25 \%$ hydrogen. 
measurable gas volume fraction. The QSLS tests used hydrogen peroxide injection rates equivalent to superficial velocities of 0.025 to $0.1 \mathrm{~mm} / \mathrm{s}$, which produced gas volume fractions on the order of $1 \mathrm{vol} \%$. The nominal flow rate of $31 \mathrm{wt} \%$ hydrogen peroxide solution to achieve this range of superficial gas velocities in the $1 / 4$-scale test vessel ranged from 33 to $130 \mathrm{~mL} / \mathrm{min}$. Tests were conducted in a sequence similar to the previous gas retention and release tests, where hydrogen peroxide injection rates increase in sequence followed by a holding period with mixing off and a release test at the end (Bontha et al. 2005). However, the QSLS tests conducted three consecutive hydrogen peroxide injection sequences, each comprising three injection rates followed by undisturbed gas holdup and release periods. Continuous PJM and main sparging operation was used throughout the testing except for the undisturbed gas holdup test period. It is important to mention that AFA was added to reach the $350 \mathrm{mg} / \mathrm{L}$ concentration target during the rheology adjustment tasks before a test-none was added to the $1 / 4$-scale tank during testing.

The behavior of the total gas fraction (retained gas plus sparge gas holdup) during a test sequence is illustrated in Figure 5.1 with data from the 13-Pa yield stress AZ-101 simulant tests. The gas-generation superficial velocity is also shown to mark the three gas generation rates applied in each of the three cycles. The final spike in holdup occurs when PJM and sparger mixing are shut off and the residual hydrogen peroxide reacts to form gas that accumulates in the unmixed slurry. When mixing is turned on again, the gas is released. The holdup data shown are based on $\Delta \mathrm{P}$ measurements, which were more reliable but (as can be seen) contained scatter. Statistical methods were used to detect trends in holdup.

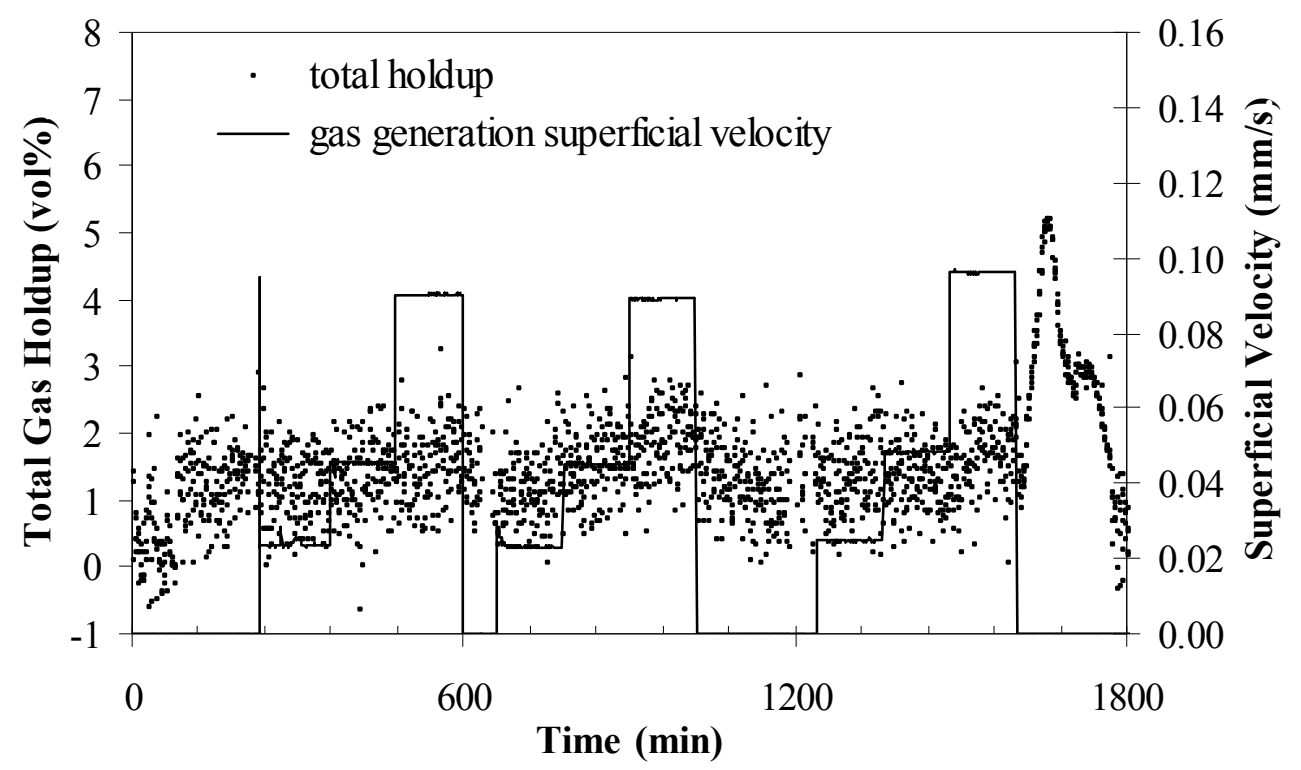

Figure 5.1. Example of Data from QSLS Tests in 13-Pa AZ-101 Simulant

To provide a sound technical basis for predicting gas retention and release behavior, retention in AZ-101 simulant with AFA must be quantitatively related to previous scaled tests in clay. Accordingly, tests were conducted in clay simulant as well as in the AZ-101 simulant over similar parameter ranges. In addition, knowledge of the shape, size, dynamics, and interaction with the PJM jets of the large sparged air bubbles is needed to understand and model the mass transfer process (full-scale sparger testing at 
SRNL provided actual mass transfer data for large bubbles). Flow visualization tests in water with and without AFA provided a visual record of this behavior, especially the transitions as AFA was added.

Because the results of the prior mixing vessel tests at SRNL (Stewart et al. 2006) indicated that the effect of AFA on gas retention increased with decreasing simulant yield stress, tests were conducted at three Bingham yield stress values as follows in both clay and AZ-101 simulant (there was no specific target value on the consistency factor):

- $30 \pm 3 \mathrm{~Pa}$ : bounding yield stress specified for WTP around which most of the previous tests have been performed.

- $13 \pm 2$ Pa: yield stress of undiluted AZ-101 simulant (Stewart et al. 2006; Eibling et al. 2003, Appendix F).

- $3 \pm 1 \mathrm{~Pa}:$ representative low yield stress in the range of maximum AFA effect observed in SRNL tests.

The functional relationship of retained gas volume fraction and in situ gas-generation superficial velocity assumes the form $\alpha_{G}=r_{1} U_{G s}^{r_{2}}$ (a line with a slope of $r_{2}$ on a $\log \log$ plot). (a) This relationship is the basis for quantifying the effect of AFA on gas retention, comparing results with past and future tests in clay at different scales and extrapolating test results to predict plant behavior. Figure 5.2 presents data in this form from past 1/4- and 1/2-scale lag storage tests in clay (Russell et al. 2005, Bontha et al. 2005) along with small-scale mixing test results with AZ-101 simulant at a similar yield stress with and without AFA (Stewart et al. 2006). The current test results given in Section 5.4 are also described in this way.

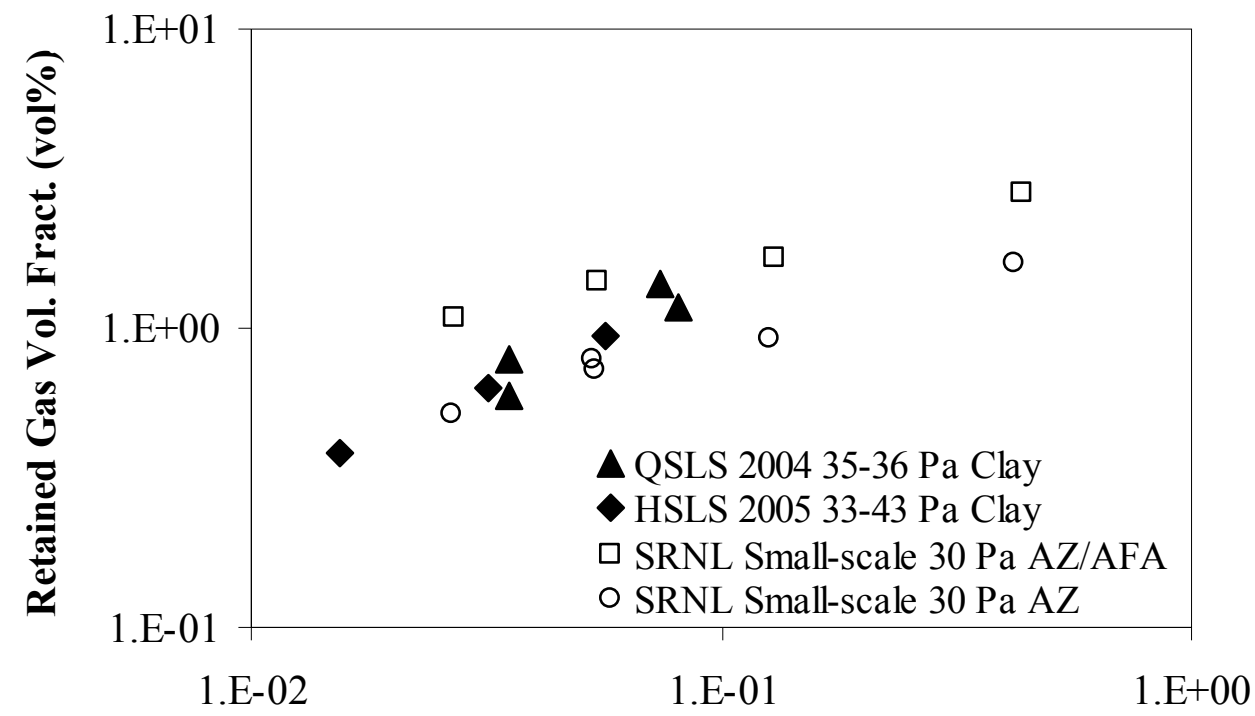

Gas Generation Superficial Velocity $(\mathrm{mm} / \mathrm{s})$

Figure 5.2. Summary of Previous Gas Retention Test Results

(a) In past work there was no need to distinguish between sparge gas and retained gas holdup, so the bulk volume fraction of retained gas was referred to as $\alpha$ and the gas-generation superficial velocity as $U_{s}$. The constants were also expressed as $A$ and $B$ but have been changed to $r_{1}$ and $r_{2}$ to avoid confusion with vessel cross-sectional area $A$. 


\subsection{QSLS Test Systems}

The QSLS test system was built on the QSLS test stand used in 2004 gas retention and release testing (Russell et al. 2005), with modifications that enable tests to use hazardous AZ-101 simulant and improve instrumentation and control. This section describes all aspects of the system. Section 5.2.1 summarizes scaling of the PJMs and sparger operation, Section 5.2.2 describes the test vessel and internals, and Section 5.2.3 covers the data acquisition and control system. The main air supply and control system is described in Section 5.2.4 and the hydrogen peroxide injection system in Section 5.2.5. Section 5.2.6 discusses simulant sampling and handling.

\subsubsection{Scaling the Mixing System}

The purpose of these tests was to measure the retained gas volume in simulants with AFA in a prototypic mixing system. Scaling must be accurate enough to ensure that mixing and the resulting gas retention and release predictions are conservative. The choice of test stand and evaluation of scaling parameters for both PJMs and spargers are discussed.

The choice of scale and test stand was constrained by the aggressive schedule of the project so the choice was limited to those available. These included (in order of decreasing size) the HSLS system in the 336 Building, the QSLS test stand, the 1/4.94-scale UFP test stand, the 1/4-scale 4-PJM system, (a) and a 1/9-scale 4-PJM system at SRNL. The HSLS test stand was being used for other tests; the others were disassembled but could be put back into operation within the time available. However, the non-sparged 4-PJM systems were not prototypic of the WTP vessels being designed to handle non-Newtonian slurries and the 1/4.94-scale UFP test stand was not prototypic because it has fewer PJMs than the full-scale system.

This left the QSLS test stand as the only usable prototypic system. The important components of the QSLS mixing system (actually 1:4.29 scale on tank diameter) are described in Section 5.2.2. All components were appropriately scaled geometrically with the following exceptions:

- PJMs were built using standard pipe size (12-inch schedule 40 stainless steel) with an inside diameter (ID) of 12 inches instead of the 11.2 inches required for rigorous scaling. However, the length of the PJM tube was reduced so the PJM stroke volume maintains the correct scale.

- The PJM nozzles are standard pipe size (1-inch schedule 40 stainless steel) of 1.049 inch ID, $13 \%$ larger than the required 0.93 inches.

- The number of full-length spargers is reduced from 28 in 3 rings to 7 in a single ring to match the layout of the HSLS test stand (Bontha et al. 2005). The sparger tube diameter is adjusted (using standard pipe size) to keep the air velocity similar to the full-scale value at a constant superficial velocity, as described below.

(a) Full scale for the 4-PJM systems was a large-scale vessel that is now occupied by the $1 / 2$-scale lag storage test stand. Thus, the 1/4-scale and 1/9-scale 4-PJM systems are thus actually $1 / 8$-scale and $1 / 17$-scale, respectively, compared to the HLW lag storage vessel (HLP-27A/B). 
Scaling of PJM operation for mixing non-Newtonian slurries was established through a comprehensive scaled testing program performed in 2003 through 2005 (Meyer et al. 2005). The primary nondimensional group that directly affects the size of the PJM mixing cavern is the yield Reynolds number, $\operatorname{Re}_{\tau}$, defined as the ratio of dynamic stress to the shear stress of the non-Newtonian slurry:

$$
\mathrm{Re}_{\tau}=\frac{\rho u_{0}^{2}}{\tau_{0}}
$$

where $\rho$ is the slurry density $\left(\mathrm{kg} / \mathrm{m}^{3}\right), \mathrm{u}_{0}$ is the peak-average PJM jet velocity $(\mathrm{m} / \mathrm{s})$, and $\tau_{0}$ is the Bingham yield stress or the shear strength $(\mathrm{Pa})$ of the slurry. With uniform properties, the ratio of the height of the PJM mixing cavern to tank diameter is constant in a geometrically scaled system if the PJM jet velocity is held constant with scale.

At smaller scales, viscous effects begin to have a significant effect on the degree of turbulence and the thickness of boundary layers at the vessel wall and cavern ceiling. This effect is described by the jet Reynolds number, $\mathrm{Re}_{0}$, which is the ratio of dynamic stress to viscous stress, expressed as

$$
\operatorname{Re}_{0}=\frac{\rho u_{0} d_{0}}{\mu_{B}}
$$

where $\mu_{\mathrm{B}}$ is the Bingham consistency factor (Pa-s). With the jet velocity held constant, the jet Reynolds number decreases in direct proportion to the scale factor, eventually indicating a transition to laminar flow that sets the minimum size of a test vessel.

Maintaining a constant PJM jet velocity at all scales requires reducing the drive time in proportional to the scale factor, $S_{\text {test }}$, to expel the scaled volume of slurry. The volume of fluid expelled from the PJMs is the product of the nozzle flow area, jet velocity, and drive time. Because the flow area varies as $S_{\text {test }}^{2}$, the drive time must decrease with $S_{\text {test }}$ to make the volume vary correctly as $S_{\text {test }}{ }^{3}$. This scaling is also applied to the total cycle time.

The PJM scaling parameters for a range of scales based on the WTP lag storage vessel geometry filled with a non-Newtonian slurry with a Bingham yield stress of $30 \mathrm{~Pa}$ and a consistency factor of $30 \mathrm{cP}$ are shown in Table 5.1. These include the full-scale WTP lag storage (HLP-27A/B) vessels, perfectly scaled 1/2- and 1/4-scale lag storage vessels, the QSLS vessel (shown in bold), the 1/4-scale lag storage vessel as used in the 2004 testing (Russell et al. 2005), and a perfectly scaled 1/16-scale vessel. The yield Reynolds number is constant for all scales, but the jet Reynolds number decreases, indicating decreasing turbulence intensity at smaller scale. Reducing the simulant viscosity or consistency factor would compensate for this, but, because consistency roughly follows the yield stress, would also increase the yield Reynolds number, thereby increasing the relative size of the PJM cavern.

The dynamics of sparger operation cannot be scaled as precisely as PJMs. Rather than a relatively well-characterized jet, the active agent in sparging is a sequence of poorly characterized, interacting bubbles whose size, speed, and number are highly variable and not directly related to geometric scale ratios. The current sparge mixing design strategy is based on covering the region to be mixed/mobilized adequately with the up-flowing ROB and surrounding down-flowing ZOI (Claghorn and Waddell 2006). 
Table 5.1. Scaled PJM Parameters for Lag Storage Vessels

\begin{tabular}{|l|c|c|c|c|c|c|c|}
\hline \multicolumn{1}{|c|}{ Vessel } & $\begin{array}{c}\text { Scale } \\
\text { Factor }^{(\mathrm{a})}\end{array}$ & $\begin{array}{c}\text { Tank } \\
\text { Diameter } \\
\text { (in.) }\end{array}$ & $\begin{array}{c}\text { Nozzle } \\
\text { diameter } \\
\text { (in.) }\end{array}$ & $\mathbf{R e}_{\tau}{ }^{(\mathrm{b})}$ & $\mathbf{R e}_{\mathbf{0}}{ }^{(\mathrm{b})}$ & $\begin{array}{c}\text { Drive } \\
\text { time } \\
\text { (s) }\end{array}$ & $\begin{array}{c}\text { Cycle } \\
\text { Time } \\
\text { (s) }\end{array}$ \\
\hline Full scale $^{(\mathrm{c})}$ & 1.0 & 300 & 4 & 5,760 & 48,800 & 30 & 223 \\
\hline $1 / 2$-scale $^{(\mathrm{c})}$ & 2 & 150 & 2 & 5,760 & 24,400 & 15 & 112 \\
\hline $1 / 4-$ scale $^{(\mathrm{c})}$ & 4 & 75 & 1 & 5,760 & 12,200 & 7 & 56 \\
\hline QSLS (2007) $^{(\mathrm{d})}$ & $\mathbf{4 . 2 9}$ & $\mathbf{7 0}$ & $\mathbf{1 . 0 5}$ & $\mathbf{4 , 4 1 0}$ & $\mathbf{1 1 , 2 0 0}$ & $\mathbf{6}-\mathbf{7}$ & $\mathbf{5 4}$ \\
\hline Quarter-scale (2004) $^{(\mathrm{d})}$ & 4.29 & 70 & 0.96 & 10,200 & 15,600 & 5 & 45 \\
\hline $1 / 16$-scale $^{(\mathrm{c})}$ & 16 & 18.75 & 0.25 & 5,760 & 3,050 & 1.9 & 14 \\
\hline
\end{tabular}

(a) Based on tank diameter.

(b) Based on jet velocity of $12 \mathrm{~m} / \mathrm{s}$ except for 2004 1/4 scale, where $16 \mathrm{~m} / \mathrm{s}$ was used, and the QSLS (2007), where $11 \mathrm{~m} / \mathrm{s}$ was used.

(c) 1/17 is ideal based on tank diameter assumed for nozzle diameter and timing; for illustration, 1/16 is used.

(d) Actual values as built and operated.

Correlations based on large-scale sparging test data provide the diameters of the ROB and ZOI as they appear on the surface in terms of the sparge actual volume flow rate as follows (Poloski et al. 2005):

$$
\begin{aligned}
& \mathrm{D}_{\mathrm{ROB}}=11 \mathrm{Q}^{0.34} \\
& \mathrm{D}_{\mathrm{ZOI}}=34 \mathrm{Q}^{0.34}
\end{aligned}
$$

where $\mathrm{D}_{\mathrm{ROB}}$ and $\mathrm{D}_{\mathrm{ZOI}}$ are the diameters of the ROB and ZOI (inches) at the surface, and $\mathrm{Q}$ is the sparge flow rate (acfm). Above a $\sim 1.5 \mathrm{~m}$ transition zone, the ROB diameter is essentially constant with depth while the ZOI diameter increases somewhat with depth. To maintain similar coverage across scales, the ratio of $\mathrm{D}_{\mathrm{ROB}}$ to tank diameter should be approximately constant.

Though the processes of bubble formation, coalescence, and breakup are not completely understood for Newtonian liquids and much less so for non-Newtonian fluids, a measure of the power generated by rising bubbles can be expressed in terms of bulk gas conditions. The total power per unit volume, $\mathrm{P}_{\mathrm{BH}}$, generated by a steady population of bubbles rising through a slurry depth, $\mathrm{H}$, can be expressed as

$$
P_{B H}=\frac{U_{A s}}{H} p_{a}\left(1+\frac{\rho g H}{p_{a}}\right) \ln \left(1+\frac{\rho g H}{p_{a}}\right)
$$

where $\mathrm{U}_{\mathrm{As}}$ is the sparge gas superficial velocity and $\mathrm{p}_{\mathrm{a}}$ is ambient pressure at the surface (Guzman-Leong et al. 2007). At a constant superficial velocity, $\mathrm{P}_{\mathrm{BH}}$ decreases slowly with reduced scale.

Because mixing effectiveness is related to power input, Eq. (5.5) implies that the most practical strategy to maintain similar sparger effectiveness across scales is to maintain a constant superficial velocity of sparge air flow at the sparger tube exit. The number of spargers should also be arranged such that the flow rate per tube produces the proper coverage of the tank area and maintains a constant exit 
velocity. Sparge bubbles tend to remain relatively large even at low flow rates, so very small-scale tests are impractical. The quantities derived for the test vessels presented in Table 5.1 are shown in Table 5.2 using a constant superficial velocity (QSLS test stand shown in bold).

Table 5.2. Scaled Sparger Parameters for Lag Storage Vessels

\begin{tabular}{|c|c|c|c|c|c|c|}
\hline Vessel & $\begin{array}{c}\text { Scale } \\
\text { Factor }^{(a)}\end{array}$ & $\begin{array}{c}\text { No. } \\
\text { Spargers }\end{array}$ & $\begin{array}{c}\text { Flow/tube }{ }^{(\mathrm{b})} \\
\text { (acfm) }^{\text {acfm }}\end{array}$ & $\mathbf{A}_{\mathrm{ROB}} / \mathbf{A}_{\mathrm{T}}$ & $\begin{array}{c}\text { Velocity } \\
(\mathrm{m} / \mathrm{s})\end{array}$ & $\begin{array}{c}\mathbf{P}_{\mathbf{B H}} \\
\left(\mathrm{w} / \mathrm{m}^{3}\right)\end{array}$ \\
\hline Full scale $^{(\mathrm{c})}$ & 1.0 & 28 & 18 & 0.27 & 4.2 & 85 \\
\hline $1 / 2$ scale $^{(\mathrm{c})}$ & 2 & 28 & 4.5 & 0.42 & 4.2 & 73 \\
\hline $1 / 4$ scale $^{(\mathrm{c})}$ & 4 & 28 & 1.1 & 0.65 & 4.2 & 69 \\
\hline QSLS (2007) ${ }^{(\mathrm{d})}$ & 4.29 & 7 & 3.9 & 0.44 & 3.6 & 67 \\
\hline $1 / 4$ scale $(2004)^{(\mathrm{d}, \mathrm{e})}$ & 4.29 & $4^{(\mathrm{d}, \mathrm{e})}$ & 3.0 & 0.21 & 20.4 & 30 \\
\hline $1 / 16$ scale $^{(\mathrm{c})}$ & 16 & 28 & 0.07 & $\mathrm{~N} / \mathrm{A}$ & 4.2 & 63 \\
\hline \multicolumn{7}{|c|}{$\begin{array}{l}\text { (a) Based on tank diameter. } \\
\text { (b) Based on a constant superficial velocity of } 5.22 \mathrm{~mm} / \mathrm{s} \text {. } \\
\text { (c) } 1 / 17 \text { is the ideal scaling based on tank diameter with constant superficial velocity; for illustration } 1 / 16 \text { is used. } \\
\text { (d) Seven larger spargers of approximately same total area as } 28 \text { scaled spargers. } \\
\text { (e) Seven spargers were installed but only four were used for testing. }\end{array}$} \\
\hline
\end{tabular}

\subsubsection{Description of the QSLS Vessel and Internals}

The main components of the QSLS test setup included the test vessel, the pulse tube cluster, the support and containment system, the drive and sparge manifolds, and the ventilation system. Various instruments were used to control the system and to collect data.

The QSLS test vessel was cylindrical clear acrylic, 70-inch ID and 91-inch high. At the nominal test depth, $\sim 1.54 \mathrm{~m}$, the operation of the pulse tubes resulted in a linear relationship between the volume change and the level change; i.e., the level ranged over straight 2-inch pipe sections above the pulse tubes. The bottom contour of the tank consisted of a 100:6 flanged and dished stainless steel head. Six stainless steel legs were welded to the underside of the stainless steel bottom, and these legs and the center of the head rested on the flat tank bottom. The gap between the top of the stainless steel head and the acrylic wall was filled with urethane adhesive, and the space below the stainless steel head was filled with laponite.

The top of the test vessel was closed with a flat stainless steel ceiling. Whereas the previous QSLS vessel had been open at the top, using the caustic AZ simulant dictated that possible splashing. Worker protection was one reason to contain the simulant; another was that the cluster support structure and the support frame were aluminum, and corrosion by the simulant was a concern. The ceiling also contained any aerosols generated during testing. The test vessel was supported on a steel plate with a sheet of rubber between the steel and plastic to help distribute the load. The steel plate was supported on six load cells, one each under each leg on the stainless steel bottom.

The test vessel was placed inside a secondary containment and surrounded by a support structure and scaffolding. The secondary containment was large enough to contain the vessel contents if it should rupture. One end of the support structure surrounded the vessel and the other was used to support the 
cluster when removed from the vessel. The secondary containment also provided containment if simulant were to drip from the cluster. The scaffolding was used by staff when they worked around the top to the test vessel and cluster. A gantry crane was also used to move the cluster in and out of the test vessel.

Figure 5.3 is a photograph of the PJM cluster supported on the opposite end of the support structure from the test vessel. The PJM cluster was fabricated using pulse tubes originally fabricated for the previous testing program. The lag storage arrangement is seven equally spaced pulse tubes surrounding a single central pulse tube. Each PJM was made of 1 - $\mathrm{ft}$ schedule 40 stainless steel pipe and was 2.58 - $\mathrm{ft}$ tall with a 1.06-ft outer diameter. The pitch diameter of the outer pulse tubes was approximately 29.4 inches. The nozzle of the center PJM points vertically down, while the nozzles of the perimeter PJMs were inclined at an angle of $45^{\circ}$ from vertical and point radially outward. All nozzles were positioned approximately 1.5 inches from the tank floor. Stainless steel plates were welded to the pulse tubes at both ends of the cylindrical pipe sections. The outer pulse tubes were assembled so that they were as close together as possible. The gaps between the pulse tubes were sealed with urethane adhesive and were not

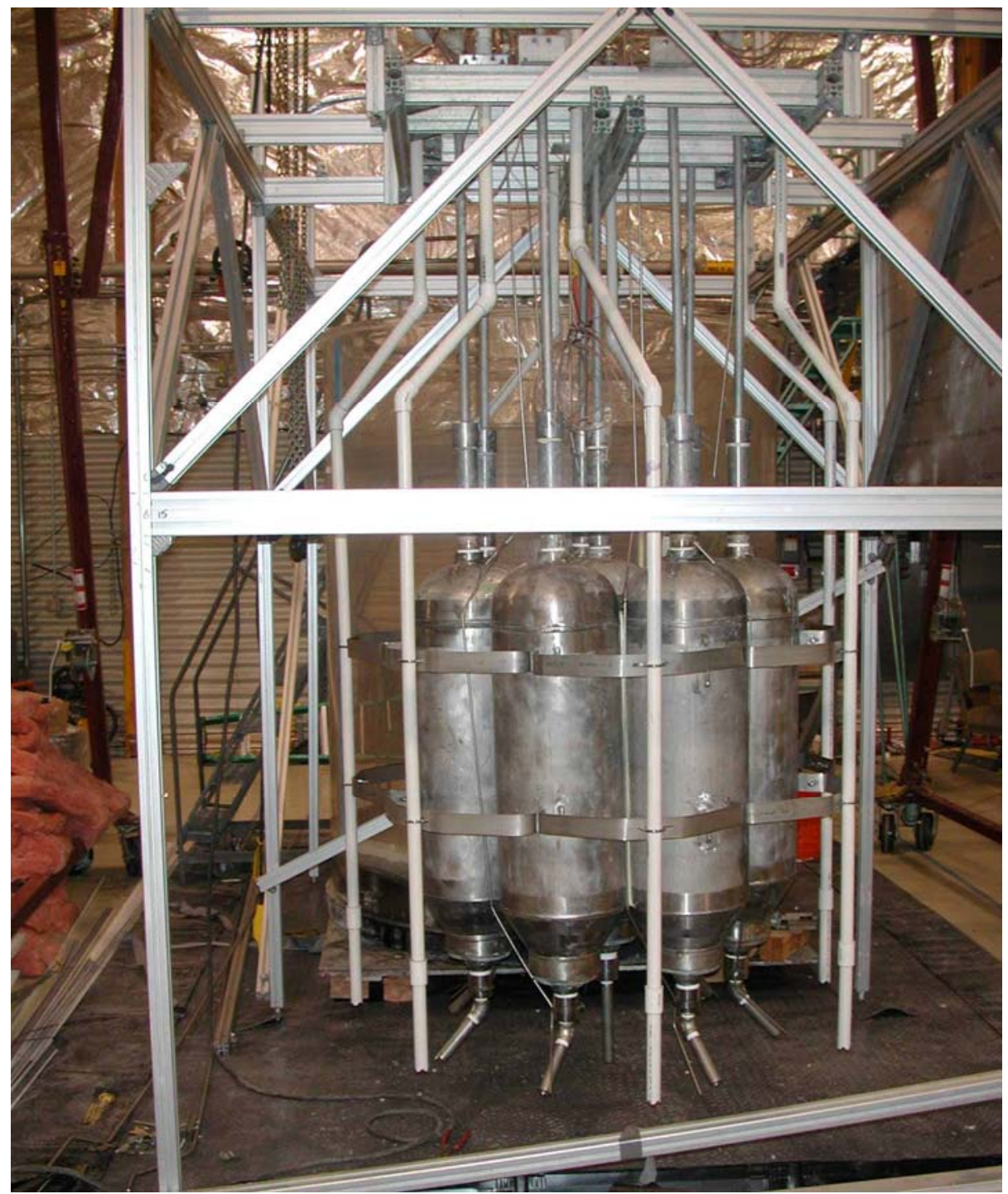

Figure 5.3. Photograph of the PJM Cluster 
welded. Water was used to fill the cavity between the pulse tubes to reduce any buoyancy effects. After completion of testing, the water was drained and no sign of simulant leaking into the cavity was found.

Figure 5.4 presents plan and elevation views of the PJM cluster assembly. The cluster was supported from above by the eight pipes. Inside of each pulse tube was a Drexelbrook capacitive level sensor. The level sensors were supported from above with the head of the level sensor enclosed in the sections of 2-inch stainless steel pipe directly above the pulse tubes. Supports for the sparge lines were stainless steel straps bolted to tabs on the pulse tubes. The sparge lines were fabricated from one inch PVC pipe with the section below the simulant surface being straight and vertical. Sample lines were $3 / 8$-inch outside diameter stainless steel tubing. Sample locations were approximately the bottom of the pulse tubes and at each of the levels of sparge line supports. Two thermocouples were mounted to sparge lines. One had its active end near the end of the sparge line, and the other was slightly below the simulant surface level. The hydrogen peroxide injection lines were $1 / 4$-inch stainless steel lines that were routed along the pulse tubes with the injection points near the PJM nozzles. Two delta pressure trees were also supported from the sparger supports.

The cluster was supported by an aluminum frame attached to the support structure. A soft, foam rubber seal was set between the top of the acrylic tank and the stainless steel ceiling, which as an integral part of the cluster.

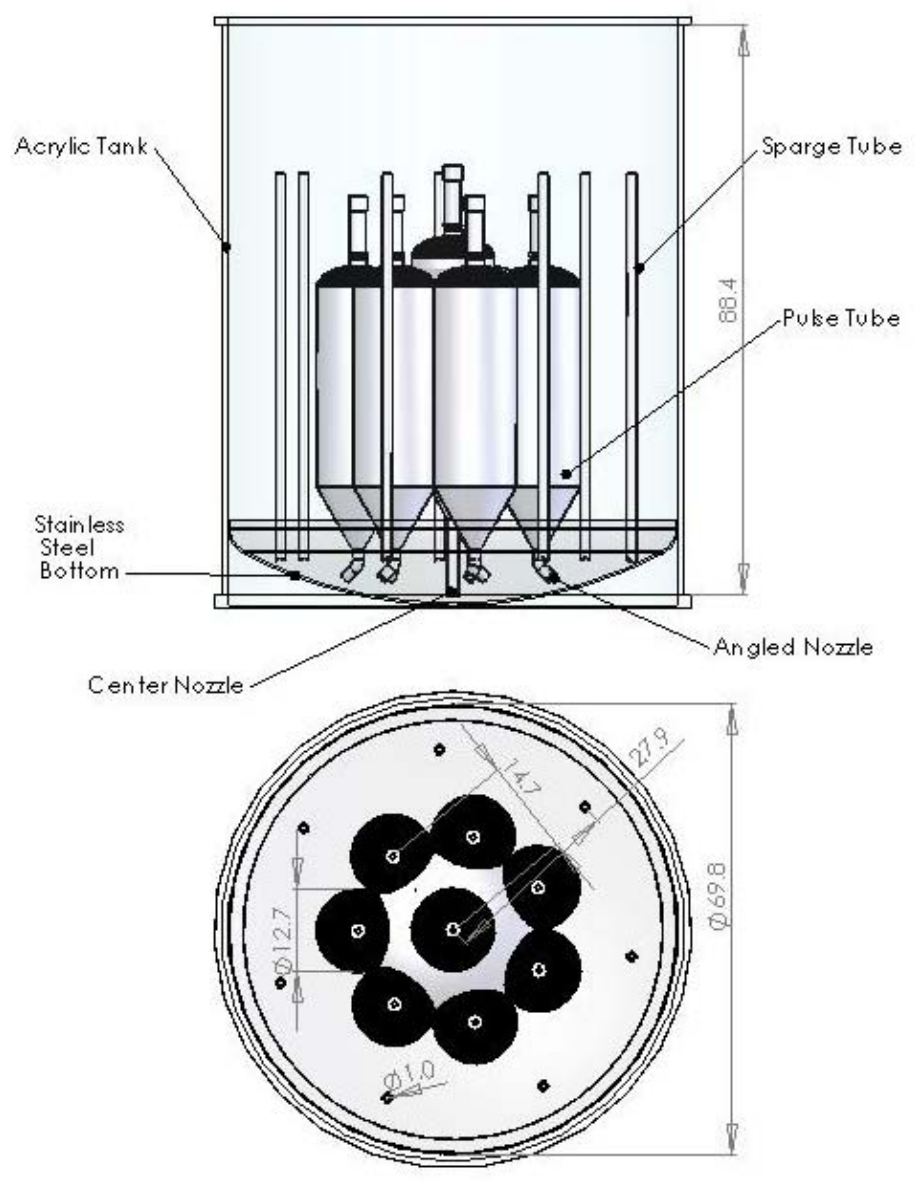

Figure 5.4. QSLS Vessel with PJM Cluster and Sparge Tubes (units in inches) 
In addition to the PJMs, seven spargers are installed equally spaced around the perimeter between the PJM nozzles at a pitch diameter of 56 inches (Figure 5.4) with tips positioned approximately 2.5 inches from the tank floor. The sparger tubes are 1-inch-ID PVC piping with $45^{\circ}$ angle groves cut at the discharge end, as shown in Figure 5.5. The sparge tubes are attached directly to the PJM cluster.

It is not practical to attach hardware to the acrylic tank walls, so the PJM cluster with attached spargers and other hardware is positioned securely within the QSLS tank using the independent support structure. The support structure 1) bears the weight of the PJM/sparger assembly and air supply hoses, 2) prevents lateral movement of the PJM cluster, and 3) provides additional bracing of the sparger tubes, hydrogen peroxide injection lines and the analytical instruments installed within the QSLS vessel.

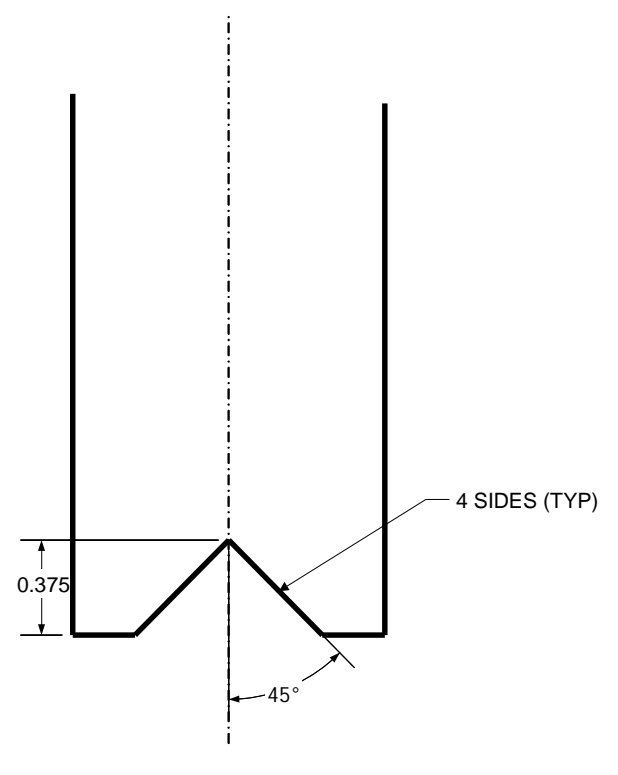

Sparge Ends

Figure 5.5. Schematic of the Sparger Nozzle

\section{QSLS Instrumentation}

Instrumentation for the QSLS was used both for control and collection of data for analyses. Most of the instrumentation was associated with the air supply and ventilation system. The process and instrumentation description and diagram are presented in Appendix D.

The temperature, pressure, and humidity at the receiver tank was measured and recorded to characterize the conditions of the incoming air supply. A mass flow meter was installed between the receiver tank and the drive/vacuum/sparge manifolds. These instruments measured the amount of water vapor entering the system. To prevent oil from entering the sparge lines or PJMs and affecting the AFA/simulant interactions, desiccant canisters were placed inline between the receiver tank and the inlet mass flow meter. The canisters contained silica gel to remove any liquid water and charcoal to remove oil. The humidity, temperature, and pressure were also measured in the dome space of the test vessel, inside the more downstream of the two 500-gallon surge tanks and in the ambient air in the room. For 
each of the seven sparge lines, the pressure and temperature were measured downstream of the rotameters. Just downstream of the drive manifold, a pressure transducer was installed at the upstream end of the hose connecting the pulse tube to the manifold. Inside each pulse tube, a capacitive level was used to determine the level of the simulant inside the pulse tube.

Instrumentation for the test vessel included six load cells under the tank, four laser level sensors for measuring surface level, and two delta pressure trees attached to the PJM cluster. There was a seal between the top of the acrylic tank and the dome ceiling. The cluster was supported by the support frame, so the load cells did not measure the total weight of the test vessel and its contents. The pressure differential between the inside and outside of the test vessel made the load cells fluctuate during PJM operation. This transferred some of the tank/simulant weight to the support structure. The load cell reading proved to be a sensitive diagnostic tool for monitoring the dynamics of PJM operation. The laser level sensors were used to determine the elevation of the simulant surface at four locations. Interference with a sparge line meant one of the laser level sensors was usually not available. In addition, simulant buildup on vessel components occasionally obscured other laser level sensors during testing. The two delta pressure trees were attached to the cluster with a fixed distance between the upper and lower pressure transducers. As the void fraction in the simulant changed, the change in the pressure differential between the transducers measured the amount of trapped gas.

\subsubsection{Data Acquisition and Control}

All data from the tests, such as tank and PJM liquid levels; PJM pressures; flow rates; pressure and temperature of the sparger air; temperatures of the simulant, tank headspace, and ambient air; hydrogen peroxide solution flow rates; and tank weight were recorded using LabVIEW Version 8.2 data acquisition and control system (DACS) software. In addition to acquiring the data, the DACS screens also provided manual control of ON/OFF cycling for the PJMs, spargers, and hydrogen peroxide injection rates.

The majority of input channels on the DACS were sampled at $100 \mathrm{~Hz}$ and the data recorded as averages or medians over 1-second intervals. Simulant level external and internal to the PJMs and the PJM internal pressure were also recorded at $10 \mathrm{~Hz}$ to compute actual drive times and nozzle discharge velocity. The 1-second averages were saved as ASCII or text files. Each electronic entry in the file included a date/time stamp. The file name contained information regarding the test objective, rheology of the simulant, and the PJMs/sparger operating conditions.

\subsection{Data Analysis Methods}

This section summarizes the data analysis methods employed in setting the test operating conditions and computing the gas volume fractions reported in Section 5.4. Detailed descriptions of the methodologies are given in Appendixes B and E. PJM mixing is accomplished by periodically pressurizing the PJM pulse tubes to expel fluid through the PJM nozzles at high velocity, then applying a vacuum to refill the pulse tubes for the next cycle. The "peak average" nozzle velocity and its duration determine the volume of slurry mixed by the PJMs (the region of turbulent flow termed the "PJM cavern"). The methods for calculating the peak average velocity are described in Section 5.3.1. Air sparging mixes the portion of the slurry above the PJM cavern. The air flow rate is set to achieve a constant superficial velocity of the air bubbles as discussed in Section 5.3.2. 
Typical PJM cycles are illustrated in Figure 5.6 by slurry surface level and hydrostatic pressure difference recorded at $1 \mathrm{~Hz}$ in 13-Pa AZ-101 simulant. Two cycles are shown, each starting with the $\sim 6$ second drive period where 1.3-1.5 atm gauge pressure is applied to the pulse tubes. Slurry is expelled from the PJMs causing the slurry surface level in the tank to rise $\sim 20 \mathrm{~cm}$. (a) The pressure difference is not directly affected by the surface level rise, but indicates a brief disturbance of $\sim 1 \mathrm{kPa}$ during the peak jet velocity period. After the drive period the pulse tubes are re-filled by applying a vacuum of 0.3 to $0.5 \mathrm{~atm}$ gauge for 20 seconds then $\sim 2-\mathrm{kPa}$ gauge vacuum for 12 seconds to assist gravity refill. Fluid momentum and residual pressure maintains a high PJM nozzle velocity several seconds into the refill period. During the final $\sim 16$-second vent period, the pressure inside the pulse tubes is equal to that in the tank headspace so slurry levels inside and outside the pulse tubes are nearly in equilibrium. The only disturbance is from sparger action.

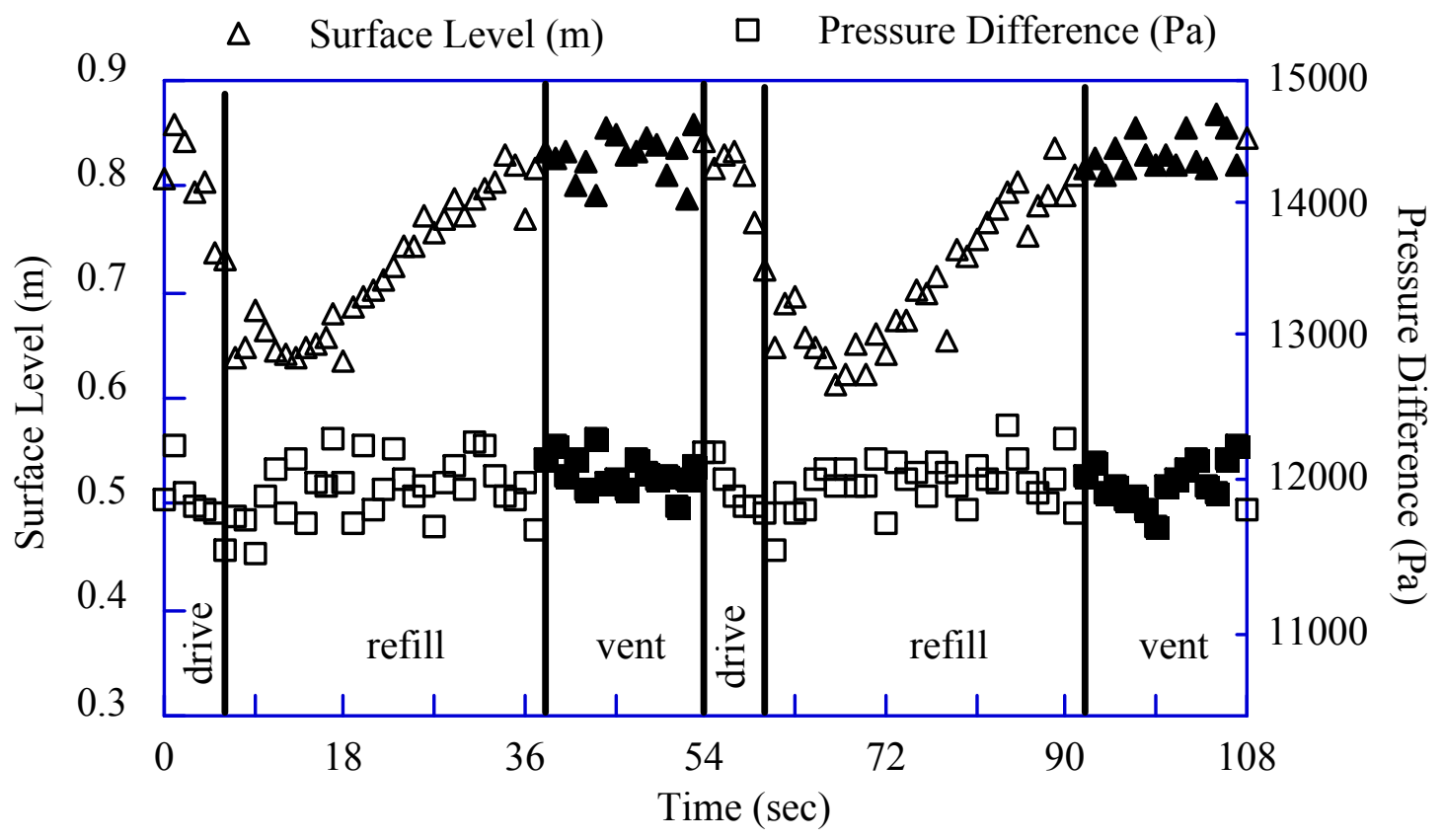

Figure 5.6. PJM Drive Cycle Illustration Showing Equilibrium Period

The median of the 16 level and pressure difference data points indicated by the filled symbols during the vent period is used to calculate the gas volume fraction. (b) This creates one aggregated value of gas volume fraction per PJM cycle that tracks increases and decreases of gas holdup from a starting baseline value during a test. The calculation of the gas volume fraction is described in Section 5.3.3, and further aggregation of the 1/cycle results and determination of uncertainty are summarized in Section 5.3.4.

(a) Surface level is measured down from the tank rim so a level rise is indicated by a decrease in measured level.

(b) The median was better than the mean for aggregating these data because the mean amplifies the influence of infrequent random large fluctuations that do not reflect the bulk gas content of the slurry (Stewart et al. 2006). 


\subsubsection{PJM Drive Cycle Analysis}

An idealized nozzle velocity profile during discharge is shown in Figure 5.7. The discharge time is the period of relatively constant discharge velocity defined as $t_{d}=t_{\text {end }}-t_{\text {start }}$. The start and end times must be determined by visual inspection of the velocity profile. The peak average velocity $\mathrm{U}_{\text {peak }}$ over the discharge time is defined as (Bamberger et al. 2005)

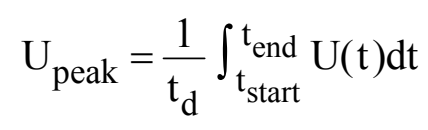

The term in brackets defines the slope of the linear surface level versus time trend. With randomly fluctuating data, this can be most accurately calculated as the slope of a linear regression through all the pulse tubes. The tank simulant surface level provides the most accurate analysis. (a) Assuming an incompressible fluid, the nozzle velocity is related to the rate of change of the average slurry level in the tank, $\mathrm{H}_{\mathrm{t}}$, by the ratio of areas as defined by

$$
U(t)=-\left(\frac{A_{t}}{N A_{n}}\right) \frac{d H_{t}(t)}{d t}
$$

where

$$
\begin{aligned}
& A_{t}=\text { area of the cylindrical portion of a pulse tube }\left(\mathrm{m}^{2}\right) \\
& A_{n}=\text { area of a PJM nozzle }\left(\mathrm{m}^{2}\right) \text { [the area ratio is 549] } \\
& N=\text { number of PJM nozzles }(8) .
\end{aligned}
$$

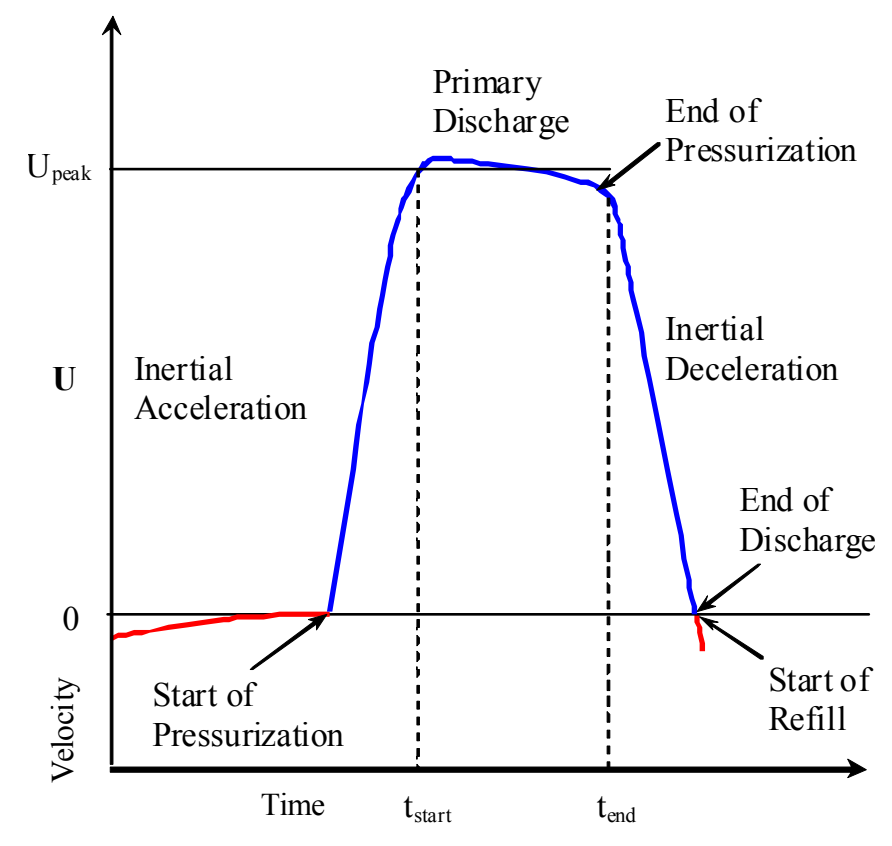

Figure 5.7. Illustration of PJM Peak Velocity

(a) The method using pulse tube levels and another applying Bernoulli's equation with pulse tube pressures are discussed in Appendix B. 
Substituting Eq. (5.7) into Eq. (5.6) and integrating leads to

$$
\left.U_{\text {peak }}=\left(\frac{A_{t}}{N A_{n}}\right) \frac{H\left(t_{\text {end }}\right)-H\left(t_{\text {start }}\right)}{t_{d}}\right]
$$

The term in brackets defines the slope of the linear surface level versus time trend. With randomly fluctuating data, this can be most accurately calculated as the slope of a linear regression through all the level data between $t_{\text {start }}$ and $t_{\text {end }}$. The start and end times are set by comparing an actual velocity plot with the "ideal" trend in Figure 5.7.

Because the differences required by all methods amplify random fluctuations in the surface levels and pressures, $10-\mathrm{Hz}$ data from 5 to 10 PJM cycles with spargers off are combined to produce a single composite cycle to smooth the velocity calculations. A typical analysis that provides the peak average velocity and the discharge time is shown in Figure 5.8.

The analysis provides one further metric of the PJM drive cycle. The PJM stroke is defined as the fraction of the volume of the cylindrical section of the PJMs that is discharged during the discharge at average velocity $U_{\text {peak }}$ between $t_{\text {start }}$ and $t_{\text {end }}$. The stroke can be calculated as

$$
\text { Stroke }=\frac{t_{d} U_{\text {peak }}}{L_{p t}}\left(\frac{A_{n}}{A_{p t}}\right)
$$

where

$A_{p t}=$ internal area of the cylindrical section of a pulse tube $\left(\mathrm{m}^{2}\right)$ (the area ratio is $\left.1 / 130.3\right)$

$\mathrm{L}_{\mathrm{pt}}=$ length of the cylindrical section of a pulse tube $(0.775 \mathrm{~m})$.

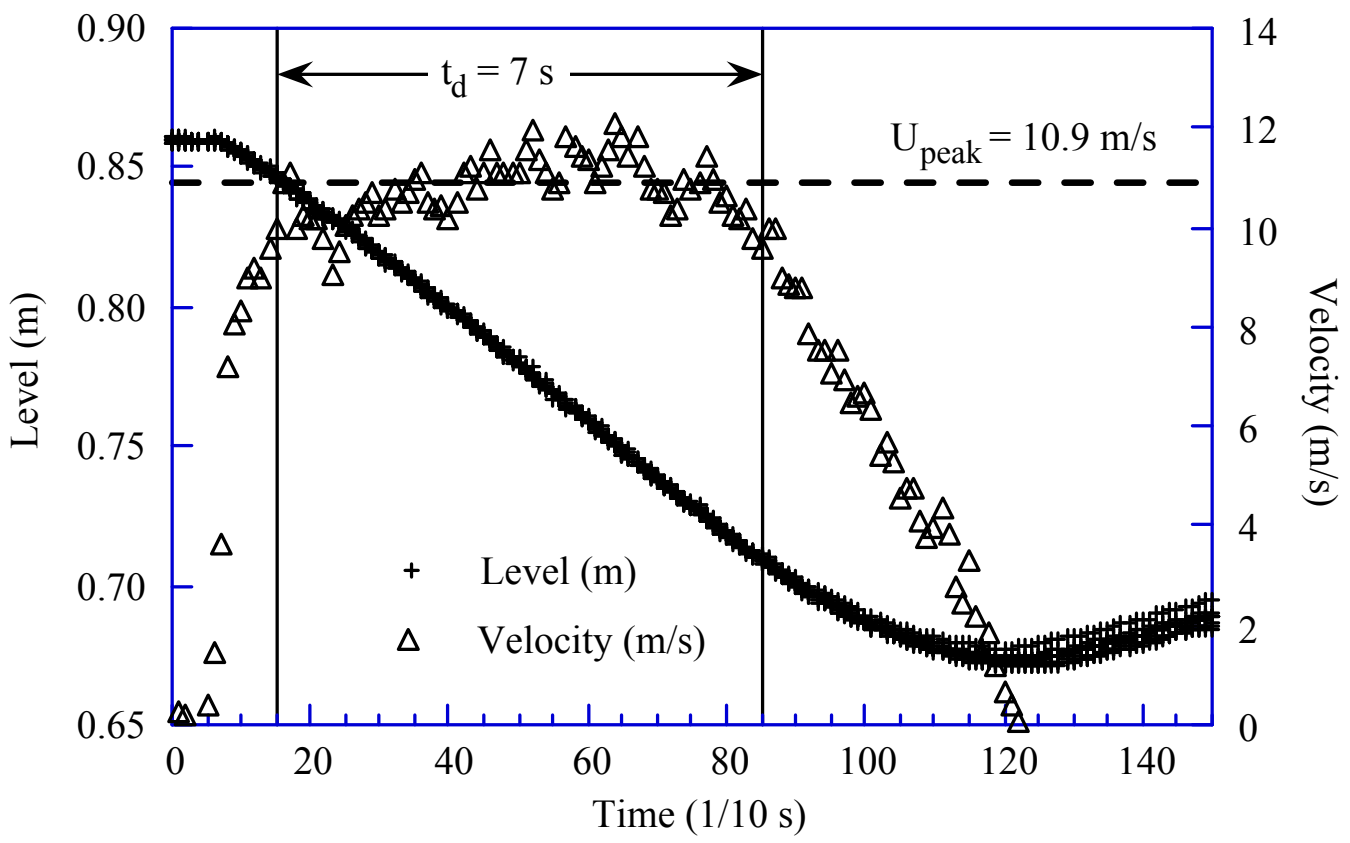

Figure 5.8. Illustration of PJM Drive Cycle Analysis 


\subsubsection{Sparger Air Flow Rate}

The sparger flow rate is set to maintain a constant superficial velocity of $5.2 \mathrm{~mm} / \mathrm{s}$, which requires a volume flow rate of $3.9 \mathrm{acfm}$ from each tube (see Table 5.2). The flow to each of the seven sparge tubes is controlled with a separate calibrated Rotameter ${ }^{\circledR}$ that reads in standard cubic feet per minute (scfm). Given the depth of simulant, its temperature, and degassed density, the proper Rotameter setting in scfm to provide the desired actual flow rate is given by:

$$
\mathrm{Q}_{0}=\mathrm{Q}_{\mathrm{a}} \frac{\mathrm{T}_{\mathrm{std}}}{\mathrm{T}_{\mathrm{s}}} \frac{\mathrm{P}_{\mathrm{amb}}+\rho g \mathrm{H}_{\mathrm{t}}}{\mathrm{P}_{\mathrm{std}}}
$$

where

$$
\begin{array}{ll}
\mathrm{Q}_{0} & =\text { standard sparger flow rate }(\mathrm{scfm}) \\
\mathrm{Q}_{\mathrm{a}} & =\text { actual sparger flow rate }(\mathrm{acfm}) \\
\mathrm{T}_{\text {std }} & =\text { standard temperature in the rotameter specifications }(294 \mathrm{~K}) \\
\mathrm{T}_{\mathrm{s}} & =\text { simulant temperature }(\mathrm{K}) \\
\mathrm{P}_{\mathrm{amb}} & =\text { ambient atmospheric pressure above the simulant }(\mathrm{Pa}) \\
\mathrm{P}_{\text {std }} & =\text { standard pressure }(101,325 \mathrm{~Pa}) \\
\rho & =\text { simulant degassed density }\left(\mathrm{kg} / \mathrm{m}^{3}\right) \\
\mathrm{g} & =\text { acceleration of gravity }\left(9.81 \mathrm{~m} / \mathrm{s}^{2}\right) \\
\mathrm{H}_{\mathrm{t}} & =\text { degassed depth of simulant }(\mathrm{m}) .
\end{array}
$$

The variation of the sparge tip temperature and pressure are so small that Eq. (5.10) gives an essentially constant standard sparger flow rate of $4.5 \mathrm{scfm}$ for all test conditions.

\subsubsection{Gas Volume Fraction}

Gas volume fraction was calculated in two separate ways, each of which depended on different data. In the first method, the baseline simulant volume, $\mathrm{V}_{\mathrm{Tb}}$, and the simulant volume at time $\mathrm{t}, \mathrm{V}_{\mathrm{T}}$, are determined by measuring the simulant surface level and applying a predetermined relationship between level and volume, $\mathrm{V}_{\mathrm{T}}=\mathrm{F}_{\mathrm{V}}[\mathrm{H}]$. The volume/level relation, $\mathrm{F}_{\mathrm{V}}$, is described in Appendix A. Over a lengthy test period ( 24 hours or more) the volume of gas-free simulant can change significantly due to water added with hydrogen peroxide injection partially balanced by water loss by evaporation. The total gas volume fraction $\alpha_{\mathrm{T}}$, sparger plus generated-gas holdup, can be found as

$$
\alpha_{T}=1-\frac{\rho_{b}\left(1-\alpha_{b}\right) V_{T b}+W}{\rho V_{T}}
$$

where

$$
\begin{aligned}
\rho_{\mathrm{w}}= & \text { density of water at the current simulant temperature }\left(\mathrm{kg} / \mathrm{m}^{3}\right) \\
\rho_{\mathrm{b}}= & \text { density of slurry at the baseline conditions }\left(\mathrm{kg} / \mathrm{m}^{3}\right) \\
\alpha_{\mathrm{b}}= & \text { gas volume fraction at the baseline conditions (conditions are selected to allow a gas fraction } \\
& \text { of zero, but the term is included for completeness) } \\
\mathrm{W}= & \text { water mass gain }(\mathrm{kg}) \\
\rho= & \text { density of slurry at time } \mathrm{t}\left(\mathrm{kg} / \mathrm{m}^{3}\right) .
\end{aligned}
$$


The calculation of the water loss by evaporation and water addition during hydrogen peroxide injection is detailed in Appendix B.

The gas volume fraction can also be calculated independently from the difference, $\Delta \mathrm{P}$, between two hydrostatic pressure measurements separated by a known elevation, $\Delta \mathrm{H}$. Ignoring the contribution of the gas mass to the pressure, the total gas volume fraction is

$$
\alpha_{T}=1-\frac{\Delta P}{\Delta P_{b}} \frac{\rho_{b}\left(1-\alpha_{b}\right)}{\rho}
$$

where

$\Delta \mathrm{P}_{\mathrm{b}} \quad=$ pressure differential at baseline conditions $(\mathrm{Pa})$

$\Delta \mathrm{P} \quad=$ pressure differential at time $\mathrm{t}(\mathrm{Pa})$.

The density $\rho$ is a function of time, varying with water addition, and is calculated by a continuing mass and water balance. Additional details of the derivation are given in Appendix B.

Although the gas holdup was calculated from both types of measurements, level and $\Delta \mathrm{P}$, it was found that the transients induced by PJM operation and the surface disturbances caused by sparger air bubbles had much less effect on pressure transducer data than on the level measurements. Also, the simulant splatter accumulation occasionally obstructed the laser beams and made readings unreliable. Consequently, the gas volume fraction data appearing in this report, except for the gas release transients in Section 5.4.4, are based on $\Delta \mathrm{P}$.

The sparge holdup calculations were based on data from pressure transducers in the constricted flow region, that is, the annulus around the PJM cluster, so the calculated sparge gas volume fraction is expected to overestimate the tank-average sparge holdup in the vessel as a whole. The sparge superficial velocity is higher in the annulus, producing a higher local sparger gas fraction. The same effect is not expected for the generated-gas volume fraction because the gas is generated in the bulk liquid.

The sparge gas fraction in the areas other than the annulus, for instance, the volume above the PJM cluster, was not measured. Molina Grima et al. (1997) cite data for a bubble column in which the riser area equaled that of the downcomer; in this case, the downcomer gas fraction was less than $63 \%$ of that in the riser. In the QSLS vessel, the "riser" (the annulus) has an area more than twice that in the "downcomer" (central region), which could lead to a higher downcomer gas volume fraction relative to the riser than was seen in the reference configuration. Because the annulus area is a large fraction of the total tank area, about $71 \%$, the assumption that the tank-average sparge gas volume fraction is equal to the annulus gas volume fraction should cause the tank-average sparger gas volume fraction to be overestimated by no more than 10 to $20 \%$.

\subsubsection{Determining Steady-State Values}

There are two basic criteria for determining a steady-state gas volume fraction data point: the gas

volume fraction must have a time rate of change that is less than some acceptable criterion, and the 
aggregated steady-state gas volume fraction must be statistically different from the baseline (i.e., initial "zero" value). The following is a brief overview of the method; more details can be found in Appendix E.

As described earlier in this section, an individual value of total gas volume fraction (retained sparge plus generated gas) is calculated for each PJM cycle using the median values of surface level and pressure difference for $161-\mathrm{Hz}$ data points recorded during the equilibrium period at the end of each cycle. Figure 5.1 illustrates the collection of these calculated values over the course of a typical test involving three sets of three hydrogen peroxide injection rates (plus a release test at the end). A steady-state total gas volume fraction value is determined for each of the nine injection rates plus the initial two-hour baseline period.

The steady state is evaluated based on the slope obtained from a linear regression on the last 30 $1 /$ cycle values of gas volume fraction. A steady state is assumed when the absolute value of the slope is less than a specified limit. If this criterion is met, the steady-state gas volume fraction is computed as the mean of the 30 values evaluated. If this mean value satisfies a T-test for significance, it is considered an acceptable steady state. The pooled variance for the T-test also represents the uncertainty.

Only 1/cycle values from the last 60 minutes of a two-hour test segment are evaluated in this way. This means that the first steady state can represent no period earlier than that from 60 to 87 minutes after the current hydrogen peroxide injection rate began, and the last one represents the last 27 minutes (30 cycles $\times 54 \mathrm{sec} /$ cycle $/ 60 \mathrm{sec} / \mathrm{min}=27 \mathrm{~min}$ ). The final steady-state gas volume fraction representing the specific hydrogen peroxide injection rate is calculated as the mean of all steady-state values meeting the two criteria. The criteria are adjusted to produce at least four values for each injection rate.

\subsection{QSLS Test Results}

Testing with non-Newtonian simulants was conducted in the QSLS system over a two-month period from early July to early September 2007 and one day of water visualization tests were run in early June. The list of tests performed is given in chronological order in Table 5.3. Tests are identified by simulant type (AZ = AZ-101 HLW simulant) and nominal Bingham yield stress. Tests were conducted in order of decreasing yield stress because it was far easier to decrease the yield stress by dilution with water than to increase it by evaporation. One "cycle" in the description is a test segment with three hydrogen peroxide injection rates unless fewer are indicated. Injection rates are referenced as equivalent steady-state superficial velocities of the generated gas, nominally $0.025,0.05$, and $0.1 \mathrm{~mm} / \mathrm{s}$. Several of the tests were repeated because of equipment problems or unanticipated simulant behavior as described in later sections.

Tests with AZ-101 simulant with AFA were performed first because the project schedule required information on the effect of AFA as soon as possible. This represents the first large-scale tests using this simulant, earlier tests being conducted mainly with clay. Qualitatively the AZ-101 simulant behaved differently from clay even with similar rheological properties. AZ simulant was more difficult to pump though the transfer lines. It also tended to settle when not being mixed overnight or weekend with a shallow layer of supernatant liquid on top and a thin gray layer on the bottom. On the other hand, the AZ simulant did not coat the tank wall or internal structure nearly as readily as clay. In fact, it would spontaneously fall off any vertical or near-vertical surface so that the tank wall would be transparent after sitting undisturbed overnight. 
Table 5.3. QSLS Tests Conducted in Chronological Order

\begin{tabular}{|c|c|c|}
\hline Test & Start/Finish & Description \\
\hline Water + AFA Visualization & $6 / 6 / 06$ & $\begin{array}{l}\text { Video at } 0-, 10-, 30-, 100-, \text { and } 350-\text { ppm AFA } \\
(0-, 10-, 30-, 100-, \text { and } 350-\mathrm{mg} / \mathrm{L})\end{array}$ \\
\hline AZ 30-Pa simulant + AFA & $7 / 6 / 07-7 / 7 / 07$ & 3 cycles plus release $^{(\mathrm{a})}$ \\
\hline AZ 13-Pa simulant + AFA & $7 / 9 / 07-7 / 10 / 07$ & 2 cycles plus release $^{(\mathrm{b})}$ \\
\hline AZ 13-Pa simulant + AFA repeat & $7 / 16 / 07-7 / 17 / 07$ & 3 cycles plus release \\
\hline AZ 3-Pa simulant + AFA & $7 / 20 / 07-7 / 21 / 07$ & 3 cycles at 0.05 and $0.1 \mathrm{~mm} / \mathrm{s}$ plus release ${ }^{(\mathrm{c})}$ \\
\hline AZ 3-Pa simulant + AFA repeat 1 & $7 / 23 / 07$ & 2 cycles at 0.025 and $0.05 \mathrm{~mm} / \mathrm{s}$. \\
\hline Clay $30 \mathrm{~Pa}$ & $8 / 14 / 07-8 / 15 / 07$ & 2 cycles $^{(\mathrm{d})}$ \\
\hline Clay $30 \mathrm{~Pa}$ repeat & $8 / 21 / 07-8 / 23 / 07$ & 3 cycles plus release \\
\hline Clay $13 \mathrm{~Pa}$ & $8 / 27 / 07-8 / 28 / 07$ & 3 cycles plus release \\
\hline Clay $3 \mathrm{~Pa}$ & $8 / 29 / 07-8 / 30 / 07$ & 3 cycles plus release \\
\hline AZ 3 Pa simulant + AFA repeat 2 & $9 / 10 / 07-9 / 11 / 07$ & 3 cycles plus release $^{(\mathrm{c})}$ \\
\hline \multicolumn{3}{|c|}{$\begin{array}{l}\text { (a) First cycle at } 0.01,0.03 \text {, and } 0.1 \mathrm{~mm} / \mathrm{s} \text {; changed to } 0.025,0.05,0.1 \mathrm{~mm} / \mathrm{s} \text { because no holdup seen at } 0.0 \\
\text { (b) PJM vacuum lost during the first cycle; decision to stand down for repair made after the second cycle. } \\
\text { (c) High and variable sparge holdup prevented obtaining useful data. } \\
\text { (d) Yield stress fell to } 25 \mathrm{~Pa} \text { after second cycle due to dilution. }\end{array}$} \\
\hline
\end{tabular}

Test procedures and operations evolved with experience. Some of the major changes are listed in order below. They do not affect the validity of the data, but need to be considered in interpreting the full body of data.

- During dilution to $13 \mathrm{~Pa}$ following $30 \mathrm{~Pa} \mathrm{AZ}$ simulant test 7/8/07:

- Remove shutdown feature from PJM overblow warning

- Revise test instruction to run release test last after holdup series completed

- Recalibrated laser levels (30 Pa data were corrected to new calibration)(a)

- During stand down following $2^{\text {nd }} 13-\mathrm{Pa} A Z$ simulant test 7/11-15/07:

- Revise test instruction to run a short sparger holdup test prior to reference period

- Revise test instruction to run initial reference period for two hours prior to test

- During simulant change prior to initial 30-Pa clay series 7/24/07 - 8/13/07:

- Modify DACS to control PJM valves on 0.1-second intervals

- During stand down following initial 30-Pa clay series 8/16-20/07:

- Modify test instruction for a full two-hour mixing period between test cycles

- During dilution to $3 \mathrm{~Pa}$ following 13 Pa clay test $\sim 8 / 28 / 07$

- Add running plot of gas volume fraction based on pressure difference to DACS screens.

(a) The lasers were initially calibrated to the height of a water surface. During the dilution of AZ simulant from 30 to $13 \mathrm{~Pa}$, it was discovered that the lasers were not sensing the surface of the water accurately. 
Specific test conditions for each cycle are given in more detail in later sections. Section 5.4.1 describes the effects of AFA on sparge bubble behavior observed in the water visualization tests. Sections 5.4.2 and 5.4.3 present the steady-state gas holdup in terms of gas volume fraction versus superficial velocity of gas generation in clay simulant and AZ-101 HLW simulant, respectively. Gas release behavior for the two simulants is described in Section 5.4.4.

\subsubsection{Visualization of AFA Effects in Water}

The purpose of the water visualization tests was to qualitatively describe the effects of increasing AFA concentration on sparger holdup, bubble size and behavior. AFA was added by pouring stock solution (10\% AFA in water by volume) directly into the tank across from the cameras while mixing with spargers and PJMs. Because this test was performed prior to installation of in-tank instrumentation the sparger holdup was measured with a tape affixed to the side of the tank.

High-speed video was recorded at 250 frames/sec from two cameras, one viewing a sparger tube tip and another near the surface, as sketched in Figure 5.9. The bottom camera was tilted to view the sparger tube tip over the metal dish tank bottom. The resulting distortion through the curved tank wall obscured the images from this camera, especially at higher AFA concentrations. The top camera provided the best overall view of the bubbles. Bubble behavior was recorded during the transition to the next higher AFA concentration and again after the AFA concentration reached an approximately steady state.

Bubble behavior was recorded without AFA and at AFA concentrations of 10-, 30-, 100-, and $350 \mathrm{ppm}(350 \mathrm{mg} / \mathrm{L})$, the latter being the concentration specified for the WTP. As shown in Figure 5.10, the surface tension of the liquid fraction of AZ-101 simulant decreases rapidly to $43 \mathrm{mN} / \mathrm{m}$ at $3.6 \mathrm{mg} / \mathrm{L}$ of AFA and more gradually at higher concentrations. Thus the effect of AFA on bubble behavior was most dramatic at the $10 \mathrm{mg} / \mathrm{L}$ concentration with more gradual changes at higher concentrations.

The change in bubble size distribution with AFA concentration is evident in the video. A series of high-speed video clips is provided on the DVD attached inside the back cover of this report. The video of the entire transition from zero to $10 \mathrm{ppm}$ AFA $(10 \mathrm{mg} / \mathrm{L})$ on the DVD shows the effect of AFA on the sparger bubbles most clearly.

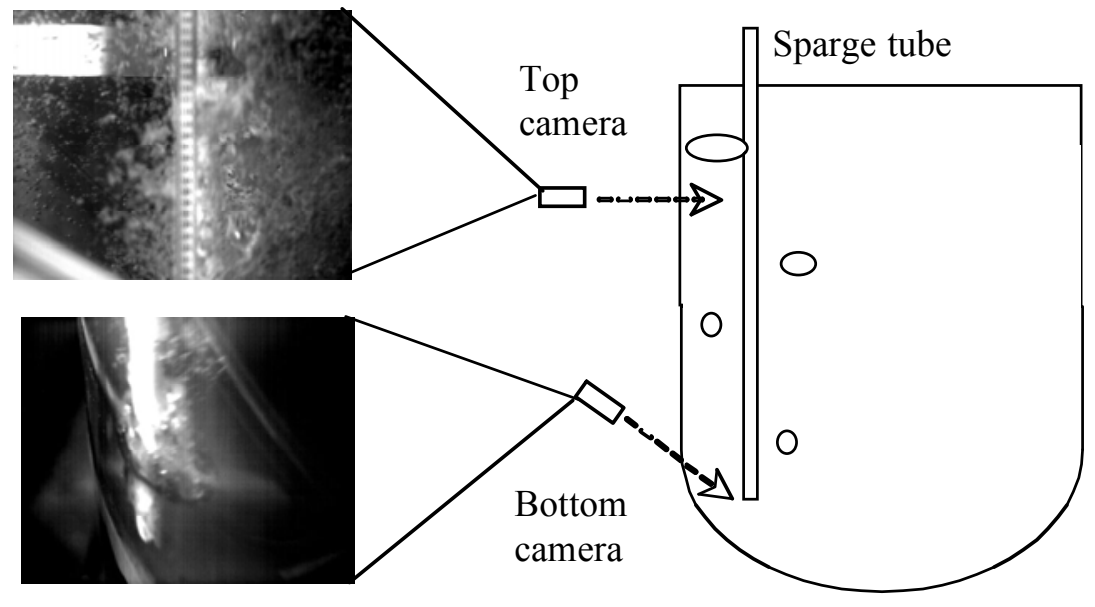

Figure 5.9. Video Camera Position for Water Tests 


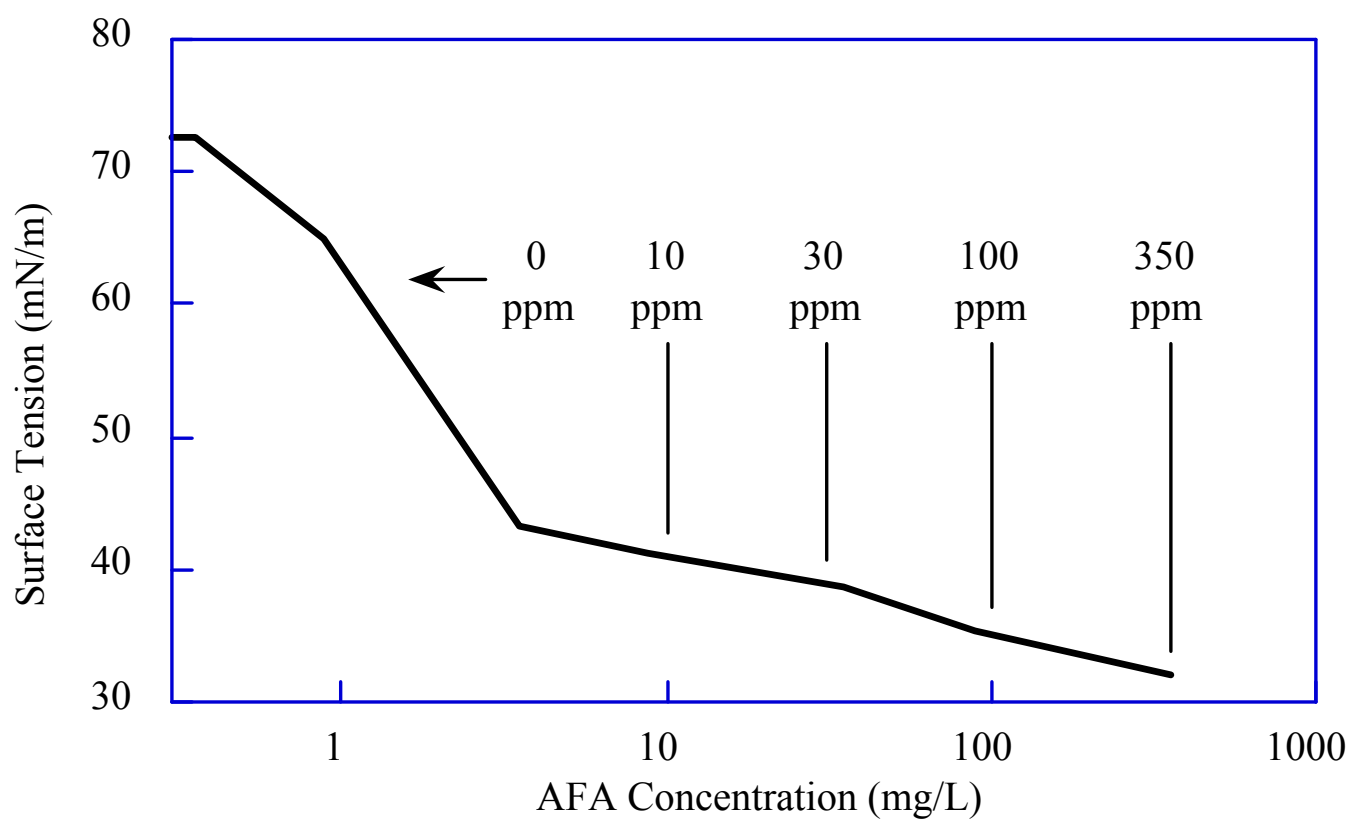

Figure 5.10. Surface Tension of AZ-101 Simulant Liquid Fraction Versus AFA Concentration

The effect of AFA appeared to be mainly a dramatic increase in the number of very small bubbles. Tiny bubbles less than $100 \mu \mathrm{m}$ in diameter appeared to be a haze. However, the behavior (e.g., size, formation frequency, breakup and coalescence) of the largest bubbles and bubble swarms appeared to be affected little by AFA. Also the volume occupied by the increased population of the smallest bubbles is low. The sparger holdup remained essentially constant at $1.6 \pm 0.8 \mathrm{vol} \%$ at all AFA concentrations.

The bubble behavior observed can only be studied effectively by viewing the motion on the DVD. What follows is a qualitative description of this action. The sparge bubbles interacted intensely in the low-viscosity water and never assumed the classic Taylor cap shape expected to occur in the nonNewtonian slurries. Bubbles were created at a relatively high rate with a resulting small separation distance that produced continually evolving swarms (Stewart 1995). The individual bubbles would accelerate and gather in a loose column behind a larger leader quickly overtaking the leaders. At this point the swarm spread out in a "mushroom" shape and quickly decelerated only to be re-gathered and accelerate with the next larger bubble rising through them. The process of one or more bubbles overtaking another caused both coalescence and breakup, often simultaneously. The presence of AFA appeared to increase the number of small bubbles created in these events. Though the sparger tube tips are near the PJM nozzle outlet, the PJM jet seemed only to cause a large-scale circulation of smaller bubbles in the lower portion of the tank. The additional turbulence of the jet did not appear to cause additional bubble breakup. Whatever breakup occurred was due to bubble interaction in the sparger ROB.

\subsubsection{Gas Retention in Clay}

Results of tests in clay are presented first though they were performed after those in $\mathrm{AZ}$ simulant because clay tests form the basis for scaling up test data to the full scale lag storage vessel. The lag storage vessel is the only one represented by gas retention data at two large scales over a sufficient range of gas generation rates (superficial velocities) to permit reasonable extrapolation to plant conditions. 
The tests conducted with clay simulant in the QSLS test stand are described in Table 5.4 in terms of the following simulant properties and PJM drive conditions:(a)

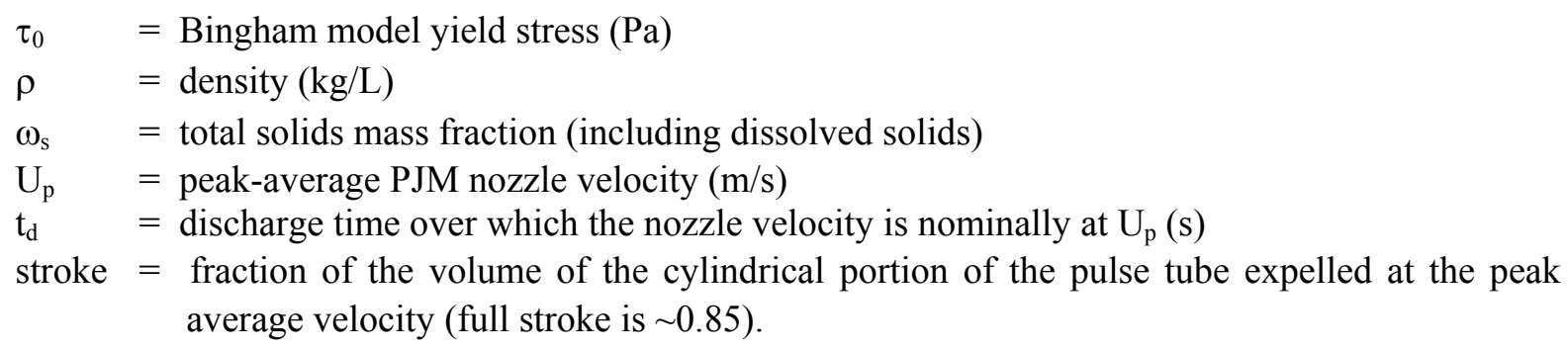

All 30-Pa clay data reported are from the repeat test. The initial $30-\mathrm{Pa}$ test was terminated when the yield stress was found to have decreased to $25 \mathrm{~Pa}$ after the second cycle, below the minimum allowable $27 \mathrm{~Pa}$. The mean retained gas volume fraction versus gas generation superficial velocity in 30-Pa clay QSLS tests are compared with earlier scaled lag storage data in Figure 5.11. The error bars indicate \pm 1 standard deviation of the mean gas fraction. Within the uncertainty of the data, the current QSLS data matches the prior HSLS (HSLS 2005) and QSLS results. The curve fit to the data shown represents the technical basis for scaling the lag storage vessel for 30-Pa clay simulant. Because the same curve was fit to data at 1/4- and 1/2-scale for $30 \mathrm{~Pa}$ clay simulant, the curve fits for other simulants in $1 / 4$-scale tests are considered to be appropriate for scaling holdup predictions in those slurries.

It is noteworthy that data from the three test series correspond as well as they do considering the variety of test conditions and operating modes. These differences are summarized in Table 5.5. Not only do simulant depth (H/D), PJM nozzle velocity, and stroke vary, but a different PJM configuration and secondary mixing system were also used. Nevertheless, data from all these variant tests give consistent results and trends. Gas holdup is apparently not very sensitive to the system configuration or operating conditions.

All of the current retained gas holdup data in clay simulant are shown in Figure 5.12. For 30-Pa clay simulant, the measured holdup ranged from 0.4 to 0.5 vol\% at the low end of the gas-generation superficial velocity range to $1.1-1.4 \mathrm{vol} \%$ at the highest superficial velocity. The gas holdup at $13 \mathrm{~Pa}$ was consistently lower and more scattered; the range was 0.05 to $0.1 \mathrm{vol} \%$ at the lowest superficial velocity and 0.3 to $0.6 \mathrm{vol} \%$ at the highest. Thus, as superficial velocity decreased, the holdup in 13-Pa clay fell off more rapidly than that in 30-Pa clay. The gas holdup in the 3-Pa clay tests was detected only at the higher superficial velocities; considering the problems with detection, the uncertainty is probably higher than the error bars indicate. It would be appropriate to state that the gas holdup in 3-Pa clay was similar to that at $13 \mathrm{~Pa}$ for the upper end of the experimental velocity range, but the difficulty in detecting it at lower velocities may mean it was lower in 3-Pa clay than in 13-Pa clay in that velocity range.

(a) The target scaled PJM nozzle velocity and discharge time were $12 \mathrm{~m} / \mathrm{s}$ and 7 seconds, respectively; however, the drive parameters obtained in the clay tests were approximately $9-11 \mathrm{~m} / \mathrm{s}$ velocity and $\sim 6$ to 7.5 seconds drive time. The discrepancy can be attributed primarily to the slightly larger than scale nozzle diameter of the standard stainless steel pipe and the high pressure drop in the air supply manifold that reduced the available drive pressure in the pulse tubes early in the cycle. This lengthened acceleration time, which reduced the time at peak velocity, and decreased the peak velocity. The resulting stroke was approximately 0.6 to 0.7 , or about $\sim 70 \%$ of the $\sim 0.85$ at full stroke. 
Table 5.4. Tests Conducted with Clay Simulant

\begin{tabular}{|c|c|c|c|c|c|c|c|c|c|}
\hline Test/Segment & Start/Finish & $\begin{array}{c}\tau_{\mathbf{0}} \\
(\mathbf{P a})\end{array}$ & $\begin{array}{c}\text { Pre-test } \\
\mu_{\mathrm{B}} \\
(\mathrm{Pa} s)\end{array}$ & $\begin{array}{c}\rho \\
(\mathrm{kg} / \mathrm{L})\end{array}$ & $\begin{array}{c}\omega_{\mathrm{s}} \\
\mathrm{wt} \%\end{array}$ & $\begin{array}{c}\mathbf{U}_{\mathbf{p}} \\
(\mathbf{m} / \mathbf{s})\end{array}$ & $\begin{array}{l}\mathbf{t}_{\mathbf{d}} \\
(\mathbf{s})\end{array}$ & $\begin{array}{c}\text { Stroke } \\
(-)\end{array}$ & Comment \\
\hline Clay $30 \mathrm{~Pa}$ & $8 / 14 / 071633-8 / 15 / 070853$ & & & & & & & & \\
\hline Cycle 1 & 8/14/07 1903-8/15/07 0103 & 32.7 & 0.0594 & 1.268 & 34.5 & 10.4 & 5.6 & 0.6 & \\
\hline Cycle 2 & $8 / 15 / 070203-0834$ & 25 & & 1.264 & 34.2 & 10.6 & 6.0 & 0.6 & Test terminated due to low yield stress \\
\hline Clay $30 \mathrm{~Pa}$ repeat & $8 / 21 / 07$ 1700-8/23/07 0414 & & & & & & & & \\
\hline Cycle 1 & $8 / 21 / 072255-8 / 22 / 070455$ & 35.2 & 0.0694 & 1.273 & 35.2 & 10.5 & 6.7 & 0.7 & \\
\hline Cycle 2 & $8 / 22 / 070828-1427$ & 33.4 & & 1.27 & 35 & 10.0 & 6.8 & 0.7 & \\
\hline Cycle 3 & $8 / 22 / 071754-2323$ & & & & & 9.6 & 7.5 & 0.7 & \\
\hline Release & $8 / 22 / 072324-8 / 23 / 070414$ & 34.4 & & 1.269 & 34.9 & - & - & - & \\
\hline Clay $13 \mathrm{~Pa}$ & $8 / 27 / 070010-8 / 28 / 070715$ & & & & & & & & \\
\hline Cycle 1 & $8 / 27 / 070500-1059$ & 14.1 & 0.0353 & 1.245 & & 10.2 & 5.8 & 0.6 & \\
\hline Cycle 2 & $8 / 27 / 07$ 1349-1950 & 13.6 & & 1.241 & 32.0 & 10.0 & 6.3 & 0.6 & \\
\hline Cycle 3 & $8 / 27 / 072150-8 / 28 / 070351$ & - & & - & - & 9.8 & 7.1 & 0.7 & \\
\hline Release & $8 / 28 / 070352-0715$ & 15.0 & & 1.243 & 32.0 & - & - & - & \\
\hline Clay $3 \mathrm{~Pa}$ & $8 / 29 / 070627-8 / 30 / 071229$ & & & & & & & & \\
\hline Cycle 1 & $8 / 29 / 07$ 1151-1749 & 3.7 & 0.0132 & 1.199 & 27.3 & 9.5 & 6.7 & 0.6 & Low gas holdup difficult to measure \\
\hline Cycle 2 & $8 / 29 / 07$ 1938-8/30/07 0137 & 3.7 & & 1.200 & 27.2 & 9.4 & 7.1 & 0.7 & “ \\
\hline Cycle 3 & $8 / 30 / 070400-0959$ & 4.0 & & 1.199 & 27.1 & 9.7 & 5.9 & 0.6 & “ \\
\hline Release & $8 / 30 / 07$ 0959-1229 & 4.2 & & 1.198 & 27.0 & - & - & - & \\
\hline
\end{tabular}




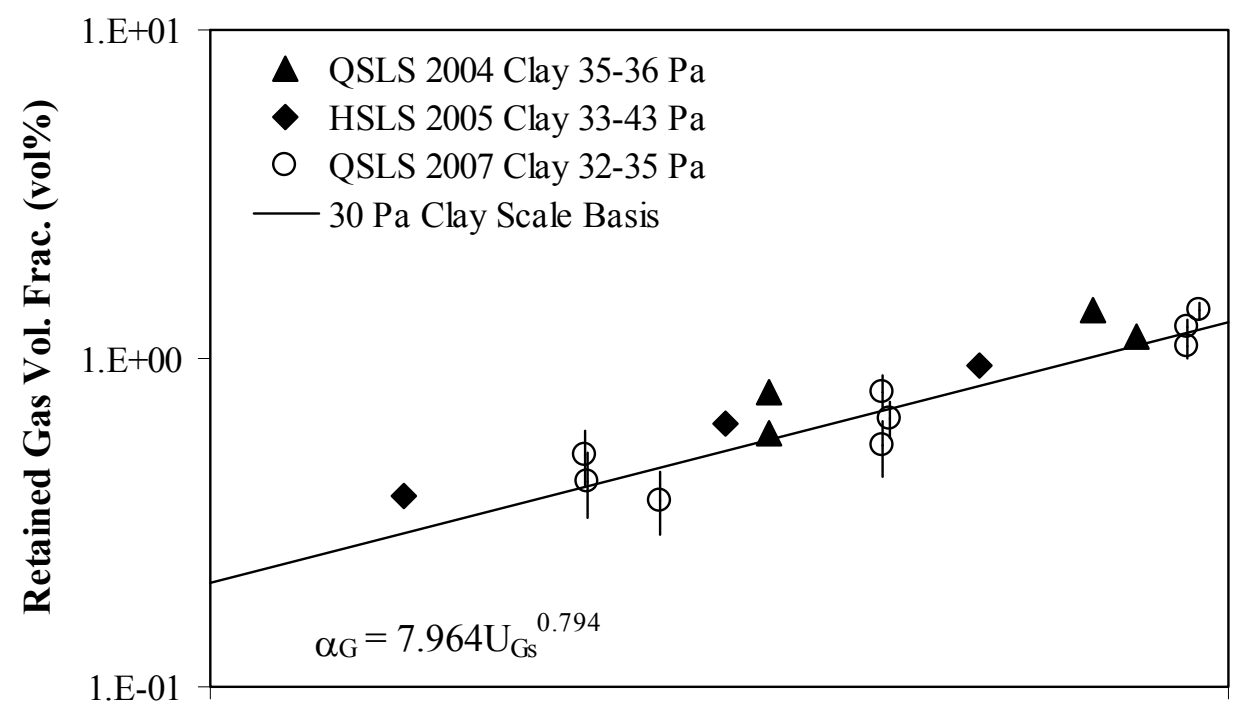

1.E-02

Gas generation superficial velocity $(\mathrm{mm} / \mathrm{s})$

1.E-01

Figure 5.11. 30-Pa Clay Gas Holdup Scaling Basis

Table 5.5. Comparison of 30-Pa Clay Test Conditions

\begin{tabular}{|c|c|c|c|}
\hline Test & H/D & PJM Parameters & Secondary Mixing \\
\hline QSLS $2004 \mathrm{~A}^{(\mathrm{a})}$ & 0.74 & $\begin{array}{l}3 @ 135^{\circ}, 4 @ 45^{\circ}, 1 \text { center } @ 0^{\circ} \\
\mathrm{U}=17 \mathrm{~m} / \mathrm{s}, \mathrm{t}_{\mathrm{d}} \sim 4 \mathrm{~s}, \sim 80 \% \text { stroke }\end{array}$ & 4 spargers@ 3 acfm each \\
\hline QSLS $2004 \mathrm{~B}^{(\mathrm{b})}$ & 0.74 & $\begin{array}{l}7 @ 45^{\circ}, 1 \text { center @ } 0^{\circ} \\
\mathrm{U}=16 \mathrm{~m} / \mathrm{s}, \mathrm{t}_{\mathrm{d}} \sim 5 \mathrm{~s}, \sim 93 \% \text { stroke }\end{array}$ & $\begin{array}{l}4 \text { recirc. nozzles @ } 114 \mathrm{~L} / \mathrm{min} \text { each } \\
(6.5 \text { min vol. exch. time) }\end{array}$ \\
\hline HSLS $2005^{(\mathrm{c})}$ & 0.93 & $\begin{array}{l}7 @ 45^{\circ}, 1 \text { center } @ 0^{\circ} \\
\mathrm{U}=12 \mathrm{~m} / \mathrm{s}, \mathrm{t}_{\mathrm{d}} \sim 4 \mathrm{~s}, \sim 50 \% \text { stroke }\end{array}$ & 7 spargers@ 18 acfm each \\
\hline QSLS 2007 & 0.84 & $\begin{array}{l}7 @ 45^{\circ}, 1 \text { center } @ 0^{\circ} \\
\mathrm{U}=10 \mathrm{~m} / \mathrm{s}, \mathrm{t}_{\mathrm{d}} \sim 6 \mathrm{~s}, \sim 70 \% \text { stroke }\end{array}$ & 7 spargers@3.9 acfm each \\
\hline \multicolumn{4}{|c|}{\begin{tabular}{|l} 
(a) Lag storage sequence 14, run 3, 2/6/04 (Russell et al. 2005). \\
(b) Lag storage sequence 15A, run 3, 2/14/06 (Russell et al. 2005).
\end{tabular}} \\
\hline
\end{tabular}

\subsubsection{Gas Retention in AZ-101 Simulant}

AFA was used in all tests with AZ simulant because foaming precluded holdup measurements in tests without AFA at SRNL. Thus there are no data to deduce the independent effect of AFA on gas holdup. However, the tests satisfied the primary objective of comparing gas holdup and release in AZ simulant with AFA to that in clay simulant without AFA.

Test results from AZ-101 simulant in the QSLS test stand are summarized in Table 5.6. The cycle superficial velocities for gas generation were planned to be $0.01,0.03$ and $0.1 \mathrm{~mm} / \mathrm{s}$. Because no gas holdup was detected on the first cycle 30-Pa AZ simulant test, the superficial velocity sequence was 


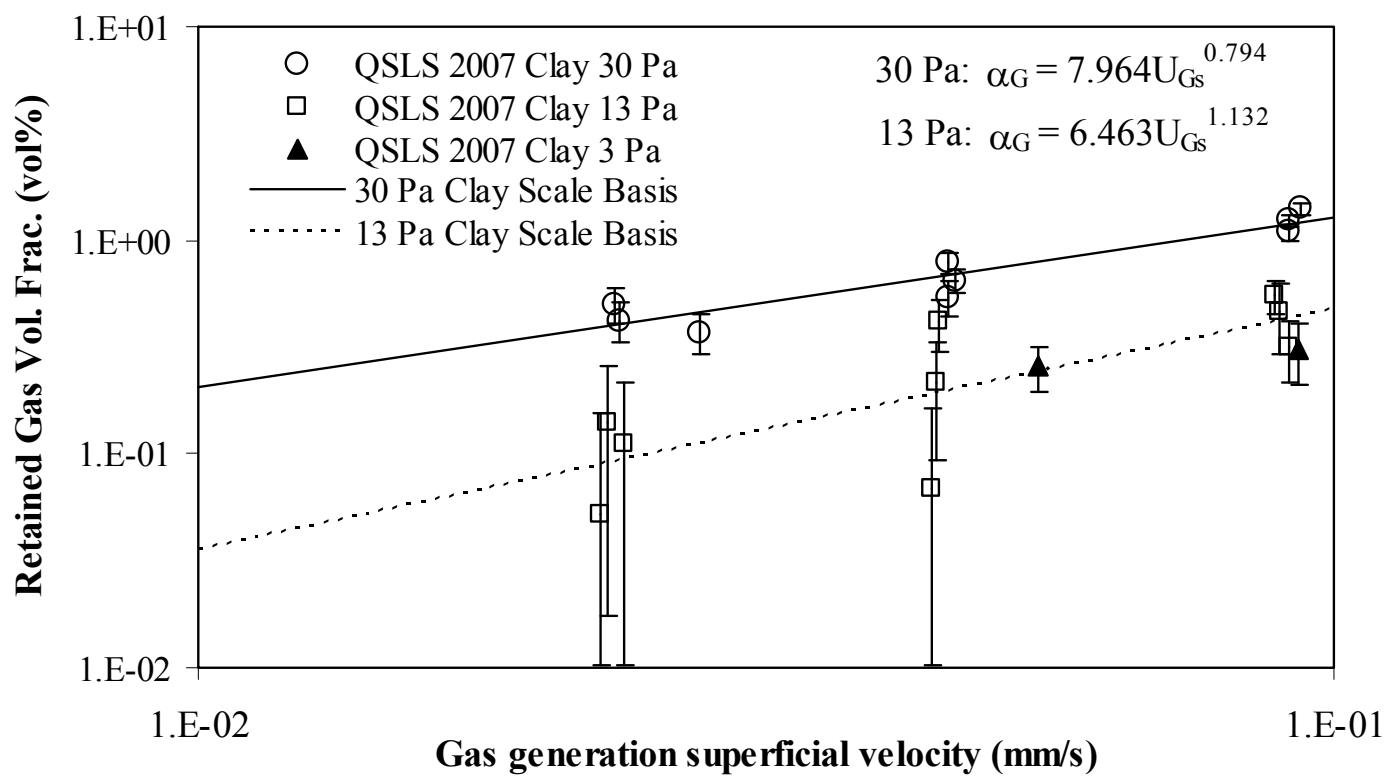

Figure 5.12. Summary of QSLS Clay Gas Holdup Data

adjusted upward to $0.025,0.05$ and $0.1 \mathrm{~mm} / \mathrm{s}$ for all subsequent tests. A high and variable sparger/PJM holdup occurred during the initial 3-Pa AZ simulant test that made it impossible to calculate accurate gas holdup due to generation. Similar problems occurred on two subsequent repeats, as described below.

Data from the tests in AZ simulant at 30, 13, and $3 \mathrm{~Pa}$ are shown in Figure 5.13. The 30- and 13-Pa AZ simulant scaling bases (curve-fit lines) are included. In 30-Pa AZ simulant with AFA, the measured retained gas holdup ranged from 0.7 to $0.9 \mathrm{vol} \%$ at the low end of the gas-generation superficial velocity range, to 1.7 to $1.8 \mathrm{vol} \%$ at the highest superficial velocity. The gas holdup in the 13-Pa AZ simulant with AFA was consistently lower than at $30 \mathrm{~Pa}$, like it was in clay, but was harder to detect than in the clay. The measured value at the middle superficial velocity was $0.2 \mathrm{vol} \%$ and at the highest was 0.4 to 0.6 vol\%. The holdup in 13-Pa AZ simulant with AFA fell off more rapidly with decreasing velocity than the holdup in the 30-Pa simulant, as had also been true in the clay without AFA. The gas holdup in the tests with 3-Pa AZ simulant with AFA were detected across the whole superficial velocity range. However, the sparger holdup in these tests was about 9 vol\% and variable, causing more uncertainty in calculating the relatively small generated gas holdup (total holdup minus sparger) than the error bars indicate. The visible scatter in the 3-Pa data is some indication of the true uncertainty. It would be appropriate to say that gas holdup in 3-Pa AZ simulant with AFA was similar to the 13-Pa simulant; the evidence, though unclear because of complications from sparger holdup, does not prove conclusively that the holdup in 3-Pa AZ simulant with AFA is less than in 13-Pa simulant. 
Table 5.6. Tests Conducted with AZ-101 HLW Simulant with AFA

\begin{tabular}{|c|c|c|c|c|c|c|c|c|c|}
\hline Test/Segment & Start/Finish & $\begin{array}{c}\tau_{0} \\
(\mathbf{P a})\end{array}$ & $\begin{array}{c}\text { Pre-test } \\
\mu_{\mathrm{B}} \\
(\mathrm{Pa} \mathrm{s})\end{array}$ & $\begin{array}{c}\rho \\
(\mathbf{k g} / \mathbf{L})\end{array}$ & $\begin{array}{c}\omega_{s} \\
(w t \%)\end{array}$ & $\begin{array}{c}\mathbf{U}_{\mathbf{p}} \\
(\mathbf{m} / \mathbf{s})\end{array}$ & $\begin{array}{c}\mathbf{t}_{\mathrm{d}} \\
(\mathbf{s})\end{array}$ & $\left|\begin{array}{c}\text { Stroke } \\
(-)\end{array}\right|$ & Comment \\
\hline $30-\mathrm{Pa}$ & $7 / 6 / 07$ 1009-7/7/07 1035 & & & & & & & & $\begin{array}{l}\text { No holdup detectable at } 0.01 \mathrm{~mm} / \mathrm{s} \text {; rest of tests use } 0.025 \text {, } \\
0.05,0.1 \mathrm{~mm} / \mathrm{s}\end{array}$ \\
\hline Cycle 1 & $7 / 6 / 071132-1729$ & 32.4 & 0.0152 & 1.215 & 26.3 & 8.9 & 6.4 & 0.56 & $\begin{array}{l}\text { The holdup did not reach a final value in this cycle (lower than } \\
\text { in the later cycles) }\end{array}$ \\
\hline Release & $7 / 6 / 071730-2139$ & 33.4 & & 1.223 & 26.4 & - & - & - & \\
\hline Cycle 2 & $7 / 6 / 072140-7 / 7 / 070339$ & - & & - & - & - & - & - & \\
\hline Cycle 3 & 7/7/07 0431-1035 & 30.2 & & 1.221 & 26.0 & - & - & - & \\
\hline $13 \mathrm{~Pa}$ & 7/9/07 1937-7/10/07 1848 & & & & & & & & \\
\hline Cycle 1 & $7 / 9 / 072200-7 / 10 / 070400$ & 14.4 & 0.0096 & 1.168 & 22.8 & - & - & - & PJM vacuum lost 0056 , discovered 7/10/07 0800 \\
\hline Release & $7 / 10 / 070405-0829$ & 13.4 & & 1.157 & 22.7 & - & - & - & System shut down $08 / 29$ to $12 / 12$ to restore PJM vacuum \\
\hline Cycle 2 & 7/10/07 1300-1848 & 13.4 & & 1.139 & 22.6 & - & - & - & Stand down for repairs and procedure revision after Cycle 2 \\
\hline 13 Pa repeat & 7/16/07 1720-7/17/07 2153 & & & & & & & & \\
\hline Cycle 1 & $7 / 16 / 07$ 1920-7/17/07 0100 & 13.9 & 0.0094 & 1.173 & 22.8 & 10.9 & 5.7 & 0.62 & $\begin{array}{l}\text { The holdup did not reach a final value in this cycle (lower than } \\
\text { in the later cycles) }\end{array}$ \\
\hline Cycle 2 & $7 / 17 / 070230-0830$ & - & & - & - & 10.7 & 6.7 & 0.71 & \\
\hline Cycle 3 & $7 / 17 / 071211-1809$ & 14.3 & & 1.178 & 22.7 & 10.4 & 7.5 & 0.77 & \\
\hline Release & 7/17/07 1815-2153 & 13.4 & & 1.129 & 22.6 & - & - & - & \\
\hline Cycle 4 & $7 / 17 / 072154-7 / 18 / 070440$ & 13.5 & & 1.132 & 22.6 & - & - & - & \\
\hline $3 \mathrm{~Pa}$ & 7/20/07 0254-7/21/07 0135 & & & & & & & & $\begin{array}{l}\text { Only } 0.05 \text { and } 0.1 \mathrm{~mm} / \mathrm{s} \text { used; large, variable sparge holdup, no } \\
\text { holdup from generation were detected }\end{array}$ \\
\hline Cycle 1 & $7 / 20 / 070715-1115$ & 4.2 & 0.0060 & 1.110 & 18.4 & - & - & - & No holdup determined \\
\hline Cycle 2 & $7 / 20 / 071213-1613$ & - & & - & - & 10.1 & 5.9 & 0.59 & No holdup determined \\
\hline Cycle 3 & $7 / 20 / 07$ 1703-2101 & & & & & 9.8 & 6.8 & 0.66 & No holdup determined \\
\hline Release & $7 / 20 / 072102-7 / 21 / 070135$ & 4.1 & & 1.141 & 18.3 & - & - & - & No release data obtained \\
\hline $3 \mathrm{~Pa}$ repeat 1 & $7 / 23 / 070803-2319$ & & & & & & & & Sparge holdup large but stable; only 0.025 and $0.05 \mathrm{~mm} / \mathrm{s}$ used \\
\hline Cycle 1 & $7 / 23 / 071426-1824$ & 4.1 & 0.0059 & 1.150 & 18.5 & 9.7 & 6.3 & 0.61 & Holdup determination approximate \\
\hline Cycle 2 & 7/23/07 1918-2306 & 4.2 & & 1.144 & 18.3 & 10.0 & 5.9 & 0.58 & Holdup determination approximate \\
\hline $3 \mathrm{~Pa}$ repeat 2 & 9/10/07 0932-9/11/07 1200 & & & & & & & & High and variable sparger holdup \\
\hline Cycle 1 & $9 / 10 / 071632-2030$ & 3.7 & 0.0055 & 1.144 & 17.5 & 10.3 & 6.8 & 0.70 & Holdup determination approximate \\
\hline Cycle 2 & $9 / 11 / 070120-0718$ & 3.6 & & 1.137 & 17.5 & 10.4 & 6.8 & 0.70 & Holdup determination approximate \\
\hline Cycle 3 & 9/11/07 0844-1443 & 3.6 & & 1.147 & 17.5 & 10.6 & 6.5 & 0.68 & Holdup determination approximate \\
\hline Release & 9/11/07 1444-1810 & 3.3 & & - & 17.2 & - & - & - & No release data obtained \\
\hline
\end{tabular}




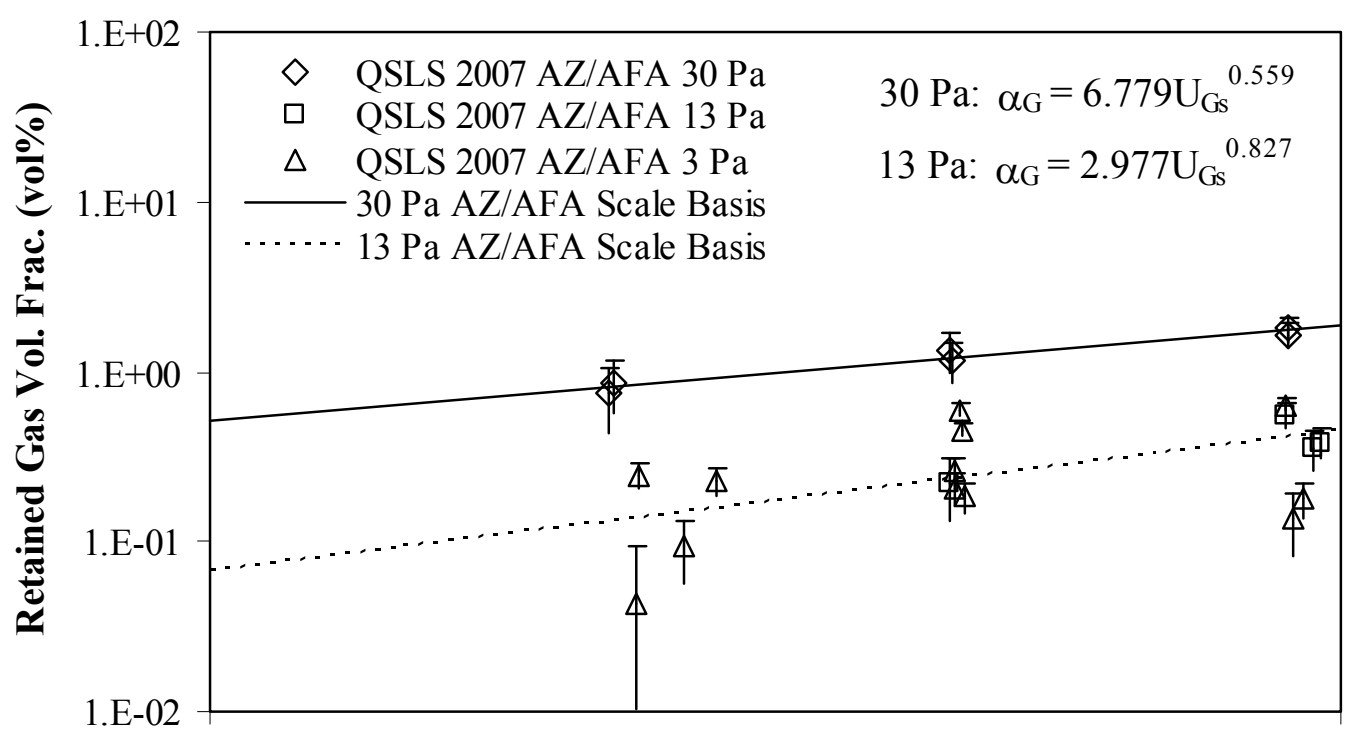

1.E-02

Gas generation superficial velocity $(\mathrm{mm} / \mathrm{s})$

1.E-01

Figure 5.13. Summary of AZ-101 HLW Simulant Gas Holdup Data

The ratio of holdup in AZ-101 simulant with AFA to holdup in clay simulant at the same superficial velocity has been referred to in past studies as $F_{w}$ (Stewart et al. 2006). The expressions for $F_{w}$ in 30 - and 13-Pa simulant can be found by taking the ratios of the scaling basis curve fits in Figures 5.13 and 5.12.

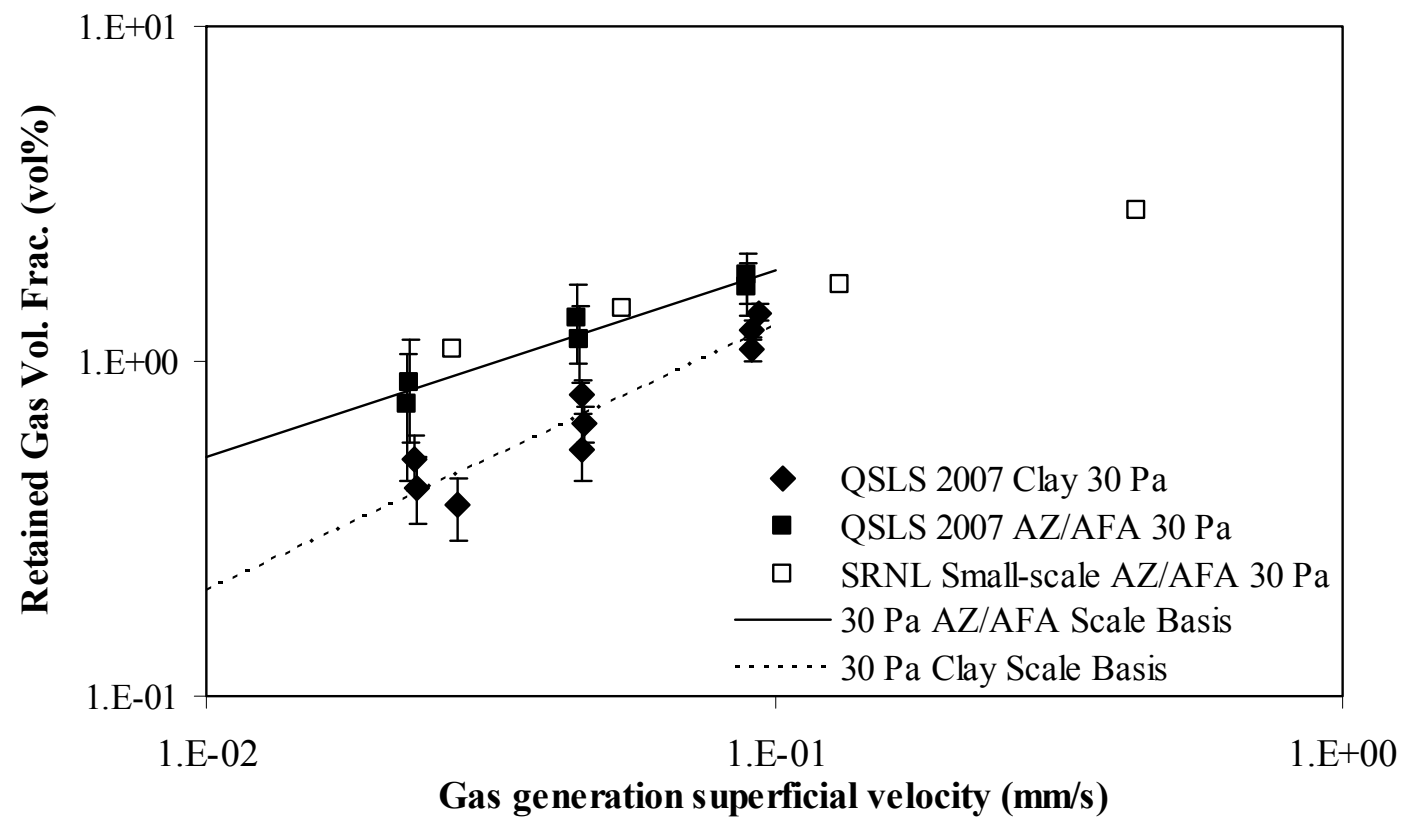

Figure 5.14. Summary of AZ-101 HLW Simulant Gas Holdup Data 


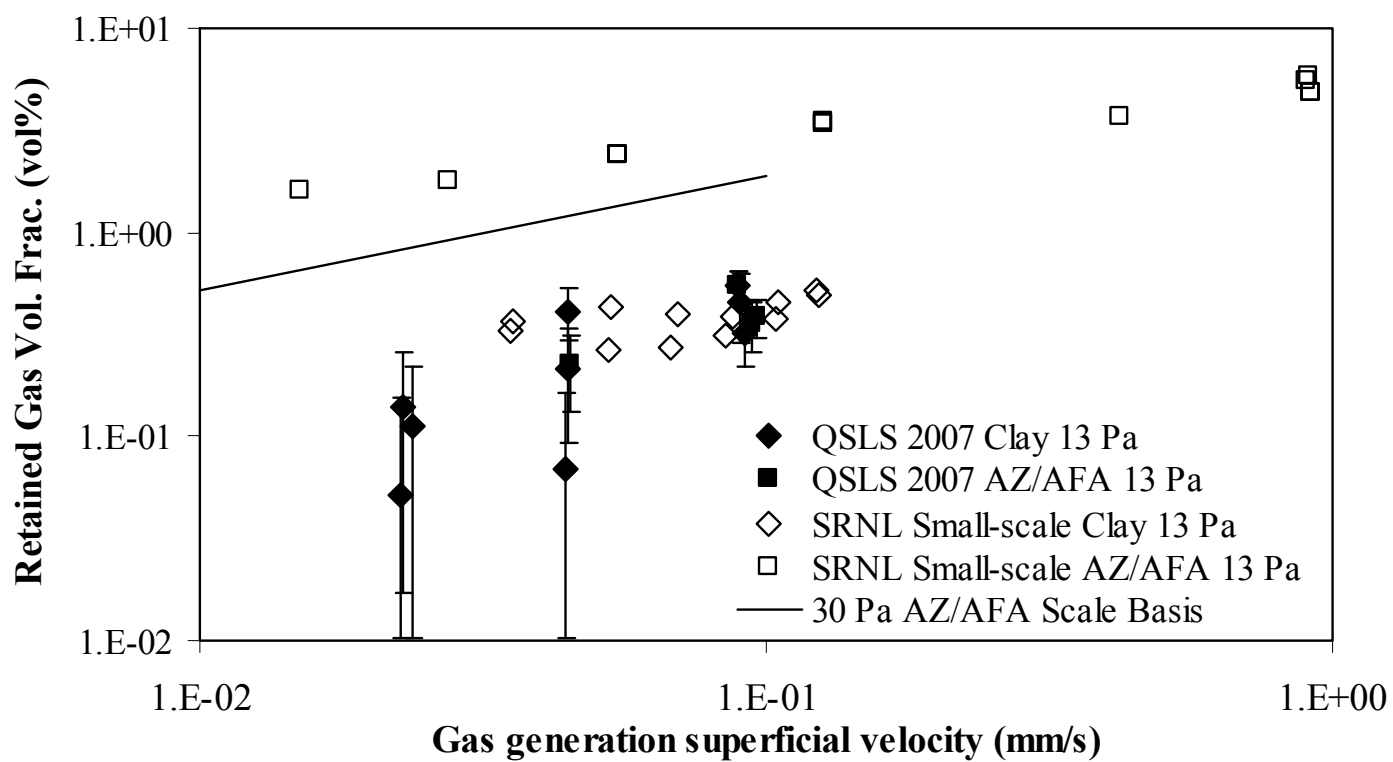

Figure 5.15. Comparison of Gas Holdup in $13 \mathrm{~Pa}$ Clay and AZ-101 HLW Waste Simulant

$$
\begin{aligned}
& F_{w}(30 P a)=0.851 U_{G s}^{-0.235} \\
& F_{w}(13 P a)=0.461 U_{G s}^{-0.305}
\end{aligned}
$$

These equations differ from the corresponding equations that were determined based on data from the SRNL impeller-mixed small-scale test stand, Eq. (5.19) and (5.20) of Stewart et al. (2006). The values of $F_{w}$ predicted over a range of gas-generation superficial velocities are shown in Table 5.7.

The difference between the holdup in clay and that in AZ simulant with AFA tends to increase (that is, $F_{w}$ tends to increase) as the superficial velocity decreases. At both $30 \mathrm{~Pa}$ and $13 \mathrm{~Pa}$, when the superficial velocity is extrapolated to $10^{-4} \mathrm{~mm} / \mathrm{s}$ by using the scaling basis equations (curve fits), the estimated holdup in AZ simulant with AFA is 7 to 8 times that in clay of the same yield stress. This estimate should be treated with caution, however, since the effect of the uncertainty in the coefficients of the scaling basis equations has not been accounted for.

Table 5.7. Comparison of $F_{w}$ Values for QSLS-07 and SRNL (2006) Test Stands

\begin{tabular}{||c|l|c|c|c|}
\hline \multirow{2}{*}{ Simulant } & \multirow{2}{*}{ Test Stand } & \multicolumn{3}{|c|}{ Gas-Generation Superficial Velocity $\boldsymbol{U}_{\mathbf{G s}}(\mathbf{m m} / \mathbf{s})$} \\
\cline { 3 - 5 } & & $10^{-4}$ & $10^{-2}$ & $10^{-1}$ \\
\hline \multirow{3}{*}{$30-\mathrm{Pa}$ simulant } & QSLS (2007) & 7.4 & 2.5 & 1.5 \\
\cline { 2 - 5 } & SRNL (2006) & 3.2 & 2.5 & 2.2 \\
\hline 13-Pa simulant & QSLS (2007) & 7.6 & 1.9 & 0.9 \\
\cline { 2 - 5 } & SRNL (2006) & 24 & 11 & 7.1 \\
\hline
\end{tabular}


As discussed in Appendix E, calculations have been made of the $95 \%$ confidence upper and lower bounds for the gas-volume fraction predicted for 30-Pa AZ-101 simulant. At $0.05 \mathrm{~mm} / \mathrm{s}$ (the center of the tested superficial velocity range) the predicted $\alpha_{G}$ is 1.27 vol\% with lower and upper $95 \%$ prediction interval limits of 0.97 and $1.66 \mathrm{vol} \%$, respectively. At $10^{-4} \mathrm{~mm} / \mathrm{s}$ (plant operating range for the HSLS) the predicted $\alpha_{G}$ is $0.04 \mathrm{vol} \%$, with lower and upper $95 \%$ prediction interval limits of 0.01 and $0.12 \mathrm{vol} \%$, respectively. Extrapolation to $10^{-4} \mathrm{~mm} / \mathrm{s}$ increases the quantifiable part of the uncertainty, as can be seen by comparing the relative uncertainties at the two velocities. It also creates a non-quantifiable uncertainty, because the applicability of the power-law correlation form has not been demonstrated at gas generation rates lower than the tested range.

As can be seen in Figures 5.14 and 5.15 and in Table 5.7, the holdups measured in the prototypic QSLS test stand clearly do not follow the same trends as those measured in the nonprototypic SRNL test stand. In the experimental range of superficial velocities, the data from the SRNL vessel tend to indicate higher $F_{w}$ for the AZ simulant with AFA than do the data from the QSLS, more so at $13 \mathrm{~Pa}$ than at $30 \mathrm{~Pa}$. In the plant operations range, $10^{-4} \mathrm{~mm} / \mathrm{s}$, the $13-\mathrm{Pa} F_{w}$ is nearly three times as high in the SRNL results as in the QSLS results. These predictions, indicating an increase in $F_{w}$ with decreasing simulant yield stress, were the primary driver for conducting the current QSLS test program. Possible reasons for the difference between the SRNL and QSLS data are discussed in Section 5.5.

Though carried out three times, tests in $3 \mathrm{~Pa}$ AZ-101 simulant with AFA produced few or no useful data for generated gas holdup because a large and variable sparger holdup obscured the effects of gas generation. An example of this behavior is shown in Figure 5.16, plotting the total gas volume fraction (retained plus sparge gas holdup) versus time for the final repeat. Initially, PJMs are off and spargers are at the idle flow rate. Holdup quickly rises to nearly 9 vol\% as the spargers and PJMs are turned on. At $1.95 \mathrm{hr}$ the spargers and PJMs were turned off again, reducing the holdup to zero. At $3.1 \mathrm{hr}$ the PJMs were turned on while leaving spargers at idle flow rate, causing the holdup to increase to $2.3 \mathrm{vol} \%$, which was probably less than the final holdup would have been under those conditions. At $4.1 \mathrm{hr}$ the spargers were set to main flow rate, raising the holdup to 8.6 to $9.4 \mathrm{vol} \%$. The holdup showed some increase during the first high-rate $(0.1 \mathrm{~mm} / \mathrm{s})$ hydrogen peroxide injection period but then began decreasing while injection continued and kept on decreasing after it was shut down. Holdup decreased sharply when spargers were shut down at $\sim 14 \mathrm{hr}$ but quickly rose when turned on again. The same pattern was seen in the subsequent two cycles. Holdup decreased quickly when the spargers were turned off at the end of the test. No gas accumulation was observed during the time the mixing system was shut down, so the gas release test produced no data.

It was also observed that when AFA was added to the 3-Pa AZ simulant in preparation for running the $\mathrm{H}_{2} \mathrm{O}_{2}$-addition tests, the increase in level was greater than the volume of the AFA solution could account for. Apparently the addition of AFA to this particular simulant produced an increase in sparger gas holdup under conditions where both spargers and PJMs were operating. Five hours after the AFA addition, the rate of level increase (sparger holdup) was still greater than before the addition, indicating a continuing effect. The concentration of AFA in the 3-Pa simulant before AFA addition was not known, so the relation between AFA concentration and sparger holdup in 3-Pa AZ simulant in the QSLS is not quantitatively established. 


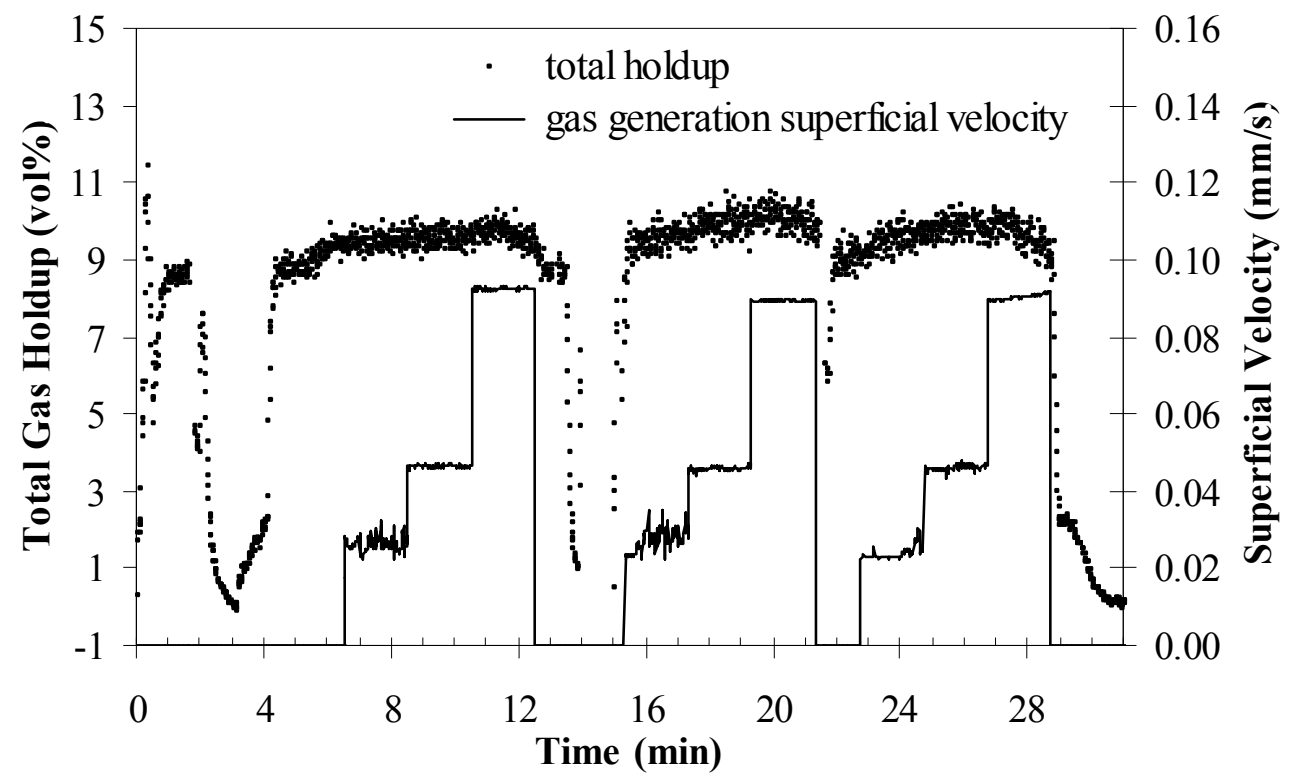

Figure 5.16. Gas Volume Fraction Versus Time: $3 \mathrm{~Pa}$ AZ Simulant Test

Simulant samples drawn during some of the 3-Pa AZ simulant tests retained relatively high volumes of gas in the laboratory days later. Some of this gas was observed to be released as small spherical bubbles $\sim 1 \mathrm{~mm}$ in diameter by tapping the sample container. By contrast, no evidence of high holdup of gas was observed in 3-Pa clay.

\subsubsection{Gas Release}

Gas release tests were run by shutting down the mixing system (PJMs off, spargers set to idle flow) immediately after a 2-hour period of hydrogen peroxide injection at the highest flow rate. The unreacted hydrogen peroxide remaining in the simulant would then decompose and generate gas that would remain trapped in the simulant in the absence of mixing. After the retained gas volume ceased increasing, mixing was resumed to release trapped gas, resulting in a transient decrease in the gas volume fraction over time.

Analysis of the gas release transient is based on the assumption that the superficial velocity of gas rising through the simulant is related to the bulk gas volume fraction by a power function of the same form, $\alpha=r_{1} U_{s}^{r_{2}}$, that expresses the trend of gas holdup tests (Stewart et al. 2006). ${ }^{\text {(a) With no gas }}$ generation, the rate of change of the gas volume fraction during a release is related to the gas volume fraction and the speed at which bubbles leave the simulant surface, $U_{f}$, by $(b)$

(a) In this section, the same form of equation is used for sparge gas release and retained gas release, so the subsequent equations refer to gas volume fraction simply as $\alpha$, the superficial velocity of rising bubbles as $U_{s}$, and the velocity of bubbles escaping at the surface as $U_{f}$ (in previous work, $U_{R}$ ). Also, in previous work the constants in the power law were expressed as $A$ and $B$ but have been changed to $r_{1}$ and $r_{2}$ to avoid confusion with the vessel crosssectional area $A$. Equations in the plots are in terms of $\alpha_{G}$ and $U_{G s}$, for retained gas, and $\alpha_{A}$ and $U_{A s}$, for sparge gas.

(b) The release model was based on the assumption that $\mathrm{H}$ was constant at the gasless value during the release. The actual variation was several percent; in the case of 30-Pa clay, it was more than $10 \%$. 


$$
\frac{d \alpha}{d t}=\frac{-\alpha U_{f}}{H}
$$

Here the subscript $f$ denotes the final velocity, i.e. the velocity at the surface. Assuming that the gas volume fraction remains relatively uniform so that $\alpha \mathrm{U}_{\mathrm{f}}=\mathrm{U}_{\mathrm{S}}$ and applying the power law relation between superficial velocity and gas volume fraction yields

$$
\frac{d \alpha}{d t}=\frac{-1}{H}\left(\frac{\alpha}{r_{1}}\right)^{1 / r_{2}}
$$

For $\alpha(t=0)=\alpha_{0}$, Eq. (5.15) has the solution

$$
\alpha(t)=\left[\alpha_{0}^{\left(r_{2}-1\right) / r_{2}}-\left(\frac{r_{2}-1}{r_{2}}\right) \frac{t}{H r_{1}^{1 / r_{2}}}\right]^{\frac{r_{2}}{r_{2}-1}}
$$

Though the form $\alpha=r_{1} U_{s}^{r_{2}}$ and Eq. (5.16) consistently provides a good fit to most gas release data (Stewart et al. 2006), the coefficient and exponent derived from a fit to release data generally differ significantly from those expressing the gas holdup versus superficial velocity trend for the same simulant and test stand. In some cases the actual release is slower than described by the holdup parameters. This finding also applies to the current QSLS data, although the holdup-derived parameters express the release somewhat more closely.

The releases from 30- and 13-Pa clay are shown in Figure 5.17. In these plots, like the other release transient plots, release data were taken from the level measurement-based gas volume fractions and normalized such that the final gas fraction was zero. (a) This normalization simplified model fitting and correctly represented the variation of holdup with time.

The 13-Pa clay releases gas faster than 30-Pa clay, but both release essentially all the retained gas in less than 10 minutes. Eq. (5.17) indicates that the time for release scales linearly. Thus, a similarly complete release in the full-scale lag storage (FSLS) vessel would occur in less than $\sim 40$ minutes.

The releases of generated gas in AZ simulant with AFA plotted in Figure 5.18 are similar to those in clay. The fit parameters derived from Eq. (5.17) are different from those expressing the steady-state holdup given in Figure 5.18. The holdup parameters for 13-Pa AZ simulant predict a faster release than the data, and those from holdup tests in the 30-Pa AZ simulant show a slower release.

It is also interesting to analyze the release of sparger gas holdup during the tests with 3-Pa AZ-101 simulant with AFA. In both the initial and second repeat tests, sparger holdup approached $\sim 10$ vol\% but decayed relatively quickly when the spargers and PJMs were shut down. Figure 5.19 shows a sparger holdup release from the pretest portion of the second repeat before hydrogen peroxide injection began.

(a) In the original data, the release from the 30 -Pa clay ended at a gas volume fraction between -1 and -2 vol\%. The reason for this post-transient offset is unknown, but it lasted long enough to be a consistent endpoint. 


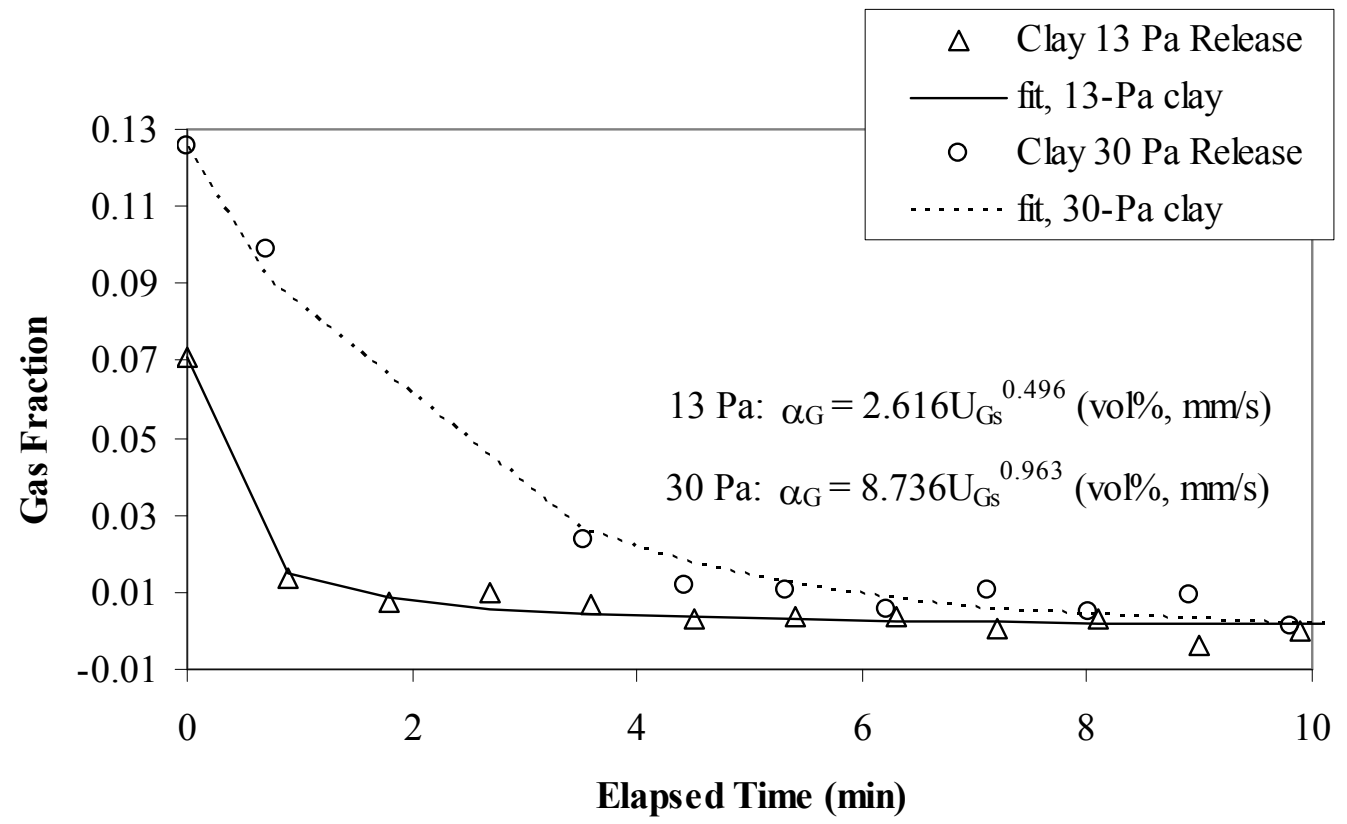

Figure 5.17. Gas Release Transients in Clay Simulant

Like the others presented in this section, this release is essentially complete and is modeled closely by Eq. (5.17). However, the sparge gas release is much longer than the release of generated gas, requiring almost an hour. Unlike the others, this release occurred in the absence of mixing, meaning that only gas bubbles large enough to overcome the 3-Pa yield stress, larger than $\sim 1 \mathrm{~mm}$ (Stewart et al. 1996), could rise through the material. Their rise speed would be slower than that in an already mobilized slurry.

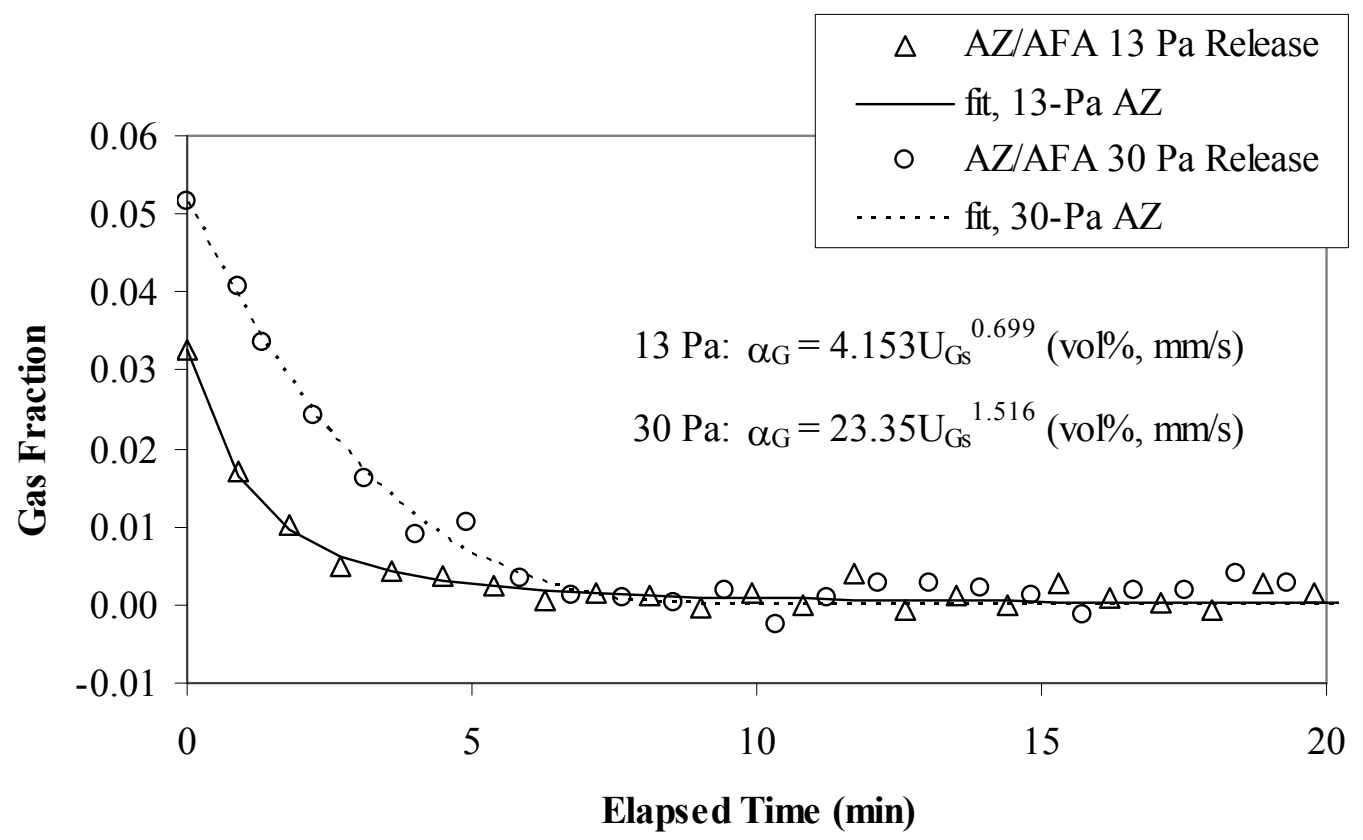

Figure 5.18. Gas Release Transients in AZ-101 HLW Simulant 
If the power relationship given in Figure 5.19 can be assumed to represent steady-state holdup as well, a sparger holdup of $10 \mathrm{vol} \%$ would require a sparge superficial velocity of $0.25 \mathrm{~mm} / \mathrm{s}$. For the simulant in the QSLS tank (approximately 3,100 L with a depth of $1.4 \mathrm{~m}$ ) this is equivalent to a gas generation rate of $34 \mathrm{~L} / \mathrm{min}$ or $1.2 \mathrm{acfm}$. This represents about $4 \%$ of total sparge air flow rate of $27 \mathrm{acfm}$. This high sparger holdup was observed only in $3 \mathrm{~Pa} \mathrm{AZ} \mathrm{simulant} \mathrm{with} \mathrm{AFA} \mathrm{(the} \mathrm{sparger} \mathrm{holdup}$ in water + AFA with zero yield stress was closer to 1 vol\%). SRNL staff also observed an increasing tendency toward foaming in the AZ-101 simulant without AFA, and even with AFA at $3 \mathrm{~Pa}$, so the high holdup may be an artifact of this batch of simulant rather than of AFA.

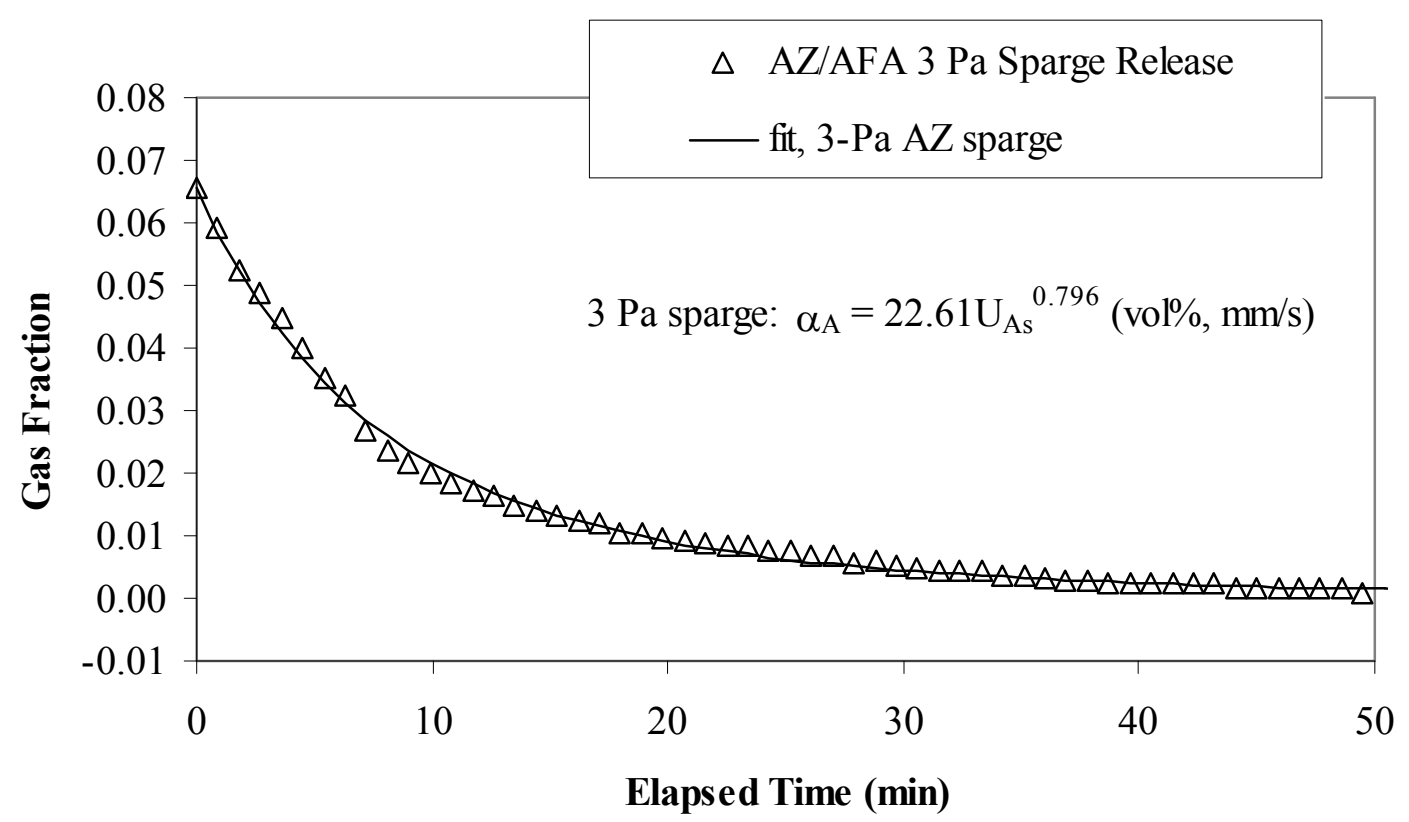

Figure 5.19. Sparger Holdup Release Transients in 3-Pa AZ HLW Simulant

\subsection{Conclusions}

The primary conclusions based on the results of the gas retention and release tests in the QSLS test stand are listed as follows:

- The prototypic gas retention and release tests performed in this test program indicate that gas holdup with AZ-101 simulant with AFA is higher than that in clay, over a range of yield stresses, but not to the extent that initially raised WTP design concerns. A factor $F_{w}$, can be defined as the ratio of holdup in AZ-101 simulant with AFA to holdup in clay simulant at the same gas generation superficial velocity. The $F_{w}$ observed in these prototypic tests is 8 or less compared to a maximum factor of 20 found in previous tests in smaller nonprototypic systems.

- $\quad F_{w}$ was found to be about the same in 13-Pa simulant as in 30-Pa simulant, whereas in smaller nonprototypic systems $F_{w}$ was observed to increase with decreasing yield stress. Concerns raised by previous studies regarding $F_{w}$ of up to 20 at the low gas generation rates of plant operations and the potential for even higher $F_{w}$ at low yield stress have not been borne out by current prototypic tests. 
- Release of retained generated gas was relatively rapid (within $\sim 10$ minutes) and complete in both clay and in AZ-101 simulant with AFA at both 30- and 13-Pa yield stress.

- Sparger holdup was about 9 vol\% in 3-Pa AZ-101 simulant with AFA, higher than 30-Pa AZ101 simulant with AFA. It self-released over about 1 hour when sparging shut down. This may be an artifact of the simulant or a combination of the properties of AFA and low yield stress.

- Prediction of gas retention and release in the full scale lag storage and HLW feed blending vessels can be made using the existing scaling basis.

- Gas holdup is not sensitive to mixing system configuration or scale, within the range of PJM and sparger hybrid configurations and scales of lag storage test stands that have been used at PNNL.

The difference between these results, showing little effect of AFA on gas holdup, and those of the 2006 tests in the SRNL small mixing vessel showing a big increase in holdup with AFA at lower yield stress requires some explanation. The primary factor appears to be the fundamental difference in the cause-and-effect relationship of the bubble size distribution to the mixing system between the small SRNL agitator-mixed vessel and the scaled PJM hybrid mixing system. The faster the bubbles rise the lower the holdup, and smaller bubbles rise slower than large ones (Fan and Tsuchiya 1991). Any process that enhances breakup or reduces coalescence creates smaller bubbles. The radial agitator in the SRNL vessel was designed specifically to break up larger bubbles introduced through small tubes, as shown schematically in Figure 5.20 (Stewart et al. 2006). Thus this system creates the bubble size distribution by the intense turbulence around the agitator blades.

The resulting bubble size distribution depends on the agitator speed, the properties of the fluid surrounding the bubbles, and whether surfactants or other contaminants are present that affect the interface surface tension and mobility (Grau 2006). This mixing system therefore amplifies the effects of AFA, which reduces the surface tension, and of reduction in yield stress, which increases the intensity of

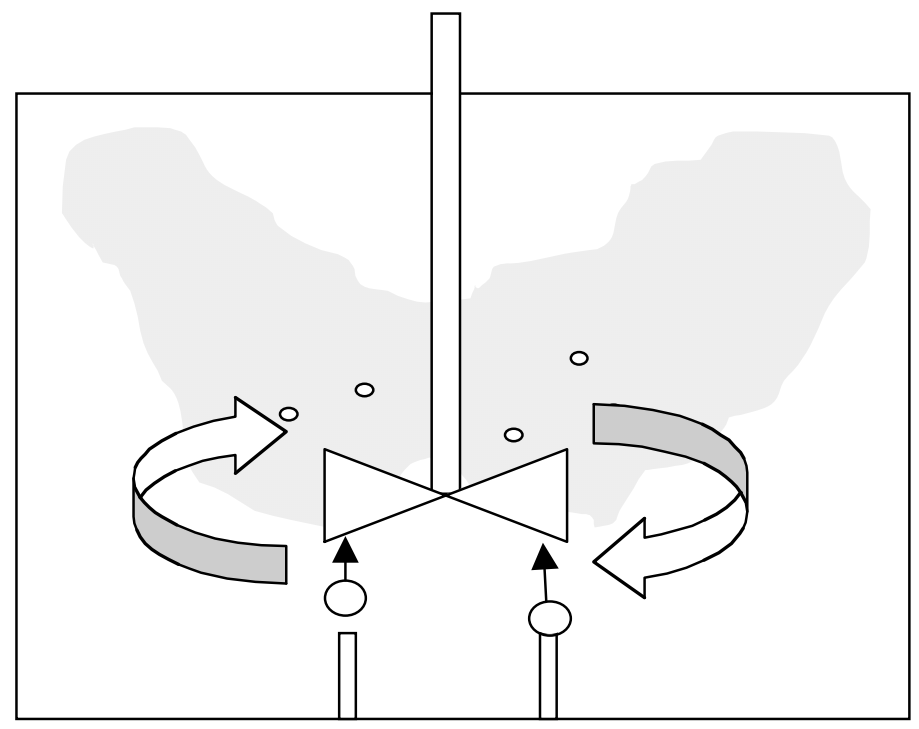

Figure 5.20. Schematic of Bubble Breakup by a Rotating Agitator 
turbulence while decreasing its scale. Both effects tend to create smaller bubbles and thus greater gas holdup, which is consistent with data from the SRNL small agitator-mixed vessel (Stewart et al. 2006).

This behavior was also observed in bubble column tests (Russell et al. 2005) where turbulence is not a major factor in breaking up bubbles. Instead, the bubble size is set by their formation at a bottom orifice or frit modified by coalescence (depending on interface conditions) above the orifice. Bubble formation at an orifice is also strongly affected by properties of the fluid, surfactants, and surface contaminants (Kulkarni and Joshi 2005), producing effects similar to the mixing vane.

In the prototypic hybrid mixing system using PJMs and spargers, the gas bubbles of interest are nucleated out of the liquid onto small particles and grow by diffusion of dissolved gases and by an occasional coalescence (the large sparger air bubbles introduced for mixing are not considered in the generated gas holdup analysis). As they grow larger, their increasing buoyancy increases their vertical relative velocity with respect to the slurry, and they eventually escape through the surface. But bubbles can only rise through the simulant while it is being mobilized by the mixing system unless they grow large enough to overcome the constraint of the material yield stress. An equivalent diameter approaching $1 \mathrm{~cm}$ is required to rise through a stagnant material with a yield stress of $30 \mathrm{~Pa}$ (Stewart et al. 1996). During their residence time in the slurry, they may occasionally be carried near the PJM jets, where the largest might break up in the turbulence while the smaller ones remain unaffected. Except for a few being captured, the small bubbles are not likely to be affected by the rising column of large air sparge bubbles.

This process creates a bubble size distribution that depends mainly on the balance of nucleation, growth, and release, and little on turbulent breakup and bubble interaction. Accordingly, the surface tension, interface phenomena, and simulant yield stress have little direct effect on the size of bubbles produced by gas generation. The yield stress does affect the rise speed of these bubbles but with the "normal" trend; a higher yield stress slows the rise speed and increases holdup. This is consistent with the current results of testing in the QSLS vessel. 


\subsection{Modeling}

This section describes how the results of the FY 2007 QSLS tests and earlier tests in 1/2- and 1/4-scale vessels (Bontha et al. 2005, Russell et al. 2005) can be applied to predict gas retention and release behavior at full plant scale. The scale-up process uses a gas mass conservation model fit to the test data based on scaling relationships derived from the basic principles of gas bubble dynamics. The model covers release periods that occur while the slurry is being mixed by spargers and PJMs and accumulation periods that occur when PJMs are off and the sparger flowrate is reduced to an idle value.

Section 6.1 summarizes the significant mechanisms in gas retention and release. Prior modeling work is summarized in Section 6.2, and Section 6.3 describes the model defined in the present study (the model is derived in detail in Appendix C). Section 6.4 briefly describes the SRNL bubble-column tests in which mass transfer coefficients and gas volume fractions associated with sparging were measured. The inputs required to apply the model are given in Section 6.5, and the model is tested against past data and extended to full plant scale in Section 6.6.

\subsection{Gas Retention and Release Mechanisms}

The gas present in WTP slurries comes from more than one source. Gases such as hydrogen, nitrous oxide, and nitrogen, to mention only the predominant species, are generated in the liquid phase at rates that depend on the waste composition, level of radioactivity, and temperature. The solution quickly supersaturates; bubbles nucleate and grow. In addition, air gases (predominantly oxygen and nitrogen) enter the slurry either by dissolution from the air in contact with the waste or (more substantially, as discussed in Section 5.4.3) as bubbles generated either by sparging or by entrainment at moving waste surfaces in the PJMs or at the top of the slurry.

The retained gas is primarily present as bubbles, though a fraction-generally a small fraction because of the low solubility of the gases - is also present in solution in the slurry liquid. Dissolved gases are released by mass transfer, primarily into already existing bubbles whose composition is different enough to provide a driving force for mass transfer across the bubble interface. Bubbles are retained by the viscosity of the slurry; their escape velocity is proportional to the bubble diameter raised to some power that depends on the bubble size. For bubbles that originate from gas generation and exsolution (the change of dissolved to undissolved gas), the rise velocity was found in past work to be strongly related to the gas volume fraction (Stewart et al. 2006, Section 5.1). When the slurry is not mixed, the absence of mechanically driven shear stress allows the non-Newtonian slurry to gel. Under these conditions, most, if not all, bubbles are trapped because they are too small to make the gel yield and thereby escape it. Thus, little of the continually generated gas is released, and the gas fraction increases steadily.

\subsection{Prior Modeling Work}

Gas generation, retention, and release in well-mixed slurry can be described by a general model for bubble migration that explains the basic elements of gas retention and release associated with operation of hybrid PJM plus sparger systems in non-Newtonian slurries. Though portions of such a hybrid system are intermittently mixed due to the cyclic nature of PJM operation, time- and space-averaged values of gas 
release rates and rates of change of gas content can be applied such that the well-mixed model is applicable to the pulsed system.

\subsubsection{Gas Release-Prior Models}

For simplicity, consider a case in which only one gas species is present, as assumed in past modeling, and in which all the gas is generated, denoted by the subscript G. The gas is present both as bubbles, whose volume fraction at the average hydrostatic pressure is $\alpha_{G}$, ${ }^{(a)}$ and as dissolved gas, whose molar concentration $\left(\mathrm{mol} / \mathrm{m}^{3}\right)$ is $C_{D}^{*}$, in the liquid of the slurry. The asterisk in the variable name reflects the assumption that this dissolved gas concentration is in equilibrium with the partial pressure of the gas.

According to Henry's Law, the equilibrium relation between the dissolved gas and the gas phase is

$$
C_{D}^{*}=\frac{\bar{P}}{K_{H}}
$$

where $K_{H}$ is the Henry's Law constant for the gas in the liquid $\left(\mathrm{Pa} /\left(\mathrm{mol} / \mathrm{m}^{3}\right)\right)$, and $\bar{P}$ is the average pressure of the gas (the average hydrostatic pressure in $\mathrm{Pa}$ ). ${ }^{(\mathrm{b})}$ The total moles of gas contained in the slurry is the sum of

and

$$
V_{L} C_{D}^{*} \text { moles in dissolved form }
$$

$$
\frac{\bar{P} \alpha_{G} V_{T}}{R T} \text { moles in bubble form }
$$

where $V_{L}$ is the volume of liquid in the slurry $\left(\mathrm{m}^{3}\right), V_{T}$ the total gassy slurry volume $\left(\mathrm{m}^{3}\right), R$ the ideal gas constant $(\mathrm{J} / \mathrm{mol} \mathrm{K})$, and $T$ the slurry temperature $(\mathrm{K})$. Therefore, the total moles of gas in the slurry, $N_{T}$, is

$$
N_{T}=\frac{\bar{P} \alpha_{G} V_{T}}{R T}+V_{L} \frac{\bar{P}}{K_{H}}=\frac{\bar{P} V_{L}}{R T}\left(\frac{\alpha_{G}}{\left(1-\alpha_{G}\right)(1-\phi)}+\frac{R T}{K_{H}}\right)
$$

where $\phi$ is the volume fraction of solid in the gas-free slurry.

Gas generation increases the moles of gas at a rate of $g_{m} V_{L}$, where $g_{m}$ is the moles of gas generated per unit volume of slurry liquid per unit time. Mass transfer between the liquid and some gas phase other than the retained-gas bubbles may cause either a gain or a loss of moles from the gassy slurry system. The rate of loss of dissolved slurry gas by mass transfer $(\mathrm{mol} / \mathrm{s})$ is denoted by $\Delta$. The release of gas

(a) In past work there was no need to distinguish between sparge gas holdup and retained gas holdup, so the bulk volume fraction of retained gas was referred to simply as $\alpha$.

(b) In some past work, the Henry's Law constant has been used within the inverse definition; i.e., $C_{D}^{*}=K_{H} \bar{P}$. Both definitions are used in the literature. 
bubbles at the slurry surface causes a rate of loss equal to $\alpha_{G} A U_{G f} \bar{P} / R T$, where $U_{G f}$ is the final (at surface) rise velocity of the bubbles $(\mathrm{m} / \mathrm{s})$ and $A$ the total surface area $\left(\mathrm{m}^{2}\right)$ they escape through (implicitly including the slurry surface area inside the PJMs). (a)

The principle of conservation of mass leads to the following general equation:

$$
\frac{d N_{T}}{d t}=V_{L} g_{m}-\Delta-\frac{A U_{G f} \bar{P}}{R T} \alpha_{G}
$$

This can be rearranged to

$$
\frac{d}{d t}\left(\frac{\alpha_{G}}{1-\alpha_{G}}\right)=\frac{g_{m} R T(1-\phi)}{\bar{P}}-\frac{\Delta R T(1-\phi)}{\bar{P} V_{L}}-\frac{(1-\phi) A U_{G f}}{V_{L}} \alpha_{G}
$$

Prior models have omitted mass transfer, treated the dissolved gas as negligible, and approximated gas generation as being based in the total gas-free slurry volume rather than in the liquid portion alone. With these assumptions the gas generation rate can be expressed as $g_{m}^{\prime} V_{T}\left(1-\alpha_{G}\right)$, and

$$
\frac{d}{d t}\left(\frac{\alpha_{G}}{1-\alpha_{G}}\right)=\frac{g_{m}^{\prime} R T}{\bar{P}}-\frac{A U_{G f}}{V_{T 0}} \alpha_{G}
$$

On the further assumption, also made in prior models, that $\alpha_{G}$ was much smaller than unity, Eq. (6.7) was simplified to the form that appears in earlier reports:

$$
\frac{d \alpha_{G}}{d t}=g_{m}^{\prime} \frac{R T}{\bar{P}}-\frac{A U_{G f}}{V_{T 0}} \alpha_{G}=g_{v}-\frac{U_{G f}}{H} \alpha_{G}
$$

where $g_{v}$ is the rate of gas volume generation per volume of gas-free slurry per time (units of $\mathrm{s}^{-1}$ ) and $H$ is the depth of the slurry $(\mathrm{m})$.

Russell et al. (2005) and Bontha et al. (2005) treated $H / U_{G f}$ as a constant, defining a time constant $\tau$, and therefore obtained an exponential release model for $\alpha_{G}$ as a function of time:

$$
\alpha_{G}(t)=\alpha_{G}(0) e^{-t / \tau}+g_{v} \tau\left(1-e^{-t / \tau}\right)
$$

For data-correlation purposes, Russell et al. generalized Eq. (6.9) to be a sum of several exponentials each with a different time constant, hypothetically reflecting physical processes with different characteristic speeds.

(a) In past work $U_{G f}$ was referred to as $U_{R}$. The change in terminology was needed to make the distinction between the rise velocity of retained gas (subscript $G$ ) and sparge air gas (subscript $A$ ), and to indicate that the velocity was the final value (subscript $f$ ), i.e., the value at the slurry surface. 
A later study (Stewart et al. 2006) reviewed data from gas retention (holdup) experiments and found that at dynamic steady state - when the rate of gas release equaled the rate of gas generation and $\alpha_{G}$ was constant with time - there was a clearly defined relationship between $\alpha_{G}$ and the gas generation rate. The relation followed a power-law form:

$$
\alpha_{G s s}=h_{1} U_{G S}^{h_{2}}
$$

where

$\alpha_{G s s}=$ gas volume fraction at dynamic steady state

$h_{1}, h_{2}=$ correlating constants (units of gas fraction per $(\mathrm{m} / \mathrm{s})^{-\mathrm{h} 2}$ )

$U_{G S}=$ gas generation superficial velocity, equal to $g_{v} H(\mathrm{~m} / \mathrm{s})$.

At dynamic steady state, it follows from conservation of mass that the gas generation rate equals the gas release rate at the steady-state velocity, $U_{G f s s}$, and $U_{G S}=\alpha_{G s s} U_{G f s s}$. Therefore, the steady-state relation between rise velocity and gas volume fraction is as follows:

$$
U_{G f s s}=\frac{1}{h_{1}^{1 / h_{2}}} \alpha_{G s s}^{\left(\frac{1}{h_{2}}-1\right)}
$$

Assuming that Eq. (6.11) is valid to relate $U_{G f}$ to $\alpha_{G}$ during non-steady-state conditions, Eq. (6.8) becomes

$$
\frac{d \alpha_{G}}{d t}=g_{v}-\frac{1}{H} \frac{1}{h_{1}^{1 / h_{2}}} \alpha_{G}^{1 / h_{2}}
$$

This equation cannot be solved analytically except for certain specific values of $h_{2}$. Stewart et al. (2006) solved this equation for $g_{v}=0$, the condition present during release tests, which were carried out after all the gas generation was complete. The solution was found to be

$$
\alpha_{G}(t)=\alpha_{G}(0)\left[1-\left(\frac{h_{2}-1}{h_{2}}\right) \frac{U_{G f}(0)}{H} t\right]^{\left(\frac{h_{2}}{h_{2}-1}\right)}
$$

\subsubsection{Gas Accumulation-Prior Models}

During extended periods when the PJMs are off and sparging is reduced to idle flow, the slurry gradually gels and little generated gas is released. For modeling purposes, it was conservatively assumed that no gas was released during these periods. When $U_{G f}$ is set to zero, the solution of Eq. (6.8) becomes

$$
\alpha_{G}\left(t_{S}\right)=\alpha_{G}\left(t_{S}=0\right)+g_{v} t_{S}
$$

In Eq. (6.14), $t_{S}$ is the elapsed time (seconds) since mixing was shut off. 


\subsection{A New Model for Gas Retention and Release}

Like previous models, the present model treats the vessel (during release periods) as a well-mixed reactor in which conditions are uniform in space and constant with time. The cyclic changes caused by PJM operation are, in effect, averaged over the cycle. The present model considers multiple gas species, not one, and accounts for their solubility and for mass transfer between dissolved gas and sparge bubbles.

Four gases $\left(\mathrm{H}_{2}, \mathrm{O}_{2}, \mathrm{~N}_{2}\right.$, and $\left.\mathrm{N}_{2} \mathrm{O}\right)$ are treated as appearing in two forms in the mixed slurry. The first form, which is referred to as "sparge gas," is present in the large, relatively rapidly moving sparge bubbles and consists of air with traces of generated gases that sparging extracts from the slurry. The second form, "equilibrated gas," is present both as gas dissolved in the liquid and as gas in the small gas bubbles produced primarily by gas generation. These bubbles are in equilibrium with dissolved gases in the liquid and therefore contain air-derived gas as well as generated gas.

A detailed derivation of the model appears in Appendix C. Only a summary of the equations for release and accumulation is presented in this section.

\subsubsection{Gas Release}

For gas species $i$, the differential equation for conservation of mass of the equilibrated gas is

$$
\frac{d N_{T i}}{d t}=V_{L} g_{m i}-\Delta_{A i}-\frac{A U_{G f} K_{H i} C_{D i}}{R T} \alpha_{G}
$$

Many of the variables are analogous to those appearing in Eq. (6.5), but are subscripted with $i$ to identify gas species $i$ or with $G$ to identify the gas as retained gas (originating in generation). The product of variables $K_{H i}$, the Henry's Law constant, and $C_{D i}$, the molar concentration of dissolved gas in the liquid of the slurry, is the equilibrium partial pressure of gas $i$. The term $\Delta_{A i}$ is the rate of transfer of moles of gas from dissolved gas to the sparge bubbles; here the subscript $A$ identifies the type of gas as sparge gas.

The total moles of each equilibrated gas can be expressed as the sum of moles in bubble gas and moles in dissolved form:

$$
N_{T i}=\frac{\alpha_{G} V_{T} K_{H i} C_{D i}}{R T}+V_{L} C_{D i}
$$

An additional constraint comes from the necessity for the sum of the partial pressures of the gas species to equal the average dry hydrostatic gas pressure:

$$
\sum K_{H i} C_{D i}=\bar{P}-p_{v}=P_{a}+0.5 \rho g H-p_{v}
$$

where $p_{v}$ is the water vapor pressure $(\mathrm{Pa}), P_{a}$ is the pressure at the surface of the slurry $(\mathrm{Pa}), \rho$ is the density of the gas-free slurry $\left(\mathrm{kg} / \mathrm{m}^{3}\right)$, and $H$ the slurry depth (m). 
The mass transfer term can be expressed in simplified form as

$$
\Delta_{A i}=F_{C i} C_{D i}-F_{x i}
$$

where $F_{C i}$ and $F_{x i}$ are constants that depend on the properties of the sparge bubbles and the slurry, as discussed in Section 6.4, not equilibrated-gas properties. Their units are $\left(\mathrm{m}^{3} / \mathrm{s}\right)$ and $(\mathrm{mol} / \mathrm{s})$, respectively.

The initial conditions for the equilibrated-gas ordinary differential equations (ODEs) are

$$
N_{T i}=\left(\frac{\alpha_{G 0} V_{T}}{R T}+\frac{V_{L}}{K_{H i}}\right) x_{G i 0}\left(\bar{P}-p_{v}\right)
$$

where $\alpha_{G 0}$ is the equilibrated-gas volume fraction at $t=0$, and $x_{G i 0}$ is the mole fraction of gas $i$ present in the total moles of gas (dissolved and bubble together) at $t=0$.

The ODEs cannot be solved analytically. Commercially available solver packages such as MathCad $^{\mathrm{TM}}$ or Mathematica ${ }^{\mathrm{TM}}$ could be used to solve them directly and numerically, which in the future would be the best option. For this report, the model was implemented in Excel and tested against parallel calculations in FORTRAN. The method of solution was to convert the ODEs to centrally differenced differential equations and solve for all four values of $N_{T i}$. The first step in conversion was to combine Eq. (6.15) and (6.16) to express the total moles in terms of equilibrated gas phase and remove the dissolved concentration from the ODEs. Then the difference equations to calculate the values at timestep $k+1$ from the values at step $k$ are

$$
N_{T i}^{k+1}=\frac{\left(\frac{1}{\delta t}-\frac{F_{C i} R T+A K_{H i} \alpha_{G}^{k} U_{G f}^{k}}{2\left(\alpha_{G}^{k} V_{T}^{k} K_{H i}+V_{L} R T\right)}\right) N_{T i}^{k}+V_{L} g_{m i}+F_{x i}}{\frac{1}{\delta t}+\frac{F_{C i} R T+A K_{H i} \alpha_{G}^{k+1} U_{G f}^{k+1}}{2\left(\alpha_{G}^{k+1} V_{T}^{k+1} K_{H i}+V_{L} R T\right)}}
$$

The presence of $\alpha_{G}^{k+1}, U_{G f}^{k+1}$, and $V_{T}^{k+1}$ in the equation denominator is an additional reason for iterative solution. Consistent with the discussion in Section 6.2.1, the at-surface rise velocity of equilibrated bubbles, $U_{G f}$, is a power-law function of $\alpha_{G}$. $V_{T}^{k+1}$ is also a function of $\alpha_{G}^{k+1}$, being equal to $V_{T 0} /\left(1-\alpha_{A}-\alpha_{G}^{k+1}\right)$, where $V_{T 0}$ is the gas-free slurry volume and $a_{A}$ is the sparger gas volume fraction (assumed constant). At each timestep, the model iterates $\alpha_{G}^{k+1}$ to meet the criterion in Eq. (6.17) by adjusting the balance between moles in the equilibrated gas phase and moles in solution.

The volume fraction of sparge bubbles in the gassy slurry, $\alpha_{A}$, affects Eq. (6.20) in only two ways. It has an effect on the mass transfer factors $F_{C i}$ and $F_{x i}$; and it is part of the gassy slurry volume, $V_{T}$. 


\subsubsection{Gas Accumulation}

The model and parameters described in Section 6.3.1 can be used to model full mixing with PJMs on and spargers on full flow rate. Other possible modes are 1) PJMs off with spargers on full flow rate; 2) PJMs on with spargers on idle flow rate; and 3) no mixing, with PJMs off and spargers on idle flow rate. HSLS data (Bontha et al. 2005, Table 7.3) indicate that it is reasonable to assume a lower rise velocity for equilibrated bubbles in modes 1 and 2 . The manner in which the decreased velocity is modeled is based on HSLS data and is discussed in Section 6.6.2.

The lesser bubble rise velocities in modes 1 and 2, associated with the reduced mixing, may include unmixed heel effects as well as true bubble rise effects. This caveat applies in particular to the spargersalone mode of operation (mode 1) because HSLS test results (Bontha et al. 2005, Table 6.12) made it clear that the spargers could not completely mix the slurry without PJM operation.

The present model conservatively assumes that no gas is released during periods when mixing is off (mode 3). Thus the equilibrated-gas bubble rise velocity is zero, as is mass transfer to sparge bubbles. As a result, Eq. (6.15) can be solved analytically, giving

$$
N_{T i}\left(t_{S}\right)=N_{T i}\left(t_{S}=0\right)+V_{L} g_{m i} t_{S}
$$

Eq. (6.20) automatically produces this result when the rise velocity and the mass transfer to sparge bubbles are both set to zero.

\subsection{Mass Transfer-Model and Experiments}

An analytical expression for the term $\Delta_{A i}$ used in previous sections can be derived based on the following assumptions, which are discussed in Appendix C:

- The slurry is well-mixed, providing a constant and uniform environment during the rise of each sparge bubble

- Mass transfer to the sparge bubbles is controlled by the mass transfer rate on the liquid side, not the gas side

- The capture of generated-gas holdup gas bubbles by sparge bubbles is negligible

- Mass transfer can be reasonably approximated by using values for the bubble rise velocity and volumetric mass transfer coefficient that are averages over the slurry depth. The only available data for these properties are averages of this kind.

Section 6.4.1 briefly describes the recent SRNL sparged column tests, whose mass transfer and holdup results are summarized in Section 6.4.2. Section 6.4.3 gives the sparge bubble mass transfer model that is derived at more length in Appendix C. The SRNL data are applied to the model in Section 6.4.4. 


\subsubsection{SRNL Sparged Column Test Apparatus and Methods}

The object of the sparged-column tests was to provide data, at several depth scales, for mass transfer and gas volume fraction from sparging at a range of relevant superficial velocities. These tests are detailed elsewhere $^{(\mathrm{a})}$ and summarized here, with data tabulated in Appendix C. A column $28 \mathrm{ft}$ tall and 30 inches in diameter was filled with simulant to the level of $1.31 \mathrm{~m}$ (representing $1 / 4.29$ scale), $3.63 \mathrm{~m}$ (half-scale), or $7.41 \mathrm{~m}$ (full-scale). The column was leveled to within 1/8 inch of plumb. The simulants included process water, process water with AFA (Dow Corning Q2-3183), and AZ simulant slurry at a nominal 13-Pa Bingham yield stress (measured value 14.4 Pa). The AZ simulant also contained AFA.

In preparation for a test, the simulant was injected with oxygen through a sintered metal filter and was recirculated up through the column and through an external static mixer until saturated with oxygen. At that point, air was introduced through a concentric vertical sparger tube, whose downward-pointing nozzle was at the bottom of the column. The air, injected at superficial velocities of 2,5 , or $10 \mathrm{~mm} / \mathrm{s}$, stripped the oxygen from solution. Dissolved oxygen sensors were set at three of six possible locations (the choice of locations depended on which simulant depth was tested). Dissolved oxygen concentrations were monitored to allow determination of the mass transfer coefficients, which were calculated from rate of change of concentration on the assumption of complete mixing. Five pressure transducers and three laser level indicators measured changes in pressure (i.e., simulant density) and level; these data were used to find the gas volume fraction.

\subsubsection{SRNL Sparged Column Test Results}

The volumetric mass transfer coefficient of the sparge bubbles, $k_{L} a_{v}$ (units of $\mathrm{s}^{-1}$ ), depends on the following system-dependent properties:

- The length of time for which a liquid element at the bubble surface is exposed to the bubble gas: under turbulent conditions, the contact time is governed more by the rate of turbulent energy dissipation in the liquid than by the bubble slip velocity. The rigidity of the bubble interface, whether produced by surfactants or small particles, also affects the contact time. The rate of energy dissipation is linearly proportional to the sparge superficial velocity, and $k_{L}$ is inversely proportional to the square root of the contact time.

- The bubble specific area (area per volume): the specific area depends on the bubble diameter and shape, which both depend on the stable bubble size produced by coalescence versus breakup. The turbulence in the liquid phase is a major cause of breakup, whereas increased liquid viscosity tends to promote bubble coalescence.

- The sparge bubble holdup: the gas volume fraction depends on the bubble rise velocity and the sparge superficial velocity. Larger bubbles have higher rise velocities and escape the liquid more rapidly, decreasing the gas holdup. The value of $k_{L} a_{v}$ is also expected to depend on the square root of the molecular diffusivity of the species in the liquid phase, $D_{i}$.

(a) Guerrero HN, CL Crawford, MD Fowley, RA Leishear, and ML Restivo. 2007. Effects of Alternate Antifoam Agents, Noble Metals, Mixing Systems, and Mass Transfer on Gas Holdup and Release from non-Newtonian Slurries. WSRC-STI-2007-00537 (SRNL-RPP-2007-00023) Draft A, Westinghouse Savannah River Co., Aiken, South Carolina. 
Figure 6.1 summarizes the $k_{L} a_{v}$ measurements made for $\mathrm{O}_{2}$ in the SRNL sparged-column tests. The addition of AFA to water decreased the volumetric mass transfer coefficient by a factor of roughly 2 , and the higher viscosity of the 13-Pa AZ-101 simulant produced a further decrease. The $k_{L} a_{v}$ is also dependent on the superficial velocity - a nearly linear dependence, but increasing slightly more rapidly than strict linearity. The dependence on liquid height is less strong, and is most apparent for AZ simulant with AFA and least apparent for water with AFA.

Figures 6.2 and 6.3 show the sparge gas volume fractions, $\alpha_{A}$, based on the pressure-difference and surface-level measurements, respectively. The differences produced by the two methods of measurement are apparent, perhaps particularly for the 13-Pa AZ-101 simulant with AFA. In $1.31 \mathrm{~m}$ of simulant, the QSLS case, the gas holdup is higher in the AZ-101 simulant than in water. In $7.41 \mathrm{~m}$ of simulant, the full-scale case, the opposite is true. The dependence of holdup on superficial velocity is approximately linear for the water, water/AFA, and $1.31-\mathrm{m} \mathrm{AZ}$ simulant/AFA cases. The dependence is harder to determine for the 7.41-m AZ simulant/AFA case because the two methods disagree.

The retained sparge gas volume fraction in 13-Pa AZ-101 simulant with AFA was between 1 and 2 vol\% in the QSLS, lower than the 2.5 to 3.5 vol\% observed at equivalent superficial velocities (9 to $10 \mathrm{~mm} / \mathrm{s}$ ) in the sparged column. The difference could be the result of under-measurement of sparge gas fraction in the QSLS or of wall effects in the bubble column. The large bubbles that were observed in the 13-Pa simulant - with apparent at-surface diameters of 8 to 20 inches, compared to a 30-inch column ID - make wall effects seem likely. Godbole et al. (1984) reported that in a power-law non-Newtonian liquid the main effect of the column walls was to force bubble flow into the slug-flow regime, which increased the holdup compared to that seen in churn-turbulent flow. This type of wall effect in the column could explain why its holdup was higher than in the QSLS.

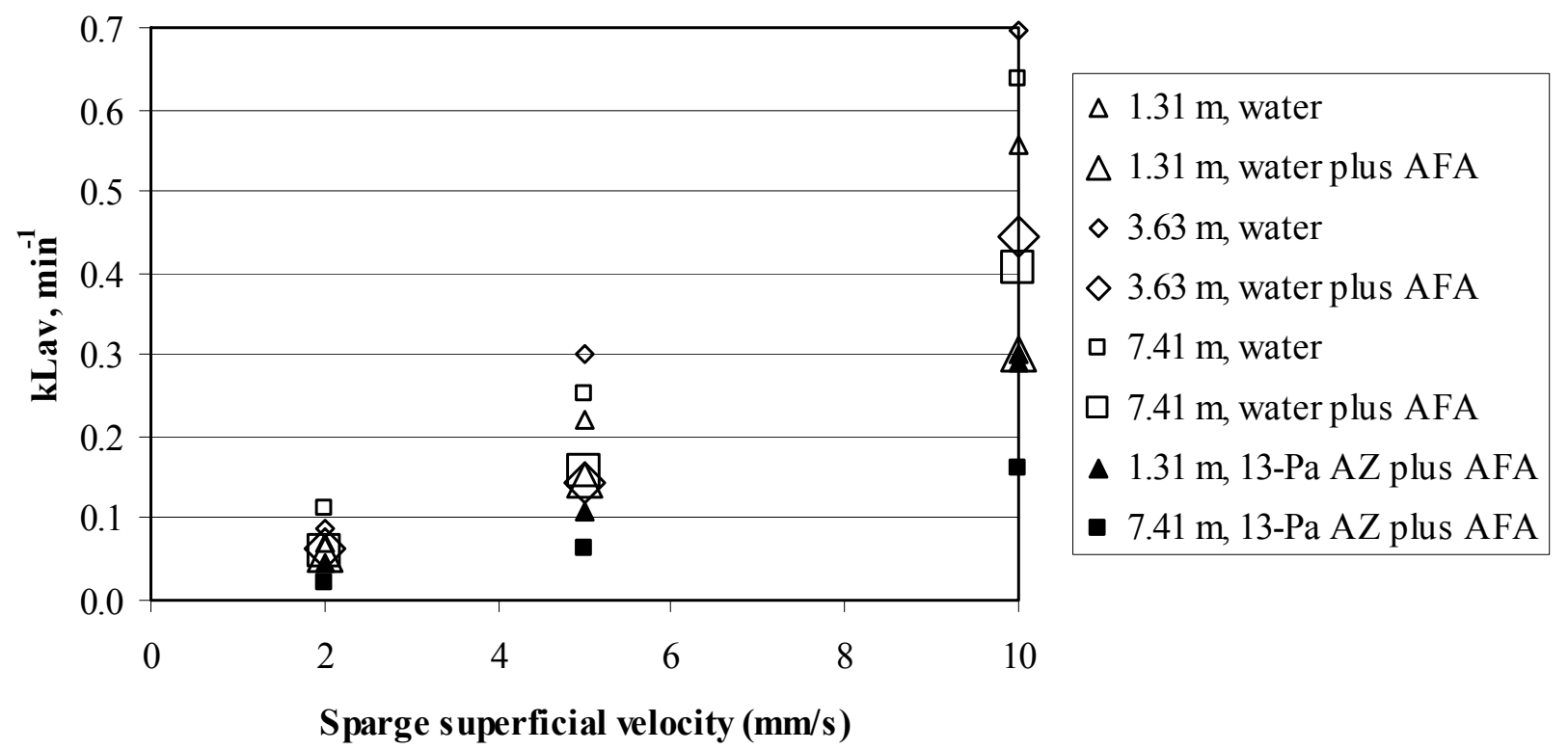

Figure 6.1. Volumetric Mass Transfer Coefficients in the SRNL Sparged Column 


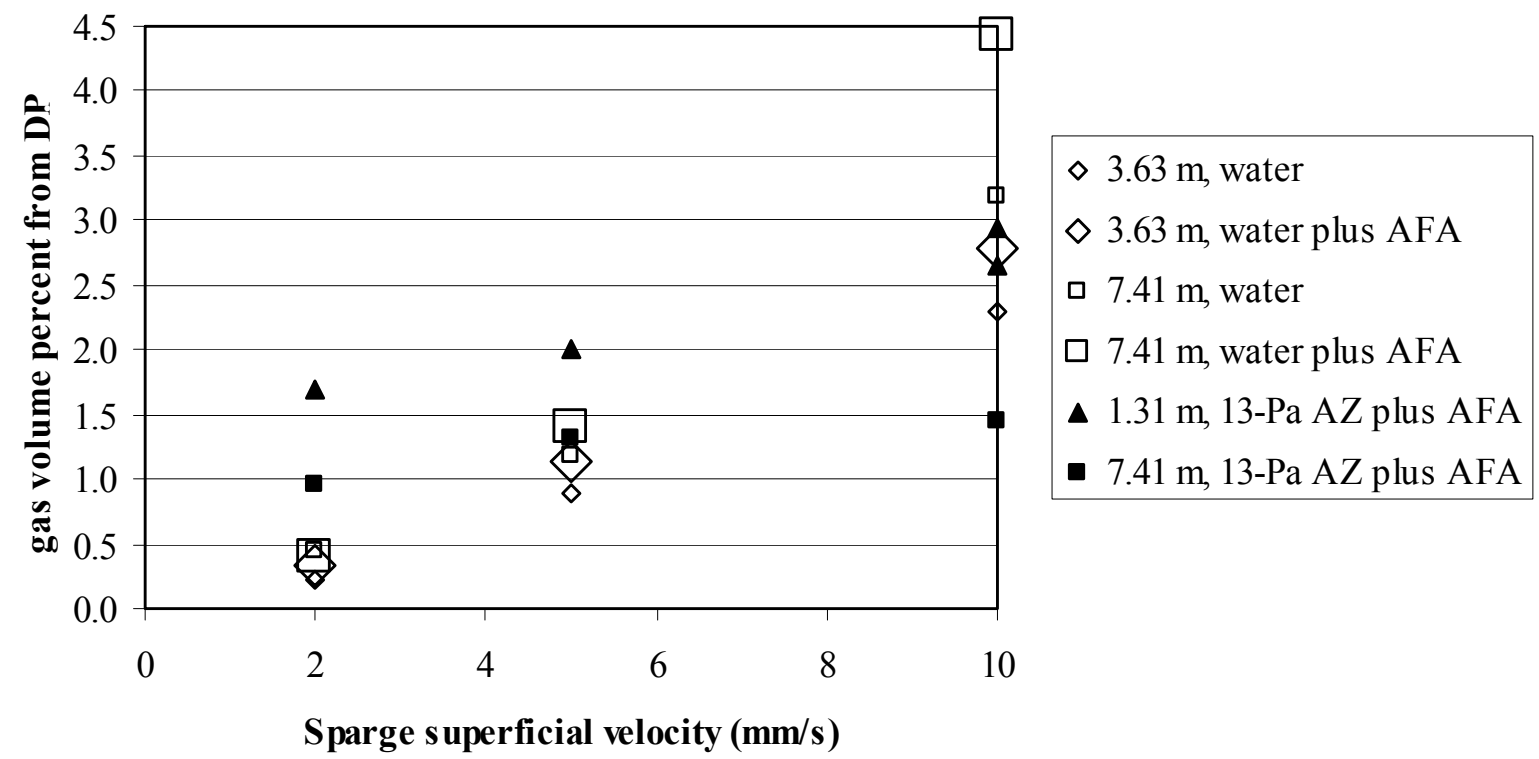

Figure 6.2. Gas Holdup in the SRNL Sparged Column, Measured Using $\Delta \mathrm{P}$

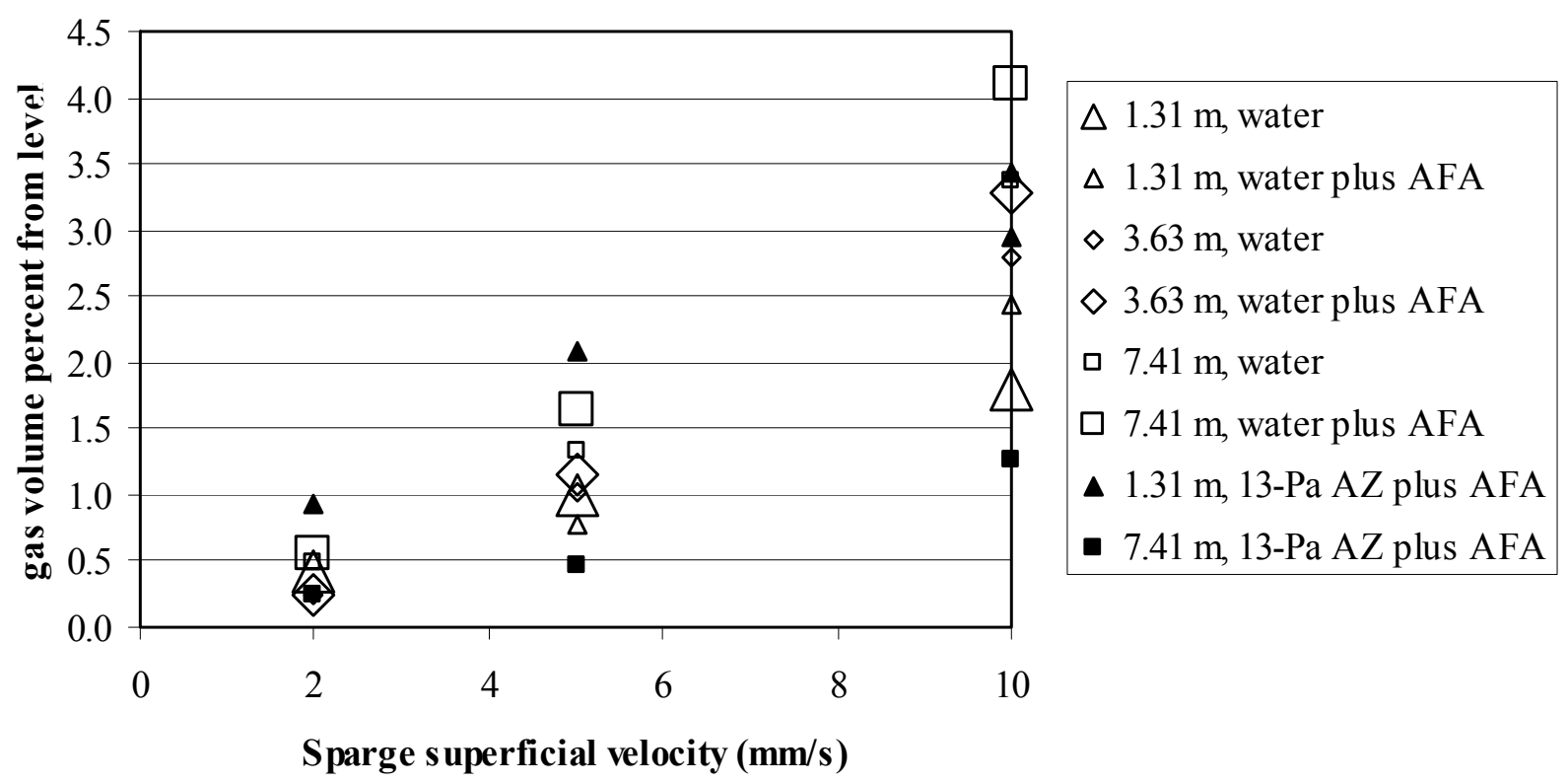

Figure 6.3. Gas Holdup in the SRNL Sparged Column, Measured Using Level

In addition, Godbole et al. (1984) reported that for flow in the churn-turbulent flow regime an increase in viscosity typically caused a decrease in holdup. This does not match the trend in the data in Figures 6.2 and 6.3, except possibly for the 7.4-m AZ simulant/AFA, suggesting that the flow regime was not churn-turbulent. 


\subsubsection{Mass Transfer Model}

The equation describing the contents of a single rising bubble can be found from conservation of mass and expressed in terms of bubble elevation $z$, using the facts that $d x / d t=(d x / d z)(d z / d t)$ and the sparge bubble rise velocity $U_{A b}=d z / d t$ :

$$
\frac{d n_{A i}}{d t}=U_{A b} \frac{d n_{A i}}{d z}=k_{L i} a V_{A b}\left(C_{D i}-\frac{n_{A i} R T}{V_{A b} K_{H i}}\right)
$$

where

$$
\begin{aligned}
& n_{A i}=\text { moles of gas species } i \text { in a single sparge bubble }(\mathrm{mol}) \\
& k_{L i}=\text { liquid-side mass transfer coefficient at the bubble interface }(\mathrm{m} / \mathrm{s}) \\
& a=\text { bubble surface area divided by bubble volume }\left(\mathrm{m}^{-1}\right) \\
& V_{A b}=\text { bubble volume }\left(\mathrm{m}^{3}\right) .
\end{aligned}
$$

On the assumption that the incoming sparge gas is dry and that the sparge bubble size is negligibly affected by the gas gained or lost through mass transfer, the sparge bubble volume as a function of elevation $z$ above the sparge nozzle is simply

$$
V_{A b}=\frac{R T \sum n_{A i f}}{\left(P_{a}-p_{v}+\rho g H\right)-\rho g z}=\frac{V_{A b f}\left(P_{a}-p_{v}\right)}{\left(P_{a}-p_{v}+\rho g H\right)-\rho g z}
$$

where $V_{A b f}$ is the final sparge bubble volume $\left(\mathrm{m}^{3}\right)$ at the slurry surface. Eq. (6.22) becomes

$$
\frac{d n_{A i}}{d z}+\frac{k_{L i} a R T}{U_{A b} K_{H i}} n_{A i}=\frac{k_{L i} a V_{A b} C_{D i}}{U_{A b}}
$$

This equation cannot be solved analytically unless some of the bubble parameters are treated as constants; i.e., elevation-averaged values are used. Then the solution is the change in number of moles per bubble:

$$
n_{A i f}-n_{A i 0}=\left(\frac{\bar{V}_{A b} C_{D i} K_{H i}}{R T}-n_{A i 0}\right)\left(1-e^{-\frac{k_{L i} a R T}{K_{H i}}} \frac{H}{\bar{U}_{A b}}\right)
$$

where

$$
\begin{array}{ll}
\bar{V}_{A b} & =\text { bubble volume, averaged over elevation }\left(\mathrm{m}^{3}\right) \\
n_{A i 0} & =\text { moles of gas } i \text { in the bubble at the sparge nozzle }(\mathrm{mol}) \\
\bar{U}_{A b} & =\text { bubble rise velocity, averaged over elevation }(\mathrm{m} / \mathrm{s}) .
\end{array}
$$

The rate of transfer of dissolved gas from solution to the sparge gas flow, denoted by $\Delta_{A i}$, is

$$
\Delta_{A i}=\left(\frac{P_{a}-p_{v}}{\rho g H} \ln \left(\frac{P_{a}+\rho g H-p_{v}}{P_{a}-p_{v}}\right) \frac{C_{D i} K_{H i}}{R T}-\frac{x_{A i 0} P_{0}}{R T}\right)\left(1-e^{-\frac{k_{L i} a R T}{K_{H i}} \frac{H}{\bar{U}_{A b}}}\right) \frac{P_{s t d}}{P_{a}-p_{v}} \frac{T}{T_{s t d}} N_{s} Q_{s t d}
$$


where

$x_{A i 0}=$ mole fraction of $i$ in the sparge bubble at the nozzle

$P_{0}=$ hydrostatic pressure at the nozzle $(\mathrm{Pa})$

$P_{\text {std }}=$ standard atmospheric pressure $(\mathrm{Pa})$

$T_{\text {std }}=$ standard temperature $(\mathrm{K})$

$N_{s}=$ number of spargers

$Q_{s t d}=$ standard flow rate of sparger air per sparger $\left(\mathrm{std}^{3} / \mathrm{s}\right)$.

The mass transfer factors referred to in Eq. (6.18) and (6.20) are defined in the following way:

$$
\begin{gathered}
F_{C i} \equiv\left(\frac{P_{a}-p_{v}}{\rho g H} \ln \left(\frac{P_{a}+\rho g H-p_{v}}{P_{a}-p_{v}}\right) \frac{K_{H i}}{R T}\right)\left(1-e^{-\frac{k_{L i} a_{v} R T}{\alpha_{A} K_{H i}} \bar{U}_{A b}}\right) \frac{P_{s t d}}{P_{a}-p_{v}} \frac{T}{T_{s t d}} N_{s} Q_{s t d} \\
F_{x i} \equiv \frac{x_{A i 0}\left(P_{a}+\rho g H\right)}{R T}\left(1-e^{-\frac{k_{L i} a_{v} R T}{\alpha_{A} K_{H i}} \frac{H}{\bar{U}_{A b}}}\right) \frac{P_{s t d}}{P_{a}-p_{v}} \frac{T}{T_{s t d}} N_{s} Q_{s t d}
\end{gathered}
$$

In this equation, $k_{L i} a$ has been changed to the equivalent $k_{L i} a_{v} / \alpha_{A}$ to put the factor in terms of the directly measured volumetric mass transfer coefficient, $k_{L i} a_{v}$. The parameter $a_{v}$, by definition, is the total bubble area per volume of bubbly slurry. When $k_{L i}$ is set to zero, both $F_{C i}$ and $F_{x i}$ go to zero and the rate of transfer to the sparge gas, $\Delta_{A i}$, also becomes zero; however, $\alpha_{A}$ cannot be set to zero without causing a divide-by-zero error.

\subsection{Plant Predictive Model}

The model defined in Sections 6.3 and 6.4.3 requires a full set of input parameters before its predictions can be compared to test-stand data or scaled up to the full-scale lag-storage vessel. Table 6.1 lists the inputs that are explicitly needed. Cycle description times, $t_{O N}$ and $t_{O F F}$, are also needed to define the periods of time in each cycle during which mixing (PJMs and full spargers) is on and off.

The corresponding system information that can be used for the HSLS test stand (Bontha et al. 2005), the QSLS test stand in the FY-07 study, and the FSLS vessel is given in Table 6.2. Many of the other inputs listed in Table 6.1 are slurry properties or are strongly related to slurry properties. The basis for Table 6.3, which summarizes these properties, is as follows. The assumptions built into the inputs are discussed in the model results section.

- Density: sample measurements.

- Solid volume fraction in slurry: the weight fraction of water was measured in samples. For both AZ-101 and clay simulants it was assumed that the solids present in dissolved form were negligible compared to those in the solid phase. This was a reasonable assumption; even in $\mathrm{AZ}$ simulant at $30 \mathrm{~Pa}$, the measured density of the liquid in the slurry was only $1.018 \mathrm{~g} / \mathrm{cc}$, compared to a slurry density greater than $1.2 \mathrm{~g} / \mathrm{cc}$. 
Table 6.1. Inputs for the Plant Predictive Model

\begin{tabular}{|c|c|c|}
\hline Input category & $\begin{array}{c}\text { Input } \\
\text { parameter }\end{array}$ & Source of information \\
\hline \multirow{7}{*}{$\begin{array}{l}\text { System and slurry } \\
\text { description }\end{array}$} & $V_{T 0}$ & Gas-free slurry volume; from operating specs \\
\hline & $\phi$ & $\begin{array}{l}\text { Volume fraction of undissolved solids in the gas-free slurry, used to calculate } \\
V_{L} ; \text { from operating specs }\end{array}$ \\
\hline & $H$ & $\begin{array}{l}\text { Both the slurry depth and the distance of the sparge nozzles below the surface; } \\
\text { from operating specs or system configuration }\end{array}$ \\
\hline & $A$ & $\begin{array}{l}\text { Surface area of slurry through which equilibrated bubbles can escape, } \\
\text { approximately equal to } V_{T 0} / H \text {; from system configuration }\end{array}$ \\
\hline & $T$ & Slurry temperature; from operating specs \\
\hline & $P_{a}$ & Pressure in dome of tank; from operating specs \\
\hline & $\rho$ & Gas-free slurry density; from operating specs. Should be consistent with $\phi$. \\
\hline \multirow[t]{2}{*}{$\begin{array}{l}\begin{array}{l}\text { Equilibrium } \\
\text { properties of slurry }\end{array} \\
\end{array}$} & $K_{H i}$ & $\begin{array}{l}\text { Henry's Law constant: partial pressure of } i \text { per dissolved molar concentration } \\
\text { of } i \text { in the liquid. Discussed in Section C.2. }\end{array}$ \\
\hline & $p_{v}$ & Vapor pressure of water in the slurry; standard methods of estimation. \\
\hline \multirow{4}{*}{$\begin{array}{l}\text { Conditions } \\
\text { pertaining to } \\
\text { generation of gas } \\
\text { and its release }\end{array}$} & $g_{m i}$ & $\begin{array}{l}\text { Moles of gas } i \text { generated per time per volume of liquid in slurry; from operating } \\
\text { specs }\end{array}$ \\
\hline & $h_{1}, h_{2}$ & $\begin{array}{l}\text { Coefficient and exponent in power-law relation between the equilibrated-gas } \\
\text { volume fraction and the gas-generation superficial velocity; user choice. Used } \\
\text { to calculate } U_{G f} ; \text { setting } h_{2} \text { to a very large number yields a constant rise } \\
\text { velocity. Discussed in Section } 5 \text {. }\end{array}$ \\
\hline & $\alpha_{G 0}$ & Initial condition for equilibrated-gas volume fraction; user choice. \\
\hline & $x_{\text {Gio }}$ & $\begin{array}{l}\text { Initial condition for mole fraction of gas } i \text { in the equilibrated gas (sum of } \\
\text { dissolved and bubble gas); user choice. }\end{array}$ \\
\hline \multirow[t]{5}{*}{ Sparge properties } & $Q_{\text {std }}$ & $\begin{array}{l}\text { The standard air flow rate through each sparger under full operating conditions; } \\
\text { operating specs. }\end{array}$ \\
\hline & $N_{s}$ & Number of spargers; system configuration. \\
\hline & $\alpha_{A}$ & $\begin{array}{l}\text { Sparge gas volume fraction; user choice. Discussed in Sections 6.4.2, C.4.3, } \\
\text { and C.4.2. }\end{array}$ \\
\hline & $\bar{U}_{A b}$ & $\begin{array}{l}\text { Sparge bubble rise velocity, average over the rise height. User choice, must be } \\
\text { consistent with } \alpha_{A} \text {. Discussed in Section C.4.2. }\end{array}$ \\
\hline & $k_{L i} a_{v}$ & $\begin{array}{l}\text { Volumetric mass transfer coefficient. User choice, should be consistent with } \\
\text { the conditions used to set } \alpha_{A} \text {. Discussed in Sections } 6.4 .2 \text { and C.4.4. }\end{array}$ \\
\hline
\end{tabular}

Table 6.2. System Parameters for Lag Storage Systems

\begin{tabular}{|l|c|c|c||}
\hline & QSLS FY-07 & HSLS & FSLS \\
\hline$V_{T 0}\left(\mathrm{~m}^{3}\right)$ & $\sim 3.2$ & 36.0 & 359 \\
\hline$H(\mathrm{~m})$ & $\sim 1.5$ & 3.61 & 8.39 \\
\hline$T(\mathrm{~K})$ & 299 & 298 & 323 \\
\hline \multirow{3}{*}{$g_{m}^{\prime}$, MOT $\left(\mathrm{mol} / \mathrm{m}^{3}\right.$ slurry $\left./ \mathrm{s}\right)$} & Oxygen: & Oxygen: & Hydrogen: \\
& $\sim 8.0 \mathrm{E}-04$ (rate 1) & $2.6 \mathrm{E}-04$ (avg. HSLS-2, HSLS-3) & \\
& $\sim 1.5 \mathrm{E}-03$ (rate 2) & 4.5E-04 (HSLS-8) & $4.4 \mathrm{E}-07$ \\
\hline$P_{a}(\mathrm{~Pa})$ & $\sim 2.9 \mathrm{E}-03$ (rate 3) & $7.9 \mathrm{E}-04$ (HSLS-9) & 101,325 \\
\hline$N_{s} Q_{\text {std }}\left(\right.$ std. $\left.\mathrm{m}^{3} / \mathrm{s}\right)$ & $\sim 99,000$ & 101,325 & 0.637 \\
\hline$V_{H}\left(\mathrm{~m}^{3}\right)$, headspace volume & not needed & open to atmosphere & 106 \\
\hline \hline
\end{tabular}


Table 6.3. Slurry-Related Parameters for QSLS and HSLS Tests and an FSLS Case ${ }^{(a)}$

\begin{tabular}{|c|c|c|c|c|c|c|c|c|}
\hline & "HSLS & \multicolumn{6}{|c|}{ QSLS FY-07 } & $\begin{array}{l}\text { FSLS } \\
\end{array}$ \\
\hline & $>30-\mathrm{Pa}$ clay & 30-Pa AZ/AFA & 13-Pa AZ/AFA & $\begin{array}{c}3-\mathrm{Pa} \\
\mathrm{AZ} / \mathrm{AFA}\end{array}$ & 30-Pa Clay & 13-Pa Clay & 3-Pa Clay & $\begin{array}{c}30-\mathrm{Pa} \\
\mathrm{AZ} / \mathrm{AFA}\end{array}$ \\
\hline$\rho,\left(\mathrm{kg} / \mathrm{m}^{3}\right)$ & 1215 & 1215 & 1173 & 1144 & 1273 & 1245 & 1199 & 1215 \\
\hline$\phi,($ vol $\%$ solid $)$ & 0.111 & 0.099 & 0.080 & 0.066 & 0.171 & 0.154 & 0.125 & 0.099 \\
\hline holdup $U_{G f},(\mathrm{~m} / \mathrm{s})$ & $0.0242 \alpha_{G}^{0.259}$ & $0.123 \alpha_{G}^{0.789}$ & $0.0701 \alpha_{G}^{0.209}$ & $\mathrm{n} / \mathrm{a}$ & $0.0242 \alpha_{G}^{0.259}$ & $0.0112 \alpha_{G}^{-0.117}$ & $\mathrm{n} / \mathrm{a}$ & $0.123 \alpha_{G}^{0.789}$ \\
\hline$\alpha_{A}$ & 0.005 & 0.003 & 0.01 & 0.09 & 0.003 & 0.005 & 0.003 & 0.010 \\
\hline $\begin{array}{l}K_{\mathrm{HO} 2}, \\
\left(\mathrm{~Pa} /\left(\mathrm{mol} / \mathrm{m}^{3}\right)\right)\end{array}$ & \multicolumn{7}{|c|}{$8.6 \mathrm{E}+04$} & $1.0 \mathrm{E}+05$ \\
\hline $\begin{array}{l}K_{H H 2}, \\
\left(\mathrm{~Pa} /\left(\mathrm{mol} / \mathrm{m}^{3}\right)\right)\end{array}$ & \multicolumn{7}{|c|}{$1.3 \mathrm{E}+05$} & $1.4 \mathrm{E}+05$ \\
\hline $\begin{array}{l}K_{H N 2}, \\
\left(\mathrm{~Pa} /\left(\mathrm{mol} / \mathrm{m}^{3}\right)\right)\end{array}$ & \multicolumn{7}{|c|}{$1.6 \mathrm{E}+05$} & $1.9 \mathrm{E}+05$ \\
\hline $\begin{array}{l}K_{\text {HN2O }} \\
\left(\mathrm{Pa} /\left(\mathrm{mol} / \mathrm{m}^{3}\right)\right)\end{array}$ & \multicolumn{7}{|c|}{$4.8 \mathrm{E}+03$} & $6.8 \mathrm{E}+03$ \\
\hline$p_{v},(\mathrm{~Pa})$ & \multicolumn{7}{|c|}{3143} & 12236 \\
\hline$k_{\mathrm{LO} 2} a_{v},\left(\mathrm{~s}^{-1}\right)$ & $3 \mathrm{E}-03$ & $3 \mathrm{E}-03$ & $3 \mathrm{E}-03$ & $3 \mathrm{E}-03$ & $3 \mathrm{E}-03$ & $3 \mathrm{E}-03$ & $3 \mathrm{E}-03$ & $3 \mathrm{E}-03$ \\
\hline$k_{L H 2} a_{v},\left(\mathrm{~s}^{-1}\right)$ & $4 \mathrm{E}-03$ & $4 \mathrm{E}-03$ & $4 \mathrm{E}-03$ & $5 \mathrm{E}-03$ & $4 \mathrm{E}-03$ & $4 \mathrm{E}-03$ & $5 \mathrm{E}-03$ & $4 \mathrm{E}-03$ \\
\hline$k_{L N 2} a_{v},\left(\mathrm{~s}^{-1}\right)$ & $2 \mathrm{E}-03$ & $2 \mathrm{E}-03$ & $3 \mathrm{E}-03$ & $3 \mathrm{E}-03$ & $2 \mathrm{E}-03$ & $3 \mathrm{E}-03$ & $3 \mathrm{E}-03$ & $2 \mathrm{E}-03$ \\
\hline$k_{L N 2 O} a_{v},\left(\mathrm{~s}^{-1}\right)$ & $2 \mathrm{E}-03$ & $2 \mathrm{E}-03$ & $2 \mathrm{E}-03$ & $3 \mathrm{E}-03$ & $2 \mathrm{E}-03$ & $2 \mathrm{E}-03$ & $3 \mathrm{E}-03$ & $2 \mathrm{E}-03$ \\
\hline
\end{tabular}


- Generated-gas bubble release velocity at the surface: for QSLS, the release velocity and the volume fraction of generated gas were correlated in power-law form, as discussed in Section 5. There were separate correlations for the steady-state conditions achieved during mixing (holdup) and the transients observed when the mixing was turned on after a period of quiescent gas accumulation (release). These same equations were used for other scales.

- Sparge gas volume fraction: measurements, typically only good to one significant figure. As discussed in Appendix $\mathrm{C}$, the tank-average sparge gas holdup was approximated as being equal to the holdup measured in the annulus around the PJM cluster.

- Sparge bubble average rise velocity: approximated from the sparge gas volume fraction and the sparge gas superficial velocity, as discussed in Section C.4.2.

- Henry's Law constants: values for pure water at $29.8^{\circ} \mathrm{C}$ were taken from Norton and Pederson (1995). The small amount of dissolved salts in the AZ-101 simulant liquid would increase the constants. A liquid simulant with a density of $1.18 \mathrm{~g} / \mathrm{cc}$ had $K_{H}$ values that were 6 to 13 times the values for pure water, depending on the gas. The correction for salt is omitted because the liquid is nearly water; this assumption would describe waste liquid in the lag storage vessel, but would not describe the supernatant and caustic leach solutions found in the ultrafiltration process vessel.

- Water vapor pressure: valid for standard temperature and pure water. No reduction for the presence of dissolved salts was carried out, a reasonable assumption for the slurry liquid in the lag storage but not for all vessels.

- Volumetric mass transfer coefficients: the values for $\mathrm{O}_{2}$ are approximations based on the data in Table C.3. Other gases are scaled from $\mathrm{O}_{2}$ by the ratio of the square roots of the diffusion coefficients in water because $k_{L}$ depends on the square root of the diffusion coefficient.

The most important outputs of the plant predictive model are $\alpha_{G}$, the holdup of retained gas (also called equilibrated gas) and the headspace concentration of hydrogen $c_{H H 2}$ that the generated-gas holdup could produce if instantly released into the head if the vessel.

The moles of each gas species in the equilibrated gas, $n_{G i}$, can be found by subtracting dissolved gas from total gas:

$$
n_{G i}=N_{T i}-V_{L} C_{D i}
$$

The moles of dry gas the vessel head can contain, if the headspace gas is saturated with water vapor at the slurry temperature $T$, is

$$
N_{H \max }=\frac{\left(P_{a}-p_{v}\right) V_{H}}{R T}
$$

where $V_{H}$ is the headspace volume $\left(\mathrm{m}^{3}\right)$, assumed to be constant. The instant release of equilibrated gas is conservatively assumed to push the pre-existing headspace gas out without mixing with it, as in plug flow. Under this assumption, 


$$
\begin{gathered}
c_{H i}=\frac{n_{G i}}{\sum n_{G i}}\left(\frac{P_{a}-p_{v}}{P_{a}}\right) \text { if } \sum n_{G i} \geq N_{H \max } \\
c_{H i}=\frac{n_{G i}+\left(1-\frac{\sum n_{G i}}{N_{H \max }}\right) x_{H d i} N_{H \max }}{N_{H \max }}\left(\frac{P_{a}-p_{v}}{P_{a}}\right)_{\text {if }} \sum n_{G i}<N_{H \max }
\end{gathered}
$$

where $X_{H d i}$ is the dry-basis mole fraction of species $i$ in the headspace gas before the release.

\subsection{Plant Predictive Model}

The plant predictive model (PPM) described in Sections 6.3 and 6.4 and the inputs in Section 6.5 were applied to produce results that were compared to experimental data for the 2007 QSLS tests and the 2005 HSLS tests. These comparisons are described in Sections 6.6.1 and 6.6.2, respectively. The model was then applied to predict FSLS conditions, with results given in Section 6.6.3.

Mass transfer between sparge bubbles and the dissolved gas inventory was modeled for the HSLS tests, to determine its effect on operating cycles, and for the FSLS vessel, to estimate its effect on gas composition. The conclusions about the modeled effect of mass transfer, and other conclusions, are presented in Section 6.6.4.

\subsubsection{Comparison of Model Output to 2007 QSLS Data}

The QSLS tests were carried out at steady-state at three different oxygen-generation rates under fully mixed conditions (PJMs on and spargers on full). No operating cycle tests were performed.

Because the bubble-release input parameters in Table 6.3 were developed from the 2007 tests, an extensive comparison of these test data to model predictions was considered redundant. A small set of comparisons was made simply to check the calibration of the model against the data that was its source. The test cases were chosen to include both 30- and 13-Pa AZ-101 simulant with AFA; results for clay simulant are covered by comparison with HSLS data in Section 6.6.2. Runs in the lower range of $\mathrm{O}_{2}$ generation rates were selected because in these the contribution of sparge gas mass transfer to retainedgas bubble volume would be more visible and less swamped by gas generation. The model tests in this section assumed a retained bubble rise velocity that varied with retained gas volume fraction via the power-law relations that were shown in Table 6.3 and obtained from 2007 QSLS data. The model was the one described in Sections 6.3, 6.4.3, and 6.5; it was implemented in Excel with a timestep of 0.025 to $0.04 \mathrm{hr}$ with a macro to iterate the solution at each timestep.

Zero mass transfer between the solution and the sparge bubbles was assumed in one set of tests, consistent with the assumption that the volume fraction and behavior of retained-gas bubbles were not strongly affected by dissolved gases whose source was sparge gas. This assumption, that generated gas is the controlling factor in retained gas bubbles, was implicit in the correlation of bubble rise velocity against generated gas superficial velocity. The other set of tests assumed nominal mass transfer for comparison. Table 6.4 shows the measurements and model predictions for the lowest gas generation rate 
(Table 6.2) in 30-Pa AZ-101 simulant with AFA and the second-highest gas-generation rate in 13-Pa AZ101 simulant with AFA.

The model matches well with observations, whether mass transfer between the sparge bubbles and the dissolved gas inventory is assumed or not. At these gas generation rates, the effect of sparge bubble mass transfer on the retained gas volume fraction is negligible even though air is a major constituent of the retained gas bubble, judging by the predicted nitrogen content. This can be demonstrated by considering Eq. (6.15). The change in total moles of retained gas in bubbles is driven by both the moles/sec of gas generation, $V_{L} g_{m i}$, and the moles/sec of gas transferred from the dissolved-gas inventory to the retained gas bubbles, $-\Delta_{A i}$. It is possible to calculate a total superficial velocity of gas supply to the retained gas bubbles. This parameter, $U_{\Delta s}$, is

$$
U_{\Delta s}=\frac{R T \sum_{i}\left(V_{L} g_{m i}-\Delta_{A i}\right)}{\bar{P} A}
$$

By comparison, the gas-generation superficial velocity that has been used to correlate data, $U_{G s}$, does not include the mass transfer term. In the case of QSLS 2007 data, the model-predicted $U_{\Delta s}$ is within a few percent of $U_{G s}$ at mass transfer steady state. Ideally, the gas volume fraction $\alpha_{G}$ would have been correlated against $U_{\Delta s}$ instead of $U_{G s}$, but the difference is trivial for the QSLS tests and would be more so at the higher gas-generation tests (for which the model was not run).

A negligible concentration of nitrogen was predicted for the retained gas in the zero mass transfer case, even though the initial condition on the dissolved gas inventory included nitrogen, consistent with initial equilibrium with air.

Table 6.4. Comparison of Measurement and Model Predictions for 2007 QSLS

\begin{tabular}{|c|c|c|c|}
\hline \multirow[b]{2}{*}{ Simulant } & \multirow[b]{2}{*}{$\begin{array}{c}\text { Measured } \\
\text { Holdup }^{(a)} \\
(\text { vol\%) }\end{array}$} & \multicolumn{2}{|c|}{ Predicted Holdup (vol\%) } \\
\hline & & $\begin{array}{c}\text { No Mass Transfer; } \\
\text { Varying Bubble Rise } \\
\text { Velocity }\end{array}$ & $\begin{array}{c}\text { Nominal Mass Transfer; } \\
\text { Varying Bubble Rise } \\
\text { Velocity }\end{array}$ \\
\hline $\begin{array}{l}\text { 30-Pa AZ-101 simulant with } \\
\text { AFA; lowest gas generation }\end{array}$ & $0.74,0.86$ & 0.93 & $\begin{array}{c}0.91 \\
\left(59 \% \mathrm{~N}_{2}\right)\end{array}$ \\
\hline $\begin{array}{l}\text { 13-Pa AZ-101 simulant with } \\
\text { AFA; } 2^{\text {nd }} \text {-highest gas gen. }\end{array}$ & 0.22 & 0.26 & $\begin{array}{c}0.27 \\
\left(52 \% \mathrm{~N}_{2}\right)\end{array}$ \\
\hline
\end{tabular}

Because the QSLS runs of the model did not include changes in the operating mode (PJMs switched on or off, spargers switched between full and idle), the limitations of the model implementation were not expected to affect the model predictions. These limitations arose from the relatively large timestep that was needed to allow for reasonable computation times in Excel. They are discussed further in Sections 6.6.2 and 6.6.3, where they are pertinent. 


\subsubsection{Comparison of Model Output and HSLS Data}

The HSLS tests (Bontha et al. 2005) included both steady-state tests, for which the steady-state retained-gas holdup was related to bubble rise velocity and gas-generation superficial velocity, and cyclicoperation tests that represented the cycling that is planned to occur during normal operation, post-DBE, and NTAR conditions. Retained gas holdup data were based on level measurements taken during static conditions, with PJMs briefly turned off and spargers switched to idle flow). The retained gas was modeled as being released at a bubble rise velocity that did not vary with the gas volume fraction but that depended on the operating mode (the combination of PJM operation and sparger flow rate). Four different bubble rise velocities were determined using a Monte Carlo method to fit the model to the data and obtain a distribution of possible velocities for each operating mode. The bubble rise velocity during the unmixed operating mode (PJMs off, spargers on idle) was fitted as being non-zero, implying some gas release even in the absence of mixing.

The tests denoted as HSLS-1 Run 1, HSLS-1 Run 2, HSLS-1 Run 3, HSLS-2 Run 3, and HSLS-3 Run 3a were selected for comparison of PPM predictions to measurements. These runs include a full suite of operating modes. Tests HSLS-8 and HSLS-9 were excluded as superfluous because these runs were based on the same operating mode as HSLS-1 but had higher gas generation rates.

The effect of partly mixed operating modes, defined as mode 1 and mode 2 in Section 6.3.2, is described using bubble rise velocity adjustment coefficients $f_{(i)}$ and $f_{(i i)}$, which are applied to the scalingbasis relation. The scaling-basis curve fit determined for 30-Pa clay simulant in the QSLS tests was $\alpha_{G}=7.964 U_{G s}^{0.794}$, expressed in units of vol\% for $\alpha_{G}$ and $\mathrm{mm} / \mathrm{s}$ for $U_{G s}$, as shown in Figure 5.16. The same figure shows that this curve fit is equally applicable to the slightly higher-strength clay simulant used in the HSLS tests. For modeling purposes, the scaling basis is expressed in terms of a relationship between the bubble rise velocity $U_{G f}$ and the gas volume fraction by applying the relation $\alpha_{G}=U_{G s} / U_{G f}$. The resulting bubble-rise power-law relation, after converting to $U_{G f}$ units of $\mathrm{m} / \mathrm{s}$ and $\alpha_{G}$ units of volume fraction, is $U_{G f}=0.0242 \alpha_{G}^{0.259}$, as shown in Table 6.3. This relation applies only to the fully mixed operating mode with PJMs on and spargers on full.

The adjustment coefficients that are required as model input for other modes are determined by assuming that the exponent of the power law relation is the same for other modes as for full mixing, then using data for steady-state gas fraction and rise velocity to find the coefficient of the power law. It is not clear whether the exponent would be the same for all mixing modes. The exponent reflects some interaction between the retained gas bubbles that tends to give them higher release velocities when more gas is present - except in the case of 13-Pa clay, where the release velocity decreases with increasing gas fraction, as seen in Table 6.3. The mechanism is unknown but may be related to the non-Newtonian nature of the slurry; perhaps a higher density of retained gas bubbles adds to the stress on the fluid and decreases the effective viscosity. If the mechanism behind the exponent is related to non-Newtonian rheological behavior, the stress imposed by mixing action could also have an effect. In that case, the exponent could be affected by the operating mode, contrary to the present simplifying assumption. This question cannot be answered without, at minimum, re-correlating the HSLS data to provide a fit for both coefficients and exponents of the power law release velocity relationship for the different operating modes. 
The rise velocity data used are the median values of the bubble rise velocity distributions that were fitted, in the HSLS model, for PJMs off and spargers on full (mode 1) and for PJMs on and spargers off (mode 2). From Bontha et al. (2005, Table 7.3), these median velocities were 0.00268 and $0.000951 \mathrm{~m} / \mathrm{s}$ based on a slurry depth $H$ of $3.61 \mathrm{~m}$. From Figure 6.16 and p. 6.12 of the same reference, the steady-state retained gas fractions in the two models were about $0.9 \mathrm{vol} \%$ and $2.55 \mathrm{vol} \%$. The adjustment coefficient for model $1, f_{(i)}$, is then found from the calculation:

$$
0.00268=f_{(i)} * 0.0242 *\left(0.009^{0.259}\right) ; f_{(i)}=0.375
$$

The adjustment coefficient for model $2, f_{(i i)}$, is then found from the calculation

$$
0.000951=f_{(i i)} * 0.0242 *\left(0.0255^{0.259}\right) ; f_{(i i)}=0.102
$$

Because the exponent of the gas fraction is small, the adjustment coefficients are not sensitive to the exact value of the gas volume fraction.

A different set of model adjustment coefficients is required as input for runs in which it is assumed that the bubble rise velocity is constant with gas volume fraction, as was assumed in the original HSLS model (Bontha et al. 2005). The fully mixed bubble rise velocity was $0.00288 \mathrm{~m} / \mathrm{s}$, and the power law exponent was by definition zero. Under this assumption, $f_{(i)}$ was $0.00268 / 0.00288$, or 0.931 , and $f_{(i i)}$ was $0.000951 / 0.00288$, or 0.331 .

Using this information for the effect of operating mode, and assuming zero gas release during unmixed conditions, the model was run for three different sets of assumptions:

- Zero mass transfer to the sparge bubbles and bubble rise velocity constant with gas volume fraction

- Zero mass transfer to the sparge bubbles and bubble rise velocity varying with gas volume fraction according to the 30-Pa clay scaling basis relation

- Nominal mass transfer to the sparge bubbles (as given by the $k_{L} a_{v}$ values in Table 6.3) and bubble rise velocity varies with gas volume fraction according to the $30-\mathrm{Pa}$ clay scaling basis relation.

The first set of assumptions is most consistent with the original HSLS model, but differs in that the gas release during periods when mixing is off is conservatively assumed to be zero, not finite. The measured and predicted results for the HSLS-1 tests are given in Table 6.5. HSLS-1 Run 1 gave a fully mixed steady state; HSLS-1 Run 2 gave a steady state in mode 2; and HSLS-1 Run 3 tested 20 cycles of the half-scale normal operating cycle, which was $0.5 \mathrm{hr}$ at full mixing and $1 \mathrm{hr}$ at mode 2.

The test case with no mass transfer and no variation of bubble rise velocity with gas fraction is not a perfect match to observations, but it is closely consistent with the predictions made by the original HSLS model. Applying the assumption that $U_{G f}$ varies with $\alpha_{G}$ produces somewhat better agreement with observations. In both of these cases, since there was no mass transfer there was no mechanism for $\mathrm{N}_{2}$ from the sparge air to be incorporated into the retained gas bubbles. 
Table 6.5. Comparison of Measurement and Model Predictions for HSLS-1

\begin{tabular}{|l|c|c|c|c|}
\hline \multirow{2}{*}{ Simulant } & \multirow{2}{*}{$\begin{array}{c}\text { Measured } \\
\text { Holdup } \\
(\mathbf{v o l})\end{array}$} & $\begin{array}{c}\text { No Mass Transfer; } \\
\text { Constant Bubble Rise } \\
\text { Velocity }\end{array}$ & $\begin{array}{c}\text { No Mass Transfer; } \\
\text { Varying Bubble Rise } \\
\text { Velocity }\end{array}$ & $\begin{array}{c}\text { Mass Transfer; } \\
\text { Varying Bubble Rise } \\
\text { Velocity }\end{array}$ \\
\hline Fully mixed, steady state & $0.22-0.41$ & 0.55 & 0.29 & $\begin{array}{c}0.95 \\
\left(69 \% \mathrm{~N}_{2}\right)\end{array}$ \\
\hline Mode 2, steady state & 2.55 & 1.65 & 1.80 & 1.79 \\
$\left(0.5 \% \mathrm{~N}_{2}\right)$
\end{tabular}

In the third case, where a nominal mass transfer rate is assumed between the sparge bubbles and the dissolved gases in the liquid, nitrogen does move from solution into the retained gas. When sparge is on full, as in the fully mixed case, the retained bubbles are composed primarily of gas from air, not from oxygen generation, and the volume fraction of retained gas is increased compared to the no-mass transfer value. When sparge is on idle, as in mode 2, the bubble composition is dominated by the in-situ gas generation. In the third case, the model with mass transfer overpredicts the low, fully mixed end of the holdup range. This overprediction was not seen for the QSLS model runs (Section 6.6.1). The difference may arise from the lower gas generation rate in HSLS-1 tests (about one-fourth of the lowest rate tested in QSLS). The air gases loaded into solution by mass transfer from the sparge bubbles are not dominated by the lower gas generation rate in the HSLS system.

The Excel model run for the normal operating cycle (HSLS-1 Run 3), assuming nominal mass transfer, was checked during review by running parallel calculations in a FORTRAN program. When the timestep was decreased in the FORTRAN runs to test for stability, it was found that the maximum gas volume fraction was being underpredicted by the Excel implementation by about $4 \%$ and the minimum was underpredicted by $9 \%$. Thus the values given for that particular model run in Table 6.5 are known to be low due to using a relatively large timestep of 0.04 hour to reduce computational time.

Table 6.6 contains the results for the HSLS-2 and -3 tests. HSLS-2 Run 3 was 20 cycles of the 1/2-scale post-DBE cycle, 1 hour of full mixing followed by 2 hours without mixing (PJMs off and spargers on idle). HSLS-3 Run 3a represented 11 cycles of the N-TAR cycle. The PJMs were off at all times, with 1 hour of full sparging (mode 1 ) and 2 hours of idle sparging.

The model consistently over-predicts the cycle maximum retained gas volume fractions because it assumes zero gas release when PJMs are off and spargers idle. The original HSLS model fit a small finite bubble rise velocity to this operating mode and consequently provided a closer match to the maxima. The physical meaning of this bubble rise velocity is unclear because the vessel contents as a whole are stagnant and effectively solid, while only a small region above each sparger tip is fluid. Thus, assuming that the bubble rise velocity is zero under unmixed conditions introduces significant conservatism. 
Table 6.6. Comparison of Measurement and Model Predictions for HSLS-2 and -3

\begin{tabular}{|l|c|c|c|c|}
\hline \multirow{2}{*}{ Simulant } & \multirow{2}{*}{$\begin{array}{c}\text { Measured } \\
\text { Holdup } \\
\text { (vol\%) }\end{array}$} & $\begin{array}{c}\text { No Mass Transfer; } \\
\text { Constant Bubble } \\
\text { Rise Velocity }\end{array}$ & $\begin{array}{c}\text { No Mass Transfer; } \\
\text { Varying Bubble Rise } \\
\text { Velocity }\end{array}$ & $\begin{array}{c}\text { Mass Transfer; } \\
\text { Varying Bubble } \\
\text { Rise Velocity }\end{array}$ \\
\cline { 3 - 5 } & $0.90-1.23$ & 0.94 & 0.35 & $\begin{array}{c}0.97 \\
\left(68 \% \mathrm{~N}_{2}\right)\end{array}$ \\
\hline $\begin{array}{l}\text { Post-DBE cycle, minimum } \\
\text { value }\end{array}$ & $2.46-3.20$ & 4.63 & 4.09 & $\begin{array}{c}4.12 \\
\left(27 \% \mathrm{~N}_{2}\right)\end{array}$ \\
\hline $\begin{array}{l}\text { Post-DBE cycle, maximum } \\
\text { value }\end{array}$ & $1.26-1.29$ & 1.05 & 0.88 & $\begin{array}{c}2.14 \\
\left(68 \% \mathrm{~N}_{2}\right)\end{array}$ \\
\hline N-TAR cycle, minimum value & 4.73 & 4.58 & $\begin{array}{c}5.29 \\
\left(34 \% \mathrm{~N}_{2}\right)\end{array}$ \\
\hline N-TAR cycle, maximum value & $2.40-2.75$ & \multicolumn{3}{|l|}{} \\
\hline
\end{tabular}

The current model's prediction of cycle minima is consistent with the observations and predictions made by the original HSLS model when the same assumptions of zero mass transfer and constant bubble rise velocity are made. The minima were underpredicted when the varying velocity assumption was introduced. A similar outcome was seen in the HSLS-1 runs. It is possible that the mode adjustment coefficients could be improved if calculated not by single-point calculations, as in Eq. (6.32) and (6.33), but by the same kind of Monte Carlo fits to the entire HSLS data set that were performed before. In the prior case, the fit assumed a constant bubble rise velocity in each operating mode. A new fit would assume the bubble rise velocity was proportional to $\alpha_{G}^{0.259}$ in all modes and solve for the coefficients.

The inclusion of sparge-bubble mass transfer in the model leads to overpredicting the gas volume fraction in the N-TAR cycle, in which bubble rise release velocities are lower because the PJMs are turned off throughout. The gas volume fraction is increased because gas is being supplied to the retained bubbles not only by gas generation but by gas transferred through the solution from the sparge bubbles.

A comparison of $U_{\Delta s}$ to $U_{G s}$ gives some idea of the effect of mass transfer relative to that of gas generation. For HSLS data, the model-predicted $U_{\Delta s}$ is $30-60 \%$ greater than $U_{G s}$ at mass transfer steady state; the difference results from gas supplied by sparge bubbles. If $U_{\Delta s}$ had been used to correlate the gas volume fraction, the data points for HSLS in Figure 5.16 would be further to the right on the x-axis. This change would, if anything, make the HSLS data closer to the QSLS scaling-basis line for 30-Pa clay. However, the gas volume fraction for HSLS were taken during static periods when spargers and PJMs were briefly turned off, so $U_{\Delta s}$ during these periods may well have been less than the steady-state value, implying a smaller rightward correction on the plot. Although it would be possible to re-correlate versus $U_{\Delta s}$ instead of $U_{G s}$, the uncertainty introduced by measurement while sparge was off would make it difficult to improve the correlation.

With the timestep used $(0.04 \mathrm{hr})$, the Excel model runs in Table 6.6 in which nominal mass transfer was assumed were found to have underpredicted both the maxima and the minima of the gas fraction cycle. The underprediction was $8 \%$ or less in all cases. 


\subsubsection{Prediction of Retained Gas Holdup and Composition in the FSLS}

The input parameters given in Table 6.2 for the FSLS vessel were based on

- slurry volume of 94,726 gal (24590-WTP-M4C-V11T-00004 Rev. C, p. A-20)

- corresponding slurry depth, measured from the center bottom of the vessel (24590-PTF-M6CHLP-00003_Rev_00D[1], p. 10)

- temperature of $122^{\circ} \mathrm{F}$ and hydrogen generation rate of $15 \mathrm{~L} / \mathrm{hr}$ at $1 \mathrm{~atm}$ and slurry temperature (224590-WTP-M4C-V11T-00004 Rev. C, Table 8-1)

- total sparger flow rate of 1349 scfm (24590-WTP-3YD-50-00003 Rev. B, Figure 6.19)

- vessel vapor space volume of 28,034 gal (24590-WTP-M4C-V11T-00004 Rev. C, p. A-20).

The vessel headspace is assumed to be $1 \mathrm{~atm}$ and hydrogen the only gas generated in the liquid. The slurry is assumed to have the characteristics of 30-Pa AZ-101 simulant containing AFA. The initial conditions for each run are liquid saturated with air gases and a zero inventory of retained gas bubbles.

The planned normal operating cycle for the FSLS is 1 hour of full mixing (PJMs on and spargers on full) followed by 2 hours of PJMs on and spargers on idle (mode 2). The predicted retained gas volume fractions over the final three cycles of a set of 36 cycles are shown in the top panel of Figure 6.4. The bottom panel shows the headspace $\mathrm{H}_{2}$ concentrations calculated by Eq. (6.31) on the basis of instantaneous release of all retained gas into the headspace.

Though not visible in the figure, the retained gas volume fraction predicted for the assumption of zero mass transfer varies from $0.048 \mathrm{vol} \%$ after a period of full mixing to $0.052 \mathrm{vol} \%$ after a period when PJMs were on but the spargers were set to idle. By contrast, in cases where mass transfer is present the maximum retained gas volume fraction occurs after a period of mixing, because of the gas fed into the system by the full sparge flow rate, and the minimum occurs after a period of idle sparge. While mass transfer increases the gas volume fraction, it also decreases the hydrogen concentration in the retained bubbles. The net effect is a decrease in the headspace concentration produced by hydrogen release.

In all three cases, the maximum gas volume fraction and released hydrogen concentration are continuing to trend upward at the end of 36 cycles $(108 \mathrm{hr})$. The ultimate condition, in the case of zero mass transfer, occurs when the retained gas volume fraction has equilibrated and the retained gas is pure hydrogen. At this point the predicted retained gas volume fraction is $0.057 \mathrm{vol} \%$ and the released hydrogen concentration in the headspace is about $2660 \mathrm{ppm}$. The final gas fraction and released hydrogen concentration for the mass transfer cases have not been determined, because of computational time limitations, but are expected to be lower based on the trends seen at the 108-hr point.

The planned post-DBE operating cycle for the FSLS is 2 hours of full mixing (PJMs on and sparge on full) followed by 12 hours of no mixing. Figure 6.5 depicts the predictions, over the first $98 \mathrm{hr}$, of the retained gas volume fractions and the instantaneous-release headspace $\mathrm{H}_{2}$ concentrations.

The same trends are seen as in the normal operating cycle. When no mass transfer is allowed, the retained gas volume fraction is low, reaching a maximum after the part of the cycle with the least mixing, and 98 hours is not enough to reach the full final gas volume fraction and release hydrogen concentration. 

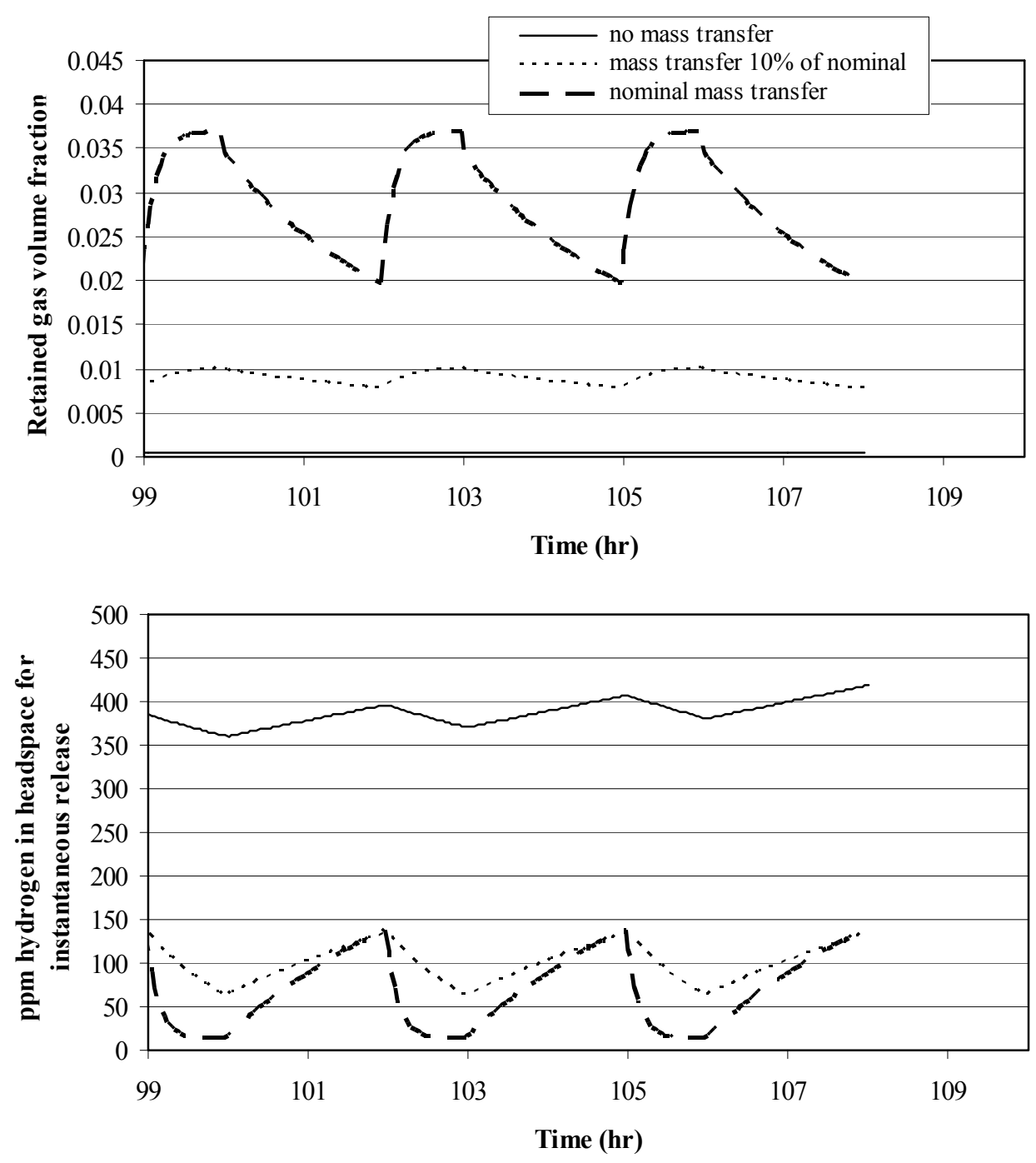

Figure 6.4. Predicted Holdup and Headspace $\mathrm{H}_{2}$ for FSLS Normal Operations

The retained gas volume fraction predicted for the assumption of zero mass transfer varies from $0.073 \mathrm{vol} \%$ after a period of full mixing to $0.11 \mathrm{vol} \%$ after the 12 -hour period without mixing. The final value of maximum gas volume fraction is $0.12 \mathrm{vol} \%$ when the retained bubble gas is pure hydrogen, and the final headspace hydrogen concentration from an instantaneous release of retained gas is $5500 \mathrm{ppm}_{2}$.

Mass transfer, at the nominal rate, produces a higher gas volume fraction and a lower concentration of released hydrogen. The gas fraction increases slightly over each unmixed period and the released hydrogen concentration increases sharply as generated hydrogen accumulates. When the sparge is turned to full, hydrogen is purged from the system and the hydrogen concentration that could be produced by a release of retained gas drops rapidly. The retained gas volume fraction is essentially constant at about the same value found for well-mixed conditions in the normal operating cycle. The blocky variation seen in the gas volume fraction in Figure 6.5 is a timestepping artifact produced by the timestep size and could be decreased by reducing the timestep, at the cost of longer computational time. 

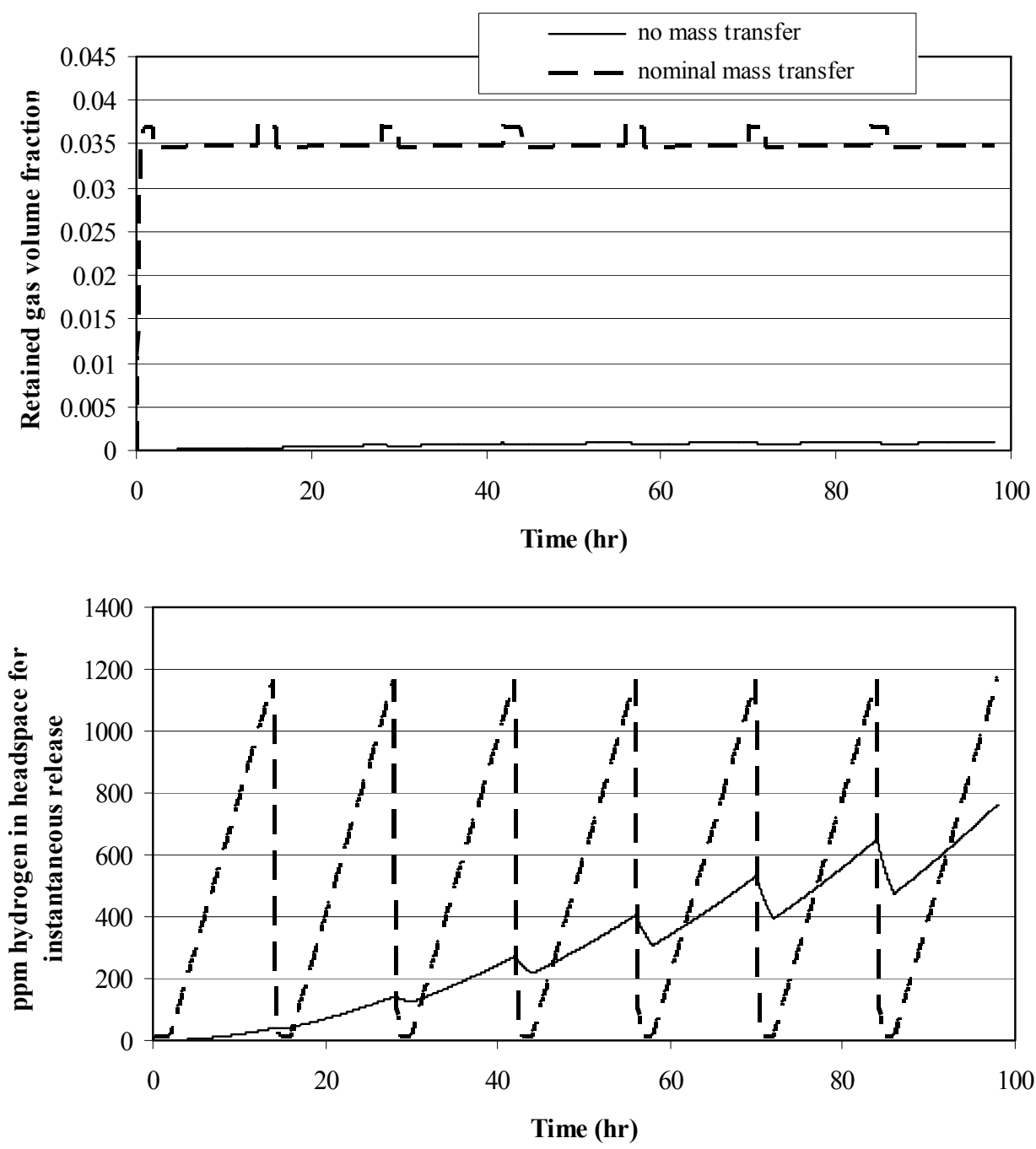

Figure 6.5. Predicted Holdup and Headspace $\mathrm{H}_{2}$ for FSLS Post-DBE Operations

The runs for both the normal operating cycle and the post-DBE cycle were tested to determine the effect of the timestep used in the Excel model that produced the predictions described above. When mass transfer was zeroed, the timestep of $0.04 \mathrm{hr}$ led to retained gas fractions and headspace hydrogen concentrations that were within $0.7 \%$ of those predicted by the faster-running FORTRAN version of the model at a fully converged timestep. This full-convergence timestep was about $0.00004 \mathrm{hr}$. When nominal mass transfer was assumed, the following comparisons were obtained:

- The predicted maximum headspace hydrogen concentration was found to be overestimated by about $1 \%$ for normal operations and about $5 \%$ for post-DBE cycling, while the minimum was underestimated by $0.2 \%$ or less.

- The predicted maximum retained gas fraction was underestimated by less than $2 \%$ for both cycles, while the minimum was underestimated by about $2 \%$ for normal operations and about $6 \%$ for post-DBE cycling. 
- Retained gas fractions and headspace hydrogen concentrations that were not at the maxima or minima were over- or underestimated by the 0.04 -hr timestep by as much as $30 \%$.

These variations from the true solution of the ODEs could be made negligible by using a faster implementation of the model, like FORTRAN, or another solution scheme that might not require such a small timestep. In any case, the inaccuracies resulting from timestep size do not change the overall trends seen in the model predictions: mass transfer from sparge bubbles, when accounted for in modeling, produces higher retained gas fractions and lower headspace hydrogen concentrations from releases.

Finally, in the FSLS, the model-predicted $U_{\Delta s}$ at steady-state mass transfer conditions is more than 1000 times the value of $U_{G s}$. Therefore, the latter alone is not a sound predictor of retained gas volume.

\subsubsection{Modeling Conclusions and Discussion}

The model developed and implemented for this study has been shown to be capable of matching observed HSLS and QSLS measurements at steady-state conditions when mass transfer from sparge bubbles is zeroed. Modeling of mode cycling (turning PJMs off and on, switching spargers between full and idle flow rates) was less successful. Results for both steady-state and cyclic operations could be improved by re-fitting HSLS cyclic operation data using the assumption that the retained bubble rise velocity is a power-law function of the retained bubble gas fraction rather than a constant value. It would also be possible to reduce conservatism for off-normal operating cycles by assuming that the retained gas bubble rise velocity is non-zero even when mixing is turned off. Finally, the model implementation should be made more efficient, so that smaller timesteps can be used to obtain complete convergence and increase the accuracy of predictions.

Mass transfer between sparge bubbles and the dissolved gas inventory is predicted to increase the retained bubble gas volume fraction and cause the retained gas to contain a substantial proportion of air gas instead of generated gas such as hydrogen. The contribution of sparge mass transfer to the gas in retained bubbles becomes more important as gas generation rates decrease. This effect has not been accounted for in past correlations, which have related gas volume fraction to gas generation alone. It would be possible to re-correlate past data in a way that takes the contribution of sparge mass transfer into account. However, there are relatively few data points to draw on and increasing the number of adjustable parameters in the model would not necessarily improve its performance.

The net effect of mass transfer was to increase predicted retained gas volume fractions in the FSLS. However, mass transfer also decreased the hydrogen concentration predicted in the vessel headspace after an instantaneous release of retained gas. Both of these results seem reasonable, but it should be recognized that they depend on three basic assumptions:

- The omission of mass transfer effects from release velocity correlations, referred to above, does not lead to an underestimate of the retained hydrogen inventory

- Mass transfer between the sparge bubbles and the dissolved gas is as rapid in the lag-storage vessel as in the SRNL bubble column

- The dissolved gases are in equilibrium with the gases in the retained gas bubbles; i.e., the mass transfer for the retained gas bubbles is essentially instantaneous. 


\subsection{Bounding Simulant Study}

Tests were performed in a small-scale mixing vessel using liquids and slurries representing major components of typical WTP waste streams to address the issue that simulants delivered to the WTP will come from various tanks besides 241-AZ-101. The following sections include the test objectives, mixing vessel description, and simulants used in the bounding simulant tests.

\subsection{Test Objective and Approach}

The objective of the bounding simulant task was to identify the AZ-101 simulant recipe that produced the greatest gas holdup. The task was performed in two phases; the first consisted of gas holdup testing using pure component solutions and slurries. These pure components were selected by examining the waste compositions analyzed by PNNL and the Tank Waste Information Network System (TWINS) database and selecting the most prevalent constituents to test. Components selected for slurry tests were based on salt compositions in solids. The results were then analyzed to determine the pure components having the greatest effect on gas holdup and then selecting the waste expected to provide the greatest gas holdup on that basis. A surrogate of that waste was then developed and tested. However, in actuality the pure component testing indicated the $\mathrm{AZ}$ waste simulant would provide the greatest gas holdup, and a new surrogate was not needed.

\subsection{Description of Test Apparatus}

The test apparatus was designed to rapidly determine gas holdup in aqueous solutions and slurries. Figure 7.1 is a schematic of the apparatus. The mixing vessel was a 20 -inch-tall acrylic flat-bottomed vessel with an internal diameter of 5.5 inches and an approximately 4.7-L working volume. Four 12inch-long, 0.4-inch-wide baffles were positioned perpendicular to each other and $\sim 0.5$-inch from the vessel base. Oxygen gas was delivered to the mixing vessel through a mass flow meter (Aalborg Mass Flow Controller, GFC, Aalborg Instruments \& Controls, Inc., Orangeburg, NY) and a sparge ring located centrally between the baffles. Mixing was provided by a mechanical agitator (IKA® Eurostar, IKA Works, Inc., Wilmington, NC). The lower radial-flow flat-bladed impeller of approximately 2-inch diameter was approximately 1 inch above the sparge ring and was intended to disperse the gas. The 2.5-inch-diameter axial flow propeller was situated approximately midway between the lower impeller and fluid surface for tests with non-Newtonian fluids. The axial-flow propeller provided fluid mixing throughout the working volume independent of that provided by the rising gas bubbles. The fluid level

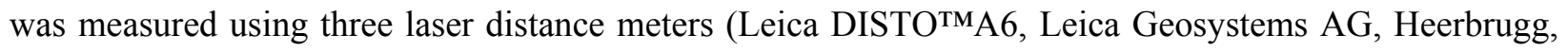
Switzerland). Small plastic floats were used as targets for the lasers when testing clear fluids. Distance measurements were collected by Bluetooth ${ }^{\circledR}$ data transfer to personal computers.

Gas holdup tests of Newtonian solutions and slurries were performed at an agitator speed of $800 \mathrm{rpm}$. This agitator speed was visually found to provide a homogeneous dispersion of bubbles in water without creating a large concentration of very small bubbles close to the agitator observed at higher speeds. Tests of non-Newtonian slurries with yield stresses below $20 \mathrm{~Pa}$ were performed at an agitator speed of $850 \mathrm{rpm}$ because this speed was found to provide fluid movement throughout the vessel. An agitator speed of $1090 \mathrm{rpm}$ was used at higher yield stresses to obtain fluid movement throughout the vessel. 


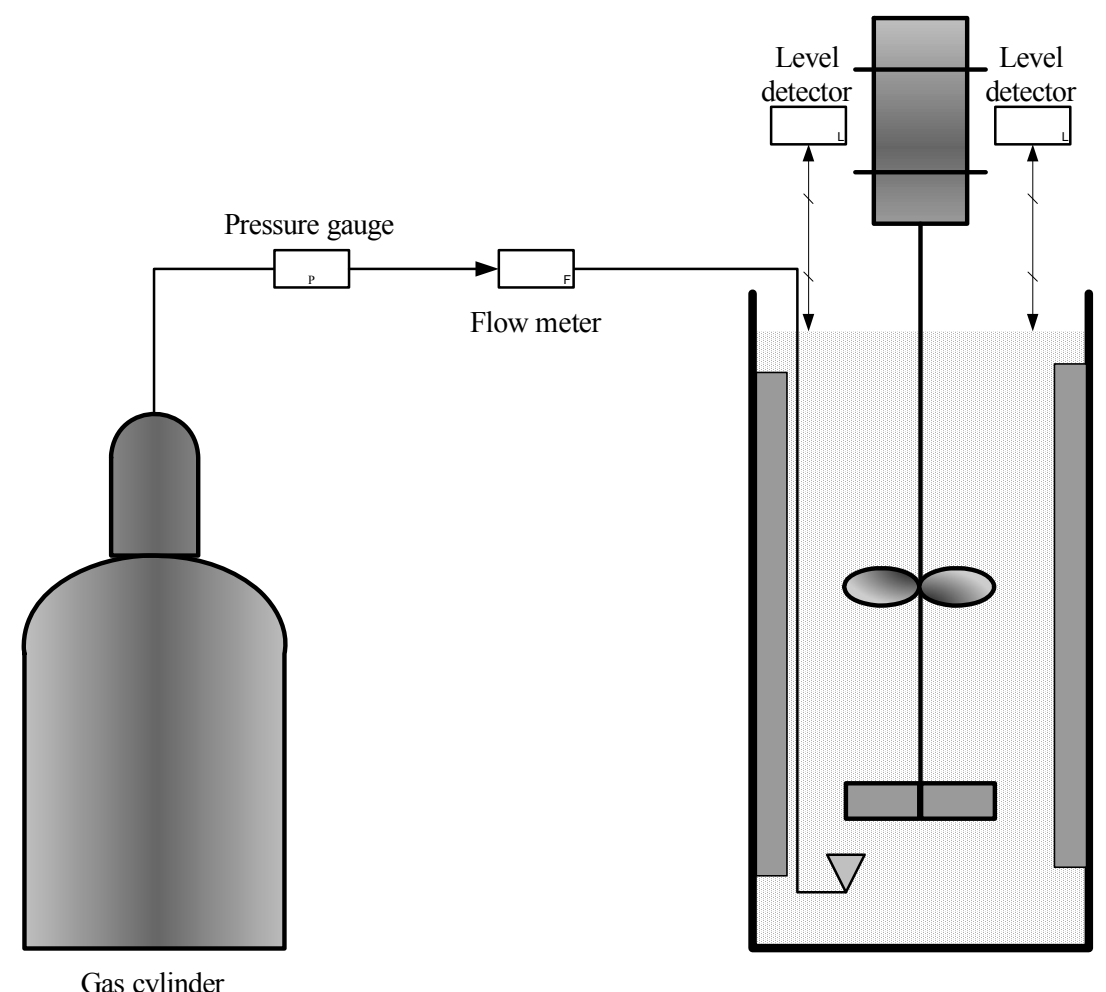

Figure 7.1. Schematic of the AFA-BS Test Apparatus

Testing was performed by increasing the gas flow rate incrementally and allowing 15 minutes to attain steady state, then 5 more minutes for data collection between each increment. The gas flow rate was incrementally decreased once testing over the full range at increasing flow rates was completed. Testing was first performed with the AFA-free material. Enough AFA to achieve a $300 \mathrm{ppm}(300 \mathrm{mg} / \mathrm{L})$ concentration was added to the contents of the vessel using a syringe and mixed for at least 30 minutes for the Newtonian fluids and overnight for the non-Newtonian slurries.

\subsection{Data Analysis}

The gas holdup, $\alpha$, is given by the equation:

$$
\alpha=1-\frac{V_{f}(t)}{V_{f}(t)+V_{g}(t)}
$$

where $\mathrm{V}_{\mathrm{f}}(\mathrm{t})$ and $\mathrm{V}_{\mathrm{g}}(\mathrm{t})$ are the volumes of fluid and gas at time $t$, respectively. The volume of gas is determined from the change of fluid height measured by the distance meters:

$$
\mathrm{V}_{\mathrm{g}}(\mathrm{t})=\mathrm{A}[\mathrm{h}(\mathrm{t})-\mathrm{h}(0)]
$$

where $\mathrm{A}$ is the cross section area of the vessel, and $\mathrm{h}(0)$, and $\mathrm{h}(\mathrm{t})$ are the fluid heights at time 0 and time $\mathrm{t}$, respectively. The calculation also took account of relatively minor evaporative losses. An average gas holdup was computed based on the average calculated volumes. 


\subsection{Simulants}

Tank waste slurry consists of liquids and solids. Both were considered in selecting the pure components to test. Concentrations of 0.1 and $1 \mathrm{M}$ sodium hydroxide, a major liquid-phase constituent, were selected for testing. The liquid phase contains many other dissolved salts; sodium nitrate was selected for testing as representative itself and others. Concentrations of 0.1 and $1 \mathrm{M}$ were again selected.

The aluminum compounds gibbsite and boehmite are major constituents of the solid phase. Two concentrations, 2 and $20 \mathrm{wt} \%$, were selected. Hydrated alumina ATH C33 (product code 4001216, lot 0617064550, Almatis Inc., Leetsdale, PA) with a volume mean particle size of $61 \mu \mathrm{m}$ was selected as the gibbsite material; slurries were prepared by simply dispersing the required mass in deionized water. Gas holdup of gibbsite with a mean particle size of $1.5 \mu \mathrm{m}$ (product code 4001257, lot 0638087602, Almatis, Inc., Leetsdale, PA) were tested but the slurry foamed, so larger particle sizes were tested.(a) The boehmite compound chosen was HiQ-30S (reference number Q-2202, BASF Catalysts LLC, Port Allen, LA) with a volume mean particle size of $52 \mu \mathrm{m}$. Slurries were prepared by dispersing the required mass in deionized water. The $2 \mathrm{wt} \%$ gibbsite and boehmite and $20 \mathrm{wt} \%$ boehmite slurries were essentially Newtonian, while the $20 \mathrm{wt} \%$ gibbsite slurry exhibited some non-Newtonian characteristics.

The other major solid phase component tested was ferric oxide. Slurries of ferric oxide were prepared by dissolving the required quantity of ferric nitrate in deionized water. Sodium hydroxide was gradually added to the solution to increase the $\mathrm{pH}$ to approximately 12 and to facilitate ferric hydroxide (deep red precipitate). This slurry was then heated at approximately $90^{\circ} \mathrm{C}$ for 24 hours to convert the precipitate to ferric oxide (tan color). Dilution of the slurry to obtain the desired concentration was achieved with $0.1 \mathrm{M}$ sodium hydroxide. The ferric oxide slurry was non-Newtonian. Simulated AZ-101 slurries were available from the QSLS testing. Testing with simulated AZ-101 slurry was only performed with AFA because foaming would prevent a meaningful test for gas holdup.

Physical properties of the Newtonian solutions and slurries with and without AFA are provided in Table 7.1. The viscosity of these solutions and slurries was consistently approximately $1.2 \mathrm{mPa}$.s, as

Table 7.1. Physical Properties of Pure Newtonian Solutions and Slurries

\begin{tabular}{|l|c|c|c|c||}
\hline \multirow{2}{*}{ Solution/Slurry } & \multicolumn{2}{|c|}{ Viscosity (mPa.s) } & \multicolumn{2}{c||}{ Surface Tension (mN/m) } \\
\cline { 2 - 5 } & No AFA & $\begin{array}{c}300 \mathrm{ppm} \mathrm{AFA} \\
(300 \mathrm{mg} / \mathrm{L})\end{array}$ & No AFA & $\begin{array}{c}300 \mathrm{ppm} \text { AFA } \\
(300 \mathrm{mg} / \mathrm{L})\end{array}$ \\
\hline Water & 1.1 & 1.0 & 73 & 32 \\
\hline $0.1 \mathrm{M}$ sodium hydroxide & 1.2 & 1.0 & 67 & 32 \\
\hline 1 M sodium hydroxide & 1.4 & 1.2 & 54 & 32 \\
\hline $0.1 \mathrm{M}$ sodium nitrate & 1.2 & 1.0 & 62 & 29 \\
\hline $1 \mathrm{M}$ sodium nitrate & 1.2 & 1.1 & 67 & 32 \\
\hline $2 \mathrm{wt} \%$ gibbsite & 1.2 & 0.95 & 73 & 31 \\
\hline $20 \mathrm{wt} \%$ gibbsite & Not measured & 0.97 & Not measured & 33 \\
\hline $2 \mathrm{wt} \%$ boehmite & 1.2 & 1.0 & Not measured & Not measured \\
\hline $20 \mathrm{wt} \%$ boehmite & 1.2 & 1.0 & \multicolumn{2}{c}{} \\
\hline
\end{tabular}

(a) Using a smaller particle size may affect gas retention behavior. 
expected. Surface tension was reduced by about half on addition of $300 \mathrm{ppm}$ AFA $(300 \mathrm{mg} / \mathrm{L})$. The physical properties of non-Newtonian slurries with AFA are listed in Table 7.2. Bingham yield stresses were near target values. Adding 300 ppm AFA (300 mg/L) approximately halved surface tension.

Table 7.2. Physical Properties of non-Newtonian Slurries with AFA

\begin{tabular}{||l|c|c||}
\hline \multicolumn{1}{|c|}{ Slurry } & $\begin{array}{c}\text { Bingham Yield Stress } \\
\text { (Pa) }\end{array}$ & $\begin{array}{c}\text { Surface Tension } \\
\text { (mN/m) }\end{array}$ \\
\hline Ferric oxide & 5.0 & 31 \\
\hline Ferric oxide & 9.4 & 29 \\
\hline Ferric oxide & 17 & 29 \\
\hline Ferric oxide & 35 & Not measured \\
\hline AZ simulant & 5.5 & 41 \\
\hline AZ simulant & $9^{(a)}$ & 37 \\
\hline AZ simulant & 17 & 34 \\
\hline $\begin{array}{l}\text { (a) The measured Bingham yield stress was 15 Pa. However, consistency of the gas } \\
\text { holdup results between this slurry and 9.4-Pa ferric oxide indicates the measurement to } \\
\text { be in error. Therefore, the value expected based on dilution is reported. }\end{array}$ \\
\hline \multicolumn{2}{|c|}{} \\
\hline
\end{tabular}

\subsection{Gas Holdup Test Results}

\subsubsection{Pure Component Tests}

Gas holdup increased with increasing sodium nitrate concentration, as illustrated in Figure 7.2. This result is consistent with the work of Zarraa (1999) who found that bubble rise velocity decreased with increasing sodium nitrate concentration. In addition, Kluytmans et al. (2001) theorized that the electrolytes would tend to stabilize the gas-liquid interfaces, making them less amenable to coalescence. The effect of AFA is to increase holdup and effectively make it independent of concentration. This indicates that the surface tension effects associated with AFA predominate over the effects of the electrolyte.

Figure 7.3 shows no apparent trend of gas holdup with sodium hydroxide concentration taking account of the profile for holdup in water. Surface tension decreases with increasing concentration and this would tend to reduce bubble size and increase holdup. In addition, the effect of increasing viscosity with increasing concentration would also tend to retard coalescence, reduce bubble size, and increase holdup. Therefore, one would expect oxygen holdup to increase with increasing concentration, as it did for sodium nitrate. Once again, the surface tension effect of AFA predominates over that of the electrolyte, making the holdup independent of concentration upon addition of AFA.

Oxygen holdup increased with increasing boehmite and gibbsite concentrations, as shown in Figures 7.4 and 7.5; this trend prevailed also upon addition of AFA. The results are consistent with those of Kluytmans et al. (2001), who found gas holdup increased with increasing concentration of 30- $\mu \mathrm{m}$ carbon particles. They theorized that the particles accumulated at the bubble surfaces and retarded their coalescence, leading to smaller bubbles and lower bubble rise velocity.

The effect of yield stress on oxygen holdup by ferric oxide slurries is shown in Figure 7.6. NonNewtonian slurries of ferric oxide have greater oxygen holdup than Newtonian slurries, particularly at 


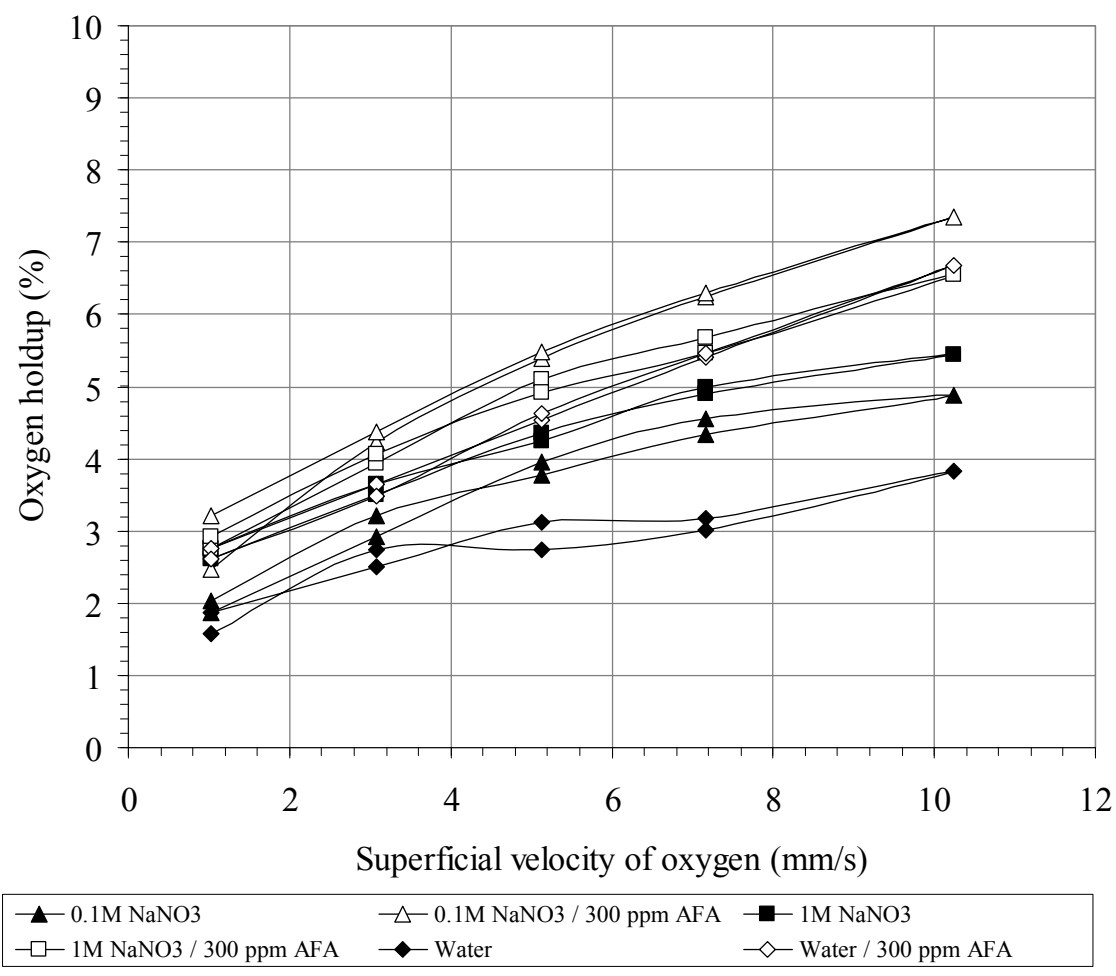

Figure 7.2. Oxygen Holdup in Sodium Nitrate Solutions

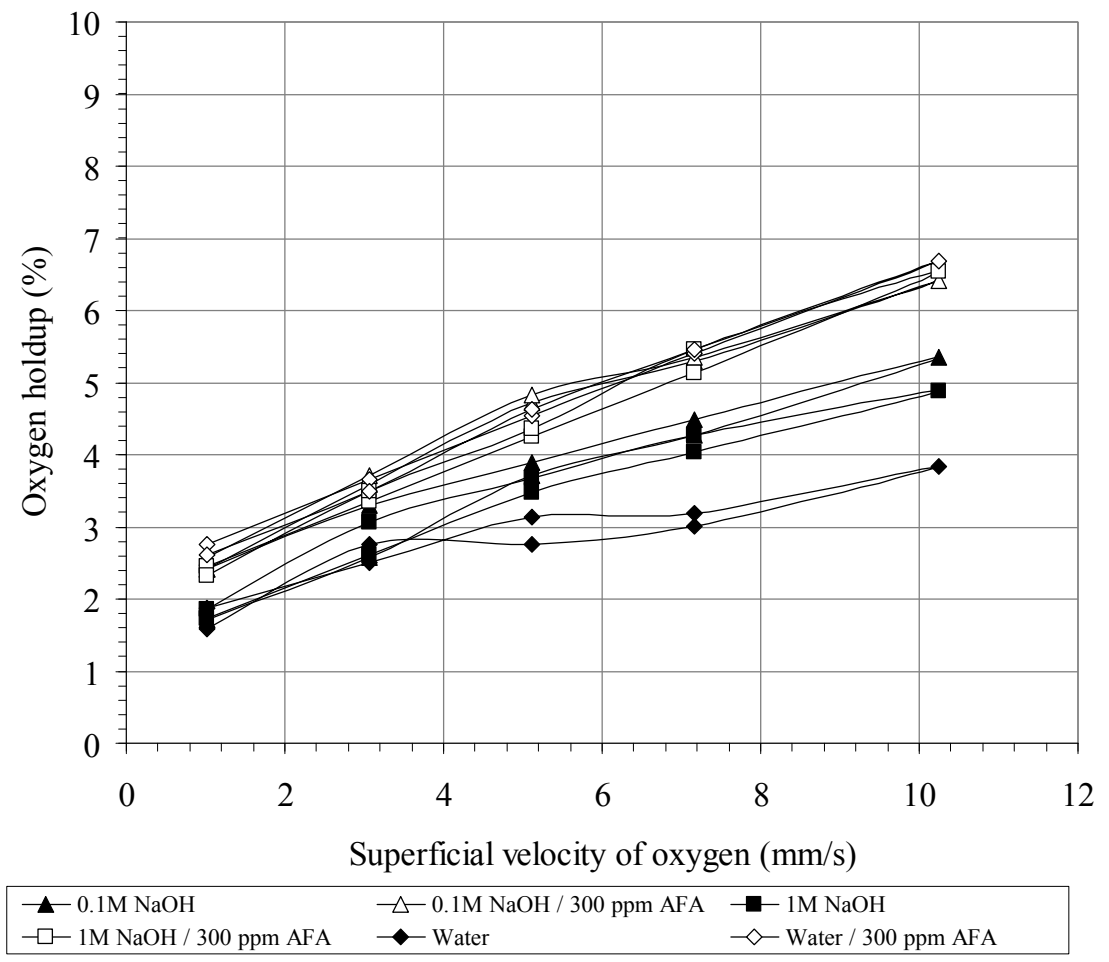

Figure 7.3. Oxygen Holdup in Sodium Hydroxide Solutions 


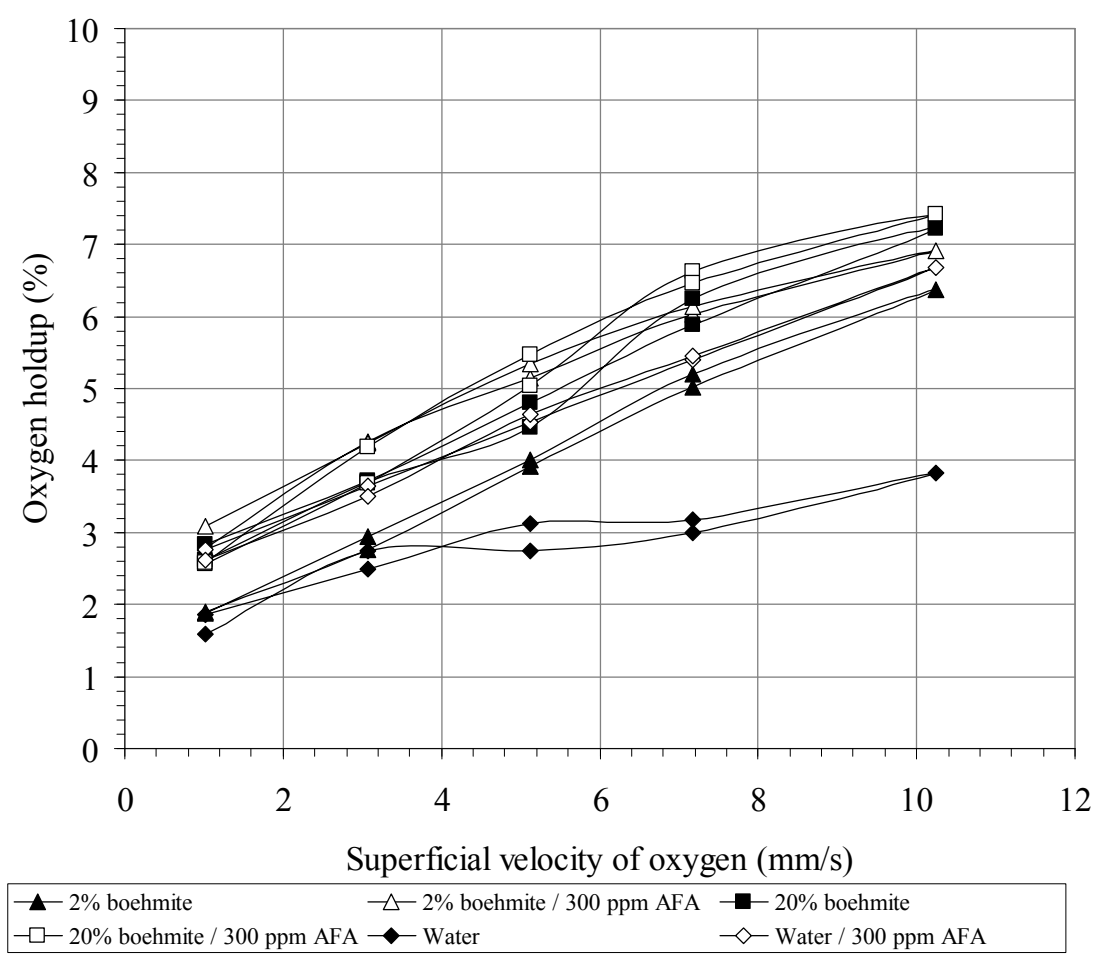

Figure 7.4. Oxygen Holdup in Boehmite Slurries

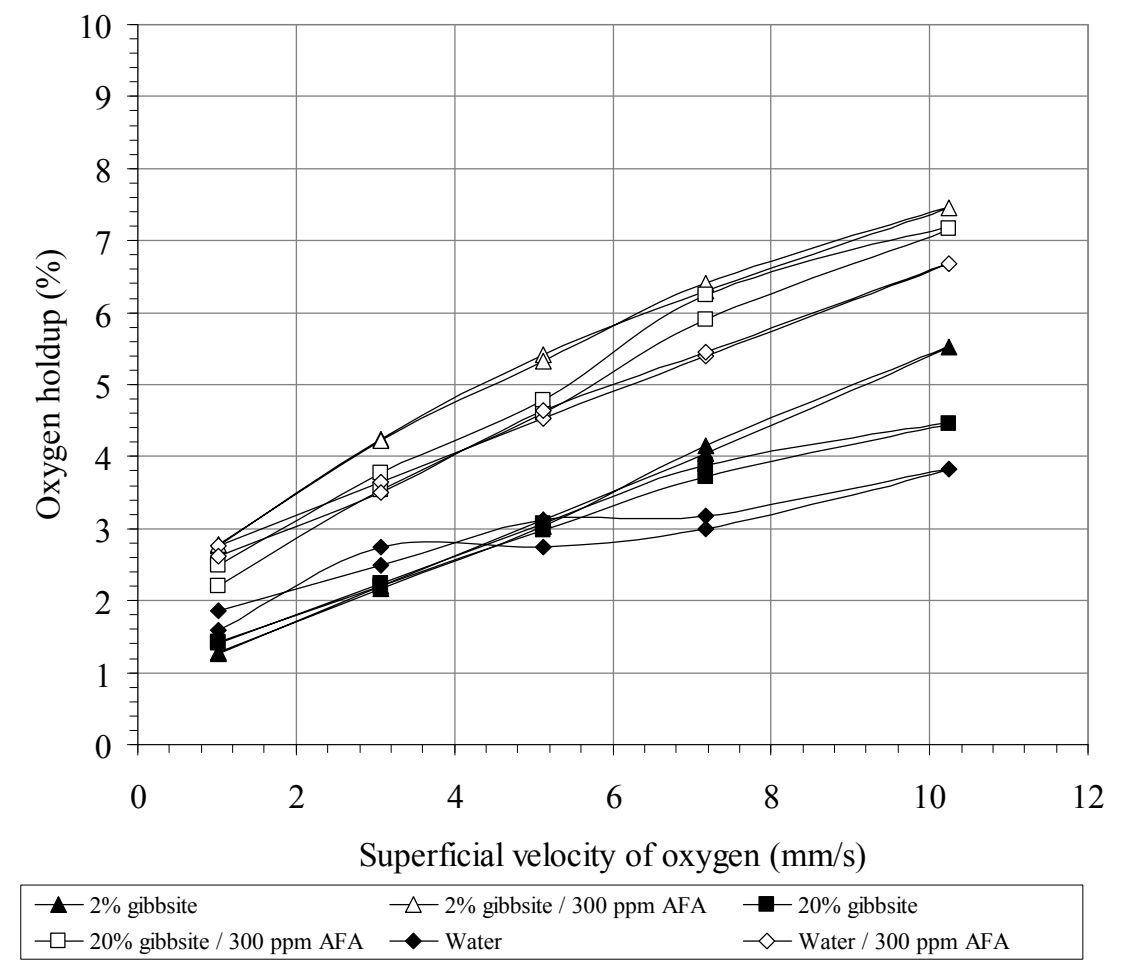

Figure 7.5. Oxygen Holdup in Gibbsite Slurries 


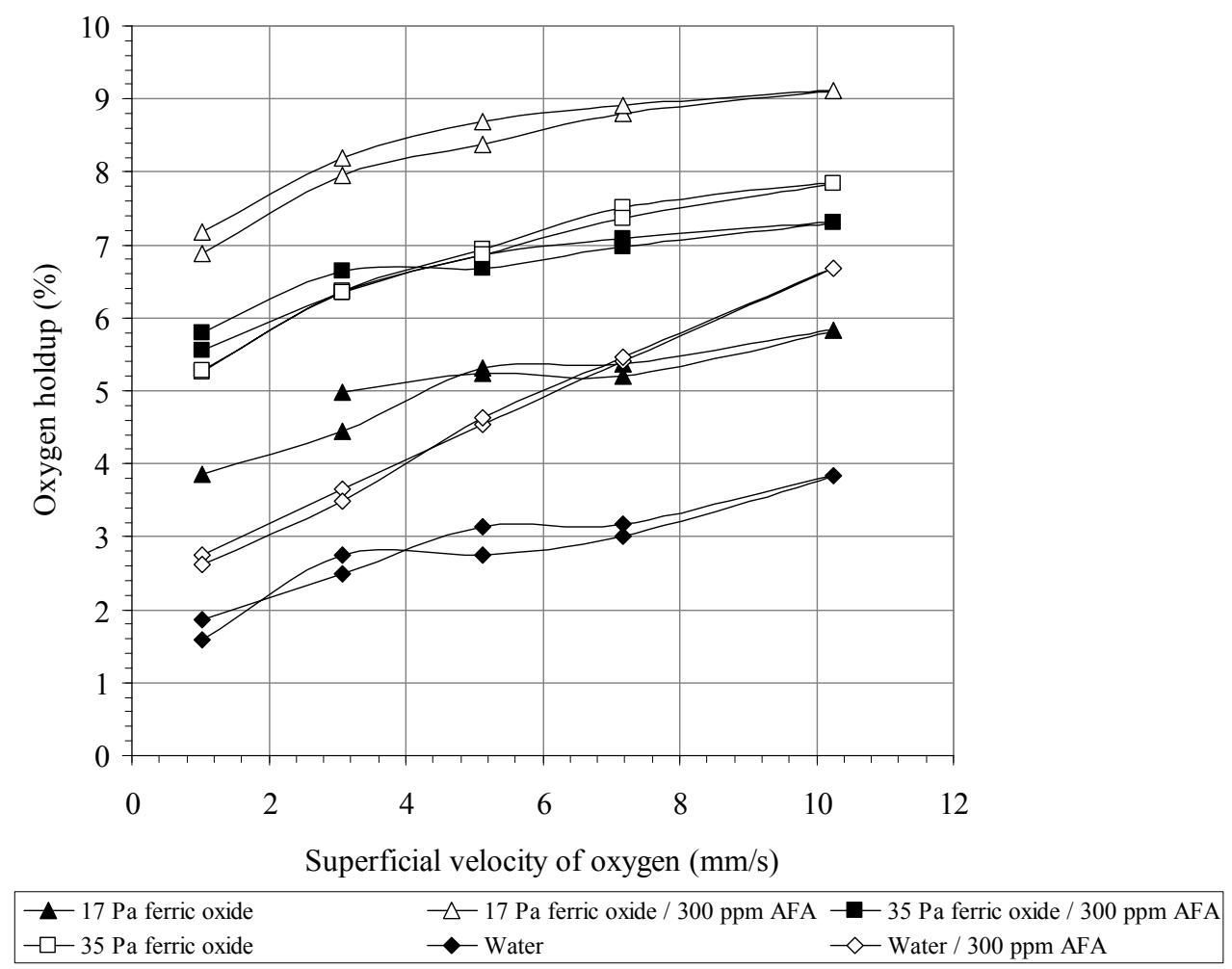

Figure 7.6. Effect of AFA on Oxygen Holdup in Ferric Oxide Slurries

lower superficial velocities of interest (oxygen holdup almost doubled). Adding AFA increases holdup, more significantly at lower yield stress, consistent with lower surface tension leading to smaller bubbles and lower rise velocities. Increasing yield stress leads to reduced oxygen holdup, as shown in Figure 7.7 for ferric oxide slurries, consistent with Russell et al. (2005). The trend prevails on adding AFA consistent with reducing surface tension, which leads to smaller bubbles and lower rise velocities.

\subsubsection{Simulated AZ-101 Slurry}

Oxygen holdup in simulated AZ slurries was investigated at three yield stresses comparable to those of the ferric oxide slurries tested. A comparison of the oxygen holdup in the ferric oxide and AZ slurry simulant is illustrated in Figure 7.8 and shows the profiles with respect to superficial velocity to be similar. This result and the fact that ferric oxide slurry provided the greatest holdup among the pure fluids tested suggest that AZ slurry simulant is the bounding waste in terms of gas holdup. 


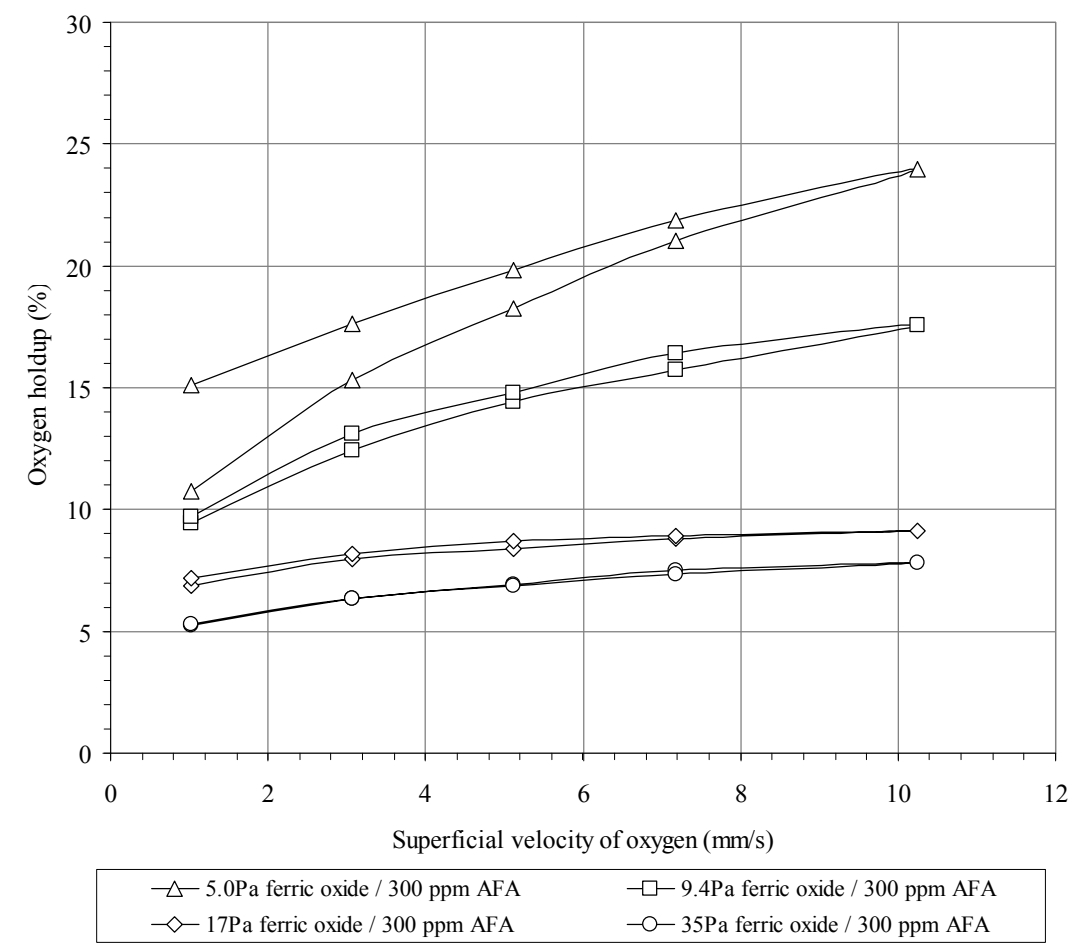

Figure 7.7. Effect of Yield Stress on Oxygen Holdup in Ferric Oxide Slurries

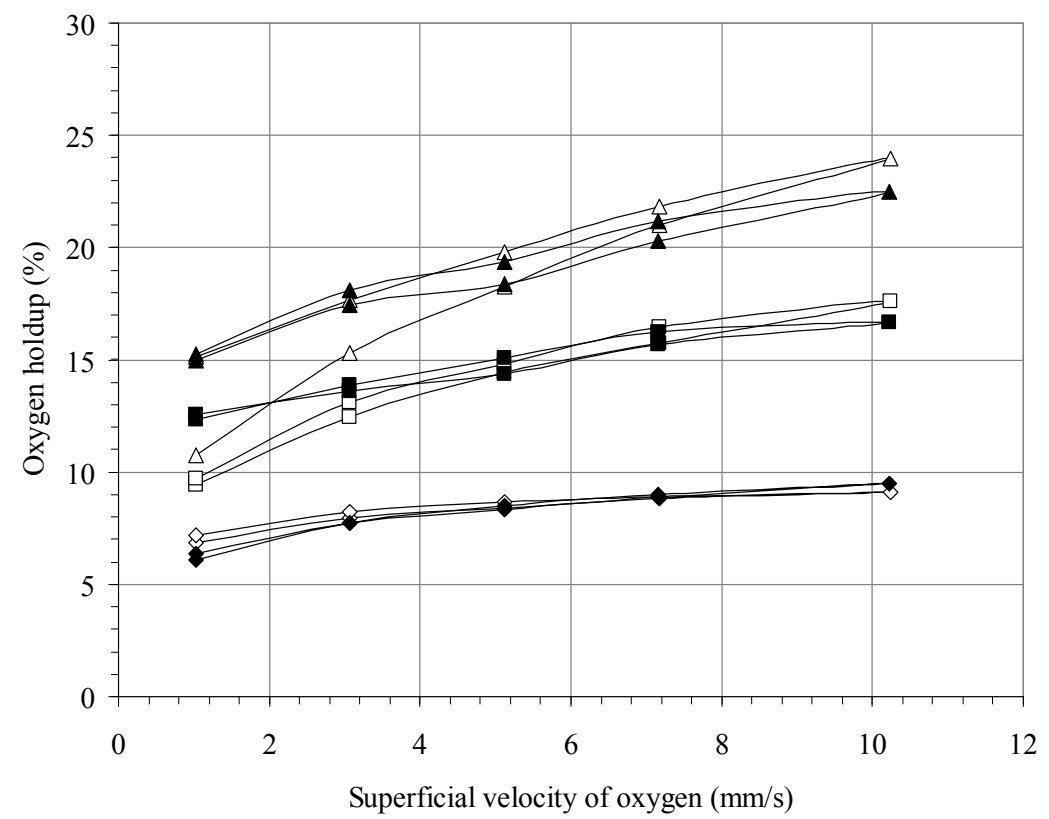

\begin{tabular}{|c|c|c|}
\hline $\begin{array}{l}\triangle-5.0 \mathrm{~Pa} \text { ferric oxide / } 300 \mathrm{ppm} \text { AFA } \\
-17 \mathrm{~Pa} \text { Simulated AZ HLW / } 300 \mathrm{ppm} \mathrm{AFA}\end{array}$ & $\square-9.4 \mathrm{~Pa}$ ferric oxide / $300 \mathrm{ppm}$ AFA & $\checkmark-17 \mathrm{~Pa}$ ferric oxide / $300 \mathrm{ppm}$ AFA \\
\hline$\multimap-17 \mathrm{~Pa}$ Simulated AZ HLW / 300 ppm AFA & $\rightarrow-9 \mathrm{~Pa}$ Simulated AZ HLW / 300 ppm AFA & $\neg-5 \mathrm{~Pa}$ Simulated AZ HLW / $300 \mathrm{ppm}$ AFA \\
\hline
\end{tabular}

Figure 7.8. Comparison of Oxygen Holdup in Ferric Oxide and Simulated AZ-101 Slurries 


\subsection{Concluding Remarks}

Table 7.3 summarizes average gas holdups relative to water for studied solutions and slurries. The surface tension effect of AFA was shown to predominate over the effect of electrolytes in solution so that their concentrations became unimportant in determining gas holdup. Gas holdup for Newtonian fluids with AFA is normalized. Gas holdup increased with increasing solids concentration in Newtonian slurries and this trend prevailed upon addition of AFA although to a lesser degree. In non-Newtonian slurries of ferric oxide, gas holdup increased with decreasing Bingham yield stress and holdup was higher than in the Newtonian fluids studied. The effect of AFA was to further increase gas holdup in ferric oxide. The magnitude of the AFA effect increased with decreasing Bingham yield stress. Gas holdup in simulated $\mathrm{AZ}$ waste slurries correlated well with that in ferric oxide at the same Bingham yield stress. Therefore, the baseline AZ waste recipe was concluded as bounding for AZ-101 tank waste because ferric oxide is the major constituent of the waste.

Table 7.3. Average Gas Holdups Relative to Water for Studied Materials

\begin{tabular}{|c|c|c|}
\hline Studied Materials & Without AFA & With AFA \\
\hline Water & 1 & 1.58 \\
\hline $0.1 \mathrm{M}$ sodium hydroxide & 1.27 & 1.57 \\
\hline $1 \mathrm{M}$ sodium hydroxide & 1.18 & 1.50 \\
\hline $0.1 \mathrm{M}$ sodium nitrate & 1.27 & 1.81 \\
\hline $1 \mathrm{M}$ sodium nitrate & 1.49 & 1.68 \\
\hline $2 \mathrm{wt} \%$ gibbsite & 1.34 & 1.78 \\
\hline $20 \mathrm{wt} \%$ gibbsite & 1.66 & 1.75 \\
\hline $2 \mathrm{wt} \%$ boehmite & 1.04 & 1.80 \\
\hline $20 \mathrm{wt} \%$ boehmite & 1.00 & 1.62 \\
\hline 5.0 Pa ferric oxide & -- & 6.78 \\
\hline 9.4 Pa ferric oxide & - & 5.10 \\
\hline 17 Pa ferric oxide & 1.89 & 3.15 \\
\hline $35 \mathrm{~Pa}$ ferric oxide & 2.52 & 2.51 \\
\hline $5.5 \mathrm{~Pa}$ simulated $\mathrm{AZ}$ & -- & 7.05 \\
\hline 9 Pa simulated AZ & -- & 5.53 \\
\hline $17 \mathrm{~Pa}$ simulated AZ & -- & 3.02 \\
\hline
\end{tabular}




\subsection{Overall Conclusions and Recommendations}

This test program was established to determine whether AFA has as strong an effect in a large-scale prototypic mixing system as it did in the small-scale non-prototypic tests. The series of gas retention and release tests was conducted using a representative AZ-101 simulant and kaolin/bentonite clay at various Bingham yield stresses. Each test consisted primarily of three sets of hydrogen peroxide injection periods followed by an undisturbed gas holdup and release test. The gas volume fractions produced by generated gas and sparge air were distinguished from one another by using data from sparger shutdown periods. A water visualization test to qualitatively describe the effects of increasing AFA concentration on sparger holdup, bubble size, and behavior, and bounding simulant tests to address the concern that simulants delivered to the WTP will come from other tanks in addition to 241-AZ-101, were also conducted. Furthermore, predictive model cases were run to predict plant-scale operations for the WTP using information from the $1 / 4$-scale testing and previous testing.

The prototypic gas retention and release tests performed in this test program indicate that gas holdup using AZ-101 simulant with AFA is higher than that in clay, but not to the extent that initially raised WTP design concerns. In addition, the trend to increasing holdup, compared to that in clay, with decreasing simulant yield stress was not seen in the prototypic system. Results for all the tests and plant predictive model are summarized in the proceeding sections.

\subsection{Effect of AFA on Gas Retention and Release}

The primary conclusions based on the results of the gas retention and release tests in the QSLS test stand are as follows:

- The prototypic gas retention and release tests performed in this test program indicate that gas holdup in AZ-101 simulant with AFA is higher than that in clay over a range of yield stresses, but not to the extent that initially raised WTP design concerns. Factor $F_{w}$ can be defined as the ratio of holdup in AZ-101 simulant with AFA to holdup in clay simulant at the same gas generation superficial velocity; the $F_{w}$ observed in these prototypic tests is 8 or less compared with a maximum factor of 20 found in previous tests in smaller nonprototypic systems.

- $F_{w}$ was found to be about the same in 13-Pa simulant as in 30-Pa simulant, whereas in smaller nonprototypic systems $F_{w}$ was observed to increase with decreasing yield stress. Concerns raised by previous studies regarding $F_{w}$ of up to 20 at the low gas generation rates of WTP operations and the potential for even higher $F_{w}$ at low yield stress were not borne out by these prototypic tests.

- The QSLS gas retention and release test results support the scaling principles applied to the lag storage and HLW feed blending vessels for predicting WTP full-scale plant operations.

- Steady-state holdup of generated gas decreases with decreasing yield stress based on the results of tests in 30-Pa and 13-Pa yield stress simulants. Sparger holdup in the 3-Pa AZ simulant with AFA was as high as 9 vol\% and made it difficult to measure the relatively small holdup from gas generation. There was no evidence that the generated gas holdup was greater in 3-Pa simulant than in 13-Pa simulant, either for clay without AFA or for AZ-101 simulant with AFA. 
- Gas holdup is not sensitive to mixing system configuration or scale within the range of PJM and sparger hybrid configurations and scales of lag storage test stands that have been used at PNNL.

- The bounding simulant tests determined the baseline AZ-101 simulant recipe to be bounding for AZ-101 tank waste in terms of gas retention.

Sparger holdup in the 3-Pa AZ simulant with AFA was higher than in the 30- and 13-Pa AZ simulant and dominated the hydrogen peroxide injection induced gas generation. The causes of this behavior were not determined, but perhaps it was the combination of the increased turbulence in the lower yield stress fluid and AFA properties increasing bubble breakup. To optimize tank capacity at the WTP, further tests designed to explain the cause of high sparger holdup could be conducted to test whether varying plant operating conditions increase or decrease sparger holdup in low yield stress AZ simulant.

The bounding tests used different concentrations of sodium nitrate, sodium hydroxide, boehmite, gibbsite, and ferric oxide with and without AFA. These pure components were selected by examining the AZ-101 waste compositions and selecting the most prevalent constituents. Higher gas retention was observed with increasing solids concentration in Newtonian slurries. This behavior continued, to a lesser degree, with AFA addition. In non-Newtonian slurries of ferric oxide, gas holdup increased with decreasing Bingham yield stress, and gas retention was greater than in the Newtonian fluids studied. Gas retention in ferric oxide was more affected by AFA addition. The magnitude of the AFA effect increased with decreasing Bingham yield stress. Gas retention in simulated AZ-101 waste slurries correlated well with that in ferric oxide for the same Bingham yield stress. Consequently, for the components tested in this bounding simulant study, the baseline recipe for AZ-101 waste bounded AZ-101 tank waste because ferric oxide is the major constituent of the waste. These tests also suggest that testing major components are sufficient for simulant characterization. However, further AZ-101 waste component testing can be conducted to confirm that the baseline $\mathrm{AZ}$ waste recipe is still bounding for AZ-101 tank waste.

Given the variety of simulant properties the full-scale WTP will see and the new or extended insight into actual waste properties that will become available, it is recommended that the waste properties be compared with the simulant properties used in the current tests to ensure bounding simulant criteria considered for WTP operations are still met.

\subsection{Effect of Simulant Type and Properties}

There was no indication that clay and AZ simulant properties evolved during testing. Clay and AZ simulant properties are summarized in Tables 5.4 (Section 5.4.2) and 5.6 (Section 5.4.3), respectively.

\subsection{Effect of Gas Composition}

Literature reviews indicate that the major gas physical property affecting bubble behavior is density, either through gas pressure or molecular weight. The sizes of bubbles formed at orifices appear to decrease with increasing gas density in both Newtonian and non-Newtonian fluids. In Newtonian fluids, bubble breakup increases with increasing gas density although there appears to be little significant difference for hydrogen and air. Gas holdup in bubble columns of non-Newtonian slurries indicate that 
bubble size decreases with increasing gas density. The effect of gas density appears more prominent in non-Newtonian fluids. There appears to be no major effect of gas density on bubble coalescence. Therefore, as gas density increases the bubble size decreases generally, although the qualitative effects are fluid-specific. Gas retention and release testing have used oxygen instead of hydrogen, and because its density is larger than hydrogen's, test results may be conservative.

\subsection{Contribution of Mass Transfer}

Mass transfer between sparge bubbles and the dissolved gas inventory is predicted to increase the retained bubble gas volume fraction and cause the retained gas to contain a substantial proportion of air gas instead of generated gas such as hydrogen. The contribution of sparge mass transfer to the gas in retained bubbles becomes more important as gas generation rates decrease. This effect has not been accounted for in past correlations, which have related gas volume fraction to gas generation alone. It would be possible to re-correlate past data in a way that takes the contribution of sparge mass transfer into account. However, there are relatively few data points to draw on and increasing the number of adjustable parameters in the model would not necessarily improve its performance.

The net effect of mass transfer was to increase predicted retained gas volume fractions in the FSLS. However, mass transfer also decreased the hydrogen concentration predicted in the vessel headspace after an instantaneous release of retained gas. The model predicted that, in the full-scale lag-storage system containing 30-Pa AZ-101 chemical simulant with AFA, mass transfer would increase the maximum retained gas fraction from $0.05 \mathrm{vol} \%$ to $3.7 \mathrm{vol} \%$ for the normal operating cycle, but that little of this increased volume would be hydrogen. The maximum headspace hydrogen concentration predicted to be produced in the case of an instantaneous release was reduced by a factor of at least three by mass transfer; the value was $2660 \mathrm{ppm} \mathrm{H}_{2}$ in the case of zero mass transfer. Similar trends were predicted for the postDBE cycle, but in this case the predicted maximum headspace concentration without mass transfer was $5500 \mathrm{ppm}$.

The trends of these results seem reasonable but it should be recognized that they depend on three basic assumptions:

- The double-counting of mass transfer effects referred to above does not lead to an underestimation of the retained hydrogen inventory;

- Mass transfer between the sparge bubbles and the dissolved gas is as rapid in the lag-storage vessel as in the SRNL bubble column; and

- The dissolved gases are in equilibrium with the gases in the retained gas bubbles, i.e., that the mass transfer for the retained gas bubbles is essentially instantaneous.

It would be beneficial to test these assumptions against existing data and information in the open literature.

A greater understanding of some of the phenomena affecting gas retention and release might be obtained by computational fluid dynamics (CFD) modeling. A sufficiently sophisticated CFD model could simulate the pulsing PJM flow, the sparger bubble streams, the flow of the non-Newtonian slurry, and the movement of the small retained-gas bubbles through the slurry. However, it would be necessary 
to supply the sizes, or more accurately the size distributions, of the sparge and retained-gas bubbles. Information on these variables is sparse. It is also unclear how CFD would represent the interactions between retained-gas bubbles that are implied by the observed power-law relation between release velocity and gas volume fraction.

Finally, in planning any future work it should be noted that the model implementation in Excel was not computationally efficient. The relatively large timesteps, $0.04 \mathrm{hr}$, used to solve the ODEs only allowed the maxima and minima of retained gas fraction and headspace hydrogen concentration to be predicted within an accuracy of $9 \%$. A more efficient implementation is needed to obtain complete convergence and increase the accuracy of predictions by using smaller timesteps. 


\subsection{References}

Akita K and F Yoshida. 1973. "Gas Holdup and Volumetric Mass Transfer Coefficient in Bubble Columns - Effects of Liquid Properties." Industrial and Engineering Chemistry Process Design and Development, 12(1):76-80.

Arm ST, AP Poloski, CW Stewart, PA Meyer, and DE Kurath. 2007. Gas Generation and Holdup in Hanford Waste Treatment Plant Process Streams Containing Anti-Foam Agent (AFA). 2007 American Nuclear Society Embedded Topical Meeting on the Safety and Technology of Nuclear Hydrogen Production, Control, and Management, Boston, Massachusetts.

Baich MA, ME Stone, TL White, TB Calloway, and JC George. 2003. Waste Treatment Plant LAW Evaporation Antifoam Performance. WSRC-TR-2003-00216, Westinghouse Savannah River Company, Savannah River Technology Center, Aiken, South Carolina.

Bamberger JA, PA Meyer, JR Bontha, CW Enderlin, DA Wilson, AP Poloski, JA Fort, ST Yokuda, HD Smith, F Nigl, M Friedrich, DE Kurath, GL Smith, JM Bates, and MA Gerber. 2005. Technical Basis for Testing Scaled Pulse Jet Mixing Systems for Non-Newtonian Slurries. PNWD-3551 (WTPRPT-113 Rev. 0), Battelle - Pacific Northwest Division, Richland, Washington.

Bontha JR, CW Stewart, DE Kurath, PA Meyer, ST Arm, CE Guzman-Leong, MS Fountain, M Friedrich, SA Hartley, LK Jagoda, CD Johnson, KS Koschik, DL Lessor, F Nigl, RL Russell, GL Smith, W Yantasee, and ST Yokuda. 2005. Technical Basis for Predicting Mixing and Flammable Gas Behavior in the Ultrafiltration Feed Process and High-Level Waste Lag Storage Vessels with NonNewtonian Slurries. WTP-RPT-132 (PNWD-3676) Rev. 0, Battelle - Pacific Northwest Division, Richland, Washington.

Chhabra RP. 1993. Bubbles, Drops, and Particles in Non-Newtonian Fluids. CRC Press, Boca Raton, Florida.

Chaudhari RV and H Hofmann. 1994. "Coalescence of Gas Bubbles in Liquids." Reviews in Chemical Engineering, 10(2):131-190.

Chen P and MP Dudukovic. 2005. "Three Dimensional Simulation of Bubble Column Flows with Bubble Coalescence and Breakup.” AIChE Journal, 51(3):696-712.

Claghorn R and P Waddell. 2006. System Description for Pulse Jet Mixers and Supplemental Mixing Systems. 24590-WTP-3YD-50-00003 Rev. B, Bechtel National Inc., Richland, Washington.

Dow Corning Corporation. 2004. "Dow Corning(R) Q2-3183A Antifoam.” Material Safety Data Sheet, Dow Corning Corporation, Midland, Michigan.

Eibling RE, RF Schumacher, and EK Hansen. 2003. "Development of Simulants to Support Mixing Tests for High Level Waste and Low Activity Waste." SRT-RPP-2003-00098, Rev. 0, Westinghouse Savannah River Company, Aiken, South Carolina. 
Fan LS and K Tsuchiya. 1990. Bubble Wake Dynamics in Liquids and Liquid-Solid Suspensions. Butterworth Heinemann, Stoneham, Massachusetts.

Godbole SP, A Schumpe, and YT Shah. 1984. "Hydrodynamics and Mass Transfer in Non-Newtonian Solutions in a Bubble Column," AIChE J 30:213-220.

Grau RA. 2005. An Investigation of the Effect of Physical and Chemical Variables on Bubble Generation and Coalescence in Laboratory Scale Flotation Cells. TKK-ME-DT-4, Doctoral dissertation, Helsinki University of Technology, Finland.

Guzman-Leong CE, CW Stewart, JM Alzheimer, LA Mahoney, ST Arm and LK Jagoda. March 2007. Test Plan for Large -Scale Testing for Effects of Anti-Foaming Agent on Gas Retention and Release. TP-RPP-WTP-476 Rev. 0. Battelle - Pacific Northwest Division, Richland, Washington.

Hikita H, S Asai, K Tanigawa, K Segawa, and M Kitao. 1980. "Gas Holdup in Bubble Columns." The Chemical Engineering Journal, Vol. 20, pp. 59-67.

Kluytmans JHJ, BGM van Wachem, BFM Kuster, and JC Schouten. 2001. "Gas Holdup in a Slurry Bubble Column: Influence of Electrolyte and Carbon Particles.” Ind. Eng. Chem. Res., Vol. 40, pp. 53265333.

Krishna R, JWA de Swart, DE Hennephof, J Ellenberger, and HCJ Hoefsloot. 1994. "Influence of Increased Gas Density on Hydrodynamics of Bubble Column Reactors." AIChE Journal, 40(1):112-119.

Kulkarni AA and JB Joshi. 2005. "Bubble Formation and Bubble Rise Velocity in Gas-Liquid Systems: A Review." Industrial and Engineering Chemistry Res., Vol. 44, pp. 5873-5931.

Laakkonen M, P Moilanen, V Alopaeus, and J Aittamaa. 2007. "Modelling Local Bubble Size Distributions in Agitated Vessels." Chemical Engineering Science, Vol. 62, pp. 721-740.

Larachi F, G Wild, A Laurent, and N Midoux. 1994. "Influence of Gas Density on the Hydrodynamics of Cocurrent Gas-Liquid Upflow Fixed Bed Reactors." Industrial and Engineering Chemistry Res., Vol. 33, pp. 519-525.

Lin TJ and GM Lin. 2003. "The Mechanisms of Bubble Coalescence in a Non-Newtonian Fluid." The Canadian Journal of Chemical Engineering, Vol. 81, pp. 476-482.

Luo H and HF Svendsen. 1996. "Theoretical Model for Drop and Bubble Breakup in Turbulent Dispersions.” AIChE Journal, 42(5):1225-1233.

Macchi A, H Bi, JR Grace, CA McKnight, and L Hackman. 2003. "Effect of Gas Density on the Hydrodynamics of Bubble Columns and Three-Phase Fluidized Beds." The Canadian Journal of Chemical Engineering, Vol. 21, pp. 846-852. 
Meyer PA, DE Kurath, and CW Stewart. 2005. Overview of the Pulse Jet Mixer Non-Newtonian Scaled Test Program. PNWD-3677 (WTP-RPT-127 Rev. 0), Battelle - Pacific Northwest Division, Richland, Washington.

Molina Grima E, Y Chisti, and M Moo-Young. 1997. "Characterization of shear rates in airlift bioreactors for animal cell culture." J. Biotechnol., 54:195-210.

Norton JD and LR Pederson. 1995. Solubilities of Gases in Simulated Tank 241-SY-101 Wastes. PNL-10785, Pacific Northwest National Laboratory, Richland, Washington.

Poloski AP. 2004. Technical Basis for HLW Vitrification Stream Physical and Rheological Property Bounding Conditions. WTP-RPT-100 Rev. 0, Battelle - Pacific Northwest Division, Richland, Washington.

Poloski AP, PA Meyer, LK Jagoda, and PR Hrma. 2004. Non-Newtonian Slurry Simulant Development and Selection for Pulse Jet Mixer Testing. PNNL-3495 (WTP-RPT-111 Rev 0), Battelle - Pacific Northwest Division, Richland, Washington.

Poloski AP, ST Arm, JA Bamberger, B Barnett, R Brown, BJ Cook, CW Enderlin, MS Fountain, M Friedrich, BG Fritz, RP Mueller, F Nigl, Y Onishi, LA Schienbein, LA Snow, S Tzemos, M White, and JA Vucelick. 2005. Technical Basis for Scaling of Air Sparging Systems for Mixing in NonNewtonian Slurries. PNNL-3541 (WTP-RPT-129 Rev. 0), Battelle - Pacific Northwest Division, Richland, Washington.

Rassat SD, LM Bagaasen, LA Mahoney, RL Russell, DD Caldwell, and DP Mendoza. 2003. Physical and Liquid Chemical Simulant Formulations for Transuranic Wastes in Hanford Single-Shell Tanks. PNNL-14333, Pacific Northwest National Laboratory, Richland Washington.

Russell RL, SD Rassat, ST Arm, MS Fountain, BK Hatchell, CW Stewart, CD Johnson, PA Meyer, and CE Guzman-Leong. 2005. Final Report: Gas Retention and Release in Hybrid Pulse Jet-Mixed Tanks Containing non-Newtonian Waste Simulants. PNWD-3552 (WTP-RPT-114 Rev. 1), Battelle - Pacific Northwest Division, Richland, Washington.

Smith GL and K Prindiville. May 2002. Guidelines for Performing Chemical, Physical, and Rheological Properties Measurements. 24590-WTP-GPG-RTD-001 Rev. 0, BNI, Richland, Washington.

Smith JM. 2006. "Large Multiphase Reactors: Some Open Questions.” Chem. Eng. Res. and Des., 84(A4):265-271.

Stewart CW. 1995. "Bubble Interaction in Low-viscosity Liquids." International J. of Multiphase Flow 21:1037-1046.

Stewart CW, ME Brewster, PA Gauglitz, LA Mahoney, PA Meyer, KP Recknagle, and HC Reid. 1996. Gas Retention and Release Behavior in Hanford Single-Shell Waste Tanks. PNNL-11391, Pacific Northwest National Laboratory, Richland, Washington. 
Stewart CW, PA Meyer, MS Fountain, CE Guzman-Leong, SA Hartley-McBride, JL Huckaby and BE Wells. 2006. Effect of Anti-Foam Agent on Gas Retention and Release Behavior in Simulated High Level Waste. WTP-RPT-147 (PNWD-3786), Battelle-Pacific Northwest Division, Richland, Washington.

Tse KL, T Martin, CM McFarlane, AW Nienow. 2003. "Small Bubble Formation via a Coalescence Dependent Breakup Mechanism.” Chemical Engineering Science, 58, 275-286.

Wilkinson PM and LL Dierendonck. 1990. "Pressure and Gas Density Effects on Bubble Breakup and Gas Holdup in Bubble Columns.” Chemical Engineering Science, 45(8):2309-2315.

Wilkinson PM, A van Schayk, and JPM Spronken. 1993. "The Influence of Gas Density and Liquid Properties on Bubble Breakup." Chemical Engineering Science, 48(7):1213-1226.

Yang GQ, B Du, and LS Fan. 2007. "Bubble Formation and Dynamics in Gas-Liquid-Solid Fluidization - A Review." Chemical Engineering Science, Vol. 62, pp. 2-27.

Zarraa MA. 1999. "Effect of Electrolytes on the Hydrodynamic Behaviour in a Batch Packed Bubble Column." Che. Biochem. Eng., 13(2):47-52. 


\section{Appendix A}

Tank Volume and PJM/Tank Fluid Surface Areas as a Function of the Height of the Liquid Surface in the Tank 


\section{Appendix A - Tank Volume and PJM/Tank Fluid Surface Areas as a Function of the Height of the Liquid Surface}

\section{A.1 Introduction}

This appendix describes a calculation (Johnson 2007) that was completed to provide results for two purposes related to the volume within the 1/4- (quarter-) scale lag storage (QSLS) tank. See Appendix A of Russell et al. (2005) for background information on level/height correlations for pulse jet mixer (PJM) systems used in testing for the WTP project.

The first objective of this calculation was to develop a correlation for the total fluid volume in the system (QSLS tank and PJMs) based on the fluid level in the tank. This correlation can be used to assess the change in total tank volume over time as gas builds up or releases from the simulant fluid. The test equipment configuration for the QSLS system differed from past applications (e.g., Russell et al. 2005, Appendix A). In the past a vacuum generator was used to fill the PJMs, resulting in simulant rising rather high up above the PJMs into the vacuum lines. With the QSLS tank, PJMs were operated using jet pump pairs (JPPs), and the intended operation of the system was to fill the PJMs with simulant fluid to a level at equilibrium with the fluid level in the tank. Under this presumption of equilibrium fluid heights within the PJMs and the QSLS tank (based on a more controllable vacuum achieved with the JPPs), a correlation can be determined based on data collected during a water fill test (with piping vented to atmosphere) without requiring PJM geometry information. However, the correlation must account for the status of the air sparger lines, hydrogen peroxide feed lines, and sample collection lines (filled with air, hydrogen peroxide, and "old" simulant, respectively) during actual QSLS test operations with simulant fluid.

The second objective of this calculation was to develop information/correlations pertaining to the area of the fluid surface in the tank and in the PJMs for use in other calculation macros related to system control and/or velocity at the PJM nozzle. Towards this second objective, an equation or correlation was desired to determine the ratio of fluid surface area inside all PJMs (at a specified height on the affixed tape scale and excluding PJM internals such as the level sensor rod), to the area of the PJM nozzles. A second, related result was the ratio of fluid surface area in the tank (at a specified height on the affixed tape scale and excluding the fluid surface area inside the PJMs) to the area of the PJM nozzles.

\section{A.2 Configuration and Test Data}

The calculation was completed based on the system configuration shown in Figures A.1 and A.2. Figure A.3 shows simple 2D profiles of relevant piping, measured lengths, and averaged lengths. Figure A.3 also shows information about PJM nozzles and the position of the affixed tape used for referencing all height measurements. Dimensions in Figures A.1 to A.3 were measured and recorded in laboratory record book entries.

A water fill test (Guzman-Leong and Zhong 2007) was conducted with all piping (air spargers, hydrogen peroxide feed lines, sample collection lines) vented to atmosphere. The data from the water fill test and associated laboratory record book notes are shown in Figure A.4, which also shows calculated values for the weight of the water added to the QSLS tank during the test, the equivalent water volume, the average water temperature, and the interpolated water density at that average temperature. 


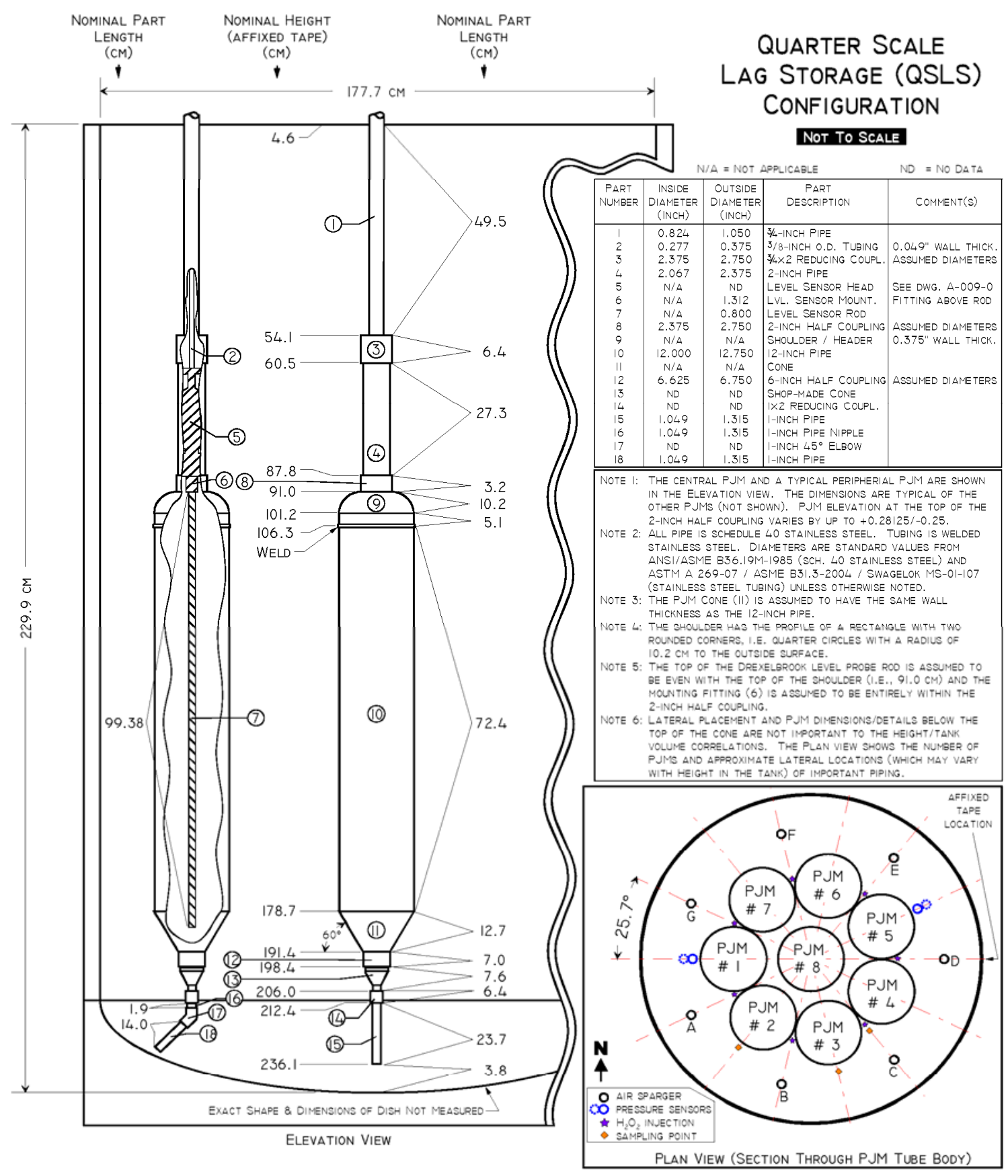

DIMENSIONS WEAE TAKEN DIAECTLY OR DERIVED FROM AS-BULT MEASUREMENTS FECORDED BY JIM ALZHEINER (LRB M59652, PP, 10-20) ANO SIVA PLLI (LRB N59652, PP, 21-2L).

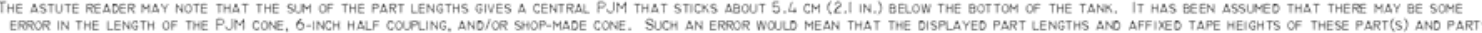
BELOW AFE INCOREECT. HOWEVER, SUCH AN ERPOR DOES NOT IMPACT THE LEVE,/VOLLME COFRELATIONS, WHICH ONLY DEAL WITH PARTS ABOVE THE TOP OF THE PJMM CONE. IF THIS ASSUMPTION WERE INCOFEECT ANO

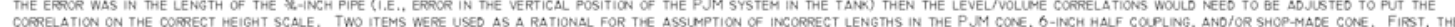
CORELATION ON THE COFRECT REIGHT SCALE. TWO ITEMS WERE USED AS A RATHONAL FOR THE ASSLMPTION OF INCORRECT LENGTHS IN THE PJM CONE, O-INCH HALF COUPLING, ANDTOR SHOP-MADE CONE. FIRST, THE MEASLRENENTS. SECONOLY. HEIGHT MEASLREMENTS FROM THE WATER FILL TEST (TI-RPP-WTP-LB2. REV. 0, 5/9/2007) AT VARIOUS LOCATIONS ABOVE THE PJM CONE AREA SEEM TO CONFIRM THIS ASSIMPTION, FOQ EXAMPLE, THE WELD QETWEEN THE PJM TUEE BODY AND THE PJM HEADER/SHOULOER WAS CALOULATED TO BE AT A HEIGHT Of 106.3 CM ANO THE WATER FILL TEST REPORTS A VALLE OF 107.2 CM FOR APPFOXIMATELY

Figure A.1. Schematic of QSLS Configuration with Relevant Dimensions 


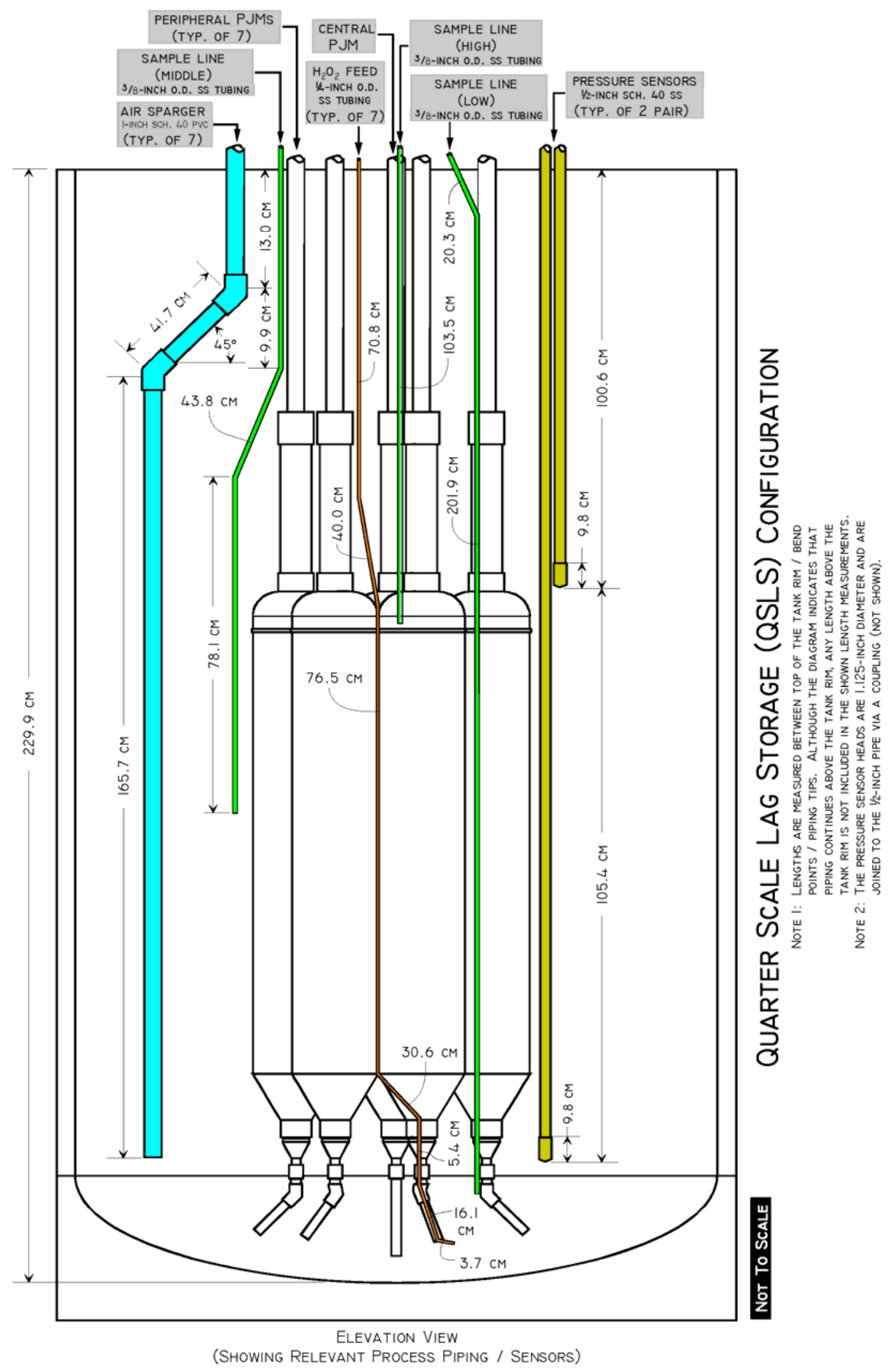

Figure A.2. Schematic of QSLS Configuration with Relevant Dimensions for Ancillary Piping 


\section{Relation of Affixed Tape to Top of Tank Rim}

Measured by Siva Pilli (see LRB \#59652, pp. 21-24)

The $10 \mathrm{~cm}$ mark on the affixed tape is 2.125 inches below the top of the tank rim.

Tank rim is at: $\quad 4.6 \quad \mathrm{~cm}$ on the affixed tape.

\section{Calculation of Average Pipe/Tube Lengths}

Lengths are for each straight section of pipe/tubing, measured between top of the tank rim/bends/end of pipe/tubing.

Lengths were measured by Siva Pilli (see LRB \#59652, pp. 21-24).

\begin{tabular}{cccc} 
& \multicolumn{3}{c}{ Pipe Lengths (in.) } \\
\cline { 2 - 4 } Air Sparger & L1 & L2 & L3 \\
\hline A & 5.125 & 14.000 & 66.250 \\
B & 5.125 & 15.875 & 64.375 \\
C & 5.125 & 16.250 & 65.000 \\
D & 5.125 & 16.000 & 65.500 \\
E & 5.125 & 13.500 & 65.375 \\
F & 5.125 & 23.000 & 65.375 \\
G & 5.125 & 16.375 & 64.750 \\
\hline Avgerage (cm) & 13.0 & 41.7 & 165.7 \\
Std. Dev. (cm) & 0.0 & 7.9 & 1.5 \\
Height at bottom (cm) & 17.6 & 47.1 & 212.8
\end{tabular}

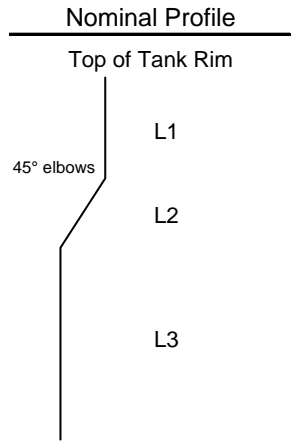

\begin{tabular}{|c|c|c|c|c|c|c|c|c|}
\hline & & \multirow{4}{*}{$\frac{\text { Nominal Profile }}{\text { Top of Tank Rim }}$} \\
\hline & & & & & & & & \\
\hline & \multicolumn{7}{|c|}{ Tubing Lengths (in.) } & \\
\hline $\mathrm{H}_{2} \mathrm{O}_{2}$ Feed Line & L1 & L2 & L3 & L4 & L5 & L6 & L7 & \\
\hline 1 & 2.000 & 6.000 & 2.000 & 12.250 & 30.000 & 15.500 & 27.500 & \\
\hline 2 & 1.000 & 6.500 & 2.000 & 12.375 & 30.000 & 16.500 & 27.500 & L6 \\
\hline 3 & 1.750 & 6.000 & 2.000 & 12.750 & 30.000 & 15.500 & 28.000 & \\
\hline 4 & 1.125 & 6.500 & 2.000 & 11.000 & 30.000 & 16.250 & 28.250 & L5 \\
\hline 5 & 1.875 & 6.000 & 2.000 & 12.250 & 29.125 & 17.375 & 28.375 & \\
\hline 6 & 1.500 & 6.375 & 2.250 & 11.750 & 30.000 & 14.750 & 28.375 & \\
\hline 7 & 1.000 & 7.000 & 2.500 & 12.000 & 31.750 & 14.250 & 27.250 & L4 \\
\hline Avgerage $(\mathrm{cm})$ & 3.7 & 16.1 & 5.4 & 30.6 & 76.5 & 40.0 & 70.8 & L3 \\
\hline Std. Dev. (cm) & 1.1 & 0.9 & 0.5 & 1.4 & 2.0 & 2.7 & 1.2 & L2 \\
\hline $\begin{array}{l}\text { Estimated Height at } \\
\text { Bottom of Tubing Section }(\mathrm{cm})\end{array}$ & $\begin{array}{c}\text { Not } \\
\text { Determined }\end{array}$ & $\begin{array}{c}\text { Not } \\
\text { Determined }\end{array}$ & $\begin{array}{c}\text { Not } \\
\text { Determined }\end{array}$ & $\begin{array}{c}\text { Not } \\
\text { Determined }\end{array}$ & 178.7 & 101.2 & 72.6 & L1 \\
\hline
\end{tabular}

\section{Sampling Tube Lengths}

Nominal Profiles

Lengths are for each straight section of pipe/tubing, measured between top of the tank rim/bends/end of pipe/tubing.

Lengths were measured by Siva Pilli (see LRB \#59652, pp. 21-24).

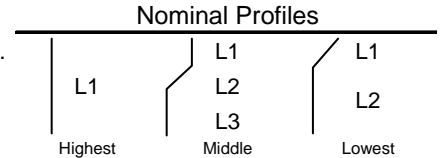

\begin{tabular}{l|ccc|cccccc|} 
& \multicolumn{4}{|c|}{ Tubing Lengths (in.) } & \multicolumn{3}{c|}{ Tubing Lengths (cm) } & \multicolumn{3}{|c|}{$\begin{array}{c}\text { Tstimated Height at Bottom of } \\
\text { Tubing Section (cm) }\end{array}$} \\
\cline { 2 - 10 } & L1 & L2 & L3 & L1 & L2 & L3 & L1 & L2 & L3 \\
\hline Highest Sampling Tube & 40.750 & Not Applicable & Not Applicable & 103.5 & Not Applicable & Not Applicable & 108.1 & Not Applicable & Not Applicable \\
Mid Height Sampling Tube & 9.000 & 17.250 & 30.750 & 22.9 & 43.8 & 78.1 & 27.5 & 58.5 & 136.6 \\
Lowest Sampling Tube & 8.000 & 79.500 & Not Applicable & 20.3 & 201.9 & Not Applicable & 19.0 & 220.9 & Not Applicable
\end{tabular}

\section{PJM Nozzle Diameter}

Jim Alzheimer noted that the nozzles are 1-inch schedule 40 stainless steel (see LRB \#59652, pp. 10-20). The inside diameter (i.d.) nozzles was obtained from ANSI/ASME B36.19M-1985 (Stainless Steel Pipe, American Society of Mechanical Engineers, New York, New York. 1985.)

PJM Nozzle inside diameter: 1.049 in. $=2.66 \mathrm{~cm}$

Figure A.3. QSLS Dimensions for Ancillary Piping, Affixed Tape Position, and Nozzle Diameter 
QSLS - MANUAlly ReCORDEd Height/WATER MASS DatA (LRB \# 59652, PAGes 5-9; TI-RPP-WTP-482, Rev. 0) AND AsSOCIATED CALCULATIONS

Measurements to define the relationship between height of the Tank Fluid Surface and the Tank Volume for the Quarter Scale Lag Storage Tank with a $7+1$ PJM configuration (PJMs and all other piping vented) Data Collected 2007-May-09

\begin{tabular}{|c|c|c|c|c|c|c|c|c|c|c|c|c|c|c|c|}
\hline \multirow{3}{*}{ Time } & \multirow{3}{*}{ Measurement/Condition } & \multirow{2}{*}{\multicolumn{2}{|c|}{$\begin{array}{l}\text { Initial Scale Weight } \\
\text { (lb) }\end{array}$}} & & & & & \multirow{2}{*}{\multicolumn{2}{|c|}{$\begin{array}{c}\text { Water Temperature } \\
\left({ }^{\circ} \mathrm{C}\right)\end{array}$}} & \multirow{3}{*}{ 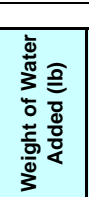 } & \multicolumn{3}{|c|}{ Calculated Values } & \multirow{3}{*}{$\begin{array}{l}\text { Observerl } \\
\text { Recorder }\end{array}$} & \multirow{3}{*}{ Comment } \\
\hline & & & & \multicolumn{2}{|c|}{$\begin{array}{l}\text { Final Scale Weight } \\
\text { (lb) }\end{array}$} & \multicolumn{2}{|c|}{$\begin{array}{l}\text { Tank Level on } \\
\text { Affixed Tape } \\
\text { (cm) }\end{array}$} & & & & 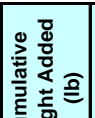 & 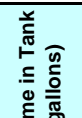 & 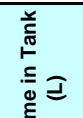 & & \\
\hline & & \begin{tabular}{|l|} 
Reading 1 \\
\end{tabular} & \begin{tabular}{|l|} 
Reading 2 \\
\end{tabular} & Reading 1 & Reading 2 & Reading 1 & Reading 2 & \begin{tabular}{|l|} 
Reading 1 \\
\end{tabular} & Reading 2 & & & & & & \\
\hline 09:25 & Addition \#1, Supply Tank Fill \#1 & 2420.0 & 2420.0 & 1269.0 & 1269.0 & 201.10 & 201.20 & 20.8 & 20.8 & 1151.0 & 1151 & 138.8 & 525.2 & $\begin{array}{l}\text { BE Wells I } \\
\text { ST Yokuda }\end{array}$ & $\begin{array}{l}\text { Point A. Read at top of the meniscus; all other levels were } \\
\text { read at the fluid surface. This point is 1mm above top of } \\
\text { tank dish. Some water was already in container from work on } \\
5 \text { t7/2007. On } 57 / 2007 \text {, the empty container, pump, and } \\
\text { transfer hose were weighted as } 216 \text { lb. }\end{array}$ \\
\hline 09:41 & Addition \#2, Supply Tank Fill \#2 & 2414.0 & 2414.0 & 999.0 & 999.0 & 174.60 & 174.60 & 19.3 & 19.3 & 1415.0 & 2566 & 309.1 & 1170.1 & $\begin{array}{l}\text { BE Wells I } \\
\text { ST Yokuda }\end{array}$ & Point $B-$ near top of PJM cones \\
\hline 10:18 & Addition \#3, Supply Tank Fill \#3 & 2406.0 & 2406.0 & 379.0 & 379.0 & 134.70 & 134.70 & 17.3 & 17.3 & 2027.0 & 4593 & 552.7 & 2092.1 & $\begin{array}{l}\text { BE Wells } 1 \\
\text { ST Yokuda }\end{array}$ & idle of PJM body \\
\hline 10:48 & Addition \#4, Supply Tank Fill \#4 & 2437.0 & 2437.0 & 1044.0 & 1044.0 & 107.20 & 107.20 & 16.4 & 16.4 & 1393.0 & 5986 & 719.9 & 2725.1 & $\begin{array}{l}\text { BE Wells I } \\
\text { ST Yokuda }\end{array}$ & Point $\mathrm{C}$ - near weld between $\mathrm{PJ} \mathrm{M}$ body a \\
\hline 11:13 & Addition \#5, Supply Tank Fill \#5 & 2438.0 & 2438.0 & 1453.0 & 1453.0 & 88.30 & 3.25 & 6.0 & 16.0 & 985.0 & 6971 & 838.3 & 3173.3 & $\begin{array}{l}\text { BE Wells I } \\
\text { ST Yokuda }\end{array}$ & Point D-near top PJM header (c \\
\hline 11:31 & Addition \#6, Supply Tank Fill \#6 & 2421.0 & 2421.0 & 2318.0 & 2318.0 & 86.40 & 86.40 & 16.1 & 16.1 & 103.0 & 7074 & 850.7 & 3220.3 & $\begin{array}{l}\text { BE Wells I- } \\
\text { ST Yokuda }\end{array}$ & Point $E-$ near top of 2 zinch half coupling \\
\hline 11:49 & Addition \#7 & 2318.0 & 2318.0 & 930.0 & 930.0 & 60.60 & 60.65 & 15.8 & 15.8 & 1388.0 & 8462 & 1017.2 & \begin{tabular}{l}
3850.7 \\
\hdashline-1
\end{tabular} & $\begin{array}{l}\text { BE Wells } 1 \\
\text { ST Yokuda } \\
\end{array}$ & point $F$ - near top of 2 zinch $p$ \\
\hline 13:01 & Addition \#8, Supply Tank Fill \#7 & 2455.0 & 2455.0 & 2291.0 & 2291.0 & 57.60 & 57.60 & 16.1 & 16.1 & 164.0 & 8626 & 1037.4 & 3926.8 & $\begin{array}{l}\text { BE Wells } 1 \\
\text { ST Yokuda }\end{array}$ & $\begin{array}{l}\text { counling } \\
\text { coar the middle of the } 34 \text {-inch } \times 2 \text {-inch reducing }\end{array}$ \\
\hline 13:17 & Addition \#9 & 2291.0 & 2291.0 & 1830.0 & 1830.0 & 49.10 & 9.05 & 16.0 & 16.0 & 61.0 & 9087 & 1092.8 & 4136.6 & $\begin{array}{l}\text { BE Wells I } \\
\text { ST Yokuda }\end{array}$ & 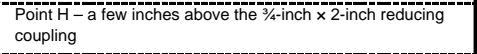 \\
\hline 13:48 & Addition \#10 & 1830.0 & 1830.0 & 505.0 & 505.0 & 24.60 & 24.60 & 16.0 & 16.0 & 1325.0 & 10412 & 1252.1 & 4739.8 & $\begin{array}{l}\text { BE Wells } 1 \\
\text { ST Yokuda }\end{array}$ & $\begin{array}{l}\text { Point } \mathrm{I} \text {-about } 20 \mathrm{~cm} \text { below top of tank rim and mid way } \\
\text { between the angled portion of the air sparger tubes }\end{array}$ \\
\hline
\end{tabular}

\section{Notes on Data:}

Started adding water to the container at 8:44 AM.

Initial and Final Weights include the water, container, pump, and transfer hose, but not the pump secondary containment

Tank volumes are calculated from the total water mass based on pure water density at the average measured temperature. Measurement equipment (LRB \#59652, page 5)

Measuring Tape: Dritz, Model 840,3.05 m, non-stretch reinforced fiberglass, located nominally on East side of the

tank, the $10 \mathrm{~cm}$ mark was designated as the "reference" point

Themometer: Fluke 5211, Calibration \# 19018, Calibration Expiration $=3 / 12 / 2008$

Thermocouple: Type $\mathrm{J}$

Scale: Toledo, Model 8140, Calibration \# PNL-66-01-004, Calibration Expiration= 4/3/2008

\begin{tabular}{|c|c|c|c|c|}
\hline $\begin{array}{l}\text { Temperature } \\
\left({ }^{\circ} \mathrm{C}\right)\end{array}$ & $\begin{array}{c}\text { Density * } \\
\text { (g/mL) }\end{array}$ & Time & $\begin{array}{l}\text { Average of } \\
\text { Measured } \\
\text { Temp. }\left({ }^{\circ} \mathrm{C}\right)\end{array}$ & $\begin{array}{l}\text { Density at } \\
\text { Avg.Temp. } \\
\text { (g/mL) }\end{array}$ \\
\hline 15 & 0.999099 & $09: 25$ & 20.8 & 0.994006 \\
\hline 16 & 0.998943 & 09:41 & 19.3 & 0.994726 \\
\hline 17 & 0.998775 & $10: 18$ & 17.3 & 0.995841 \\
\hline 18 & 0.998595 & $10: 48$ & 16.4 & 0.996356 \\
\hline 19 & 0.998405 & $11: 13$ & 16.0 & 0.996423 \\
\hline 20 & 0.998204 & 11:31 & 16.1 & 0.996406 \\
\hline 21 & 0.997992 & 11:49 & 15.8 & 0.996790 \\
\hline \multicolumn{2}{|c|}{$\begin{array}{l}\text { * From Perry, R.H., and D.W. Green. 1997. Perry's } \\
\text { Chemical Engineers' Handbook, 7th Edition. McGraw- } \\
\text { Hill, New York, NY. }\end{array}$} & $\begin{array}{l}13: 01 \\
13: 17 \\
13: 48\end{array}$ & $\begin{array}{l}16.1 \\
16.0 \\
16.0\end{array}$ & $\begin{array}{l}0.996406 \\
0.996423 \\
0.996423\end{array}$ \\
\hline
\end{tabular}

Figure A.4. Data for the May 9, 2007 QSLS Tank Water Fill Test 


\section{A.3 Calculations}

\section{A.3.1 Total Tank Fluid Volume as a Function of Fluid Level in the Tank}

The level/volume correlation was calculated in two steps. In the initial step, linear regression was used with the data from the water fill test (Figure A.4) to determine the slope and intercept of the best-fit line over several regions of interest. The intent of having a correlation was to provide a general equation that was applicable to a wide range of fluid levels (versus many equations describing small regions). However, in the interest of providing correlations that give better accuracy yet still cover a significant height range, the total height range was broken into three regions based on the heights of tank and PJM components. The curve fit coefficients, $\mathrm{R}^{2}$ values, and percent error between the correlation and the measured volumes are shown in Figure A.5 for the water fill test data (with all piping vented to atmosphere).

The second step involved correcting the measured volumes from the water fill test to account for the status of the of the air sparger lines, hydrogen peroxide feed lines, and sample collection lines during actual QSLS test operations with simulant fluid. All of these ancillary process lines are filled (with air, hydrogen peroxide, and "old" simulant, respectively) during simulant test operations, thus the volume within the piping must be subtracted from the measured water fill test volume. Figure A.6 shows the volume within the ancillary piping as a function of height (based on dimensions shown in Figures A.1 to A.3), the corrected water fill test volumes, the linear regression coefficients for these adjusted data, and the percent error between the correlation and the adjusted volumes.

\section{A.3.2 Areas and Area Ratios}

The PJM geometry (dimensions of components, position within the QSLS tank) is specified in Figures A.1 and A.7. Calculation results shown in Figure A.7 also show volumes within the PJM for the noted height range as well as volumes displaced by internal PJM components (e.g., level sensor rod). This geometry/position information was used to calculate the cross sectional area of a horizontal slice through a PJM, representing the surface area of the fluid within the PJMs. Most PJM components of interest are cylindrical in nature and the cross sectional area is readily calculated. The PJM shoulder (rounded header at the top end of the 12-inch PJM tube) is slightly more complex with a cross sectional area that changes with height. As discussed in Russell et al. (2005) (see Figure A.4 and Eq. A.4 of Appendix A in that document), the radius distance of a horizontal slice through the shoulder can be calculated from Eq. (A.1). Then the cross-sectional area (before accounting for internal PJM components) is calculated with Equation A.2.

$$
x=r_{1}+\left[r_{2}^{2}-\left(H_{\text {shoulder, bottom }}-H\right)^{2}\right]^{\frac{1}{2}} \quad \forall H_{\text {shoulder }, \text { top }}<H<H_{\text {shoulder, bottom }}
$$

where

$\mathrm{H}=$ height on the affixed tape $(\mathrm{cm})$

$\mathrm{x}=$ radius for a horizontal slice through the shoulder at the given height $(\mathrm{cm})$

$\mathrm{r}_{1}=$ radius of inner cylindrical region

$\mathrm{r}_{2}=$ radius of shoulder arc.

$$
\text { Area within shoulder }\left(\mathrm{cm}^{2}\right)=\pi \cdot x^{2}
$$




\begin{tabular}{|c|c|c|c|c|c|c|}
\hline Measurment ID & $\begin{array}{c}\text { Height } \\
\text { [Avg. Affixed } \\
\text { Tape Reading] } \\
\text { (cm) }\end{array}$ & $\begin{array}{l}\text { Volume in } \\
\text { Tank } \\
\text { (L) }\end{array}$ & $\begin{array}{c}\text { Application of } \\
\text { Linear Equation \#1 } \\
\text { (L) }\end{array}$ & $\begin{array}{c}\text { \% Error } \\
\text { (between } \\
\text { Linear Eqn. 1 } \\
\text { \& Actual) }\end{array}$ & $\begin{array}{l}\text { Application of } \\
\text { Linear Equation } \\
\# 2,3 \text {, or } 4 \\
\text { (L) }\end{array}$ & $\begin{array}{c}\text { \% Error } \\
\text { (between Linear } \\
\text { Eqn. 1, 2, or } 3 \& \\
\text { Actual) }\end{array}$ \\
\hline Addition \#1, Supply Tank Fill \#1 * & 201.2 & 525.2 & 510.4 & $-2.8212 \%$ & 525.2 (Eqn. 2) & $-0.0000 \%$ \\
\hline Addition \#2, Supply Tank Fill \#2 & 174.6 & 1170.1 & 1142.1 & $-2.3925 \%$ & 1170.1 (Eqn. 2) & $0.0000 \%$ \\
\hline Addition \#3, Supply Tank Fill \#3 & 134.7 & 2092.1 & 2091.4 & $-0.0313 \%$ & 2093.9 (Eqn. 3) & $0.0870 \%$ \\
\hline Addition \#4, Supply Tank Fill \#4 & 107.2 & 2725.1 & 2745.7 & $0.7538 \%$ & 2732.4 (Eqn. 3) & $0.2669 \%$ \\
\hline Addition \#5, Supply Tank Fill \#5 & 88.3 & 3173.3 & 3195.9 & $0.7121 \%$ & 3171.8 (Eqn. 3) & $-0.0474 \%$ \\
\hline Addition \#6, Supply Tank Fill \#6 & 86.4 & 3220.3 & 3240.6 & $0.6293 \%$ & 3215.4 (Eqn. 3) & $-0.1525 \%$ \\
\hline Addition \#7 & 60.6 & 3850.7 & 3853.8 & $0.0814 \%$ & 3852.7 (Eqn. 4) & $0.0535 \%$ \\
\hline Addition \#8, Supply Tank Fill \#7 & 57.6 & 3926.8 & 3925.8 & $-0.0264 \%$ & 3927.1 (Eqn. 4) & $0.0079 \%$ \\
\hline Addition \#9 & 49.1 & 4136.6 & 4128.6 & $-0.1934 \%$ & 4136.8 (Eqn. 4) & $0.0041 \%$ \\
\hline Addition \#10 & 24.6 & 4739.8 & 4710.9 & $-0.6088 \%$ & 4738.7 (Eqn. 4) & $-0.0233 \%$ \\
\hline
\end{tabular}

\begin{tabular}{|c|c|c|c|c|}
\hline $\begin{array}{l}\text { Linear Fit of Height (cm) vs. Tank Volume (L) : } \\
\text { Range Covered }\end{array}$ & $\begin{array}{c}\text { Linear Equation } \\
\text { Number }\end{array}$ & Slope & Intercept & $\mathbf{R}^{2}$ \\
\hline Entire Data Set, except Addition \#1 & 1 & -23.79205 & 5296.18512 & 0.999689 \\
\hline Top of Tank Dish (Point A) to Cone Top (Point B) & 2 & -24.28834 & 5410.83280 & 1.000000 \\
\hline Cone Top (Point B) to Top of 2-inch Half Coupling (Point E) & 3 & -23.21959 & 5221.54827 & 0.999970 \\
\hline Top of 2-inch Half Coupling (Point E) to Highest Point Measured (Point I) & 4 & -24.59224 & 5343.62225 & 0.999994 \\
\hline
\end{tabular}

* The first measurement was not used because it is below the height range of interest

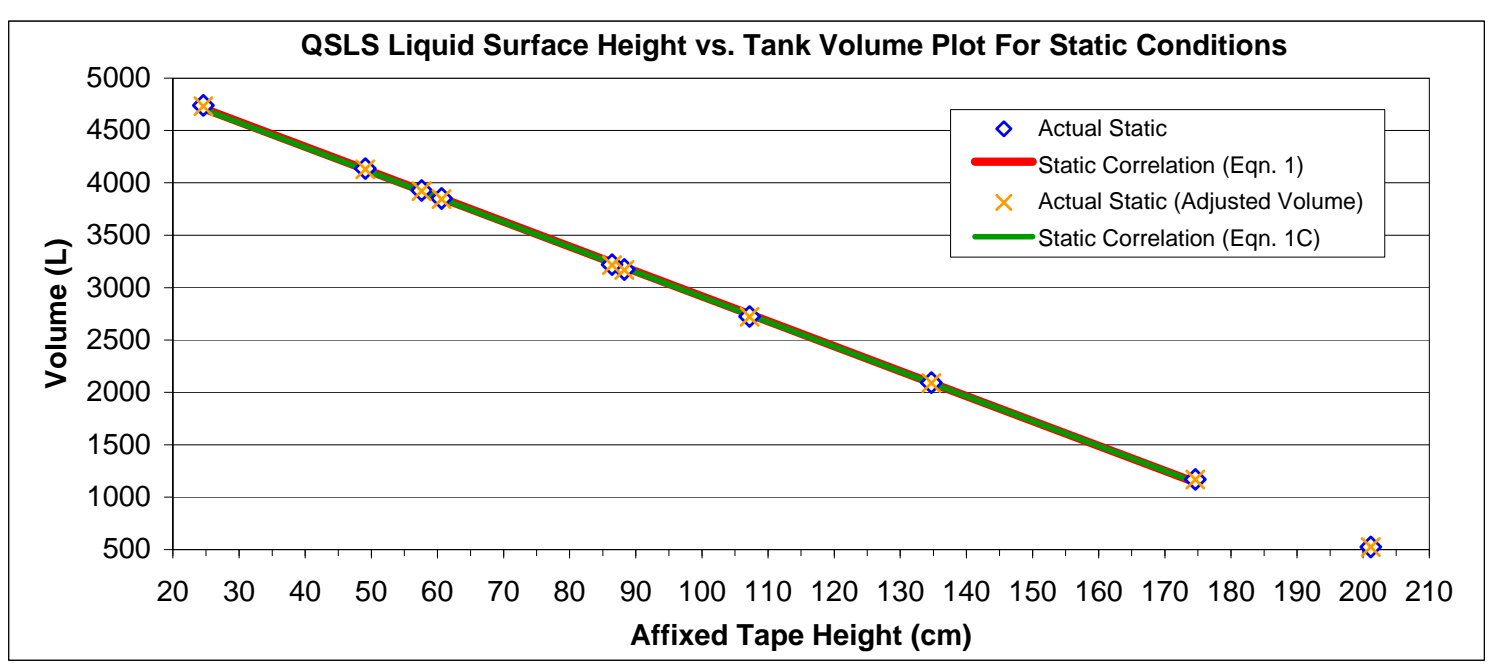

Figure A.5. Linear Correlations for Total Tank Fluid Volume as a Function of the Height of the Liquid Surface in the QSLS Tank Based on Piping Vented to Atmosphere 
The volume used for this Adjusted Static Correlation is the volume based on weight measurements minus the volume inside air sparger, hydrogen peroxide feed, and sample withdrawl pipes/tubes. This adjustment of the volume is required because during actual operations, these three types of pipes/tubes will be filed with fluids that are not part of the simulant volume in the tank.

\begin{tabular}{|c|c|c|c|c|c|c|}
\hline Measurment ID & $\begin{array}{c}\text { Height } \\
\text { [Avg. Affixed } \\
\text { Tape Reading] } \\
\text { (cm) }\end{array}$ & $\begin{array}{l}\text { Adjusted } \\
\text { Volume in } \\
\text { Tank } \\
\text { (L) }\end{array}$ & $\begin{array}{c}\text { Application of } \\
\text { Linear Equation \#1C } \\
\text { (L) }\end{array}$ & $\begin{array}{c}\text { \% Error } \\
\text { (between } \\
\text { Linear Eqn. } \\
1 C \text { \& Actual) }\end{array}$ & $\begin{array}{c}\text { Application of } \\
\text { Linear Equation } \\
\# 2 C, 3 C \text {, or } 4 C \\
\text { (L) }\end{array}$ & $\begin{array}{c}\text { \% Error } \\
\text { (between Linear } \\
\text { Eqn. 1C, 2C, or } \\
\text { 3C \& Actual) }\end{array}$ \\
\hline Addition \#1, Supply Tank Fill \#1 * & 201.2 & 524.8 & $\overline{510.1}$ & $-2.7971 \%$ & 524.8 (Eqn. 2C) & $-0.0000 \%$ \\
\hline Addition \#2, Supply Tank Fill \#2 & 174.6 & 1168.5 & 1140.6 & $-2.3878 \%$ & 1168.5 (Eqn. 2C) & $0.0000 \%$ \\
\hline Addition \#3, Supply Tank Fill \#3 & 134.7 & 2088.9 & 2088.3 & $-0.0306 \%$ & 2090.7 (Eqn. 3C) & $0.0867 \%$ \\
\hline Addition \#4, Supply Tank Fill \#4 & 107.2 & 2720.9 & 2741.4 & $0.7540 \%$ & 2728.1 (Eqn. 3C) & $0.2671 \%$ \\
\hline Addition \#5, Supply Tank Fill \#5 & 88.3 & 3168.3 & 3190.9 & $0.7118 \%$ & 3166.8 (Eqn. 3C) & $-0.0474 \%$ \\
\hline Addition \#6, Supply Tank Fill \#6 & 86.4 & 3215.2 & 3235.4 & $0.6288 \%$ & 3210.3 (Eqn. 3C) & $-0.1525 \%$ \\
\hline Addition \#7 & 60.6 & 3844.5 & 3847.6 & $0.0796 \%$ & 3846.5 (Eqn. 4C) & $0.0524 \%$ \\
\hline Addition \#8, Supply Tank Fill \#7 & 57.6 & 3920.5 & 3919.4 & $-0.0284 \%$ & 3920.8 (Eqn. 4C) & $0.0063 \%$ \\
\hline Addition \#9 & 49.1 & 4130.0 & 4121.9 & $-0.1958 \%$ & 4130.0 (Eqn. 4C) & $0.0014 \%$ \\
\hline Addition \#10 & 24.6 & 4731.8 & 4703.1 & $-0.6045 \%$ & 4730.8 (Eqn. 4C) & $-0.0210 \%$ \\
\hline
\end{tabular}

\begin{tabular}{|l|c|c|c|c|}
\hline \multicolumn{1}{|c|}{$\begin{array}{c}\text { Linear Fit of Height (cm) vs. Tank Volume (L) : } \\
\text { Range Covered }\end{array}$} & $\begin{array}{c}\text { Linear Equation } \\
\text { Number }\end{array}$ & Slope & Intercept & $\mathbf{R}^{\mathbf{2}}$ \\
\hline Entire Data Set, except Addition \#1 & 1C & -23.75004 & 5287.39773 & 0.999691 \\
\hline Top of Tank Dish (Point A) to Cone Top (Point B) & 2C & -24.24813 & 5402.26518 & 1.000000 \\
\hline Cone Top (Point B) to Top of 2-inch Half Coupling (Point E) & 3C & -23.17917 & 5212.95220 & 0.999970 \\
\hline Top of 2-inch Half Coupling (Point E) to Highest Point Measured (Point I) & 4C & -24.54555 & 5334.58126 & 0.999994 \\
\hline
\end{tabular}

The first measurement was not used because it is below the height range of interest

\begin{tabular}{|c|c|c|c|c|c|c|}
\hline \multirow{2}{*}{$\begin{array}{l}\text { Note: The exact vertical position of all tubing bends and tube tips was not } \\
\text { determined, thus these volumes are estimates based on known tubing lengths } \\
\text { and an assumption of } 45^{\circ} \text { bends. The hydrogen peroxide tubing is an exception } \\
\text { to this because of the convoluted nature of their bends; vertical positioning was } \\
\text { estimated. See attached schematics for pipe/tubing lengths. }\end{array}$} & \multicolumn{6}{|c|}{$\begin{array}{l}\text { Inside diameters are per Jim Alzheimer (LRB 59652, pp. 10-20) except the 1-inch PVC for the Air Spargers, which is from ASTM D } \\
1785-06, \text { Standard Specification for Poly(Vinyl Chloride) (PVC) Plastic Pipe, Schedules 40, } 80 \text {, and } 120 \text {. }\end{array}$} \\
\hline & Air Spargers & $\begin{array}{l}\mathrm{H}_{2} \mathrm{O}_{2} \text { Feed } \\
\text { Lines }\end{array}$ & Sample Line (Low) & $\begin{array}{c}\text { Sample Line } \\
\text { (Middle) }\end{array}$ & $\begin{array}{c}\text { Sample Line } \\
\text { (High) }\end{array}$ & \multirow{3}{*}{$\begin{array}{c}\text { Height } \\
\text { [Avg. Affixed } \\
\text { Tape Reading] } \\
\text { (cm) } \\
\end{array}$} \\
\hline $\begin{array}{r}\text { inside diameter (in.): } \\
\text { number of pipes/tubes: }\end{array}$ & $\begin{array}{c}1.049 \\
7\end{array}$ & $\begin{array}{c}0.133 \\
7 \\
\end{array}$ & $\begin{array}{c}0.277 \\
1 \\
\end{array}$ & $\begin{array}{c}0.277 \\
1 \\
\end{array}$ & $\begin{array}{c}0.277 \\
1\end{array}$ & \\
\hline Measurement Point & \multicolumn{5}{|c|}{ Volume within all pipes/tubes up to water height (L) } & \\
\hline Point A - near top of tank dish & 0.4547 & 0.0158 & 0.0077 & 0.0000 & 0.0000 & 201.15 \\
\hline Point B - near top of PJM cones & 1.4910 & 0.0370 & 0.0180 & 0.0000 & 0.0000 & 174.60 \\
\hline Point B' - near middle of PJM body & 3.0483 & 0.0620 & 0.0335 & 0.0007 & 0.0000 & 134.70 \\
\hline Point C - near weld between PJM body and PJM header (cap) & 4.1216 & 0.0792 & 0.0442 & 0.0114 & 0.0003 & 107.20 \\
\hline Point D - near top PJM header (cap/shoulder) & 4.8603 & 0.0942 & 0.0516 & 0.0188 & 0.0077 & 88.28 \\
\hline Point E - near top of 2-inch half coupling & 4.9335 & 0.0958 & 0.0523 & 0.0195 & 0.0084 & 86.40 \\
\hline Point $F$ - near top of 2-inch pipe & 5.9395 & 0.1174 & 0.0623 & 0.0295 & 0.0185 & 60.63 \\
\hline Point $G$ - near the middle of the $3 / 4$-inch $\times 2$-inch reducing coupling & 6.0576 & 0.1193 & 0.0635 & 0.0308 & 0.0196 & 57.60 \\
\hline Point $\mathrm{H}-\mathrm{a}$ few inches above the $3 / 4$-inch $\times 2$-inch reducing coupling & 6.3903 & 0.1246 & 0.0668 & 0.0355 & 0.0229 & 49.08 \\
\hline Point $\mathrm{I}$ - about $20 \mathrm{~cm}$ below tank rim \& midway through angled portion of air sparger pipes & 7.7086 & 0.1400 & 0.0763 & 0.0485 & 0.0325 & 24.60 \\
\hline
\end{tabular}

Figure A.6. Linear Correlations for Total Tank Fluid Volume as a Function of the Height of the Liquid Surface in the QSLS Tank, Adjusted for Simulant Test Operating Conditions 


\section{QSLS - Geometry}

\begin{tabular}{|c|c|c|c|c|c|c|c|c|c|}
\hline & $\begin{array}{c}\text { Part } \\
\\
--\end{array}$ & $\begin{array}{l}\text { i.d. }^{\S} \\
\text { (inch) }\end{array}$ & $\begin{array}{l}\text { o.d. }^{\S} \\
\text { (inch) }\end{array}$ & $\begin{array}{l}\text { Height at Top of } \\
\text { Part [external] * } \\
\text { (cm) }\end{array}$ & $\begin{array}{l}\text { Delta Part Height } \\
{\text { [internal }]^{\dagger}}{ }^{\text {(cm) }}\end{array}$ & $\begin{array}{l}\text { Delta Part Height } \\
\text { [external] } \\
\text { (cm) }\end{array}$ & $\begin{array}{c}\text { Total Internal } \\
\text { Volume for Part } \\
\text { (L) }\end{array}$ & \begin{tabular}{|c|} 
Total Volume \\
Displaced by Part \\
(L)
\end{tabular} & \begin{tabular}{|c|} 
Internal Part that \\
Displaces volume \\
--
\end{tabular} \\
\hline 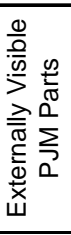 & $\begin{array}{l}\text { PJM Cone } \\
12 " \text { pipe (PJM tube) } \\
\text { header/shoulder (rnd. rect.) } \\
2 " \text { half coupling } \\
2 " \text { pipe } \\
3 / 4 " \times 2 " \text { reducing coupling (cap) } \\
3 / 4 " \text { pipe }\end{array}$ & $\begin{array}{c}\mathrm{N} / \mathrm{A} \\
12.000 \\
\mathrm{~N} / \mathrm{A} \\
2.375 \\
2.067 \\
2.375 \\
0.824 \\
\end{array}$ & $\begin{array}{c}\text { N/A } \\
12.750 \\
\text { N/A } \\
2.750 \\
2.375 \\
2.750 \\
1.050 \\
\end{array}$ & $\begin{array}{c}178.7 \\
101.2 \\
91.0 \\
87.8 \\
60.5 \\
54.1 \\
4.6 \\
\end{array}$ & $\begin{array}{c}\mathrm{N} / \mathrm{A} \\
77.5 \\
9.2 \\
4.2 \\
27.3 \\
5.9 \\
50.0 \\
\end{array}$ & $\begin{array}{c}\mathrm{N} / \mathrm{A} \\
77.5 \\
10.2 \\
3.2 \\
27.3 \\
6.4 \\
49.5 \\
\end{array}$ & $\begin{array}{c}\mathrm{N} / \mathrm{A} \\
56.5486 \\
5.2284 \\
0.1187 \\
0.5910 \\
0.1693 \\
0.1719 \\
\end{array}$ & $\begin{array}{c}\mathrm{N} / \mathrm{A} \\
63.8380 \\
6.4499 \\
0.1226 \\
0.7803 \\
0.2452 \\
0.2765 \\
\end{array}$ & \begin{tabular}{|c|} 
N/A \\
Level Probe Rod \\
Level Probe Rod \\
Level Sensor Mount \\
Level Probe Head \\
Level Probe Head \\
3/8" SS tubing \\
\end{tabular} \\
\hline 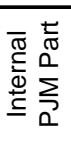 & $\begin{array}{l}\text { Level Probe Rod? } \\
\text { Level Sensor Mount } \\
\text { Level Probe Head } \\
3 / 8 " \text { o.d. SS tubing }\end{array}$ & & $\begin{array}{c}0.800 \\
1.312 \\
\text { N/A } \\
0.375\end{array}$ & $\begin{array}{c}91.0 \\
87.8 \\
53.6 \\
4.6\end{array}$ & & $\begin{array}{c}87.7 \\
3.2 \\
33.2 \\
50.0\end{array}$ & & $\begin{array}{l}0.2844 \\
0.0279 \\
0.5702 \\
0.0356\end{array}$ & \\
\hline
\end{tabular}

N/A = Measurement or Calculation is Not Applicable

* The first part in the list is presented only as a reference for the bottom of the subsequent part, hence the "N/A" values for all but the height at the top of the part.

${ }^{\S}$ Values for inside diameter (i.d.) and outside diameter (o.d.) of the stainless steel pipe were obtained from ANSI/ASME B36.19M-1985 (Stainless Steel Pipe

American Society of Mechanical Engineers, New York, New York. 1985.). The i.d. for a 2-inch collar/cap is estimated as being equal to the o.d. of a 2-inch pipe. The o.d. for a 2-inch collar/cap is assumed to be 2.75 inches.

* See associated schematics for assumptions/notes/sources on dimensions. This is the height at the top of the part as measured at the external surface. Estimated

heights for the parts internal to the PJM (shown above) and the assumed volume occupied by the level probe head ( $75 \%$ of the internal volume) were based on drawing

A-009-0 (Assembly Sketch Level Sensor/PJM Stem Assembly). All heights are relative to the affixed tape scale (east side of tank). It is assumed that when the PJMs are full, the fluid within the PJMs rises to be even with the top of the tank rim.

${ }^{\dagger}$ Where a cap or shoulder mates with a coupling or pipe, this value includes a height element equal to the wall thickness of the cap or shoulder. The horizontal portion of a cap is assumed to have the thickness of the cylindrical walls of the cap. The shoulder has a wall thickness equal to the wall thickness of the PJM tube.

* Volume displaced by internal parts is not included in this value - this is the total volume within this part for the total height of the part

The PJM level probe rod is $99.38 \mathrm{~cm}$ long, but only the length above the top of the PJM cone is included in the Delta Part Height.

Data for Shoulder \& Calculations for Shoulder Volumes

\begin{tabular}{l|r|r|}
\multicolumn{1}{|c|}{ rounded rectangle } & Internal & External \\
\hline qtr. circle radius, $\mathrm{r}_{2}(\mathrm{~cm})$ & 9.2475 & 10.2 \\
central radius, $\mathrm{r}_{1}(\mathrm{~cm})$ & 5.9925 & 5.9925 \\
shoulder height, $\mathrm{h}(\mathrm{cm})$ & 9.2475 & 10.2 \\
shoulder volume $(\mathrm{L})$ & 5.2284 & 6.4499 \\
\hline
\end{tabular}

\begin{tabular}{l|r|r|}
\hline shoulder volume $(\mathrm{L})$ & 5.2284 & 6.4499 \\
\hline
\end{tabular}

Number of PJMs in Tank $=\quad 8$

Figure A.7. Geometry and Volumes for PJM Components and PJM Internals 
Figure A.8 shows the fluid surface area within all eight PJMs (accounting for displacement by internal PJM parts), the fluid surface area in the tank (excluding the fluid within the PJMs), and the ratio of these areas to the total nozzle cross sectional area (for eight nozzles). The fluid surface area in the tank is calculated from the slope coefficient of Figure A.6 (linear equations 3C and 4C) minus the fluid surface area within the PJMs. In the PJM shoulder area, the areas and area ratios must be calculated using Eq. (A.1) and (A.2). Given $r_{1}$ and $r_{2}$ for the PJM shoulder component from Figure A.7 and noting that the applicable height range for the PJM shoulder is from 92.0 to $101.2 \mathrm{~cm}$ on the affixed tape, Figure A.9 shows example calculation results at the top and bottom of the PJM shoulder region.

\begin{tabular}{|l|c|}
\hline \multicolumn{1}{|c|}{ Nozzle } & $\begin{array}{c}\text { Internal Area } \\
\text { (all Nozzles) } \\
\left(\mathbf{c m}^{2}\right)\end{array}$ \\
\hline PJM Nozzle & 44.607 \\
\hline
\end{tabular}

\begin{tabular}{|c|c|c|c|c|c|}
\hline PJM Part & $\begin{array}{l}\text { Height Range (on affixed tape) } \\
\text { that is Covered } \\
(\mathrm{cm})\end{array}$ & \begin{tabular}{|c|} 
Total PJM \\
Internal Area \\
(all PJMs) \\
$\left(\mathrm{cm}^{2}\right)$
\end{tabular} & \begin{tabular}{|c|} 
Area Ratio \\
(All PJMs / All \\
Nozzles) \\
$(--)$
\end{tabular} & $\begin{array}{l}\text { Tank Area } \\
\left(\mathrm{cm}^{2}\right)\end{array}$ & $\begin{array}{c}\text { Area Ratio } \\
\text { (Tank / All } \\
\text { Nozzles) } \\
(--)\end{array}$ \\
\hline 12" pipe (PJM tube) & 101.2 to 178.7 & 5811.3 & 130.3 & 17367.8 & 389.4 \\
\hline header/shoulder (rnd. rect.) & 92.0 to 101.2 & varies, see Eqn below & varies, see Eqn below & varies, see Eqn below & varies, see Eqn below \\
\hline header/shoulder (rnd. rect.) wall element & 91.0 to 92.0 & 202.7 & 4.54 & 22976.5 & 515.1 \\
\hline $2 "$ half coupling & 87.8 to 91.0 & 158.9 & 3.56 & 23020.3 & 516.1 \\
\hline 2" pipe & 60.5 to 87.8 & 43.30 & 0.971 & 24502.3 & 549.3 \\
\hline $3 / 4 " \times 2 "$ reducing coupling (cap) & 54.6 to 60.5 & 57.16 & 1.28 & 24488.4 & 549.0 \\
\hline $3 / 4 " \times 2 "$ reducing coupling (cap) wall element & 54.1 to 54.6 & 21.82 & 0.489 & 24523.7 & 549.8 \\
\hline $3 / 4 "$ pipe & 4.6 to 54.1 & 21.82 & 0.489 & 24523.7 & 549.8 \\
\hline
\end{tabular}

Figure A.8. Fluid Surface Areas and Area Ratios for PJMs and the QSLS Tank as a Function of Height

\begin{tabular}{|c|c|c|c|c|}
\cline { 2 - 5 } & $\begin{array}{c}\text { Total PJM Internal } \\
\text { Area (all PJMs) } \\
\left(\mathbf{c m}^{\mathbf{2}}\right)\end{array}$ & $\begin{array}{c}\text { Area Ratio } \\
\text { (All PJMs I All } \\
\text { Nozzles) } \\
(--)\end{array}$ & Tank Area & $\begin{array}{c}\text { Area Ratio } \\
\text { (Tank / All } \\
\text { Nozzles) } \\
(--)\end{array}$ \\
\cline { 2 - 5 } Top of header/shoulder
\end{tabular}

Figure A.9. $\quad$ Example Fluid Surface Areas and Area Ratios for PJMs and the QSLS Tank for Heights in the PJM Shoulder Region

\section{A.4 Summary of Results}

Table A.1 summarizes the correlations for calculating the total tank fluid volume as a function of tank fluid surface height for simulant test operating conditions (i.e., the fluid in the PJMs is at the same height as the fluid in the tank when the PJMs are full and the volume inside the air sparger, hydrogen peroxide, and sample lines is occupied by fluids not included in the total tank fluid volume). Although there is overlap in the applicable height range for Eq. (A.3) and (A.5-A.6), all are valid correlations. The choice of which equation to use will depend on the height range of interest and whether the linear curve fit (i.e., the $\mathrm{R}^{2}$ value) is acceptable. For example, if a single equation were required that covered the entire range of 4.6 to $178.7 \mathrm{~cm}$, Eq. (A.3) would be suitable. If multiple equations can be used in the application or only a subset range is of interest, Eq. (A.5) and/or (A.6) are appropriate. Based on the percentage error comparisons in Figure A.6, it is generally preferable to use Eq. (A.5) and/or (A.6) when possible.

Areas and area ratios are determined from Figure A.8 or Eq. (A.1) and (A.2), depending on the height of interest. 
Table A.1. Level/Volume Correlations for the QSLS Tank for Simulant Test Operating Conditions

\begin{tabular}{|c|c|c|c|c|}
\hline \multicolumn{2}{|c|}{$\begin{array}{l}\text { Applicable Affixed } \\
\text { Tape Height Range } \\
\qquad(\mathrm{cm})\end{array}$} & \multirow{2}{*}{$\begin{array}{l}\text { Description of Height Range } \\
\text { in terms of PJM } \\
\text { Components } \\
\text { from the top of tank rim to bottom } \\
\text { of } 12 \text {-inch PJM tube body }\end{array}$} & $\begin{array}{l}\text { Total Tank Fluid Volume Correlation }{ }^{(a)} \\
\text { (L) }\end{array}$ & $\mathbf{R}^{2}$ \\
\hline 4.6 to & 178.7 & & $V_{\text {static }}=-23.75004 \cdot H_{\text {surface }}+5287.39773^{(\mathrm{b}, \mathrm{c})}$ & 0.999691 (A.3) \\
\hline 178.7 to & 201.2 & $\begin{array}{l}\text { from the bottom of } 12 \text {-inch PJM } \\
\text { tube body to top of tank dish }\end{array}$ & $V_{\text {static }}=-24.24813 \cdot H_{\text {surface }}+5402.26518$ & 1.000000 (A.4) \\
\hline 87.8 to & 178.7 & $\begin{array}{l}\text { from the top of the } 2 \text {-inch half } \\
\text { coupling to bottom of the } 12 \text {-inch } \\
\text { PJM tube body }\end{array}$ & $V_{\text {static }}=-23.17917 \cdot H_{\text {surface }}+5212.95220$ & 0.999970 (А.5) \\
\hline 4.6 to & 87.8 & $\begin{array}{l}\text { from within the } 3 / 4 \text {-inch pipe to the } \\
\text { top of the } 2 \text {-inch half coupling }\end{array}$ & $V_{\text {static }}=-24.54555 \cdot H_{\text {surface }}+5334.58126$ & 0.999994 (A.6) \\
\hline \multicolumn{5}{|c|}{ For the operating conditions described in the Introduction to this appendix. } \\
\hline (b) $V_{\text {static }}$ & \multicolumn{4}{|c|}{$=$ total volume of fluid in the QSLS tank when PJMs are full (L). } \\
\hline (c) $H_{\text {surface }}$ & \multicolumn{4}{|c|}{$\begin{array}{l}=\text { height of fluid surface in the QSLS tank on the affixed tape scale; values increase as one moves from } \\
\text { tank to the bottom }(\mathrm{cm}) .\end{array}$} \\
\hline
\end{tabular}

\section{A.5 References}

ASME. 1985. Stainless Steel Pipe. ANSI/ASME B36.19M-1985, American Society of Mechanical Engineers, New York, New York (reaffirmed 1994).

ASME. 2005. Process Piping. ASME B31.3-2004, American Society of Mechanical Engineers, New York.

ASTM. 2006. Standard Specification for Poly(Vinyl Chloride) (PVC) Plastic Pipe, Schedules 40, 80, and 120. ASTM D 1785 - 06, ASTM International, West Conshohocken, Pennsylvania.

ASTM. 2007. Standard Specification for Seamless and Welded Austenitic Stainless Steel Tubing for General Service. ASTM A 269-07, ASTM International, West Conshohocken, Pennsylvania.

Guzman-Leong CE and L Zhong. 2007. Quarter-Scale Lag Storage AFA Phase 2 Water Volume Correlation. TI-RPP-WTP-482 Rev. 0, Pacific Northwest National Laboratory, Richland, Washington.

Johnson CD. 2007. Tank Volume and PJM/Tank Fluid Surface Areas as a Function of the Height of the Liquid Surface in the Tank. CCP-WTPSP-237, Pacific Northwest National Laboratory, Richland, Washington.

Perry RH, DW Green, and JO Maloney. 1997. Perry's Chemical Engineers' Handbook (7 ${ }^{\text {th }}$ Edition). McGraw-Hill, New York, pp. 2-91.

Russell RL, CW Stewart, SD Rassat, CD Johnson, ST Arm, PA Meyer, MS Fountain, CE GuzmanLeong, and BK Hatchell. 2005. Final Report: Gas Retention and Release in Hybrid Pulse Jet Mixed Tanks Containing Non-Newtonian Waste Simulants. PNWD-3552 (WTP-RPT-114 Rev. 1), Battelle Pacific Northwest Division, Richland, Washington.

Swagelok. 2006. Tubing Data. MS-01-107, Swagelok Company, Solon, Ohio. 


\section{Appendix B}

QSLS Data Analysis Methodology 


\section{Appendix B - QSLS Data Analysis Methodology}

\section{B.1 PJM Drive Cycle Analysis}

The typical nozzle velocity profile during discharge is shown in Figure B.1. The discharge time is the period of relatively constant peak discharge velocity defined as $t_{d}=t_{e n d}-t_{\max }$. The peak average velocity $\mathrm{U}_{\text {peak }}$ over the discharge time is defined as

$$
\mathrm{U}_{\text {peak }}=\frac{1}{\mathrm{t}_{\mathrm{d}}} \int_{\mathrm{t}_{\max }}^{\mathrm{t}_{\text {end }}} \mathrm{U}(\mathrm{t}) \mathrm{dt}
$$

Because there is no direct measurement of the nozzle velocity, it must be defined either by the velocity of the slurry descending in the pulse tubes or the velocity of the slurry rising in the tank outside the pulse tubes. Assuming an incompressible fluid, the nozzle velocity is related to the rate of change of the average slurry level in all eight the tubes, $\mathrm{H}_{\mathrm{pt}}$, by the ratio of areas as defined by

$$
U(t)=-\left(\frac{A_{p t}}{A_{n}}\right) \frac{d H_{p t}(t)}{d t}
$$

where

$$
\begin{aligned}
& A_{p t}=\text { area of the cylindrical portion of a pulse tube }\left(\mathrm{m}^{2}\right) \\
& A_{n}=\text { area of a PJM nozzle }\left(\mathrm{m}^{2}\right)
\end{aligned}
$$

The rate of change of simulant level in the pulse tubes, $\mathrm{dH}_{\mathrm{pt}} / \mathrm{dt}$, is computed using a finite difference or as the slope of a linear regression on several data points.

Likewise, using the change in slurry surface level in the tank, $\mathrm{H}_{t}$, the nozzle velocity can be computed as follows with the same techniques for calculating the rate of change in surface level, $\mathrm{dH}_{\mathrm{t}} / \mathrm{dt}{ }^{\text {(a) }}$

$$
U(t)=-\left(\frac{A_{t}}{N A_{n}}\right) \frac{d H_{t}(t)}{d t}
$$

where

$\mathrm{A}_{\mathrm{t}}=$ surface area of the slurry in the tank $\left(\mathrm{m}^{2}\right)$

$\mathrm{N}=$ number of PJM nozzles.

(a) The sign on the derivative remains negative because the surface level measurement is down from the tank rim. 


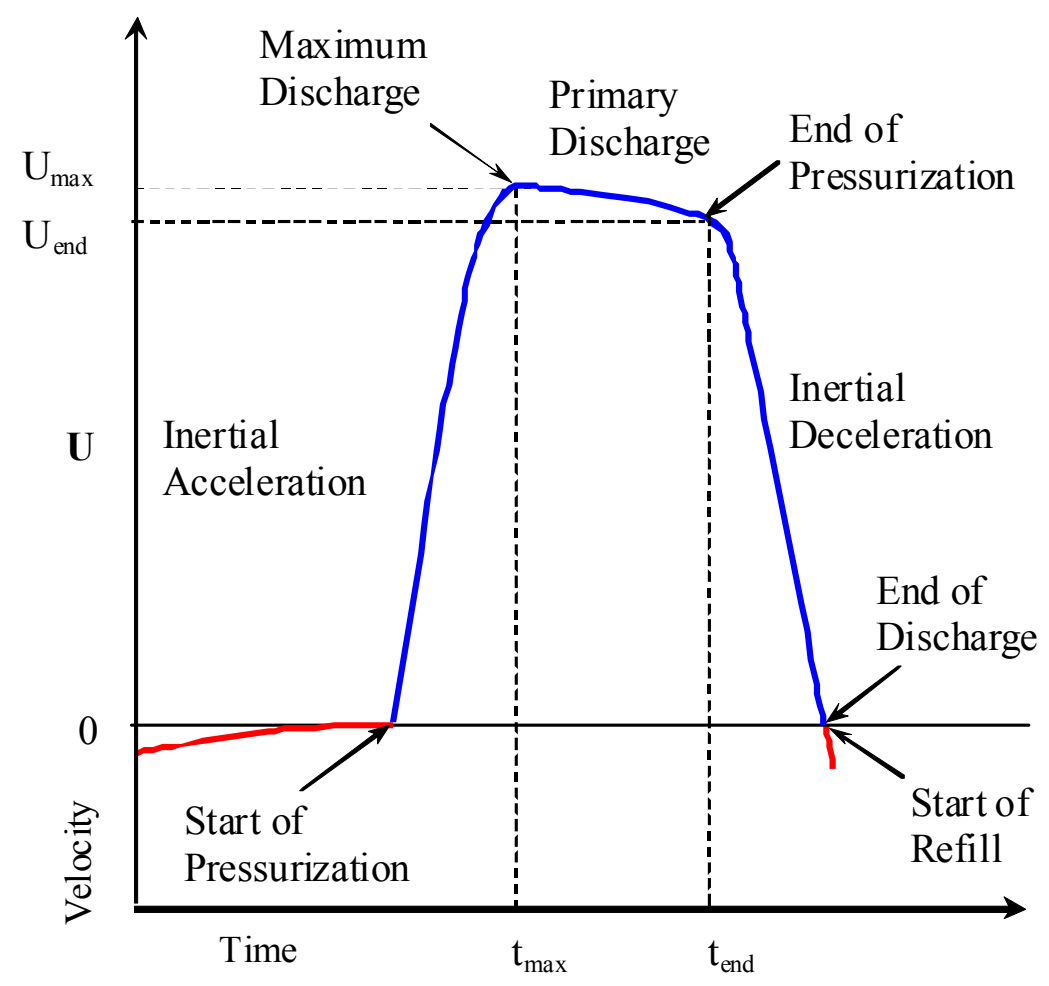

Figure B.1. Illustration of PJM Peak Velocity

A third method to estimate the PJM nozzle velocity employs Bernoulli's equation with the nozzle drag loss taken into account. Temporal inertia is ignored with respect to the pressure drop through the nozzle. The following form of Bernoulli's equation is solved for the square of the nozzle velocity:

$$
U^{2}=\frac{P_{p t}-P_{a}+\rho g\left(H_{p t}^{0}-H_{p t}-H_{t}\right)}{\frac{1}{2} \rho\left[1+k_{d}-\left(A_{n} / A_{p t}\right)^{2}\right]}
$$

where

$\mathrm{P}_{\mathrm{pt}}=$ pressure inside the pulse tube above the slurry $(\mathrm{Pa})$

$\mathrm{P}_{\mathrm{a}}=$ ambient pressure above the slurry in the tank $(\mathrm{Pa})$

$\rho=$ slurry density $\left(\mathrm{kg} / \mathrm{m}^{3}\right)$

$\mathrm{g}=$ acceleration of gravity $9.81 \mathrm{~m} / \mathrm{s}^{2}$

$\mathrm{k}_{\mathrm{d}}=$ overall drag loss coefficient for flow through the nozzle.

The pressures are known from measurements and $\mathrm{H}_{\mathrm{pt}}{ }^{0}$ is the initial level inside the pulse tubes defined by solving Eq. (B.4) with $\mathrm{U}=0$

$$
\mathrm{H}_{\mathrm{pt}}^{0}=\frac{\mathrm{P}_{\mathrm{a}}-\mathrm{P}_{\mathrm{pt}}^{0}}{\rho \mathrm{g}}+\mathrm{H}_{\mathrm{t}}^{0}
$$


where

$\mathrm{P}_{\mathrm{pt}}{ }^{0}=$ initial pressure inside the pulse tubes $(\mathrm{Pa})$

$\mathrm{H}_{\mathrm{t}}{ }^{0}=$ measured initial slurry surface level in the tank (m).

The solution to Eq. (B.4) is performed successively at each data point in the following steps:

1. Solve Eq. (B.5) for the nozzle velocity $U$

2. $\frac{\mathrm{dH}_{\mathrm{pt}}}{\mathrm{dt}}=\mathrm{U}\left(\frac{\mathrm{A}_{\mathrm{n}}}{\mathrm{A}_{\mathrm{pt}}}\right)$

3. $\mathrm{H}_{\mathrm{pt}}=\mathrm{H}_{\mathrm{pt}}^{\mathrm{old}}+\Delta \mathrm{t} \frac{\mathrm{dH}}{\mathrm{pt}}$

4. $\mathrm{H}_{\mathrm{t}}=\mathrm{H}_{\mathrm{t}}^{0}+\left(\frac{\mathrm{A}_{\mathrm{pt}}}{\mathrm{A}_{\mathrm{t}}}\right)\left(\mathrm{H}_{\mathrm{pt}}-\mathrm{H}_{\mathrm{pt}}^{0}\right)$

The loss coefficient is adjusted so that the Bernoulli method provides results consistent with analysis of the pulse tube level and tank simulant level.

Because the differences required by all methods amplify random fluctuations in the surface levels and pressures, $10-\mathrm{Hz}$ data files were taken using 5 to 10 PJM cycles with spargers off to capture PJM and tank levels and PJM pressures. All three methods for calculating the velocity were incorporated into an automated LabView program so the PJM cycle could be analyzed and adjusted in near-real time. The LabView program produced a velocity profile for each of the three methods described.

\section{B.2 Gas Volume Fraction}

The total gas volume fraction, $\alpha$, in the slurry was calculated by two different approaches, one based on level measurements and one on $\Delta \mathrm{P}$ measurements. Each measurement that was employed was the median of 16 points from each of the available instruments. When the PJMs were operating, the 16 points at the end of the equilibration part of each cycle, when disturbances were smallest, were used to represent the cycle. When the PJMs were off, 16-point medians were taken once every 54 seconds (a period equal to the PJM cycle length) to maintain consistency of data-handling.

Under the best conditions, four laser instruments were available to support the first method (potentially 64 data points), and two instrument trees, each with both a shallow and a deep pressure transducer, were available for the second method (potentially 32 data points). However, in many cases one or more instruments were malfunctioning as determined by data reviews (which were conducted and documented under QA guidelines). Level instrument malfunctions were manifested by inability to read the level because the slurry surface was below the laser's range, large data scatter, or complete absence of data. Pressure instrument malfunctions were shown as inconsistencies between the two trees and large percentage changes from measurements in previous similar runs. Table B.1 shows which instruments were available for each test run and sequence. ("Run" refers to a particular combination of simulant and rheology, "sequence" to a set of $\mathrm{H}_{2} \mathrm{O}_{2}$ flow rates. In most cases there were three sequences per run.) 
Table B.1. Instrument Availability ${ }^{(a)}$

\begin{tabular}{|c|c|}
\hline Run and Sequence & Available instruments \\
\hline 7/6/07 30-Pa AZ/AFA, Sequence 1 & No level, two $\Delta \mathrm{P}$ \\
\hline 7/6/07 30-Pa AZ/AFA, Sequence 2 & No level, two $\Delta \mathrm{P}$ \\
\hline 7/6/07 30-Pa AZ/AFA, Sequence 3 & No level, two $\Delta \mathrm{P}$ \\
\hline 7/16/07 13-Pa AZ/AFA, Sequence 1 & No level, two $\Delta \mathrm{P}$ \\
\hline 7/16/07 13-Pa AZ/AFA, Sequence 2 & Three level, two $\Delta \mathrm{P}$ \\
\hline 7/16/07 13-Pa AZ/AFA, Sequence 3 & Three level, two $\Delta \mathrm{P}$ \\
\hline 7/16/07 13-Pa AZ/AFA, Sequence 4 & Two level, two $\Delta \mathrm{P}$ \\
\hline 7/23/07 3-Pa AZ/AFA, Sequence 1 & No level, two $\Delta \mathrm{P}$ \\
\hline 7/23/07 3-Pa AZ/AFA, Sequence 2 & No level, two $\Delta \mathrm{P}$ \\
\hline 9/10/07 3-Pa AZ/AFA, Sequence 1 & No level, one $\Delta \mathrm{P}$ \\
\hline 9/10/07 3-Pa AZ/AFA, Sequence 2 & Three level, one $\Delta \mathrm{P}$ \\
\hline 9/10/07 3-Pa AZ/AFA, Sequence 3 & Three level, one $\Delta \mathrm{P}$ \\
\hline 8/21/07 30-Pa clay, Sequence 1 & No level, two $\Delta \mathrm{P}$ \\
\hline $8 / 21 / 0730-\mathrm{Pa}$ clay, Sequence 2 & Two level, two $\Delta \mathrm{P}$ \\
\hline 8/21/07 30-Pa clay, Sequence 3 & One level, two $\Delta \mathrm{P}$ \\
\hline $8 / 27 / 07$ 13-Pa clay, Sequence 1 & One level, two $\Delta \mathrm{P}$ \\
\hline $8 / 27 / 07$ 13-Pa clay, Sequence 2 & One level, two $\Delta \mathrm{P}$ \\
\hline 8/27/07 13-Pa clay, Sequence 3 & One level, two $\Delta \mathrm{P}$ \\
\hline 8/29/07 3-Pa clay, Sequence 1 & No level, two $\Delta \mathrm{P}$ \\
\hline 8/29/07 3-Pa clay, Sequence 2 & No level, two $\Delta \mathrm{P}$ \\
\hline 8/29/07 3-Pa clay, Sequence 3 & One level, two $\Delta \mathrm{P}$ \\
\hline
\end{tabular}

The equations used in calculating the total gas volume fraction depend on the correct tracking of changes in volume (i.e., level) and gas-free slurry density that come from the addition of $\mathrm{H}_{2} \mathrm{O}_{2}$ solution and loss by evaporation. Assuming the unreacted $\mathrm{H}_{2} \mathrm{O}_{2}$ mass and the mass of generated $\mathrm{O}_{2}$ are negligible, mass balance on the total mass of slurry and on the water mass in the slurry yield

$$
\begin{gathered}
\rho(1-\alpha) V_{T}=\rho_{b}\left(1-\alpha_{b}\right) V_{T b}+f_{w} \rho_{H} \int_{0}^{t} Q_{H} d t-F_{e}\left(R_{s a t}-R_{i}\right) \int_{0}^{t} \dot{m}_{a} d t \\
\omega \rho(1-\alpha) V_{T}=\omega_{b} \rho_{b}\left(1-\alpha_{b}\right) V_{T b}+f_{w} \rho_{H} \int_{0}^{t} Q_{H} d t-F_{e}\left(R_{s a t}-R_{i}\right) \int_{0}^{t} \dot{m}_{a} d t
\end{gathered}
$$

where

$\rho=$ gasless density of slurry at time $\mathrm{t}$

$\omega=$ water mass fraction in gasless slurry at time $\mathrm{t}$

$V_{T}=$ gassy slurry volume at time $\mathrm{t}$

$\alpha=$ gas volume fraction at time $\mathrm{t}$

$\rho_{b}=$ gasless density of slurry for sample taken at baseline conditions

$\omega_{b}=$ water mass fraction in gasless slurry for sample taken at baseline conditions 
$V_{T b}=$ gassy slurry volume at baseline conditions; selected from data that at least approximate nosparge, no-generation conditions and should therefore allow $\alpha_{b}$ to be considered zero

$\alpha_{b}=$ gas volume fraction in in-situ slurry at baseline conditions; approximately zero

$f_{w}=$ mass fraction of water in peroxide solution, including the water produced by reaction

$\rho_{H}=$ density of peroxide solution

$Q_{H}=$ volume flow rate of peroxide solution

$F_{e}=$ unitless adjustment factor for water evaporation rate; a value of unity means the sparge air becomes saturated with water vapor

$R_{i}=$ mass water vapor/mass wet air at sparger nozzle; a value of zero means the supplied air is dry

$R_{\text {sat }}=$ mass water vapor/mass wet air at saturated condition at slurry surface pressure and temperature

$\dot{m}_{a}=$ total mass flow rate of sparger air at nozzle conditions.

To simplify these two equations, define a quantity $W$, which is both the net change in water mass and the net change in total slurry mass:

$$
W \equiv f_{w} \rho_{H} \int_{0}^{t} Q_{H} d t-F_{e}\left(R_{s a t}-R_{i}\right) \int_{0}^{t} \dot{m}_{a} d t
$$

Equations (B.6) and (B.7) become

$$
\begin{gathered}
\rho(1-\alpha) V_{T}=\rho_{b}\left(1-\alpha_{b}\right) V_{T b}+W \\
\omega \rho(1-\alpha) V_{T}=\omega_{b} \rho_{b}\left(1-\alpha_{b}\right) V_{T b}+W
\end{gathered}
$$

Many of the parameters in the equations are measured. Others, $\alpha_{b}, F_{e}$ and $R_{i}$, are user-adjustable inputs; these are set at zero, unity, and zero, respectively. The remaining parameters must be calculated. The first, the saturated humidity, $R_{\text {sat }}$, is equal to

$$
R_{\text {sat }}=\frac{M_{w} P_{s a t}}{M P_{a}}
$$

where

$M_{w}=$ molecular weight of water

$P_{\text {sat }}=$ saturated water vapor pressure at slurry temperature

$M=$ average molecular weight of air/vapor in sparge bubble gas at surface

$P_{a}=$ pressure in dome of tank.

The average molecular weight, $M$, is equal to

$$
M=\frac{1}{\frac{R_{\text {sat }}}{M_{w}}+\frac{1-R_{\text {sat }}}{M_{a}}}=\frac{M_{w} M_{a}}{R_{\text {sat }} M_{a}+M_{w}\left(1-R_{\text {sat }}\right)}
$$


where $M_{a}$ is the molecular weight of dry air. Substituting Eq. (B.12) into Eq. (B.11) gives a final equation for the saturated humidity:

$$
R_{\text {sat }}=\frac{1}{1+\frac{M_{a}}{M_{w}}\left(\frac{P_{a}}{P_{s a t}}-1\right)}
$$

The water vapor pressure $(\mathrm{Pa})$ for pure water for $284<\mathrm{T}<441 \mathrm{~K}$ is given by the Antoine equation, with constants for water provided by Reid et al. (1977) as follows: (a)

$$
p_{v}(T)=\frac{1}{0.00750062} \exp \left[18.3036-\frac{3816.44}{T-46.13}\right]
$$

The fraction $f_{w}$, the mass of water added to the slurry per mass of $\mathrm{H}_{2} \mathrm{O}_{2}$ solution inflow, is

$$
f_{w}=\frac{\left(1-\omega_{H}\right) \rho_{H} Q_{H}+\omega_{H} \rho_{H} Q_{H} \frac{M_{w}}{M_{H}}}{\rho_{H} Q_{H}}=1-\omega_{H}\left(1-\frac{M_{w}}{M_{H}}\right)
$$

where

$$
\begin{aligned}
M_{H} & =\text { molecular weight of } \mathrm{H}_{2} \mathrm{O}_{2} \\
\omega_{H} & =\mathrm{H}_{2} \mathrm{O}_{2} \text { mass fraction in peroxide solution. }
\end{aligned}
$$

The density of the solids (dissolved and undissolved) in the slurry is needed to track density as a function of time. The solids density can be found from the baseline slurry density and water fraction by assuming linear additivity of solids and liquid densities:

$$
\rho_{s}=\frac{1-\omega_{b}}{\frac{1}{\rho_{b}}-\frac{\omega_{b}}{\rho_{w}}}
$$

where

$$
\begin{aligned}
& \rho_{s}=\text { average density of total solid in slurry (undissolved and dissolved) } \\
& \rho_{w}=\text { density of water. }
\end{aligned}
$$

Using this expression for solid density, the slurry density as a function of time can be calculated as

(a) In the AZ simulant, the presence of dissolved salts reduces the water vapor pressure in approximate proportion to the mole fraction of water in the liquid according to Raoult's law (Reid et al. 1977). However, the relatively low density of the bulk simulant, which includes undissolved solids, and the low concentration of dissolved sodium indicate that the reduction would be small. It is therefore ignored. 


$$
\rho=\frac{1}{\frac{\omega}{\rho_{w}}+\left(\frac{1}{\rho_{b}}-\frac{\omega_{b}}{\rho_{w}}\right) \frac{1-\omega}{1-\omega_{b}}}
$$

Considering the baseline slurry and water masses, as expressed in Eq. (B.9) and (B.10), and realizing that the water fraction $\omega$ is the water mass at time $t$ divided by the slurry mass at time $t$, it can be seen that

$$
\omega=\frac{\omega_{b} \rho_{b}\left(1-\alpha_{b}\right) V_{T b}+W}{\rho_{b}\left(1-\alpha_{b}\right) V_{T b}+W}
$$

Substituting this expression into Eq. (B.17) gives a final equation for the slurry density:

$$
\rho=\frac{\left(1-\omega_{b}\right) \rho_{w} \rho_{b}}{\rho_{w}-\rho_{b} \omega_{b}-\left(\rho_{w}-\rho_{b}\right) \frac{\omega_{b} \rho_{b}\left(1-\alpha_{b}\right) V_{T b}+W}{\rho_{b}\left(1-\alpha_{b}\right) V_{T b}+W}}
$$

Sections B.2.1 and B.2.2 outline the remaining equations used to calculate the total gas volume fraction. It should be noted that this gas fraction may include the sparge gas fraction, $a_{A}$, and the gas fraction resulting from gas generation, $a_{G}$. The two can be separated only by comparing measurements with and without sparger air flow, and with and without gas generation.

\section{B.2.1 Gas Volume Fraction from Level Measurements}

The volume-level correlation described in Appendix A is used to convert the measured level into a slurry volume $V_{T}$, which in turn can be converted into a slurry mass using the density. Then the total gas fraction based on level comes from Eq. (B.11) and is

$$
\alpha=1-\frac{\rho_{b}\left(1-\alpha_{b}\right) V_{T b}+W}{\rho V_{T}}
$$

\section{B.2.2 Gas Volume Fraction from $\Delta P$ Measurements}

The total gas volume based on $\Delta \mathrm{P}$ can be calculated by defining the hydrostatic pressure differences at baseline and time $t$ conditions:

$$
\begin{gathered}
\Delta P_{b}=\rho_{b}\left(1-\alpha_{b}\right) g \Delta h \\
\Delta P=\rho(1-\alpha) g \Delta h
\end{gathered}
$$

where $\Delta h$, the vertical distance between the deep and shallow pressure transducers, is constant during a run and the two pressure differences are measurements. Eq. (B.21a) and (B.21b) can be solved for the total gas volume fraction: 


$$
\alpha=1-\frac{\Delta P}{\Delta P_{b}} \frac{\rho_{b}\left(1-\alpha_{b}\right)}{\rho}
$$

\section{B.3 Details of Results of Steady-State Assessment}

Appendix E, Sections E.1 and E.2, describe the method used to assess the extent to which the $\Delta$ Pbased gas holdup reached a steady-state for every $\mathrm{H}_{2} \mathrm{O}_{2}$ flow rate used in testing. Table B.2 shows the results of the assessment.

Table B.2. Steady-State Assessment of $\Delta \mathrm{P}-$ Based Gas Holdup ${ }^{(\mathrm{a})}$

\begin{tabular}{|c|c|c|c|c|c|c|c|}
\hline & \multirow{2}{*}{$\begin{array}{l}\text { Number of } \\
\text { slope } \\
\text { standard } \\
\text { deviations }\end{array}$} & \multirow{2}{*}{$\begin{array}{l}\text { Maximum } \\
\text { allowable slope } \\
\text { (volfrac/min) }\end{array}$} & \multirow{2}{*}{$\begin{array}{c}\text { Probability of } \\
\text { detection of slope } \\
\text { exceeding } \\
\text { maximum }\end{array}$} & \multicolumn{4}{|c|}{$\begin{array}{l}\text { Number of } \alpha \text { points included in } \\
\text { average for that } \mathrm{H}_{2} \mathrm{O}_{2} \text { rate }\end{array}$} \\
\hline & & & & $\alpha_{0}$ & $\alpha_{1}$ & $\alpha_{2}$ & $\alpha_{3}$ \\
\hline \multicolumn{8}{|c|}{ 30-Pa AZ, 7/6/07 } \\
\hline cycle 1 & 3.1 & 0.00038 & $91 \%$ & 5 & 60 & 30 & 25 \\
\hline cycle 2 & 2.9 & 0.00040 & $88 \%$ & 5 & 31 & 34 & 60 \\
\hline cycle 3 & 3.0 & 0.00041 & $90 \%$ & 5 & 52 & 7 & 33 \\
\hline \multicolumn{8}{|c|}{ 13-Pa AZ, 7/16/07 } \\
\hline cycle 1 & 3.0 & 0.00035 & $90 \%$ & 46 & 63 & 30 & 42 \\
\hline cycle 2 & 2.7 & 0.00030 & $84 \%$ & 46 & 32 & 32 & 30 \\
\hline cycle 3 & 2.7 & 0.00029 & $84 \%$ & 46 & 30 & 28 & 44 \\
\hline cycle 4 & 3.1 & 0.00038 & $91 \%$ & 46 & 32 & 68 & 41 \\
\hline \multicolumn{8}{|c|}{ 3-Pa AZ, 7/23/07 } \\
\hline cycle 1 & 2.7 & 0.00023 & $84 \%$ & 59 & 18 & 56 & $\mathrm{n} / \mathrm{a}$ \\
\hline cycle 2 & 2.8 & 0.00016 & $86 \%$ & 59 & 30 & 34 & $\mathrm{n} / \mathrm{a}$ \\
\hline \multicolumn{8}{|c|}{ 30-Pa clay, 8/21/07 } \\
\hline \begin{tabular}{|l} 
cycle 1 \\
\end{tabular} & 3.5 & 0.00032 & $96 \%$ & 54 & 65 & 40 & 30 \\
\hline cycle 2 & 2.8 & 0.00032 & $86 \%$ & 54 & 34 & 31 & 30 \\
\hline cycle 3 & 3.6 & 0.00041 & $97 \%$ & 54 & 68 & 20 & 58 \\
\hline \multicolumn{8}{|c|}{ 13-Pa clay, 8/27/07 } \\
\hline cycle 1 & 2.9 & 0.00033 & $88 \%$ & 32 & 44 & 30 & 12 \\
\hline cycle 2 & 3.3 & 0.00040 & $94 \%$ & 32 & 35 & 26 & 67 \\
\hline cycle 3 & 2.9 & 0.00033 & $88 \%$ & 32 & 46 & 44 & 55 \\
\hline \multicolumn{8}{|c|}{ 3-Pa clay, 8/29/07 } \\
\hline \begin{tabular}{|l|} 
cycle 1 \\
\end{tabular} & 3.4 & 0.00028 & $95 \%$ & 67 & 23 & 28 & 34 \\
\hline cycle 2 & 2.8 & 0.00026 & $86 \%$ & 67 & 16 & 54 & 35 \\
\hline cycle 3 & 3.4 & 0.00036 & $95 \%$ & 67 & 67 & 64 & 31 \\
\hline \multicolumn{8}{|c|}{ 3-Pa AZ, 9/10/07 } \\
\hline \begin{tabular}{|l|} 
cycle 1 \\
\end{tabular} & 2.0 & 0.00015 & $62 \%$ & 33 & 68 & 66 & 59 \\
\hline cycle 2 & 3.0 & 0.00018 & $90 \%$ & 33 & 59 & 32 & 34 \\
\hline cycle 3 & 3.2 & 0.00019 & $93 \%$ & 33 & 67 & 61 & 32 \\
\hline
\end{tabular}

(a) $\mathrm{AZ}$ is the $\mathrm{AZ}-101$ waste simulant.

A "point" is the gas volume fraction calculated for one 54-second period, based on a $\Delta \mathrm{P}$ that is the median of 16 measurements collected at 1 -second intervals during the period. 
The overview of the method is as follows (details were given in Section 5). The assessment algorithm calculated the slopes of all the 30-point windows in the run that fell completely within a period of constant $\mathrm{H}_{2} \mathrm{O}_{2}$ flow rate and that included no time gaps. Here, each "point" consisted of the gas volume fraction, $\alpha$, that was calculated for one 54-second cycle based on a $\Delta \mathrm{P}$ that was the median of 16 measurements collected at 1-second intervals during the cycle.

The standard deviation of all these slopes over the entire run was then calculated, and an upper limit on what would be considered as steady-state was expressed in terms of a user-input ratio equal to (the maximum acceptable slope) / (slope standard deviation). This ratio appears in the second column of the table. A ratio was selected that was the minimum that would provide data points for all four levels of holdup. A ratio of 3 or less would have been preferred, but in a number of cycles this constraint would have led to no holdup data qualifying as steady-state. In general the resulting constraint gave the method an $80-90 \%$ probability (fourth column) of detecting a holdup variation greater than 1.5 to $2.5 \mathrm{vol} \% / \mathrm{hr}$ (third column). This is not as tight a constraint as desired, but it would have been difficult to do better given the scatter in the data.

\section{B.4 References}

Reid RC, JM Prausnitz and TK Sherwood. 1977. The Properties of Gases and Liquids. McGraw Hill, New York. 
Appendix C

Model Derivation 


\section{Appendix C - Model Derivation}

Four gases $\left(\mathrm{H}_{2}, \mathrm{O}_{2}, \mathrm{~N}_{2}\right.$, and $\left.\mathrm{N}_{2} \mathrm{O}\right)$ are treated as appearing in two forms in the mixed slurry. The first, equilibrated gas, is present both as gas dissolved in the liquid and as gas in the small bubbles produced primarily by gas generation. These bubbles are in equilibrium with the liquid and thus contain air-derived gas as well as generated gas. The second form, sparge gas, is present in the large, rapidly moving sparge bubbles and consists of air with traces of generated gases that sparging extracts from the slurry.

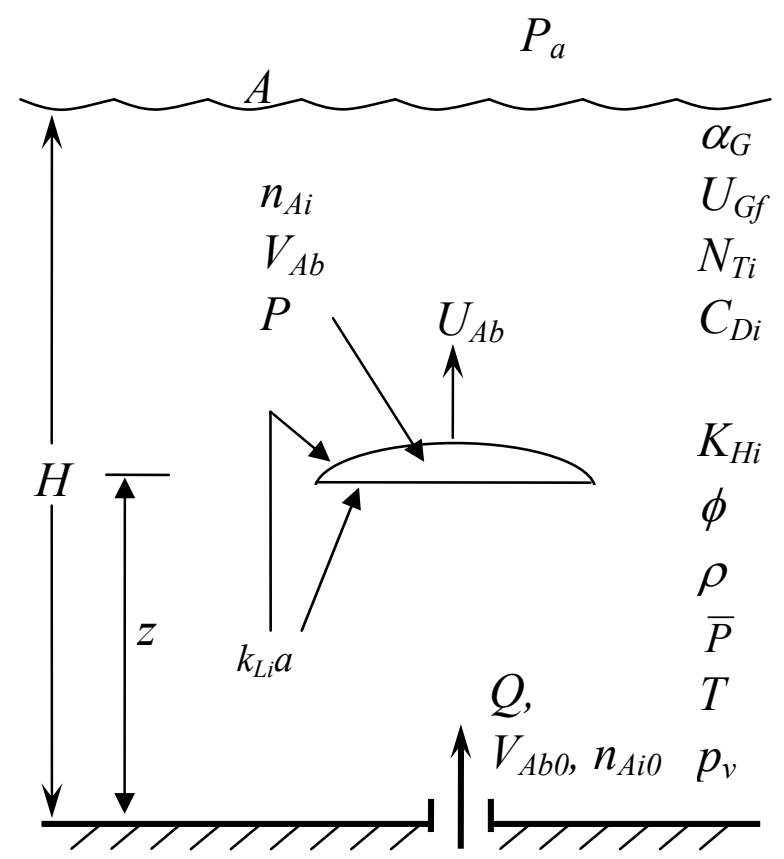

Figure C.1. Schematic of System to be Modeled

\section{$\underline{\text { System }}$}

$H=$ depth of fluid

$A=$ surface area of slurry

$\rho=$ density of slurry

$T=$ temperature of slurry

$P_{a}=$ ambient pressure

$\bar{P}=$ average pressure in slurry

$p_{v}=$ water vapor pressure

$\phi=$ solid volume fraction in slurry

\section{Sparger and Initial Sparge Bubble}

$Q$ = sparge gas flow rate at nozzle pressure and temperature

$V_{A B O}=$ initial bubble volume

$n_{A i 0}=$ initial moles of gas $i$ in bubble

\section{Local Sparge Bubble}

$Z$ = elevation of bubble

$P=$ bubble pressure

$V_{A b}=$ bubble volume

$n_{A i}=$ moles of gas $i$ in bubble

$U_{A b}=$ bubble rise velocity

$k_{L i} a=$ specific mass transfer coefficient for gas $i$

$a=$ specific interfacial area of bubble

\section{Equilibrated Gas}

$\alpha_{G}=$ holdup gas volume fraction

$U_{G f}=$ rise velocity of holdup gas bubbles at the surface elevation

$C_{D i}=$ molar concentration of dissolved gas $i$

$N_{T i}=$ total moles of gas $i$ in dissolved and holdup bubble forms

$K_{H i}=$ Henry's Law constant for gas $i$ 
The following are the principal assumptions and approximations used to develop the model:

- The slurry is well-mixed by the combination of PJMs and spargers, making the dissolved gas concentration, density, temperature, and other fluid properties a spatially uniform environment for the rise of each sparge bubble. The model does not and is not intended to apply to partially mixed conditions.

- The effective sparge bubble size is not a function of the nozzle diameter but of the fluid properties and gas flow rate, as is characteristic for sparging systems with high flow rates.

- Mass transfer is determined with values for the bubble rise velocity and volumetric mass transfer coefficient that are averages over the slurry depth. The only available data for these properties are averages of this kind.

- Every bubble (whether holdup or sparge) releases all its contents to the vessel headspace as soon as it reaches the surface.

- The fluid volume is large compared to the in-transit bubble volume, allowing the dissolved gas concentration to remain constant with time over the duration of each bubble rise.

- Both sparge and holdup bubbles are large enough to make the surface-tension contribution to the internal pressure negligible compared to the local hydrostatic pressure.

- Mass transfer to the sparge bubbles is controlled by liquid-side diffusion of dissolved gases, not by gas-side diffusion.

- The capture of holdup gas bubbles by sparge bubbles is negligible. A bubble accelerates more rapidly than the fluid around it, causing small bubbles to evade the approach of a large sparge bubble. Small bubbles can only be captured by being pulled into the back end of a large bubble, which is no more likely than having the small bubbles rising naturally directly into the flat back end of a large bubble.

- The gas composition inside the bubble is spatially uniform (bubble contents are well mixed).

- The direct release of dissolved gas by mass transfer from the slurry to the headspace at the slurry surface is negligible compared to mass transfer to sparge bubbles. Although the slurry surface has greater area than the sparge bubbles, it undergoes less disturbance (producing a lower mass transfer coefficient).

- The gases do not undergo chemical reaction (which would change the number of moles present), so a mole balance on gas species can be used instead of a mass balance.

- Gas adsorption on particle surfaces is not a significant inventory.

\section{C.1 Mass Transfer to the Sparge-Gas Bubble}

The derivation of equations to describe the sparge bubbles requires an equilibrium relation between dissolved and gas-phase gases. Henry's Law defines the equilibrium relation between a gas's dissolved concentration at a gas-liquid interface and the partial pressure of the gas:

$$
p_{A i}=K_{H i} C_{D i}^{*} \quad C_{D i}^{*}=\frac{p_{A i}}{K_{H i}}
$$


where

$p_{A i}=$ partial pressure of gas $i$ in the bubble

$K_{H i}=$ Henry's Law coefficient for gas $i$ based on correlations in the literature and measured salt concentrations in the liquid

$C_{D i}^{*}=$ saturated molar concentration of dissolved gas $i$.

Henry's Law coefficients can be determined using several methods. One used at Hanford is based on an empirical model for gas behavior in salt solutions (Hermann et al. 1995 that describes the effect of salt concentration as depending on the first power of the solution ionic strength and assumes the "salted-out" Henry's Law coefficient has the same temperature dependence as the coefficient in pure water:

$$
\log _{10}\left(\frac{K_{H i, \text { salt }}}{K_{H i, \text { water }}}\right)=\sum_{j} a_{i, j} c_{s j}
$$

where $a_{i, j}$ represents coefficients that are both gas-specific and salt-specific, and $c_{s j}$ is the molar concentration of salt $j$. The coefficients are those given by Hermann et al. (1995). Expressions for the Henry's Law coefficients of the relevant gases in pure water, $K_{H i \text { water }}$, can be taken from Norton and Pederson (1995). Those authors found that gas solubilities in a Hanford waste simulant liquid of about 6 M Na concentration could be estimated by the approach used here. It should be noted that the Henry's law coefficients used by Norton and Pederson (1995) are the inverse of those defined in Eq. (C.1); this change in definition has been taken into account in Eq. (C.2).

The ideal gas law, expressed in terms of sparge-bubble conditions, is

$$
p_{A i} V_{A b}=n_{A i} R T
$$

where $R$ is the universal ideal gas constant.

The number of moles of individual gas species $i$ in each sparged bubble, $n_{A i}$, is assumed to be controlled by mass transfer through the bubble surface. The driving force for mass transfer is the difference between the gas concentration in the bulk liquid and the saturated concentration at the bubble interface. The latter can be expressed in terms of the moles of gas in the bubble using Eq. (C.1) and (C.3). The equation describing the contents of a single rising bubble is found from conservation of moles and expressed in terms of bubble elevation $z$, using the facts that $d x / d t=(d x / d z)(d z / d t)$ and the bubble rise velocity $U_{A b}=d z / d t$ :

$$
\frac{d n_{A i}}{d t}=U_{A b} \frac{d n_{A i}}{d z}=k_{L i} a V_{A b}\left(C_{D i}-\frac{n_{A i} R T}{V_{A b} K_{H i}}\right)
$$

where

$U_{A b}=$ rise velocity of a sparge bubble; varies with elevation. The velocity at the surface of the slurry, $U_{A b f}$, can be estimated from observations of sparge gas volume fraction, $\alpha_{A}$, made in the 2007 QSLS tests or the 2007 bubble-column tests. The surface velocity can then be used to estimate velocities lower in the slurry. Pertinent models are discussed in Section C.4.2. 
$k_{L i} a=$ specific mass transfer coefficient of species $i$ for the sparge bubbles ( $a$ is the area per volume for each bubble). The average value over the depth of the slurry is used. A data correlation that is consistent with the literature is discussed in Section C.4.4.

$C_{D i}=$ molar concentration of dissolved gas $i$ in the liquid. This is in equilibrium with the holdup gas (with its relatively high specific area and long residence time) but not with the sparge gas, and therefore is not referred to in equilibrium notation (as $C_{D i}^{*}$ ). The molar concentration is an unknown to be solved for.

$R=$ ideal gas constant, $8.314 \mathrm{~J} /$ gmol K.

$T=$ slurry temperature, an input.

$V_{A b}=$ sparge-gas bubble volume at temperature $T$; varies with elevation.

At every elevation, the sum of the partial pressures of the gases in the bubble must equal the local hydrostatic pressure $P$ minus the water vapor pressure, $p_{v}$.

$$
\frac{R T}{V_{A b}} \sum n_{A i}=P-p_{v}=P_{a}-p_{v}+(1-\alpha) \rho g\left(\frac{H}{1-\alpha}-z\right)=P_{a}-p_{v}+\rho g(H-z(1-\alpha))
$$

$P_{a}=$ ambient pressure. The value in the headspace is used.

$p_{v}=$ vapor pressure of pure water at $T$. The decrease in vapor pressure resulting from the presence of dissolved salts can be ignored.

$\rho=$ density of the gas-free slurry, an input.

$G=$ acceleration of gravity.

$H=$ fill depth under degassed conditions; an input.

$\alpha=$ total gas volume fraction in the bubbly slurry, which is the sum of the sparge gas volume fraction, $\alpha_{A}$, and the holdup bubble gas volume fraction, $\alpha_{G}$.

The total gas volume fraction is expected to be less than 0.10 , whether under plant operation conditions or experimental conditions. Its effect on the local hydrostatic pressure would be about half that because the pressure head is, at maximum, roughly equal to the ambient pressure $P_{a}$. Eq. (C.5a) is therefore simplified to

$$
\frac{R T}{V_{A b}} \sum n_{A i}=P_{a}-p_{v}+\rho g(H-z)
$$

It is further assumed that the flow of sparge air, during normal operation, is large enough to make the change in moles due to mass transfer alone relatively negligible. In that case the initial, intermediate, and final values of the total moles in a sparge-gas bubble are all nearly equal, allowing Eq. (C.5b) to become

$$
V_{A b}=\frac{R T \sum n_{A i f}}{\left(P_{a}-p_{v}+\rho g H\right)-\rho g z}=\frac{V_{A b f}\left(P_{a}-p_{v}\right)}{\left(P_{a}-p_{v}+\rho g H\right)-\rho g z}
$$

Equation (C.4) can be rearranged to become 


$$
\frac{d n_{A i}}{d z}+\frac{k_{L i} a R T}{U_{A b} K_{H i}} n_{A i}=\frac{k_{L i} a V_{A b} C_{D i}}{U_{A b}}
$$

The equation cannot be solved analytically, given the $z$-dependence of both $U_{A b}$ and $V_{A b}$. As an approximation, considered justifiable because of the uncertainties in the values of these bubble properties and of $k_{L} a$, it is assumed that both of these bubble properties can be treated in terms of their average values over the slurry depth, $\bar{U}_{A b}$ and $\bar{V}_{A b}$. It is further assumed that the dissolved concentration of gas, $C_{D i}$, remains constant over the time of each sparge bubble rise. Then Eq. (C.6) can be solved to give

$$
n_{A i f}=n_{A i 0} e^{-\frac{k_{L i} a R T}{K_{H i}} \frac{H}{\bar{U}_{A b}}}+\frac{\bar{V}_{A b} C_{D i} K_{H i}}{R T}\left(1-e^{-\frac{k_{L i} a R T}{K_{H i}} \frac{H}{\bar{U}_{A b}}}\right)
$$

The change in the moles of species $i$ per bubble is

$$
n_{A i f}-n_{A i 0}=\left(\frac{\bar{V}_{A b} C_{D i} K_{H i}}{R T}-n_{A i 0}\right)\left(1-e^{-\frac{k_{L i} a R T}{K_{H i}} \frac{H}{\bar{U}_{A b}}}\right)
$$

The rate of transfer of moles from solution to the sparge gas flow, denoted by $\Delta_{A i}$, is therefore

$$
\Delta_{A i}=\left(\frac{\bar{V}_{A b} C_{D i} K_{H i}}{V_{A b f} R T}-\frac{x_{A i 0} P_{0}}{R T}\right)\left(1-e^{-\frac{k_{L i} a R T}{K_{H i}} \frac{H}{\bar{U}_{A b}}}\right) \frac{P_{s t d}}{P_{a}-p_{v}} \frac{T}{T_{s t d}} N_{s} Q_{s t d}
$$

where

$V_{A b f}=$ bubble volume at the slurry surface

$x_{A i 0}=$ mole fraction of species $i$ in the bubble at the sparge nozzle, based on standard composition of dry air

$P_{0}=$ hydrostatic pressure at the sparge tip calculated from Eq. (C.5b), with $z=0$

$P_{\text {std }}=$ standard atmospheric pressure

$T_{\text {std }}=$ standard temperature

$N_{s}=$ number of spargers

$Q_{s t d}=$ gas flow rate per sparger at standard conditions; gas is assumed to be free of water vapor.

Because the bubble volume appears only in the form of a ratio between the average and final values, and this ratio can be calculated based on hydrostatic pressure variation (Section C.4.1), no correlation to calculate the bubble volume is needed to use Eq. (C.9). Only the bubble velocity and the $k_{L} a$ are needed.

\section{C.2 Equilibrated Gas}

The total equilibrated gas in the slurry is made up of moles of holdup-bubble gas of each species and moles of dissolved gas. It is assumed that all the gases present follow the ideal gas law and Henry's law as stated in Eq. (C.1) and (C.2). It is further assumed that the molar concentration of equilibrated gas in 
the slurry is uniform throughout the slurry, being represented by the value at the average hydrostatic pressure $\bar{P}$. Based on these assumptions, the total moles of equilibrated gas in the liquid, $N_{T i}$, can be expressed as

$$
N_{T i}=\frac{\alpha_{G} V_{T} K_{H i} C_{D i}}{R T}+V_{L} C_{D i}
$$

$\alpha_{G}=$ holdup gas volume fraction in the bubbly slurry (considered to be at the average hydrostatic pressure). This is an unknown to be solved for; it is only part of the total gas volume fraction, which also includes sparge bubbles.

$V_{T}=$ total bubbly slurry volume. It is equal to $V_{T 0}$ when the slurry is gas-free.

$V_{L}=$ total volume of liquid in the slurry, derived from the input $V_{T 0}$ and the input undissolved solid volume fraction $\phi$.

Conservation of moles for each equilibrated species yields an equation for the dissolved concentration of the species, assuming the gases do not react either in the bubble or in the liquid:

$$
\frac{d N_{T i}}{d t}=V_{L} g_{m i}-\Delta_{A i}-\frac{\left(\bar{P}-p_{v}\right) \alpha_{G}}{\left(P_{a}-p_{v}\right)} \frac{A U_{G f}}{R T} \frac{\left(P_{a}-p_{v}\right) K_{H i} C_{D i}}{\left(\bar{P}-p_{v}\right)}
$$

$g_{m i}=$ moles of species $i$ generated per unit time per volume liquid in slurry. In both the mass transfer and QSLS tests, this quantity is calculated for $\mathrm{O}_{2}$ from $\mathrm{H}_{2} \mathrm{O}_{2}$ decomposition kinetics and feed rates.

$A=$ area of the surface of the slurry; calculated from known system dimensions.

$U_{G f}=$ rise velocity of holdup gas bubbles released at the slurry surface. This velocity is based on the correlation of data from past and present gas release/retention experiments. It is expected to be affected by AFA and also by the slurry yield strength (a measurement). Experiments indicate the steady-state rise velocity is related to $\alpha_{G}$ as $U_{G f}=c_{1} \alpha_{G}^{c_{2}}$, where $c_{1}$ and $c_{2}$ are constants that depend on the slurry properties (Stewart et al. 2006, Section 5.1) that are determined experimentally. It is assumed the same relation between gas fraction and atsurface rise velocity holds before steady state is reached.

In Eq. (C.11), the holdup gas volume fraction has been adjusted from its basis pressure, the average hydrostatic pressure, to the slurry surface pressure. The same basis adjustment is performed on the saturated partial pressure. The equation demonstrates that the two adjustments cancel.

Conservation of moles for the total equilibrated gas gives the following equation:

$$
\sum \frac{d N_{T i}}{d t}=V_{L} \sum g_{m i}-\sum \Delta_{A i}-\frac{\alpha_{G} A U_{G f}\left(\bar{P}-p_{v}\right)}{R T}
$$

In Eq. (C.12), a further constraint has been included because the sum of the partial pressures of gases in the holdup bubbles has been assumed equal to the average hydrostatic pressure minus water vapor pressure: 


$$
\sum K_{H i} C_{D i}=\bar{P}-p_{v}=P_{a}+0.5 \rho g H-p_{v}
$$

The average hydrostatic pressure is calculated based on degassed conditions, as was done in calculating the local hydrostatic pressure in Eq. (C.5b).

Numerical integration is necessary because of the complicated relation between $a_{G}, C_{D i}$ and $\Delta_{A i}$ (which itself is a function of $C_{D i}$ ). This development is set forth in Section C.3.

\section{C.3 Equilibrated Gas Difference Equations}

From Eq. (C.10), the equilibrium equations for a four-gas system are

$$
\begin{aligned}
& \frac{N_{T 1} R T}{\alpha_{G} V_{T} K_{H 1}+V_{L} R T}=C_{D 1} \\
& \frac{N_{T 2} R T}{\alpha_{G} V_{T} K_{H 2}+V_{L} R T}=C_{D 2} \\
& \frac{N_{T 3} R T}{\alpha_{G} V_{T} K_{H 3}+V_{L} R T}=C_{D 3} \\
& \frac{N_{T 4} R T}{\alpha_{G} V_{T} K_{H 4}+V_{L} R T}=C_{D 4}
\end{aligned}
$$

Equation (C.13), which constrains the sum of the holdup gas species partial pressures to equal the average hydrostatic pressure, results in

$$
K_{H 1} C_{D 1}+K_{H 2} C_{D 2}+K_{H 3} C_{D 3}+K_{H 4} C_{D 4}=\left(\bar{P}-p_{v}\right)
$$

An equation for the first of the equilibrated gases can be derived by combining Eq. (C.9), (C.11), and (C.14a):

$$
\frac{d N_{T 1}}{d t}+\left(\frac{F_{C 1} R T+A K_{H 1} U_{G f} \alpha_{G}}{\alpha_{G} V_{T} K_{H 1}+V_{L} R T}\right) N_{T 1}=V_{L} g_{m 1}+F_{x 1}
$$

In the above equation, the $F$ factors are defined to be

$$
F_{C 1}=\left(\frac{\bar{V}_{A b} K_{H 1}}{V_{A b f} R T}\right)\left(1-e^{-\frac{k_{L L} a R T}{K_{H 1}} \frac{H}{\bar{U}_{A b}}}\right) \frac{P_{s t d}}{P_{a}-p_{v}} \frac{T}{T_{s t d}} N_{s} Q_{s t d}
$$




$$
F_{x 1}=\frac{x_{A 10} P_{0}}{R T}\left(1-e^{-\frac{k_{L 1} a R T}{K_{H 1}} \bar{U}_{A b}}\right) \frac{P_{s t d}}{P_{a}-p_{v}} \frac{T}{T_{s t d}} N_{s} Q_{s t d}
$$

The differential equations for gases 2, 3, and 4 take the same form as that of gas 1 , with only the subscripts changing. With the dissolved concentrations of all four gases known, the total dry gas pressure in the holdup bubbles can be calculated. Then the value of $\alpha_{G}$ is iterated until the dry gas pressure meets the criterion in Eq. (C.15).

The initial conditions for the equilibrated gas (at $t=0$ ) are

$$
\begin{gathered}
\alpha_{G}=\alpha_{G 0} \\
N_{T 1}=\left(\frac{\alpha_{G 0} V_{T}}{R T}+\frac{V_{L}}{K_{H 1}}\right) x_{G 10}\left(\bar{P}-p_{v}\right) \\
N_{T 2}=\left(\frac{\alpha_{G 0} V_{T}}{R T}+\frac{V_{L}}{K_{H 2}}\right) x_{G 20}\left(\bar{P}-p_{v}\right) \\
N_{T 3}=\left(\frac{\alpha_{G 0} V_{T}}{R T}+\frac{V_{L}}{K_{H 3}}\right) x_{G 30}\left(\bar{P}-p_{v}\right)
\end{gathered}
$$

where $x_{G 10}+x_{G 20}+x_{G 30}<\frac{\bar{P}-p_{v}}{\bar{P}}$. The variables $x_{G 10}, x_{G 20}$, and $x_{G 30}$ are mole fractions of the three gases in the equilibrated gas (which is the sum of holdup bubbles and dissolved gas) at time $t=0$.

The difference equation that corresponds to Eq. (C.16) is

$$
\begin{aligned}
& \frac{N_{T 1}^{k+1}-N_{T 1}^{k}}{\delta t}+ \\
& {\left[\frac{\left(F_{C 1} R T+A K_{H 1} \alpha_{G}^{k} U_{G f}^{k}\right) N_{T 1}^{k}}{2\left(\alpha_{G}^{k} V_{T}^{k} K_{H 1}+V_{L} R T\right)}+\frac{\left(F_{C 1} R T+A K_{H 1} \alpha_{G}^{k+1} U_{G f}^{k+1}\right) N_{T 1}^{k+1}}{2\left(\alpha_{G}^{k+1} V_{T}^{k+1} K_{H 1}+V_{L} R T\right)}\right]=V_{L} g_{m 1}+F_{x 1}}
\end{aligned}
$$

Here $k$ represents the timestep just completed and $k+1$ the current timestep. Eq. (C.20) can be solved for $N_{T 1}^{k+1}$ : 


$$
N_{T 1}^{k+1}=\frac{\left(\frac{1}{\delta t}-\frac{F_{C 1} R T+A K_{H 1} \alpha_{G}^{k} U_{G f}^{k}}{2\left(\alpha_{G}^{k} V_{T}^{k} K_{H 1}+V_{L} R T\right)}\right) N_{T 1}^{k}+V_{L} g_{m 1}+F_{x 1}}{\frac{1}{\delta t}+\frac{F_{C 1} R T+A K_{H 1} \alpha_{G}^{k+1} U_{G f}^{k+1}}{2\left(\alpha_{G}^{k+1} V_{T}^{k+1} K_{H 1}+V_{L} R T\right)}}
$$

The difference equations for gases 2,3 , and 4 take exactly the same form.

\section{C.4 Sparge Bubble Properties}

The model described in earlier sections requires that certain sparge bubble properties be defined: $\bar{V}_{A b} / V_{A b f}$ (ratio of average and at-surface bubble volumes), $\bar{U}_{A b}$ (average bubble rise velocity over the rise height) and $k_{L} a$ (volumetric mass transfer coefficient). The sparge gas holdup, $\alpha_{A}$, is also needed to allow the conversion of the measured volumetric mass transfer coefficient, $k_{L} a_{V}$, to the specific-area mass transfer coefficient, $k_{L} a$, used in the sparge mass transfer model. The conversion follows from the definition of $a_{v}$ as the total bubble area per volume of bubble slurry. This section provides some basis for understanding the mass transfer test data (holdup and mass transfer coefficients) and the system and fluid properties that are relevant to them. However, a predictive method is not presented.

\section{C.4.1 General Sparge Behavior}

The primary influence on fluid flow and turbulence along most of the path traveled by the sparge bubbles is the sparging itself. The effect of PJM-induced flow is expected to be secondary, particularly in the upper portion of the vessel or during the equilibration segment of the PJM cycle. The characteristics of sparge-driven flow in clay, which could be modeled as a Bingham fluid with a yield stress, $\tau_{0}$, of $32 \mathrm{~Pa}$, were studied by Poloski et al. (2005). The induced flow was upward in an area above the single sparger nozzle; the diameter of this area, termed the ROB (for "region of bubbles"), was proportional to the 0.34 power of the actual volumetric air flow rate at the sparger nozzle. The flow turned at the top of the slurry and flowed downward. The annular downflow region was termed the ZOI ("zone of influence") and had an outer diameter that was approximately three times the ROB diameter. The flow may have been broken into more than one vertical cell over the 6 to 10 -ft slurry depth in the experiments. This flow pattern is generally similar to that observed in standard bubble columns.

In the WTP lag storage test stand, the sparger nozzles are at about the same depth as the PJM nozzles and are evenly spaced around the periphery of the vessel. For much of the vessel height, the sparge flow passes through a roughly annular area lying between the PJM cluster and the vessel wall. Because of this constriction, the size of the air flow rates, and the spacing of sparge nozzles, the sparge ZOIs overlap and more than fill the available space. Accordingly, it is reasonable to treat the sparge superficial velocity at nozzle depth, $U_{A s}$, as being uniform over the constricted area, $A_{s}$ :

$$
U_{A s 0}=\frac{N_{s} Q_{s t d}}{A_{s}} \frac{P_{s t d}}{P_{0}} \frac{T}{T_{s t d}}
$$


The local sparge superficial velocity, $U_{A s}$, increases with elevation above the sparge nozzles according to the ideal gas law:

$$
U_{A s}=U_{A s 0} \frac{P_{0}}{P_{0}-\rho g z-p_{v}}
$$

The average sparge superficial velocity, $\bar{U}_{A s}$, can be obtained by integrating $U_{A s}$ from $z=0$ to $z=H$ and dividing by $H$. The result is

$$
\bar{U}_{A s}=\frac{U_{A s 0} P_{0}}{\rho g H} \ln \left(\frac{P_{0}-p_{v}}{P_{0}-p_{v}-\rho g H}\right)=U_{A s 0}\left(1+\frac{P_{a}}{\rho g H}\right) \ln \left(\frac{P_{a}+\rho g H-p_{v}}{P_{a}-p_{v}}\right)
$$

The elevation, $\bar{z}_{A s}$, at which this velocity is reached is

$$
\bar{z}_{A s}=\left(1-\frac{1}{\ln \left(\frac{P_{a}+\rho g H-p_{v}}{P_{a}-p_{v}}\right)}\right) H+\frac{P_{a}-p_{v}}{\rho g}
$$

Equation (C.9) contains the expression $\bar{V}_{A b} / V_{A b f}$. It can be seen that this is equal to the ratio of $\bar{U}_{A s}$ to $U_{A s}$ at the slurry surface, $z=H$.

$$
\frac{\bar{V}_{A b}}{V_{A b f}}=\frac{P_{a}-p_{v}}{\rho g H} \ln \left(\frac{P_{a}+\rho g H-p_{v}}{P_{a}-p_{v}}\right)
$$

It may, for some purposes, be useful to define the apparent viscosity $\mu_{a p p}$, which depends on the bulk shear rate $\dot{\gamma}$. The latter can be estimated as Kawase and Moo-Young (1990) stated:

$$
\widetilde{\varepsilon}=\frac{\tau}{\rho} \dot{\gamma}
$$

Here $\widetilde{\varepsilon}$ is the turbulent power dissipation $(\mathrm{W} / \mathrm{kg}$ ) and $\tau$ is the average bulk shear stress in the fluid. In a bubble column, the dissipation is approximately equal to $\bar{U}_{A s} g$, the buoyant energy input. The main approximation in the estimate comes from neglecting the effects of such losses as skin friction (Grima et al. 1997).

When Eq. (C.27) is expanded, using the definition of $\tau$ in a Bingham fluid, the result is a quadratic whose solution is 


$$
\dot{\gamma}=-\frac{\tau_{0}}{2 \mu_{B}}+\sqrt{\left(\frac{\tau_{0}}{2 \mu_{B}}\right)^{2}+\frac{\widetilde{\varepsilon} \rho}{\mu_{B}}}
$$

Substitute this relation for strain rate back into the Bingham stress expression, and obtain

$$
\frac{\tau-\tau_{0}}{\tau}=\frac{\sqrt{1+\frac{4 \mu_{B} \rho \bar{U}_{A s} g}{\tau_{0}^{2}}}-1}{\sqrt{1+\frac{4 \mu_{B} \rho \bar{U}_{A s} g}{\tau_{0}^{2}}}+1}
$$

In the case where $\frac{4 \mu_{B} \rho \bar{U}_{A s} g}{\tau_{0}^{2}}<<1$

$$
\frac{\tau-\tau_{0}}{\tau} \approx \frac{1+0.5 \frac{4 \mu_{B} \rho \bar{U}_{A s} g}{\tau_{0}^{2}}-1}{1+0.5 \frac{4 \mu_{B} \rho \bar{U}_{A s} g}{\tau_{0}^{2}}+1} \approx \frac{\frac{\mu_{B} \rho \bar{U}_{A s} g}{\tau_{0}^{2}}}{1+\frac{\mu_{B} \rho \bar{U}_{A s} g}{\tau_{0}^{2}}} \approx \frac{\mu_{B} \rho \bar{U}_{A s} g}{\tau_{0}^{2}}\left(1-\frac{\mu_{B} \rho \bar{U}_{A s} g}{\tau_{0}^{2}}\right)
$$

The apparent viscosity of the sparged fluid, based on bulk shear rate alone, is defined as

$$
\mu_{a p p}=\frac{\tau}{\dot{\gamma}}=\mu_{B}\left(\frac{\tau-\tau_{0}}{\tau}\right)^{-1}
$$

A viscosity less than $\mu_{\text {app }}$ would be appropriate for use in describing and correlating bubble rise velocity and mass transfer because of the additional shear stress produced near the rising bubble by drag at its surface. This uncertainty should be kept in mind in the development hereafter, which therefore refers to viscosity simply as $\mu$.

\section{C.4.2 Bubble Rise Velocity}

The calculation of mass transfer into sparge bubbles requires a value for $\bar{U}_{A b}$, the average bubble rise velocity over the rise height. It should be noted that this is the bubble's velocity with respect to a fixed frame of reference, the $z$ axis. It therefore includes not only the velocity of the bubble with respect to the liquid, referred to as the slip velocity, but the bulk upward flow velocity of the liquid driven by the bubble stream.

The a-priori prediction of single-bubble slip velocity requires information about fluid properties and about the population-average equivalent spherical diameter of the bubbles, $d_{e}$. Two dimensionless numbers govern bubble shape and terminal rise velocity:

$$
M o=\frac{g \mu^{4}}{\rho \sigma^{3}} \text { (Morton number) }
$$




$$
E o=\frac{d_{e}^{2} \rho g}{\sigma} \text { (Eotvos number) }
$$

Fan and Tsuchiya (1990, Eq. 2.11) correlated the bubble slip velocity in Newtonian fluids, including high-viscosity liquids, in the following manner:

$$
U_{A b}=\left(\frac{\sigma g}{\rho}\right)^{1 / 4}\left[\left(\frac{M o^{-1 / 4}}{K_{b}} E o\right)^{-n}+\left(\frac{2 c}{E o^{1 / 2}}+\frac{E o^{1 / 2}}{2}\right)^{-n / 2}\right]^{-1 / n}
$$

The first term inside the brackets represents the influence of the Stokes Law regime, where velocity is controlled by viscosity. The second term becomes more important as bubble size increases; eventually, the Mendelson regime is reached, where the bubble is shaped like a spherical cap and its rise velocity is determined by its diameter and the surface tension.

Interactions between sparge bubbles are likely to affect the slip velocity, especially at the higher sparge rates. The rise velocity for a single bubble, as calculated from Eq. (C.34), may be less than that of a bubble in a swarm or string of bubbles. Trailing bubbles rise up the wake of the leading bubbles, potentially doubling their rise speed. The exact extent to which a bubble is accelerated by its predecessors depends on the type of bubbly flow that is present. The relevant measurements have typically been made in bubble columns of limited diameter ( $0.3 \mathrm{~m}$ or less), and the regime depends on gas superficial velocity (and gas volume fraction), liquid properties (particularly viscosity), and the diameter of the bubble column.

In Newtonian fluids, there is a transitional range of superficial gas velocities below which an ideal bubbly flow regime exists, and above which the regime is "churn-turbulent." The churn-turbulent regime is characterized by a swarm of bubbles with a bimodal size distribution (Krishna and Ellenburger 1996, Krishna et al. 1999). In the Newtonian fluids studies, the small bubbles were between 3 and $6 \mathrm{~mm}$ in size while the large bubbles were in the range of 2 to $8 \mathrm{~cm}$ and underwent continual coalescence and breakup. Experimental data gave an "acceleration factor", the factor by which single-bubble velocity is multiplied to obtain bubble-string velocity, of

$$
A F=2.73+4.505\left(\bar{U}_{A s}-U_{\text {trans }}\right)
$$

This correlation, unfortunately, depends on knowledge of the regime transition velocity, $U_{\text {trans. }}$ In addition, it was based on tests that had certain limitations: $\left(\bar{U}_{A s}-U_{\text {trans }}\right.$ ) was less than $0.25 \mathrm{~m} / \mathrm{s}$ (AF was between 2.7 and 3.9), equivalent bubble diameter was less than $5 \mathrm{~cm}$, and liquids were Newtonian with relatively low viscosity (less than $2.9 \mathrm{cP}$ ). In higher-viscosity Newtonian liquids, AF was less; a value of 2 was observed in $86 \mathrm{wt} \%$ glycerol $(147 \mathrm{cP})$ under the same conditions where AF was 3 for water. It is not clear to what extent the acceleration factor represented interaction between bubble wakes, as distinct from induced bulk liquid flow.

It does not seem to have been established whether, or at what superficial velocity, a break between bubbly flow regimes occurs for non-Newtonian fluids. In a bubble column filled with a power-law fluid, a solution of carboxymethylcellulose (CMC), no transition was observed in a range of superficial gas 
velocities from 0.02 to $0.05 \mathrm{~m} / \mathrm{s}$, the same range where a transition was seen for water (Halard et al. 1989). In the CMC solution, even at low gas flow rates the bubbles were large spherical caps accompanied by "a large number of very small bubbles."(a) Thus coalescence occurred at lower flow rates than in water. The bubble size distribution appeared to be bimodal as in churn-turbulent flow; it was probably driven by coalescence and breakup.

Because of the uncertainties in the prediction of bubble rise velocity in a swarm in non-Newtonian fluid, it is necessary to fall back on the sparge holdup data obtained in the 2007 QSLS bubble-column tests. Once a steady-state holdup has been reached, the conservation-based relationship between rise velocity and holdup is

$$
U_{A f}=\frac{\bar{U}_{A s}}{\alpha_{A}}
$$

where $U_{A f}$ is the bubble slip velocity at surface conditions. The slip velocity, rather than the total rise velocity, is appropriate because bulk liquid motion is horizontal at the surface and does not contribute to the upward velocity of gas release through the surface.

The at-surface bubble slip velocity can be calculated from the above relation. Table C.1 contains the results for those tests where sparge holdup data were obtainable. The holdup and superficial velocity are given only to one significant figure. Because the sparge holdup calculations were based on data from pressure transducers located in the constricted flow region, i.e., the annulus around the PJM cluster, the calculated sparge gas volume fraction is based on annulus conditions. The sparge superficial velocity is therefore calculated on the basis of the annulus area, not the total tank area.

Table C.1. At-Surface Sparge Bubble Slip Velocities Estimated From Holdup

\begin{tabular}{||l|c|c|c|c|}
\hline \multirow{2}{*}{} & \multicolumn{4}{|c|}{ 2007 QSLS Test } \\
\cline { 2 - 5 } & $\begin{array}{c}\text { 3-Pa AZ-101 Simulant } \\
\text { with AFA }\end{array}$ & $\begin{array}{c}\text { 13-Pa AZ-101 Simulant } \\
\text { with AFA }\end{array}$ & 13-Pa clay & 30-Pa clay \\
\hline$\alpha_{A}$ & 0.09 & 0.01 & 0.005 & 0.003 \\
\hline $\bar{U}_{A s}(\mathrm{~m} / \mathrm{s})$ & 0.008 & 0.009 & 0.009 & 0.008 \\
\hline$U_{A f}(\mathrm{~m} / \mathrm{s})$, calc. & 0.09 & 0.9 & 2 & 3 \\
\hline
\end{tabular}

\section{C.4.3 Bubble Holdup}

As was discussed in the last section, the steady-state sparge bubble holdup depends on the sparge superficial velocity and the bubble slip velocity. The latter, in turn, depends on the bubble diameter and on the bubble shape, which is also related to diameter. The bubble size comes from a balance between mechanisms of bubble formation at the orifice, coalescence, and breakup.

(a) Large bubbles were also seen in the non-Newtonian CMC solutions in the study of Haque et al. (1987). A maximum bubble size of $2 \mathrm{~cm}$ was found, with superficial velocities up to $15 \mathrm{~cm} / \mathrm{s}$. The reduction in the effective viscosity with increasing shear rate caused bubble size to decrease with increasing superficial velocity. It was also noted that, at the same superficial velocity, larger bubbles were observed for higher CMC concentrations. 
Kulkarni and Joshi (2005) carried out an extensive review of bubble formation at submerged orifices and found that the mode of formation (bubbling, chain bubbling, jetting) could depend on the gas velocity, orifice submergence, liquid properties, orifice configuration, and the liquid flow velocity. One study (Acharya et al. 1978) took bubble-column data in aqueous solutions of carboxymethylcellulose (CMC), polyacrylamide, and polyethylene oxide. The CMC solution was shear-thinning, while the other two were viscoelastic fluids. At the experimental shear rates, the apparent viscosities ranged from tens to hundreds of centipoise. The data were compared to the following equation for the bubble volume at the nozzle, $V_{A b 0}$ :

$$
V_{A b 0}=0.976\left(\frac{Q^{2}}{g}\right)^{3 / 5}
$$

Equation (C.37) was found to agree well with the data over a range of gas flow rates from $5 \times 10^{-7} \mathrm{~m}^{3} / \mathrm{s}$ $(0.001 \mathrm{acfm})$ to $6 \times 10^{-5} \mathrm{~m}^{3} / \mathrm{s}(0.13 \mathrm{acfm})$.

All of the studies reviewed by Kulkarni and Joshi used per-orifice gas flow rates of $2 \times 10^{-4} \mathrm{~m}^{3} / \mathrm{s}$ $(0.42 \mathrm{acfm})$ or less. The nozzle gas flow rate in the WTP and test stands can be as high as $8.5 \times 10^{-3} \mathrm{~m}^{3} / \mathrm{s}$ (18 acfm), which is substantially higher. This flow rate may be high enough to cause bubbles to form in the jetting regime rather than the chain bubbling regime that was probably present in the Acharya et al. experiments. Unfortunately, bubble size data in the jetting regime do not seem to be available, based on the review by Kulkarni and Joshi (2005). Thus, the available literature models would have to be extrapolated well beyond their data range before they could be used in describing WTP phenomena.

A further complication in predicting bubble size is bubble coalescence and breakup. The effect of and balance between these two mechanisms is unknown. The high viscosity of the slurry is expected to increase coalescence (Jin et al. 2004), but the presence of surfactants and dissolved salts could decrease it (Jin et al. 2004, Lessard and Zieminski 1971, Prince and Blanch 1990). In a single-orifice bubble column, a significant amount of coalescence would be expected to occur within a height of roughly one columndiameter from the sparge tip (Bhavaraju et al. 1978).

Higuera (2004) conducted numerical analyses that described a string of bubbles being formed and coalescing near the nozzle in a highly viscous fluid. At relatively high gas flow rates the post-coalescence bubble volume, $V_{A b}$, was found to follow the proportionality

$$
V_{A b} \propto\left(\frac{\mu \bar{U}_{A s} A_{g}}{\rho g}\right)^{3 / 4}
$$

where $A_{g}$ is the area through which the bubbles rise, which in a bubble column is proportional to the square of the column diameter, $d_{c}^{2}$. For Eq. (C.38) to hold, the gas flow rate at the nozzle must be high enough to render surface forces negligible.

Based on the earlier determination that the inertial term dominates in Eq. (C.34), the at-surface sparge bubble velocity, $U_{A f}$, can be approximated as $\sqrt{g V_{A b}^{1 / 3}}$, which in combination with Eq. (C.43) yields 


$$
U_{A f} \propto g^{1 / 2}\left(\frac{\mu \bar{U}_{A s} d_{c}^{2}}{\rho g}\right)^{1 / 8}
$$

Based on Eq. (C.36), the sparge gas holdup might be correlated with an equation of the form

$$
\alpha_{A} \propto \bar{U}_{A s}\left(\frac{\rho}{\mu \bar{U}_{A s} d_{c}^{2} g^{3}}\right)^{1 / 8} \propto\left(\frac{\rho \bar{U}_{A s}^{7}}{\mu d_{c}^{2} g^{3}}\right)^{1 / 8}
$$

The SRNL FY-2007 tests(a) included data taken in an air-sparged bubble column whose inner diameter was 30 inches. The simulant types, simulant depths, and sparge superficial velocity were varied over a range representative of the past scaled lag storage test stands and of the full-scale lag storage (FSLS) vessel. There were two different sets of rheological parameters, two values of surface tension, three simulant depths, and three superficial velocities; however, the full matrix of all combinations was not tested. The sparge gas fraction $\alpha_{A}$ was measured by two methods, the change in surface level and the change in the $\Delta \mathrm{P}$ between the top and bottom of the column. The uncertainty in the level-based gas volume fraction was estimated to be $0.6 \mathrm{vol} \%$ gas, slightly less than the uncertainty of the pressure-based gas volume fraction, which was 0.8 vol\% gas. The data appear in Table C.2.

\section{C.4.4 Bubble Mass Transfer Coefficient}

Mass transfer to and from a single spherical cap bubble has been studied in the literature. There are relatively few data or correlations for bubbles in Bingham fluids; most studies in non-Newtonian fluids employ power-law or viscoelastic fluids. The only reasonably relevant exception came from studies of oxygen transfer and gas holdup in bubble columns filled with carbopol solutions, which are Casson fluids, and mycelial fermentation broths, which are Bingham fluids (Kawase and Moo-Young 1990; Moo-Young et al. 1987). The superficial velocities were between 0.01 and $0.05 \mathrm{~m} / \mathrm{s}$. In both types of fluid, "large bubbles" (size not specified) were produced near the orifices by coalescence and rose among numerous tiny bubbles. The following proportionality equation for the mass transfer coefficient in a bubble column filled with Bingham fluid was derived by Kawase and Moo-Young (1990):

$$
k_{L i} \propto\left(\frac{\widetilde{\varepsilon} \rho D_{i}^{2}}{\mu}\right)^{1 / 4}
$$

where $k_{L i}$ is the liquid-phase mass transfer coefficient for species $i$ and $D_{i}$ is the diffusivity for the species.

(a) Guerrero HN, CL Crawford, MD Fowley, RA Leishear, and ML Restivo. 2007. Effects of Alternate Antifoam Agents, Noble Metals, Mixing Systems, and Mass Transfer on Gas Holdup and Release from Non-Newtonian Slurries. WSRC-STI-2007-00537 (SRNL-RPP-2007-00023) Draft A, Westinghouse Savannah River Co., Aiken, South Carolina. The data, which appear as plots in Section 6 of the document, were preliminary test results that were supplied by SRNL in emails sent by Hector Guerrero on October 17 and 19, 2007. The files included in the transmittals were named "kLa summary.xls," "void summary_rev.xls," and "Uncertainty analysis_mt.doc." 
Table C.2. Gas Volume Fraction Measurements Made in a 30-Inch Sparged Bubble Column ${ }^{(a)}$

\begin{tabular}{|c|c|c|c|c|}
\hline Simulant & $\begin{array}{c}\text { Simulant } \\
\text { depth } \\
(\mathbf{m})\end{array}$ & $\begin{array}{l}\text { Superficial velocity } \\
\text { at nozzle } \\
(\mathrm{mm} / \mathrm{s})\end{array}$ & $\begin{array}{c}\text { Gas volume } \\
\text { fraction from } \Delta \mathbf{P} \\
(\mathbf{v o l} \%)^{(\mathrm{b})}\end{array}$ & $\begin{array}{l}\text { Gas volume fraction } \\
\text { from level } \\
(\text { vol\%) }\end{array}$ \\
\hline Water & 1.31 & 2 & $\mathrm{n} / \mathrm{a}$ & 0.43 \\
\hline Water & 1.31 & 5 & $\mathrm{n} / \mathrm{a}$ & 0.99 \\
\hline Water & 1.31 & 10 & $\mathrm{n} / \mathrm{a}$ & 1.8 \\
\hline Water + AFA & 1.31 & 2 & $\mathrm{n} / \mathrm{a}$ & 0.52 \\
\hline Water + AFA & 1.31 & 5 & $\mathrm{n} / \mathrm{a}$ & 0.78 \\
\hline Water + AFA & 1.31 & 10 & $\mathrm{n} / \mathrm{a}$ & 2.4 \\
\hline Water & 3.63 & 2 & 0.23 & 0.25 \\
\hline Water & 3.63 & 5 & 0.89 & 1.0 \\
\hline Water & 3.63 & 10 & 2.3 & 2.8 \\
\hline Water + AFA & 3.63 & 2 & 0.33 & 0.25 \\
\hline Water + AFA & 3.63 & 5 & 1.1 & 1.1 \\
\hline Water + AFA & 3.63 & 10 & 2.8 & 3.3 \\
\hline Water & 7.41 & 2 & 0.44 & 0.49 \\
\hline Water & 7.41 & 5 & 1.2 & 1.3 \\
\hline Water & 7.41 & 10 & 3.2 & 3.4 \\
\hline Water + AFA & 7.41 & 2 & 0.40 & 0.56 \\
\hline Water + AFA & 7.41 & 5 & 1.4 & 1.6 \\
\hline Water + AFA & 7.41 & 10 & 4.4 & 4.1 \\
\hline AZ-101, $13 \mathrm{~Pa}+\mathrm{AFA}$ & 1.31 & 2 & 1.7 & 0.92 \\
\hline $\mathrm{AZ}-101,13 \mathrm{~Pa}+\mathrm{AFA}$ & 1.31 & 5 & 2.0 & 2.1 \\
\hline $\mathrm{AZ}-101,13 \mathrm{~Pa}+\mathrm{AFA}$ & 1.31 & 10 & 2.7 & 3.0 \\
\hline AZ-101, $13 \mathrm{~Pa}+\mathrm{AFA}$ & 1.31 & 10 & 3.0 & 3.4 \\
\hline $\mathrm{AZ}-101,13 \mathrm{~Pa}+\mathrm{AFA}$ & 7.41 & 2 & 0.96 & 0.25 \\
\hline AZ-101, $13 \mathrm{~Pa}+\mathrm{AFA}$ & 7.41 & 5 & 1.3 & 0.46 \\
\hline AZ-101, $13 \mathrm{~Pa}+\mathrm{AFA}$ & 7.41 & 10 & 1.4 & 1.3 \\
\hline \multicolumn{5}{|c|}{$\begin{array}{l}\text { (a) The simulant properties were assumed to be the following: } \tau_{0}=0 \mathrm{~Pa}, \mu_{B}=0.001 \mathrm{~Pa} \text { s, and } \rho=998 \mathrm{~kg} / \mathrm{m}^{3} \mathrm{fo} \\
\text { water; } \tau_{0}=13 \mathrm{~Pa}, \mu_{B}=0.009 \mathrm{~Pa} \text { s, and } \rho=1173 \mathrm{~kg} / \mathrm{m}^{3} \text { for nominal } 13-\mathrm{Pa} \mathrm{AZ}-101 \text { simulant; } \sigma=0.070 \mathrm{~N} / \mathrm{m} \\
\text { without AFA and } 0.035 \mathrm{~N} / \mathrm{m} \text { with AFA. } \\
\text { (b) "n/a" denotes a measurement that is not available. }\end{array}$} \\
\hline
\end{tabular}

By definition, the volumetric specific area, $a_{V}$, the total bubble area per volume of the bubbly liquid is related to the specific area per bubble, $a$, by

$$
a_{V} \propto a \alpha_{A}
$$

The specific area, $a$, can be arrived at from Eq. (C.40), because it is proportional to the inverse cube root of the bubble volume:

$$
a \propto\left(\frac{\rho g}{\mu \bar{U}_{A s} d_{c}^{2}}\right)^{1 / 4}
$$


Combining Eq. (C.40, C.41, C.42, and C.43) gives a possible correlating equation for $k_{L i} a_{V}$ that has the form

$$
k_{L i} a_{V} \propto\left(\frac{\bar{U}_{A s} g \rho D_{i}^{2}}{\mu}\right)^{1 / 4}\left(\frac{\rho g}{\mu \bar{U}_{A s} d_{c}^{2}}\right)^{1 / 4}\left(\frac{\rho \bar{U}_{A s}^{7}}{\mu d_{c}^{2} g^{3}}\right)^{1 / 8}
$$

All the exponents in Eq. (C.44) can be considered variables, if the equation is used for correlation.

Volumetric mass transfer coefficients for oxygen transfer to air sparge bubbles were measured between the top and bottom of the same 30-inch bubble column referred to in Section C.4.3. Table C.3 shows the measured volumetric mass transfer coefficients.

Table C.3. Volumetric Mass transfer Coefficients Measured in 30-Inch Bubble Column

\begin{tabular}{|c|c|c|c|}
\hline Simulant & $\begin{array}{c}\text { Simulant } \\
\text { Depth } \\
\text { (m) }\end{array}$ & $\begin{array}{c}\text { Superficial } \\
\text { Velocity at Nozzle } \\
(\mathbf{m m} / \mathbf{s}) \\
\end{array}$ & $\begin{array}{c}\text { Measured } \\
k_{L} a_{v} \\
\left(s^{-1}\right) \\
\end{array}$ \\
\hline Water & 1.31 & 2 & 0.0012 \\
\hline Water & 1.31 & 5 & 0.0037 \\
\hline Water & 1.31 & 10 & 0.0093 \\
\hline Water + AFA & 1.31 & 2 & 0.00091 \\
\hline Water + AFA & 1.31 & 5 & 0.0025 \\
\hline Water + AFA & 1.31 & 10 & 0.0050 \\
\hline Water & 3.63 & 2 & 0.0015 \\
\hline Water & 3.63 & 5 & 0.0050 \\
\hline Water & 3.63 & 10 & 0.0116 \\
\hline Water + AFA & 3.63 & 2 & 0.0010 \\
\hline Water + AFA & 3.63 & 5 & 0.0024 \\
\hline Water + AFA & 3.63 & 10 & 0.0074 \\
\hline Water & 7.41 & 2 & 0.0019 \\
\hline Water & 7.41 & 5 & 0.0042 \\
\hline Water & 7.41 & 10 & 0.0106 \\
\hline Water + AFA & 7.41 & 2 & 0.0010 \\
\hline Water + AFA & 7.41 & 5 & 0.0026 \\
\hline Water + AFA & 7.41 & 10 & 0.0068 \\
\hline AZ-101, 13 Pa + AFA & 1.31 & 2 & 0.00079 \\
\hline $\mathrm{AZ}-101,13 \mathrm{~Pa}+\mathrm{AFA}$ & 1.31 & 5 & 0.0018 \\
\hline $\mathrm{AZ}-101,13 \mathrm{~Pa}+\mathrm{AFA}$ & 1.31 & 10 & 0.0050 \\
\hline $\mathrm{AZ}-101,13 \mathrm{~Pa}+\mathrm{AFA}$ & 1.31 & 10 & 0.0048 \\
\hline $\mathrm{AZ}-101,13 \mathrm{~Pa}+\mathrm{AFA}$ & 7.41 & 2 & 0.00037 \\
\hline AZ-101, $13 \mathrm{~Pa}+\mathrm{AFA}$ & 7.41 & 5 & 0.0011 \\
\hline $\mathrm{AZ}-101,13 \mathrm{~Pa}+\mathrm{AFA}$ & 7.41 & 10 & 0.0027 \\
\hline
\end{tabular}


It has been assumed, in discussing and deriving the mass transfer models above, that the slurry is well-mixed on the time scale of the rise of a single sparge bubble. In the plant and in the QSLS tests the two sources of mixing will be the sparge bubbles themselves and the operation of the pulse-jet mixers (PJMs). In the bubble-column mass transfer tests, only the sparge-bubble mixing will be present. Because the sparge bubble rise time is expected to be short (on the order of seconds), while the PJMs circulate the tank slurry volume through themselves in times that are on the order of minutes, it is unlikely that PJMs alone provide the requisite degree of mixing. The mixing produced by the sparge bubbles may be adequate, however.

Axial backmixing and dispersion in bubble columns has undergone considerable study, often in the context of interpreting concentration data to derive values of $k_{L} a$ (volumetric mass transfer coefficients) for the system. Interpretation methods range from assuming zero backmixing in the liquid phase (a plugflow model) to assuming complete mixing (a continuous stirred-tank reactor model, or CSTRM), which is analogous to the fully mixed assumption in the present gas-striping model. Partial back-mixing can be described using an axial-dispersion model (ADM) that incorporates an axial dispersion coefficient (and assumes radial mixing is perfect).

A few of the pertinent studies include Deckwer et al. (1974), Deckwer et al. (1983), and Lau et al. (2004). Deckwer et al. (1983) concluded that the ADM was best suited to determining mass transfer coefficients from data in that it avoided finding incorrect dependencies of $k_{L} a$ on the liquid velocity and dispersion height, but that the $k_{L} a$ values obtained were not strongly dependent on the degree of backmixing assumed. Lau et al. (2004) determined $k_{L} a$ from data by using both ADM and CSTRM assumptions. A comparison of the results showed that the back-mixing assumption made little difference in the $k_{L} a$ over a range of gas velocities from 3 to $35 \mathrm{~cm} / \mathrm{s}$. These velocities were higher than will be used in the WTP tests and the process plant, where the superficial gas velocity will be less than $1 \mathrm{~cm} / \mathrm{s}$. At $3 \mathrm{~cm} / \mathrm{s}$, the lowest velocity studied, Lau et al. found that using the CSTRM assumption gave a $k_{L} a$ about $20 \%$ higher than the more accurate ADM-based value. Larger overestimations of $k_{L} a$ could be expected at lower velocities, judging by the data trends.

Based on the bubble column results, sparging alone produces enough mixing to allow the assumption of full mixing to be moderately accurate. The additional mixing from the PJMs assists in approximating full mixing. Of course, the accuracy of any modeling approach is necessarily limited, given the complex effects of the AFA surfactant, breakup, and coalescence. Within these limitations, the assumption of full mixing (CSTRM) is considered a reasonable approximation for a model of gas stripping in the process vessels and test stands.

\section{C.5 References}

Acharya A, RA Mashelkar, and J Ulbrecht. 1978. "Bubble formation in non-Newtonian fluids." Ind. Eng. Chem. Fundam., 17:230-232.

Bhavaraju SM, TWF Russell, and HW Blanch. 1978. "The Design of Gas Sparged Devices for Viscous Liquid Systems.” AIChE J., 24(3):454-466. 
Bontha JR, CW Stewart, LK Jagoda, CD Johnson, DE Kurath, KS Koschik, PA Meyer, DL Lessor, ST Arm, F Nigl, CE Guzman-Leong, RL Russell, MS Fountain, GL Smith, M Friedrich, W Yantasee, SA Hartley, and ST Yokuda. 2005. Technical Basis for Predicting Mixing and Flammable-Gas Behavior in the Ultrafiltration Feed Process and High-Level Waste Lag Storage Vessels with NonNewtonian Slurries. WTP-RPT-132 Rev. 0, Battelle Pacific Northwest Division, Richland, Washington.

Deckwer WD, R Burckhart, and G Zoll. 1974. "Mixing and Mass Transfer in Tall Bubble Columns." Chem. Eng. Sci., 29:2177-2188.

Deckwer WD, K Nguyen-Tien, BG Kelkar, and YT Shah. 1983. "Applicability of Axial Dispersion Model to Analyze Mass Transfer Measurements in Bubble Columns." AlChE J, 29(6):915-922.

Fan LS and K Tsuchiya. 1990. Bubble wake dynamics in liquids and liquid-solid suspensions. Butterworths-Heinemann Series in Chemical Engineering, Butterworths, Boston, Massachusetts.

Grima EM, Y Chisti, and M Moo-Young. 1997. "Characterization of shear rates in airlift bioreactors for animal cell culture.” J. Biotechnol., 54:195-210.

Guzman-Leong CE, CW Stewart, JM Alzheimer, LA Mahoney, ST Arm, and LK Jagoda. 2007. Test Plan for Large Scale Testing for Effects of Anti-Foam Agent on Gas Retention and Release. TP-RPPWTP-476 Rev. 0, Battelle - Pacific Northwest Division, Richland, Washington.

Halard B, Y Kawase, and M Moo-Young. 1989. "Mass Transfer in a Pilot Plant Scale Airlift Column with Non-Newtonian Fluids." Ind. Eng. Chem. Res., 28:243-245.

Haque HW and KDP Nigan. 1987. "Studies on Gas Holdup and Bubble Parameters in Bubble Columns with (Carboxymethyl) cellulose Solutions." Ind. Eng. Chem. Res., 26:86-91.

Hermann C, I Dewes, and A Schumpe. 1995. "The Estimation of Gas Solubilities in Salt Solutions." Chem. Eng. Sci., 50(10):1673-1675.

Jin H, S Yang, T Zhang, and Z Tong. 2004. "Bubble Behavior of a Large-Scale Bubble Column with Elevated Pressure." Chem. Eng. Technol., 27(9):1007-1013.

Kawase Y and M Moo-Young. 1987. "Theoretical Prediction of Gas Holdup in Bubble Columns with Newtonian and Non-Newtonian Fluids." Ind. Eng. Chem. Res. 26:933-937.

Kawase Y and M Moo-Young. 1990. "Oxygen Transfer in Slurry Bioreactors.” Biotech. and Bioeng. 37:960-966.

Krishna R and J Ellenberger. 1996. "Gas holdup in Bubble Column Reactors Operating in the ChurnTurbulent Flow Regime.” AIChE J. 42(9):2627-2634.

Krishna R, MI Urseanu, JM van Baten, and J Ellenberger. 1999. "Rise velocity of a swarm of large gas bubbles in liquids." Chem. Eng. Sci. 54(2):171-183. 
Kulkarni AA and JB Joshi. 2005. "Bubble Formation and Bubble Rise Velocity in Gas-Liquid Systems: A Review." Ind. Eng. Chem. Res. 44:5873-5931.

Lau R, W Peng, LG Velazquez-Vargas, GQ Yang, and L-S Fan. 2004. "Gas-Liquid Mass Transfer in High-Pressure Bubble Columns.” Ind. Eng. Chem. Res. 43:1302-1311.

Lessard RR and SA Zieminski. 1971. "Bubble Coalescence and Gas Transfer in Aqueous Electrolytic Solutions." Ind. Eng. Chem. Fundam., 10:260-269.

Moo-Young M, B Halard, DG Allen, R Burrell, and Y Kawase. 1987. "Oxygen Transfer to Mycelial Fermentation Broths in an Airlift Fermentor." Biotech. and Bioeng. 30:746-753.

Norton JD and LR Pederson. 1995. Solubilities of Gases in Simulated Tank 241-SY-101 Wastes. PNL10785, Pacific Northwest National Laboratory, Richland, Washington.

Russell RL, CW Stewart, SD Rassat, CD Johnson, ST Arm, PA Meyer, MS Fountain, CE GuzmanLeong, and BK Hatchell. 2005. Final Report: Gas Retention and Release in Hybrid Pulse Jet Mixed Tanks Containing Non-Newtonian Waste Simulants. WTP-RPT-114 (PNWD-3552) Rev. 1, Battelle Pacific Northwest Division, Richland, Washington.

Poloski AP, ST Arm, JA Bamberger, B Barnett, R Brown, BJ Cook, CW Enderlin, MS Fountain, M Friedrich, BG Fritz, RP Mueller, F Nigl, Y Onishi, LA Schienbein, LA Snow, S Tzemos, M White, and JA Vucelick. 2005. Technical Basis for Scaling of Air Sparging Systems for Mixing in NonNewtonian Slurries. WTP-RPT-129 (PNWD-3541) Rev. 0, Battelle Pacific Northwest Division, Richland, Washington.

Prince MJ and HW Blanch. 1990. "Transition Electrolyte Concentrations for Bubble Coalescence." AIChE J., 36:1425-1429.

Stewart CW, PA Meyer, MS Fountain, CE Guzman-Leong, SA Hartley-McBride, JL Huckaby, BE Wells. 2006. Effect of Anti-Foam Agent on Gas Retention and Release Behavior in Simulated High Level Waste. WTP-RPT-147 Rev. 0, Battelle - Pacific Northwest Division, Richland, Washington. 
Appendix D

Process and Instrumentation 


\section{Appendix D - Process and Instrumentation}

The DACS hardware consisted of four key components, the National Instruments FieldPoint System, the DACS data processing computer, the DACS velocity calculation computer, and the Ethernet HUB. Figure D.1 shows the schematic configuration of the hardware.

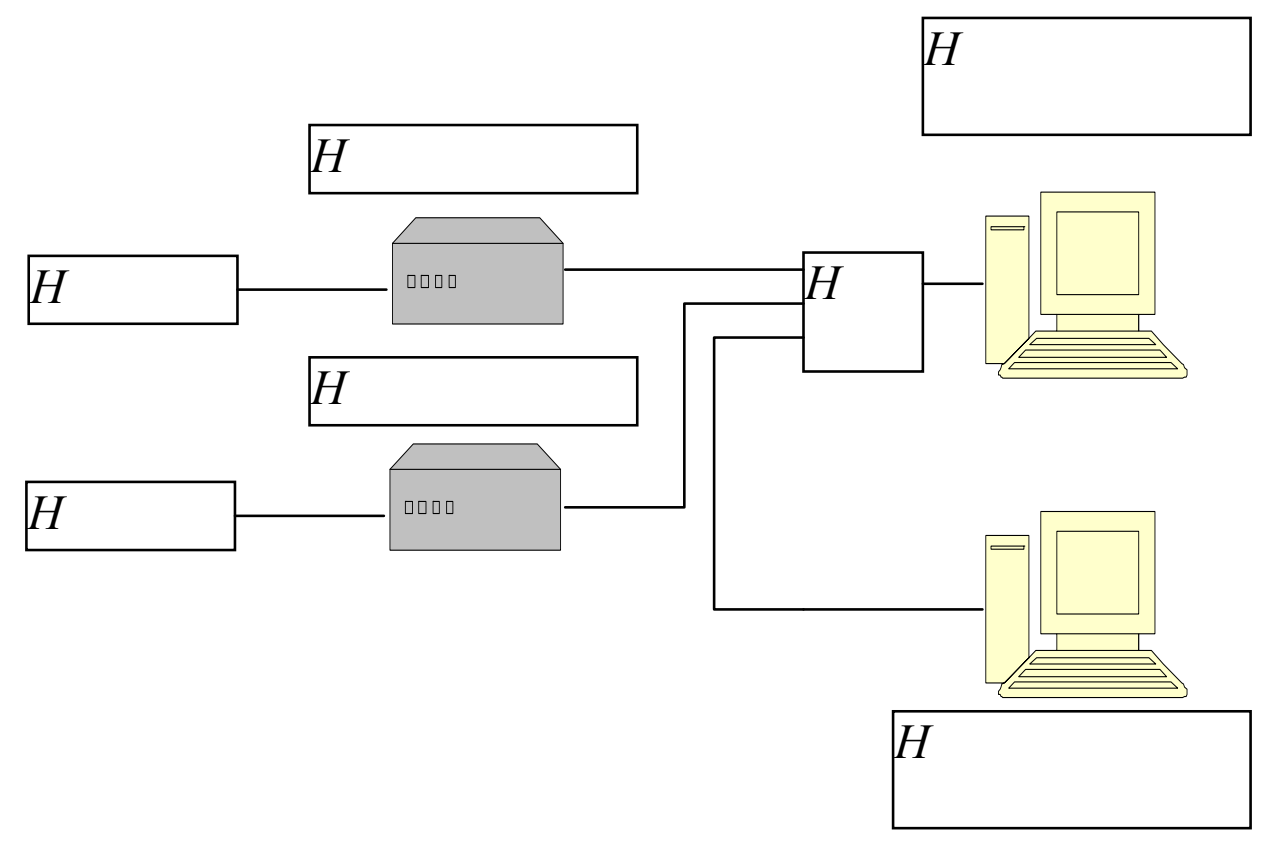

Figure D.1. AFA DACS Hardware Configuration

\section{D.1 FieldPoint Program (CollectDS4.VI)}

The FieldPoint input modules transformed the analog instrument signal to digital. The FieldPoint processor provided the digital signal without any further manipulations as "raw" data or in instrumentrelevant engineering units. The processor was programmed with the information necessary to convert the "raw" signal into "engineering unit" data. The FieldPoint program began by initializing all the arrays and variables that would be used. The two COM ports were then initialized for the hydrogen peroxide pump and scale. The hydrogen peroxide pump was then initialized and assigned an address.

Two while loops were initiated after the general initialization of the program was complete. The while loops operated simultaneously until the program was stopped. The smaller while loop's only function was the case structure; the case structure function was executed only when the program was instructed to process $1 \mathrm{~Hz}$ data. This loop cycled at a 0.1 second rate and read the valve position command from the data display computer, then set the valves to the desired positions. The valve position command also determined whether $1 \mathrm{~Hz}$ or $10 \mathrm{~Hz}$ data was being processed and whether to re-initialize the hydrogen peroxide pump. The larger while loop cycled at $1 \mathrm{~Hz}$ when $1 \mathrm{~Hz}$ data were requested and at $10 \mathrm{~Hz}$ when $10 \mathrm{~Hz}$ data were requested. This was accomplished with a dual-case structure in which the true case collected $10 \mathrm{~Hz}$ data and the false case collected $1 \mathrm{~Hz}$ data. Because the $10 \mathrm{~Hz}$ data were a subset of the $1 \mathrm{~Hz}$ data, it collected the necessary data in less than the 100 milliseconds requirement. The 
$1 \mathrm{~Hz}$ data, on the other hand, included all the data available and collected data not only from the FieldPoint channels but also from the hydrogen peroxide scale and pump; consequently, it required more time to complete a data acquisition cycle. While the valves were controlled in a separate $10-\mathrm{Hz}$ while loop during $1-\mathrm{Hz}$ operation, the valves were controlled from within the $10-\mathrm{Hz}$ case during $10-\mathrm{Hz}$ operation. Once the data were collected and converted to engineering units, they were compiled into an array and published into a data socket that was accessed from the data display computer.

\section{D.2 Display Computer (AFA.VI)}

The AFA graphical user interface (AFAGUI) in the data display computer performed the following nine functions:

1. Received data from the FieldPoint computers (FPCs). Two FPCs were centrally located with the AFA operating equipment to minimize signal loss and distortion. The FPCs collected analog input data from the system process detectors and converted it to digital data for the AFAGUI. The AFAGUI received data from the FPCs in the form of an 80-data packet, tabdelimited data string that included the data collection date and time.

2. Displayed data in a graphical format. The FPC data and some calculated results were displayed on two AFAGUI monitors. The left monitor displayed the data in a piping and instrument diagram format for easy operator interpretation and showed humidity levels, pressures, and temperatures as well.

3. Audio and/or visual alarms for out-of-range data. The AFAGUI had on-screen controls for the operator to set operating limits for some of the system parameters. The right AFAGUI monitor had a mix of audio, visual, and functional alarms that operated automatically if the operating parameter exceeded the prescribed set points.

4. Calculate and display limited results. The right AFAGUI monitor displayed some instantaneous information but focused on graphs of data and results over time. The right AFAGUI monitor also provided a set of input controls where the operator could control the time-dependent structure of the timing cycle. The results of the timed cycle were displayed for ease of analysis; some mathematical results were also displayed.

5. Compiling and storing operating records. The AFAGUI compiled designated operating parameters into structured files and saved the files to disk as permanent records, storing system data as $1-\mathrm{Hz}, 10-\mathrm{Hz}$, cycle, and alpha files.

6. Providing a graphical interface for automatic control of valve action. The right AFAGUI monitor also had controls for automatic (timed) operation of selected operating valves. When the program controls were configured for "Automatic" and "Run" operations, the control program controls the operation of the selected valves. One second and 1/10-second resolution can be programmed into automatic valve operation.

7. Providing a graphical interface for manual control of valve action. When the program controls are configured for manual operations, the manual controls became visible. The same selected valves could be manually opened and closed at operator discretion.

8. Transmitting operating timing instructions to the FPCs. The AFAGUI transmitted valve position to the FPCs, and the FPCs controlled the valves accordingly. 
9. Automatic SAFE shutdown. There is an emergency stop button, "E-STOP," on the left AFAGUI monitor that had the same functionality as the red mechanical emergency shutdown buttons. If the E-STOP- screen button was pushed, the operating system performed a controlled sequence shutdown. This function did NOT de-energize the equipment.

\section{D.3 Velocity Calculation Instrument (AFA_CALCS.VI)}

The purpose of the AFA_CALCS virtual instrument (VI) was to calculate the discharge time and peak average velocity from the contents expelled by the PJM nozzles during a PJM drive cycle. The nozzle velocity was evaluated by averaging the PJM level, laser level, and PJM pressure data obtained during a $10-\mathrm{Hz}$ data capture and transferred from the data computer. During $10 \mathrm{~Hz}$ data capture, idle sparging was used to minimize tank surface level fluctuations. Each data set calculated a velocity curve (distribution); the curves were compared to determine the system response. Refer to Appendix B for details on the analysis of the data.

One while loop started during program initialization. All program activities functioned by user input. Once the data file was loaded into the program, the user set each data analysis screen to the parameters required by the test. The user also set the number of data samples per cycle the program used in calculations. For the AFA testing, the samples were set to 540 per cycle; the entire PJM cycle was 54 seconds at a $10-\mathrm{Hz}$ sampling rate. The user also supplied the number of cycles to use, which was usually the number of cycles residing in the $10 \mathrm{~Hz}$ data samples. Velocity calculations used three sets of data: laser level, PJM level, and PJM pressure.

The user input the required parameters and selected the laser levels to use. The program averaged the laser levels throughout the number of cycles. This gave a one-cycle representation that was an average of all the laser levels.

The final velocity calculation used laser level change over a known time, in this case $100 \mathrm{~ms}$. The calculation was a basic one of distance and time. The calculation was scaled by a nozzle area factor that took into account the area of the clay at that particular level. The user input the required parameters and selected the PJM levels to use. The program averaged each PJM level throughout the number of cycles. This gave a one-cycle representation that was the average of the other PJM levels.

The user selected which PJM pressures to use. The program averaged each pressure throughout the number of cycles. This gave a one-cycle representation that was then averaged with those of the other PJM pressures. The final velocity calculation was done using PJM pressure over the same $100 \mathrm{~ms}$ and the Bernoulli principle. A tube-to-tank area factor then scaled the calculation. Each time the user calculated a velocity, a plot appeared on the main graph. Once each was calculated, they were plotted over each other for comparison.

The velocity graph had two cursors that snapped to the selected plot. Moving along this plot, the user set the start and end points to calculate the maximum peak velocity. The time of discharge was calculated by the end point time minus the start point time. The peak velocity was calculated by integrating the levels between the cursors. 


\section{D.4 Main Air Supply and Control System}

The main air supply for PJMs and spargers is supplied by a large electric air compressor outside the APEL building. The compressor supplies air at $125 \mathrm{psig}$ at up to $400 \mathrm{acfm}$ to a $\sim 100$-gal surge tank immediately upstream of the air control manifolds. An oil/dust filter and dryer assembly remove oil, particulates, and water droplets from the air before they enter the PJM control manifold and sparger arrays.

An induced draft ventilation system incorporating a cover on the top of the tank contained hazardous aerosols. A duct on top of the test vessel ceiling was connected to a nearby 500-gal tank. The pressure in this tank was kept slightly below atmospheric pressure. The air from the spargers was routed through this tank. As the level in the test vessel rose and fell, the head space pressure was maintained fairly constant by its connection to the 500-gal tank. The outlet of the PJM drive system was routed to another 500-gal tank that was also connected to the ventilation system. The air leaving the two 500-gal tanks was routed through a HEPA filter before being exhausted outside the building.

The PJM operating cycle is controlled using jet-pump pairs (JPPs) with valves controlled by the DACS connected to a pressurized air source and a vent. The PJMs are all operated simultaneously. Capacitance liquid level sensors and pressure transducers monitor the liquid height and pressure, respectively, for each pulse tube. The air to drive the PJMs was supplied by the electric compressor located outside of the building. The air was routed to a receiver tank inside the building and then through a bank of desiccant tubes. The desiccant tubes were used to remove the majority of the moisture from the compressed air but their primary purpose was to remove any oil from the air supply. The oil had to be removed to keep it from influencing the behavior of the AFA.

Downstream of the desiccant tubes, the air supply was broken into three streams. One stream was for the drive side of the JPP, one was for the vacuum side of the JPP, and the third was for the main sparger supply. Each of these streams had its own pressure regulator and control valve.

Operation of the drive system was accomplished using four angle seat valves and two JPPs. The two JPPs were configured in parallel. Both drive sides were supplied by a single control valve and both vacuum sides were also supplied by a single control valve. Manual ball valves were installed on one JPP so that it could be turned off if desired. During operation, it was determined that using both drives sides of the JPPs provided the best response but using only one of the vacuum sides provided a high level of vacuum and better response. A control valve was also located down stream of the JPP exits. During the drive portion of the cycle, this valve was closed to prevent blow by through the JPPs and increase efficiency. This valve was closed only during the drive phase. Another control valve was installed in a line between the two 500-gal tanks. During the last phase of the drive cycle this valve was opened, which equalized the pressure inside the pulse tubes with the pressure in the vessel head space. This was done to permit the simulant surface levels inside and outside of the pulse tubes to be as close as possible to reduce the errors in simulant volumes as determined by the surface level measurements.

Downstream of the JPPs was a manifold that separated the flow into eight streams. The flow restrictions for each path were similar so that the response of all PJMs would be as similar as possible. Ball valves were located in each line so that individual PJMs could be isolated but these were not closed during testing. 
The primary sparge air was controlled by a single control valve. A manifold downstream of the primary sparge air valve broke the stream into seven streams, one for each sparge line. Each stream had an adjustable rotameter so that the desired sparge flow rate could be obtained. In parallel with the primary sparge air supply was an idle sparge air system which was connected to the building air supply so that when the large outside compressor was not operating the sparge lines could be pressurized to prevent simulant from filling and potentially plugging them. Check valves between the idle sparge and primary sparge supplies prevented air crossing between systems. The air flow to the spargers is regulated through a manifold adjacent to the QSLS tank. The primary sparger system had a manual pressure regulator upstream of the manifold and a single normally closed angled seat valve to turn the spargers on and off.

The manifold controlling the operation of the PJMs and spargers is connected to the pulse tubes and sparge tubes with 1-inch PVC hose. During the suction phase, simulant can potentially rise in the pulse tube piping far above the tank liquid level. To prevent suction of the liquid into the control manifold, the piping connecting the pulse tubes to the manifold is routed over a horizontal support approximately $5 \mathrm{~m}$ above the top of the vessel.

\section{Control of the PJM Drive System}

Operation of the QSLS test setup was relatively straightforward. The PJM cycling consisted of four phases, the drive phase, vacuum phase, static phase, and the equilibration phase. Four valves were used to control the drive cycle. Upstream of the drive side of the JPPs was a normally closed angled seat valve. When this valve was opened, air flowed through the JPPs to the PJM manifold and then to the PJMs. Another normally opened angled seat valve on the downstream side of the JPP was closed during the drive phase to eliminate the normal leakage through the JPP. The air pressure to the drive side was controlled by a manual pressure regulator. During the vacuum phase, the drive valve was closed, and the normally closed angled seat valve on the vacuum side of the JPPs was opened along with the valve on the downstream side of the JPPs. The air pressure to the vacuum side of the JPP was controlled by its own manual pressure regulator. During the static phase, the valves to the JPPs were closed, and the valve on the downstream side of the JPPs was opened. This vented the residual pressure in the PJMs to the exhaust system. During the drive phase, the vacuum phase, and the static phase, a normally open angled seat valve between the PJM drive and the dome exhaust was closed. During the equilibrium phase this valve was opened, and the pressure between the dome space and the insides of the PJMs allowed coming to equilibrium. This was done to allow the simulant level inside and outside the PJMs to be as close to equal as possible, so that errors in trapped gas calculations using the surface laser level measurements would be minimal.

Tuning the drive system was relatively simple. For the drive phase, the two parameters that could be adjusted were the drive time and the pressure setting on the drive pressure regulator. For the vacuum phase, the two parameters were again the time and pressure values. The only parameters for the static and equilibrium phases were the times and only one of the times was independent because a fixed total cycle time was maintained.

\section{D.5 Hydrogen Peroxide Injection System}

The decomposition of a nominally $31 \mathrm{wt} \%$ hydrogen peroxide aqueous solution was used to generate gas in situ in each simulant used for these tests. Two instruments were associated with the hydrogen 
peroxide injection system. These were a scale measuring the weight of hydrogen peroxide in the supply vessel and a mass flow meter downstream of the injection pump. Due to sensitivity issues, the mass flow meter data was not used. However, the weight of peroxide in the vessel over time was used to determine the hydrogen peroxide injection rates. The hydrogen peroxide was injected at seven separate locations near the tip of each of the outer pulse tube nozzles and during PJM and sparger operation to ensure uniform distribution of the gas generation in the tank and mixed rapidly with the simulant. A peristaltic pump with seven tubes driven by a single rotor fed the hydrogen peroxide solution.

\section{D.6 Transfer and Sampling System Description}

The simulant transfer system was used to transfer simulant in and out of the QSLS tank, and the sampling system was used to draw samples of simulant for rheological analyses. During testing, some minor changes were made to both systems. Changes made to the transfer system were to augment the invessel mixing during rheology adjustments. Changes to the sampling system were made to overcome difficulties encountered with sampling the thicker simulant.

The simulant transfer system used with the AZ simulant consisted of a 1-inch-diameter stainless steel piping network and an air-operated diaphragm pump along with a routing valve setup. By changing the valve settings, simulant could be pumped either from the tote into the test vessel or from the test vessel into the tote. The piping network started from a tote in the secondary containment area and extended to the top of the QSLS tank. The tote and the simulant transfer system along with the test vessel were all inside of the secondary containment. The transfer system was also used to recirculate the simulant inside the test vessel while rheology adjustments were being made. In this mode, the connection to the tote was replaced with a connection to a one inch stainless steel line that terminated just under the surface of the simulant. Simulant was pumped from the top of the vessel to the bottom of the vessel to augment the pulse jet mixing only during rheology adjustments. This was not done during actual testing.

The AZ simulant transfer system was fitted with six valves to control simulant transfer into and out of the QSLS tank. Figure D.2 illustrates the simulant transfer setup described in this section. During simulant transfer into the QSLS tank, valves at the tote and inlet to the test vessel were open; the valve between the tote and the inlet (bottom) of the pump was open; the valve between the outlet (top) of the pump and the test vessel was open, and the other two valves were closed. While transferring the simulant out of the tank, the valves at the tote and test vessel remained open and the status of the other four valves was swapped. During operation of the AZ simulant transfer system, the outlet side of the pump was always connected to stainless steel pipe or pressure rated braided stainless steel hose. This was to ensure that the piping system would not be inadvertently over pressurized if a valve were inadvertently left closed. This was a requirement of the applicable codes dealing with pressurized systems containing caustic material. While using the transfer system to augment the mixing during rheology adjustments, the connection on the inlet side was a length of PVC hose. For transfer of water or clay simulant into or out of the test vessel, a different air powered diaphragm pump was used so that contamination of the AZ simulant did not occur. This pump was the same model as the AZ simulant pump but did not have the valve manifold. The connections to the pump were changed at the pump to change the direction of the simulant flow. 


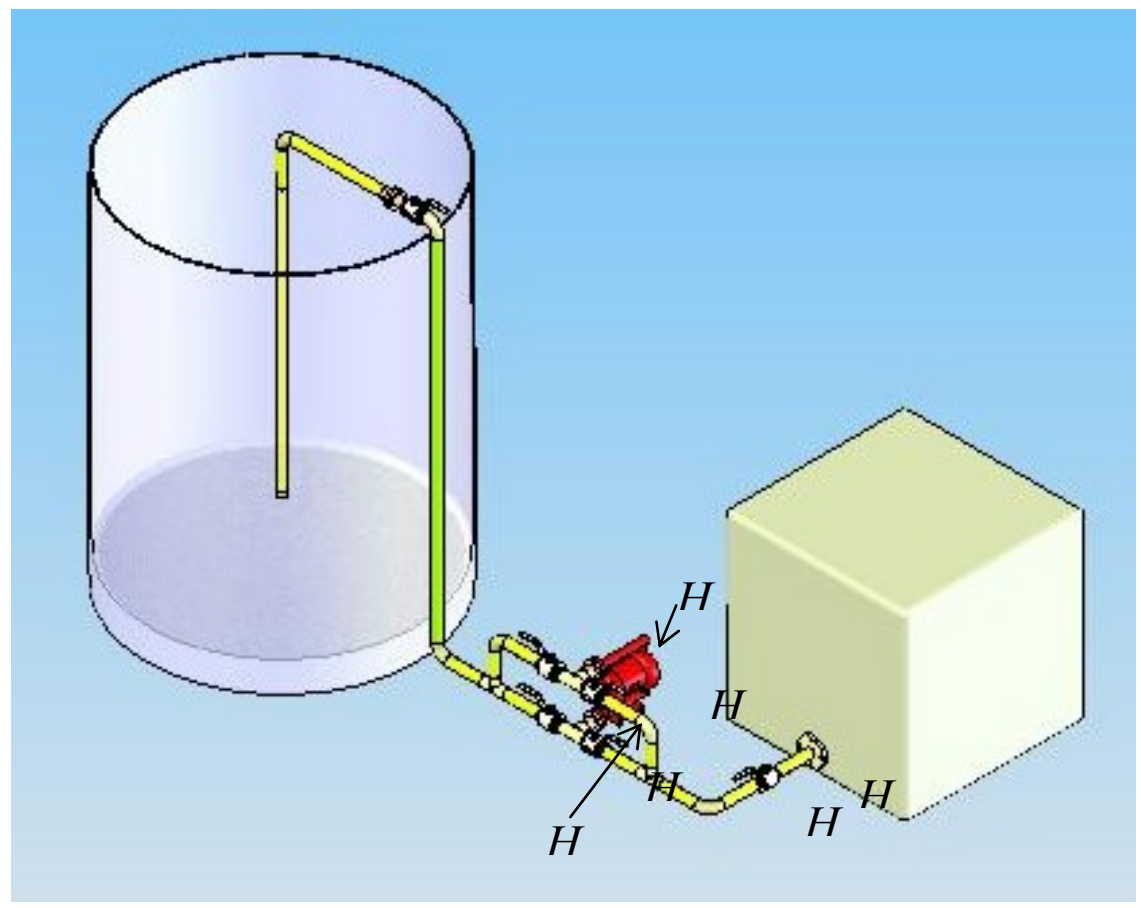

Figure D.2. Simulant Transfer System

Figure D.3 shows the layout of system setup for initial sampling operations. Samples were collected from the bottom, middle, and top of the simulant. The sampling system consisted of three stainless steel tubes (one shown in the figure) that ran from inside of the tank through the secondary containment area, where they are fitted to the suction end of individual diaphragm pumps. Three additional stainless steel tubes continue from the discharge end of each pump back into the top of the QSLS tank. When the pumps were turned on, the slurry continuously cycled in the tubes. Taps were attached to collect the material in to the sampling containers. This system worked satisfactorily for the 3- and 13-Pa simulants but was not adequate for the $30-\mathrm{Pa} \mathrm{AZ}$ simulant. With the higher strength $\mathrm{AZ}$ simulant material, plugging of the lines was a continual problem. The diaphragm pumps were not able to provide enough suction to maintain the flow through the lines. It appeared that the solids in the simulant tended to separate from the liquid at fittings and other locations with non-uniform flow. Once the solids started to collect, the line quickly plugged with additional solids. The sampling system was changed to replace the diaphragm pumps with a single vacuum source. The vacuum was provided by a vacuum pump which was connected to a chamber fabricated from PVC fittings and a section of clear PVC pipe. To collect a sample, the sample line was blown clear using compressed air, the sample line connected the PVC chamber, and the vacuum pump turned on. This drew the simulant up through the sample line and into a sample bottle which was setting inside the PVC chamber. The PVC chamber was then connected to a different sample line and the process repeated with another sample bottle. Experience showed that 30-Pa AZ simulant was about as thick as could be sampled with the $3 / 8$ inch stainless steel lines we used. The stainless steel lines between the top of the test vessel and the sampling chamber were replaced with poly tubing to reduce the flow restrictions and permit collection of good samples. Figure D.4 is a diagram of the entire process and complete instrumentation. 


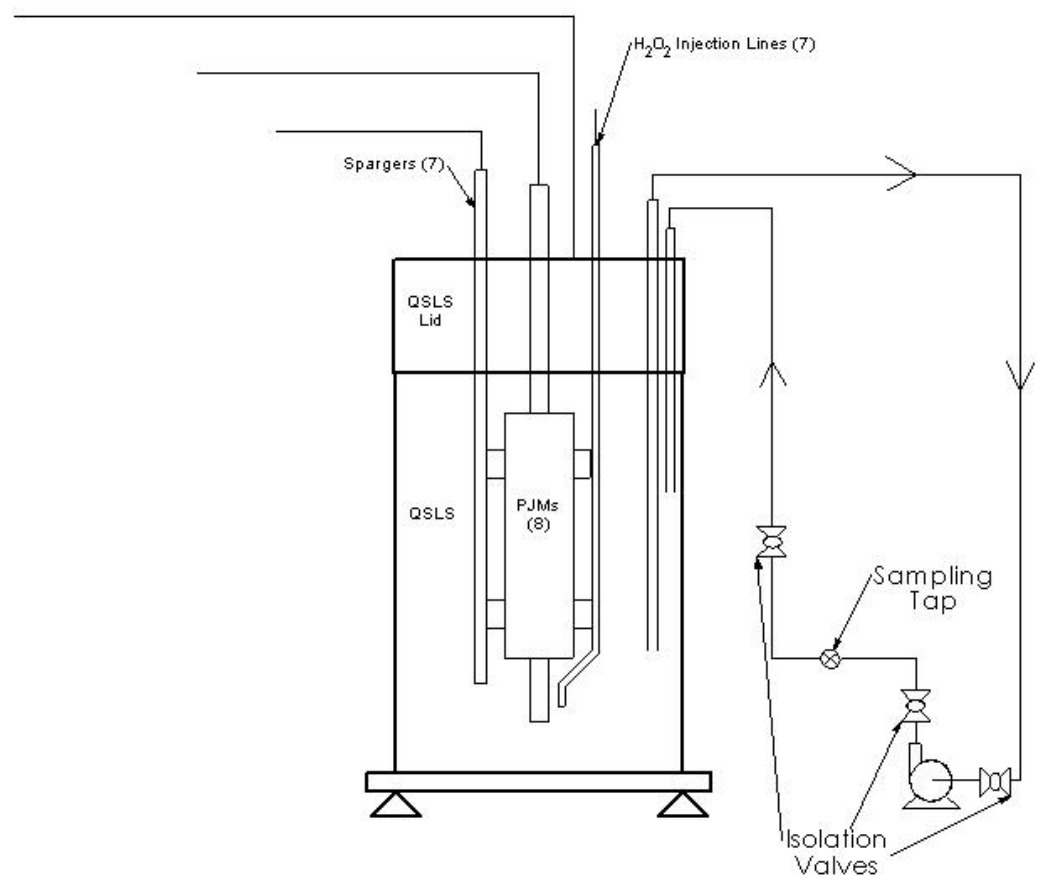

Figure D.3. Sampling System Layout 


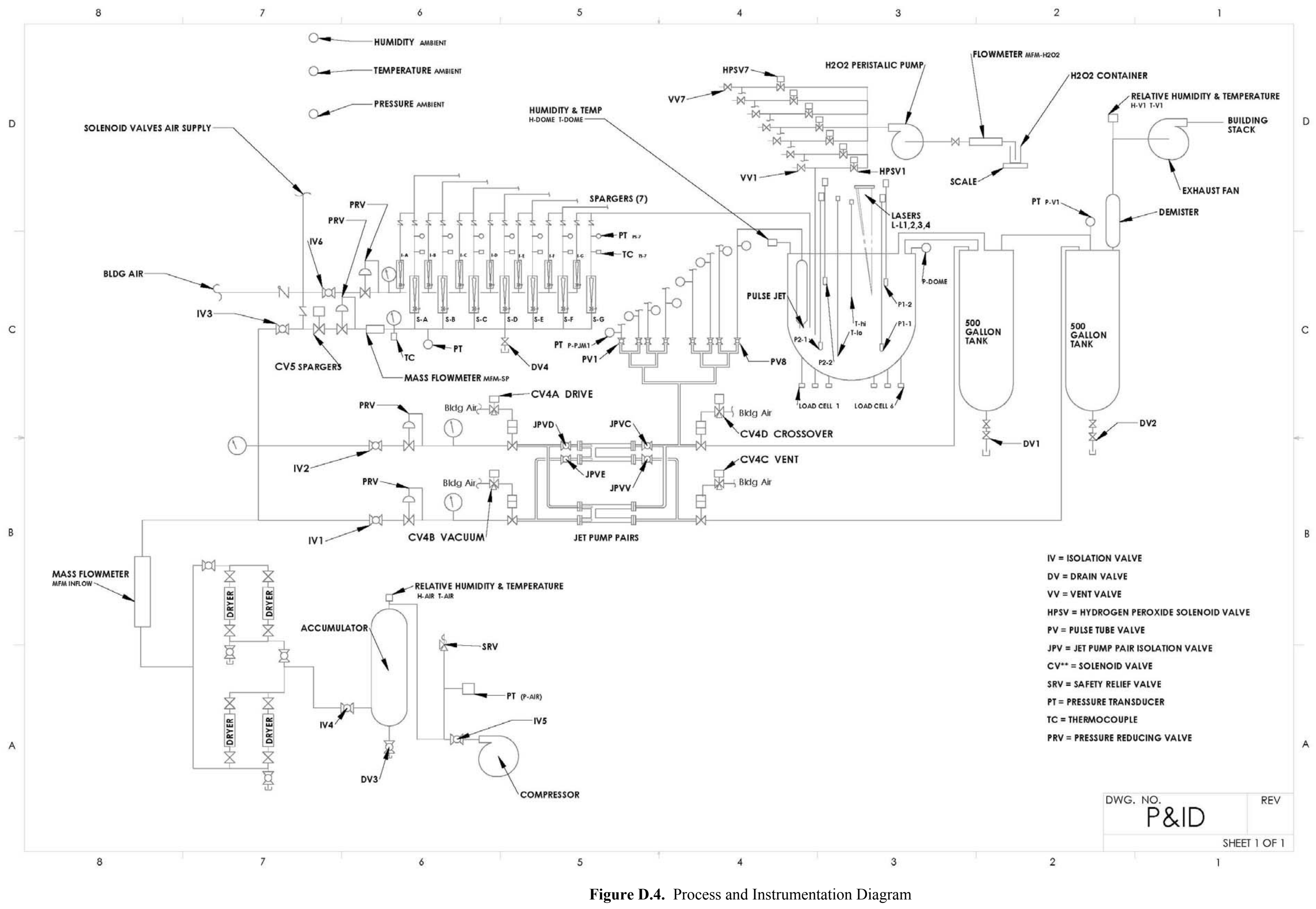

D. 9 


\section{Appendix E}

\section{Details of Statistical Analyses}




\section{Appendix E - Details of Statistical Analyses}

Several statistical analyses were performed to support the data interpretation in Section 5 of the main report. These include definition of steady-state gas fraction data sets (discussed in Section E.1), comparison of gas-fraction means measured at different $\mathrm{H}_{2} \mathrm{O}_{2}$ injection rates to determine whether their differences were statistically significant (Section E.2), determining the uncertainties in the curve-fit parameters that are used as a scaling basis and determining the prediction intervals for the curve fits (Section E.3). Section E.4 contains references cited in this appendix.

\section{E.1 Steady-State Criteria}

The current algorithm used to assess whether the gas volume fraction retained by the simulant in the QSLS test stand has reached steady state involves several statistical tests or criteria. The statistical tests are conducted using moving windows of $m$ data points across data from an experimental run. For the present test series, $m=30$. The data points in these tests are pairs of time and corresponding gas volume fraction approximations. These data pairs are denoted $\left(x_{i}, y_{i}\right)$ where $x$ represents time and $y$ represents the corresponding gas volume fraction approximation. A window of $m$ data points must qualify for assessment as a possible steady state based on process criteria. These criteria are twofold: the $\mathrm{H}_{2} \mathrm{O}_{2}$ addition rate cannot have been changed during the window (or during the 4 points before it), and there must be no large time gaps in the window (or in the 4 points before it). Windows that do not qualify are automatically treated as non-steady state.

The first statistical test involves conducting a simple linear regression using the $m$ data points for a given window, then conducting a test of hypothesis concerning the slope of the regression line. The test compares the null hypothesis that the regression slope equals zero to the alternative hypothesis that the slope does not equal zero. In terms of the steady-state assessment, a slope equal to (or close to) zero suggests steady state for the given window while a slope different from zero suggests that the given window is not at steady state. The test statistic for this test is

$$
t=\frac{b_{1}-\beta_{1}}{S D\left(b_{1}\right)}
$$

where $b_{1}$ is the slope estimate obtained from the simple linear regression with the $m$ data points, $\beta_{1}$ is the slope according to the null hypothesis $\left(\beta_{1}=0\right.$ for this test), and $S D\left(b_{1}\right)$ is the standard deviation associated with the slope estimate from the regression (Hines and Montgomery 1990). The formula for $S D\left(b_{1}\right)$ is

$$
S D\left(b_{1}\right)=\sqrt{\frac{M S E}{S_{x x}}}
$$

where 


$$
M S E=\frac{\sum_{i=1}^{m}\left(y_{i}-\hat{y}_{i}\right)^{2}}{m-2} \quad S_{x x}=\sum_{i=1}^{m}\left(x_{i}-\bar{x}\right)^{2}, \quad \bar{x}=\frac{\sum_{i=1}^{m} x_{i}}{m}
$$

In the above equation, $\hat{y}_{i}$ is the mean value of the set of $y_{i}$. The test statistic formula can be written as

$$
t=\frac{b_{1}-\beta_{1}}{\sqrt{\frac{M S E}{S_{x x}}}}
$$

Because the $y_{i}$ values are themselves medians, they have associated variance estimates that can be calculated using data from the quiet periods represented by the $y_{i}$ 's. These variance estimates could be used in the calculation of $S D\left(b_{1}\right)$ rather than MSE. However, MSE provides an appropriate estimate of the variance associated with the $y_{i}$ 's and is more convenient computationally, particularly because the $y_{i}$ 's are medians. To conduct the test of hypothesis, the observed significance level (or $p$-value) associated with the calculated test statistic is determined based on a Student's $t$-distribution with $m-2$ degrees of freedom. If the $p$-value for the test is less than a specified significance level, typically 0.10 , then the null hypothesis is rejected, suggesting that the regression slope for that particular window is not equal to zero and consequently that the gas volume fraction is not at steady state (based on this first statistical criterion) for that window.

A second statistical criterion used in the algorithm involves the power of the test of hypothesis on the regression slope as described above. The power of the test is defined to be the probability, $\operatorname{Pr}$, of correctly identifying when the true regression slope for a given window is not equal to zero (the regression slope according to the null hypothesis). Because the alternative hypothesis for the test concerning the regression slope was that the slope differed from zero, the test is a two-sided test. Hence, the power of the test is calculated using

$$
\text { power }=1-\left\{\operatorname{Pr}\left[t \leq\left(t_{S L / 2}+\frac{\Delta}{S D\left(b_{1}\right)}\right)\right]+\operatorname{Pr}\left[t \leq\left(-t_{S L / 2}+\frac{\Delta}{S D\left(b_{1}\right)}\right)\right]\right\}
$$

where

$$
\begin{aligned}
& \operatorname{Pr} \quad=\text { the probability } \\
& t \quad=\text { the calculated test statistic, as defined previously } \\
& S L \quad=\text { the specified significance level, typically } 0.10 \\
& t_{S L / 2}=\text { the value from a Student's } t \text {-distribution with } m-2 \text { degrees of freedom associated with } \\
& \text { a probability of } S L / 2
\end{aligned}
$$

Thus the power of the test can also be described as the probability that the null hypothesis (the regression slope equals 0 ) will be rejected if the true regression slope differs from zero by at least $\Delta$. 
Higher values (close to 1) for the power of the test are preferred. To apply the statistical criterion concerning the power of the test, a value of $\Delta$ appropriate for the particular experimental run must be determined. In the current algorithm, $\Delta$ is based on a specified ratio (denoted $R$ ) between $\Delta$ and an estimate of representative data from an experimental run of the standard deviation of the regression slope estimate $\left(\hat{\sigma}_{b_{1}}\right)$. That is, $R=\frac{\Delta}{\hat{\sigma}_{b_{1}}}$; hence $\Delta=R \cdot \hat{\sigma}_{b_{1}}$. Smaller values for $R$ (3 or less) are preferred.

In the current algorithm, the standard deviation estimate $\hat{\sigma}_{b_{1}}$ is calculated as the mean of $S D\left(b_{1}\right)$ values, averaged over all the windows of $m$ data points from an experimental run that that qualify based on process criteria. Determining $\Delta$ based on a specified ratio $R$ offers an intuitive interpretation; the power of the test can be interpreted as the probability of rejecting the null hypothesis if the true regression slope differs from zero (the slope according to the null hypothesis) by more than $R$ standard deviations. If the power of the test for a given window of $m$ data points exceeds a specified value, typically 0.90 for the current steady-state determination algorithm, then the gas volume fraction is considered to be at steady state (based on this second statistical criterion) for that window.

A third statistical criterion used by the steady-state determination algorithm involves a nonparametric runs up and down test for randomness. For this test, a "run" is defined to be a sequence of gas volume fraction determinations $\left(y_{i}\right.$ 's) having either consistently increasing or decreasing values. A "run up" is a sequence of consistently increasing data points; a "run down" is a sequence of consistently decreasing data points. If few runs are present for a given window of $m$ data points, then a nonrandom pattern such as that depicted in Figure E.1 is present in the data. If numerous runs are present in the data for a given window, then a random pattern such as that depicted in Figure E.2 is present in the data. If a more moderate number of runs are present for the data from a given window, then the $y_{i}$ 's are considered to occur (increase or decrease) at random.

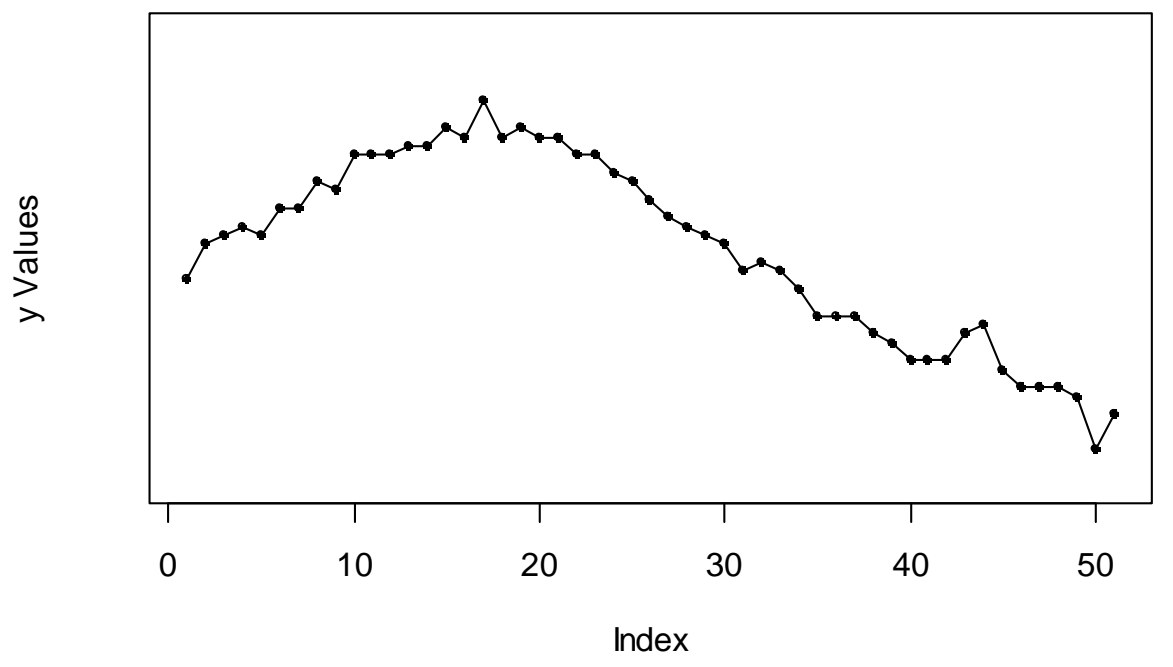

Figure E.1. Window with Nonrandom Pattern of a Few Runs 


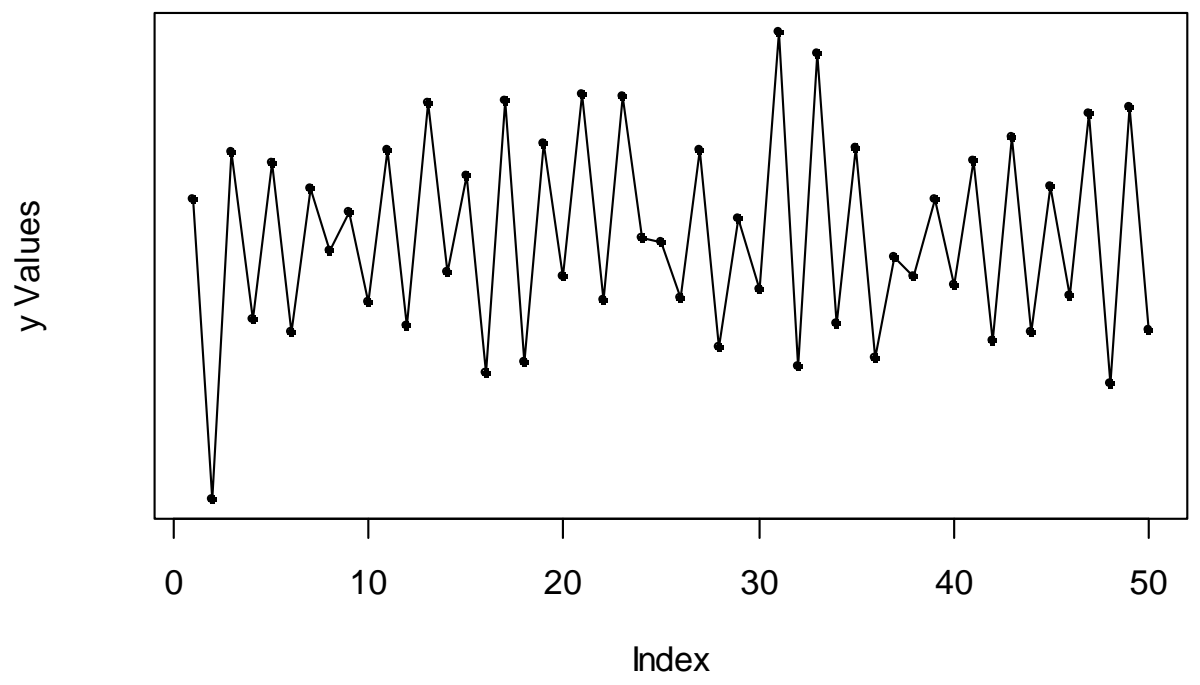

Figure E.2. Window with Random Pattern of Numerous Runs

For the steady-state determination problem, the case of too few runs is of interest. Thus, for each window of $m$ points, a one-sided runs up and down test is conducted where the null hypothesis for the test is that the number of runs present is adequately moderate to consider the $m$ points to occur at random, and the alternative hypothesis is that the number of runs is too few to consider the $m$ points to occur at random. The test statistic for this test is calculated based on $m$ and $V$, the total number of runs among the $m$ data points, whether up or down. The test statistic formula (Gibbons 1985) is based on the asymptotic sampling distribution for a standardized $V$ and is calculated as

$$
z_{L}=\frac{V+0.5-\frac{2 m-1}{3}}{\sqrt{\frac{16 m-29}{90}}}
$$

The test is conducted by comparing the calculated test statistic $z_{L}$ to a critical value obtained from a standard normal distribution. The critical value is denoted $z_{\alpha}$, where $\alpha$ represents a specified significance level for the test. The specified significance level typically used in the steady-state determination algorithm for the runs up and down test is $\alpha=0.10$, so that the corresponding critical value is $z_{\alpha}=-1.28$. The null hypothesis is rejected if the calculated test statistic $z_{L}$ is less than the critical value $z_{\alpha}$. For gas volume fraction to be considered at steady state (based on this third statistical criterion) over a given window of $m$ data points, points should be viewed as occurring at random, so the null hypothesis of the runs up and down test must not be rejected. Note that this test for randomness does not consider the potential trend in the data for the given window; the presence of trend is investigated by the test concerning regression slope describe above. The purpose of this test with respect to steady-state determination is to avoid declaring gas volume fractions from a given window to be at steady state if they display patterns such as that depicted in Figure E.1.

In summary, the current steady-state determination algorithm requires that the $m$ data points from a given window satisfy three statistical criteria in order for gas volumes represented by that window to be considered at steady state: 1) the test concerning the regression slope for that window must not be 
rejected so that the slope is not believed to differ significantly from zero, 2) the power of the test must be sufficiently high so as to be confident that a true slope significantly different from zero would have been detected, and 3) the runs up and down test for that window must not be rejected so that the gas volume fraction determinations for the window are considered to occur at random.

The $t$-test (described above) used to evaluate the regression slope requires that several assumptions be met. These assumptions can be explained based on the residuals (observed minus predicted values) from the regressions. The residuals should be independent with respect to the $x_{i}$ values. They should also be normally distributed and have the same variance at each $x_{i}$ value (homogeneity of variance). The assumptions associated with the runs up and down test are that the $y_{i}$ 's represent realizations for a continuous random variable and that relatively few ties exist among the $m$ realizations from a given window. Also, use of the asymptotic test statistic formula is generally considered appropriate if $m$ is at least 25 .

Other statistical tests and criteria could be investigated and eventually incorporated into the steadystate determination algorithm. Some methods that have been considered but are not currently implemented include the Kalman filter methodology and the nonparametric Kendall's Tau test. Kendall's Tau test is a nonparametric test on the correlation between the $x_{i}^{\prime}$ 's and corresponding $y_{i}$ 's. It is much like the test concerning the regression slope, but does not require the assumptions of normally distributed residuals and homogeneity of variance. Thus Kendall's Tau test can offer a useful backup to the $t$-tests that evaluate regression slope for cases where the necessary $t$-test assumptions may not be satisfied.

\section{E.2 Tests to Compare Mean Gas Volume Fractions}

The steady-state determination algorithm identifies steady-state intervals for the gas volume fractions (alphas) in each of the three or four $\mathrm{H}_{2} \mathrm{O}_{2}$-addition periods. The points that are used to calculate the representative (mean) alpha for each $\mathrm{H}_{2} \mathrm{O}_{2}$-rate period must be from steady-state windows that are preceded by at least three windows in sequence that were also steady-state. This criterion helps to ensure a stable steady state. The criterion may be met by more than one set of alpha points in a given $\mathrm{H}_{2} \mathrm{O}_{2}$ addition period, with the different sets of points separated by periods of non-steady-state behavior. This potentially raises the question of whether more than one steady-state might be found. To resolve this, a further constraint is placed on the alpha points that are used in the mean. They must be from the last continuous set of points in the $\mathrm{H}_{2} \mathrm{O}_{2}$ addition period, and must be within the last hour of the period. This constraint is based on process context; the longer the $\mathrm{H}_{2} \mathrm{O}_{2}$ rate has been set at a given rate, the closer to steady state the gas fraction will have come. Therefore, the steady-state data at the end of a $\mathrm{H}_{2} \mathrm{O}_{2}$ rate period are preferentially selected.

The qualifying alpha data in the intervals at non-zero $\mathrm{H}_{2} \mathrm{O}_{2}$ flow rates are then compared to the data in the initial steady-state interval representing the alpha- 0 condition (zero $\mathrm{H}_{2} \mathrm{O}_{2}$ flow). Hypothesis tests are conducted with the null hypothesis that the mean gas volume fraction for the $i^{\text {th }}$ steady-state interval (representing the alpha- $i$ period for gas volume fractions when $\mathrm{H}_{2} \mathrm{O}_{2}$ is present) equals the mean gas volume fraction for alpha- 0 . The alternative hypothesis for these tests is that the mean gas volume fraction for the $i^{\text {th }}$ steady-state interval does not equal the mean gas volume fraction for alpha- 0 . The test statistic for these tests is 


$$
t_{i}=\frac{\left(\bar{x}_{i}-\bar{x}_{0}\right)-D_{0}}{S D\left(\bar{x}_{i}-\bar{x}_{0}\right)}
$$

where $\bar{x}_{i}$ denotes the mean gas volume for the $i^{\text {th }}$ steady-state interval, $\bar{x}_{0}$ is the mean gas volume for the alpha-0 period, $D_{0}$ is the difference according to the null hypothesis between the mean gas volume fraction for the $i^{\text {th }}$ steady-state interval, and the mean gas volume fraction for the alpha- 0 phase (so $D_{0}-0$ ), and $S D\left(\bar{x}_{i}-\bar{x}_{0}\right)$ is the standard deviation of $\bar{x}_{i}-\bar{x}_{0}$. The formula used to estimate $S D\left(\bar{x}_{i}-\bar{x}_{0}\right)$ is

$$
S D\left(\bar{x}_{i}-\bar{x}_{0}\right)=\sqrt{\frac{s_{i}^{2}}{n_{i}}+\frac{s_{0}^{2}}{n_{0}}}
$$

where $s_{i}^{2}$ is the estimated variance among the $n_{i}$ data points from the $i^{\text {th }}$ steady-state interval, and $s_{0}^{2}$ is the estimated variance among the $n_{0}$ data points from the alpha- 0 steady-state interval. Thus, the test statistic formula can be written as

$$
t_{i}=\frac{\left(\bar{x}_{i}-\bar{x}_{0}\right)-D_{0}}{\sqrt{\frac{s_{i}^{2}}{n_{i}}+\frac{s_{0}^{2}}{n_{0}}}}
$$

Once the test statistic values are calculated for the different steady-state intervals, an observed significance value ( $p$-value) is determined for each $t_{i}$ based on a Student's $t$-distribution with $v_{i}$ degrees of freedom. The degrees of freedom, $v_{i}$, are determined using the approximation

$$
v_{i} \approx \frac{\left[\frac{s_{i}^{2}}{n_{i}}+\frac{s_{0}^{2}}{n_{0}}\right]^{2}}{\frac{\left[\frac{s_{i}^{2}}{n_{i}}\right]^{2}}{\left(n_{i}-1\right)}+\frac{\left[\frac{s_{0}^{2}}{n_{0}}\right]^{2}}{\left(n_{0}-1\right)}}
$$

This approach to testing the null hypothesis that two means are equal is known as the Behrens-Fisher problem (Bain and Engelhardt 1992). The $p$-values associated with these tests are the probabilities of obtaining test statistic values $t_{i}$ more extreme (farther from zero) than those calculated for the different tests if the null hypotheses were actually true. For each test comparing mean gas volume fraction for the $i^{\text {th }}$ steady-state interval to the mean gas volume of the alpha- 0 period, the null hypothesis is rejected if the corresponding $p$-value is less than a specified significance level, typically 0.05 . If the null hypothesis is rejected for the test comparing mean gas volume fractions from the alpha- $i$ period and the alpha- 0 period, then the gas volume fraction for the alpha- $i$ period is considered to be significantly different from that of the alpha-0 period.

The $t$-tests to compare mean gas volume fraction for the $i^{\text {th }}$ steady-state interval to the mean gas volume for the alpha-0 period require the assumption that the gas volume fraction determinations $\left(y_{i}\right.$ 's) 
form the different steady-state intervals have approximately normal distributions. However, the BehrensFisher approach to these tests does not require that the variances for gas volume fractions from the different steady-state intervals are equal. Similar $t$-test methods exist that do require the assumption of equal variances, $\sigma_{i}^{2}=\sigma_{0}^{2}$, and could be used here. Thus, the Behrens-Fisher approach is considered a more general approach for conducting these $t$-tests.

\section{E.3 Scaling Basis Uncertainties}

The statistical methods used to estimate the scaling-basis curve-fit uncertainties are essentially those presented in Section 4.4.3 of Stewart et al. (2006), though some notation has been changed since that report. The development is repeated here for convenience and applied to the data sets for 30-Pa AZ-101 simulant with AFA and 30-Pa clay simulant that are described in Section 5.

\section{E.3.1 Curve Fit Parameters and Corresponding Uncertainties}

If the functional relationship between the measured retained-gas volume fraction, $\alpha_{G}$, and the gasgeneration superficial velocity, $U_{G S}$, is assumed to be the power law

$$
\alpha_{G}=r_{1} U_{G S}^{r_{2}}
$$

then the parameters $r_{1}$ and $r_{2}$, along with corresponding standard errors $\sigma_{r l}$ and $\sigma_{r 2}$, can be estimated after converting the power function to a linear function via a natural logarithm transformation. Applying a natural logarithm to Eq. (E.11) yields

$$
\ln \alpha_{G}=\ln r_{1}+r_{2} \ln U_{G S}
$$

Substituting $y=\ln \alpha_{G}, R_{l}=\ln r_{l}$, and $x=\ln U_{G S}$ simplifies Eq. (E.12) to the standard linear equation

$$
y=R_{1}+r_{2} x
$$

Assuming that the errors (measured minus predicted $y$-values in log-transformed units) obtained using Eq. (E.13) are normally and independently distributed with the same variance at each $x$-value, commonly used least-squares regression equations are available for estimating $R_{1}, r_{2}, \sigma_{r l}$, and $\sigma_{r 2}$. These simple linear regression equations are

$$
\begin{gathered}
r_{2}=\frac{\sum_{i=1}^{n}\left(x_{i}-\bar{x}\right)\left(y_{i}-\bar{y}\right)}{\sum_{i=1}^{n}\left(x_{i}-\bar{x}\right)^{2}} \\
R_{1}=\bar{y}-r_{2} \bar{x}
\end{gathered}
$$




$$
\begin{gathered}
\sigma_{R 1}=\sqrt{\frac{\sum_{i=1}^{n}\left(y_{i}-\hat{y}_{i}\right)^{2}}{n-2}\left[\frac{1}{n}+\frac{\bar{x}^{2}}{\sum_{i=1}^{n}\left(x_{i}-\bar{x}\right)^{2}}\right]} \\
\sigma_{r 2}=\sqrt{\frac{\sum_{i=1}^{n}\left(y_{i}-\hat{y}_{i}\right)^{2}}{(n-2) \sum_{i=1}^{n}\left(x_{i}-\bar{x}\right)^{2}}}
\end{gathered}
$$

In Eq. (E.14) through (E.17), $\bar{x}$ is the mean of the $x$-values, $\bar{y}$ is the mean of the $y$-values, and $\hat{y}_{i}$ is the predicted $y$-value obtained using Eq. (E.13) and a given $x$-value, $x_{i}$. Exponentiating the estimate of $R_{l}$ yields an estimate of $r_{1}$

$$
r_{1}=\exp \left(R_{1}\right)=e^{R_{1}}
$$

Error propagation methods can be applied to the relationship $R_{1}=\ln r_{l}$ to obtain a formula with which to approximate the standard error in $r_{i}$;

$$
\sigma_{r 1} \approx r_{1} \sigma_{R 1}
$$

\section{E.3.2 Prediction Intervals Associated with Curve Fits}

The uncertainty in the individual fit parameters does not describe the overall uncertainty in using the results of a least-squares fit to predict values of the dependent variable. Instead, a prediction interval is used based on the $\mathrm{T}$ distribution and the variance of the data on which the fit is based. If the linear fit described by Eq. (E.13) is used to predict a future value $y_{F}$ from a given $x_{F}$, the prediction interval for $y_{F}$ is stated as $y_{F} \pm \sigma_{y}$ where $\sigma_{y}$ is defined as follows (Rencher 2000):

$$
\sigma_{y}=t_{C L, n-2} S \sqrt{1+\frac{1}{n}+\frac{\left(x_{F}-\bar{x}\right)^{2}}{\sum_{i=1}^{n}\left(x_{i}-\bar{x}\right)^{2}}}
$$

where

$\mathrm{t}_{\mathrm{CL}, \mathrm{n}-2}=$ value of the inverse $\mathrm{T}$ distribution for given 2-tail probability (i.e., $C L$ represents a combined "tail" of 0.05 for $95 \%$ confidence) and n-2 degrees of freedom. ${ }^{\text {(a) }}$

$\mathrm{S}=$ the square root of the variance of the fit expressed as

(a) The inverse T distribution is evaluated with the function TINV in Microsoft Excel. 


$$
S=\sqrt{\frac{\sum_{i=1}^{n}\left(y_{i}-\hat{y}_{i}\right)^{2}}{(n-2)}}
$$

Inverting the substitution $y=\ln \alpha_{G}$, the prediction interval at a confidence level of (1-CL) for the gas volume fraction computed using the power fit $\alpha_{G}=r_{1} U_{G S}^{r_{2}}$ can be written as

$$
e^{y_{F}-\sigma_{y}}<\alpha_{G}<e^{y_{F}+\sigma_{y}}
$$

where $y=\ln r_{1}+r_{2} \ln U_{G S}$.

\section{E.3.3 Results}

For the work described in this report, equations of the form given by Eq. (E.13) were fit for both the 30-Pa AZ-101 simulant with AFA and the 30-Pa clay simulant. The data for each simulant were drawn from the data for 1/cycle retained-gas fraction and generated-gas superficial velocity in all three $\mathrm{H}_{2} \mathrm{O}_{2}$ injection rates in sequences 2 and 3 of the run with 30-Pa AZ-101 simulant with AFA, and all three sequences of the run with 30-Pa clay simulant. Data were taken only from the qualifying steady-state time intervals at the end of each $\mathrm{H}_{2} \mathrm{O}_{2}$-rate period, as was described in Section E.26.

For these fits, the $x$-values were the natural logarithms of the mean gas-generation superficial velocities for each gas-generation rate. The $y$-values were the natural logarithms of the corresponding mean retained-gas volume fractions. For each qualifying interval, the total gas volume fractions (total including sparge gas fraction as well as retained) were converted to retained-gas fraction by subtracting the mean gas volume fraction from the period before $\mathrm{H}_{2} \mathrm{O}_{2}$ injection, when only sparge gas inventory was present. These retained gas volume fractions were then averaged, and the natural logarithm transformation was applied to the resulting means. Table E. 1 contains the $x$-values and corresponding $y$ values used to generate the linear fits described in Eq. (E.13).

Table E.1. Data Used to Generate Linear Fits

\begin{tabular}{|l|l|l|l|}
\hline \multicolumn{2}{|c|}{$\begin{array}{c}\text { 30-Pa AZ-101 } \\
\text { Simulant with AFA }\end{array}$} & \multicolumn{2}{c|}{ 30-Pa Clay Simulant } \\
\hline x-values & y-values & x-values & y-values \\
\hline-3.775759 & -4.905197 & -3.539724 & -5.597257 \\
\hline-3.091279 & -4.453044 & -3.072731 & -5.032980 \\
\hline-2.410185 & -4.099552 & -2.394924 & -4.391221 \\
\hline-3.783206 & -4.750393 & -3.761284 & -5.287496 \\
\hline-3.095718 & -4.308661 & -3.086120 & -4.839123 \\
\hline-2.409341 & -4.019456 & -2.395623 & -4.515204 \\
\hline & -3.753280 & -5.468806 \\
\cline { 3 - 4 } & & -3.083251 & -5.215110 \\
\cline { 3 - 4 } & & -2.339905 & -4.268521 \\
\hline
\end{tabular}


The curve-fit parameters given below differ slightly from those used for the scaling basis in Section 5.4. In this section, the average superficial velocities are based solely on the $1 /$ cycle $\mathrm{H}_{2} \mathrm{O}_{2}$ injection rates measured during qualifying steady-state intervals. In Section 5.3.4, all the $1 /$ cycle $\mathrm{H}_{2} \mathrm{O}_{2}$ injection rates for each injection-rate interval were averaged. The two types of averages were always within $5 \%$, and usually within $1 \%$, of each other.

Applying Eq. (E.13) to the data for 30-Pa AZ-101 simulant with AFA, as given in Table E.1, resulted in a linear fit having an R-squared value of 0.9489 and a root mean squared error value of 0.0891 . The closeness of the R-squared value to 1.0 suggests that the linear fit is quite adequate for these data. Because the regression was conducted using logarithmically transformed data, the root mean squared error can be viewed as an approximation of the relative standard deviation for mean retained gas volume fractions in the original units (volume fraction). That is, the relative uncertainty associated with mean retained gas volume fractions for the AZ-101 simulant with AFA is approximately 9\%. The same approach, applied to the 30-Pa clay data, in Table E.1 resulted in a linear fit having an R-squared value of 0.8802. Again, the R-squared value is fairly close to 1.0, suggesting that the linear fit is reasonably adequate for the clay data. Parameter estimates and corresponding standard error estimates obtained using Eq. (E.14) through (E.19) are summarized in Table E.2 for fits obtained using the data for both types of 30-Pa simulant.

Table E.2. Estimates of Parameters and Corresponding Standard Error ${ }^{(a)}$

\begin{tabular}{|c|c|c|}
\hline \multicolumn{3}{|c|}{ 30-Pa AZ-101 Simulant with AFA } \\
\hline Parameter & Parameter Estimate & Standard Error Estimate \\
\hline $\mathrm{R}_{1}$ & -2.6884 & 0.2045 \\
\hline $\mathrm{r}_{2}$ & 0.5605 & 0.0650 \\
\hline $\mathrm{r}_{1}$ & 0.0680 & 0.0139 \\
\hline \multicolumn{3}{|c|}{ 30-Pa Clay Simulant } \\
\hline Parameter & Parameter Estimate & Standard Error Estimate \\
\hline $\mathrm{R}_{1}$ & -2.5435 & 0.3418 \\
\hline $\mathrm{r}_{2}$ & 0.7921 & 0.1104 \\
\hline $\mathrm{r}_{1}$ & 0.0786 & 0.0269 \\
\hline \multicolumn{3}{|c|}{$\begin{array}{l}\text { (a) The correlation equation is } \alpha_{G}=r_{1} U_{G S}^{r_{2}} \cdot U_{G S} \text { is in units of } \mathrm{mm} / \mathrm{s} \text { and } \\
\alpha_{G} \text { is in units of gas volume fraction (not vol\% as in Section 5.4). }\end{array}$} \\
\hline
\end{tabular}

Using the linear fit from the data for AZ-101 simulant with AFA, Eq. (E.20) through (E.22) can calculate prediction intervals at a specified $x$-value. For example, to calculate a $95 \%$ prediction interval associated with a superficial velocity of $0.05 \mathrm{~mm} / \mathrm{s}$, the $x$-value would be $\ln (0.05)=-3.00$. The corresponding predicted $y$-value is $\hat{y}=-4.37$. The $95 \%$ prediction interval lower and upper limits are -4.64 and -4.10 , respectively. Exponentiation gives the predicted values for the retained gas volume fraction associated with gas-generation superficial velocity of $0.05 \mathrm{~mm} / \mathrm{s}$ and the corresponding prediction interval limits in the original units (of gas volume fraction). The resulting values are $\hat{\alpha}_{G}=0.0127$ volume fraction, with lower and upper $95 \%$ prediction interval limits of 0.0097 and 0.0166 , respectively. 
In the example calculations given above, a gas-generation superficial velocity of $0.05 \mathrm{~mm} / \mathrm{s}$ was chosen because it is clearly within the range of values available in the dataset. Thus, methods used to calculate the predicted retained gas volume fraction and corresponding prediction interval are considered valid when applied to a superficial velocity of $0.05 \mathrm{~mm} / \mathrm{s}$. Applying these methods to superficial velocities outside the range represented in the dataset would be an extrapolation. Extrapolation, particularly to values well beyond the range of values represented in the dataset used to generate the linear fit, may contain higher uncertainty than that given by the prediction interval.

Extrapolation is necessarily based on the assumption that the functional relationship (approximated by the regression equation) remains the same even at levels of variables where extrapolation is applied. Furthermore, it must be assumed that the variance structure remains the same throughout the range represented by the extrapolation. These are critical assumptions, and without having data at variable levels where the extrapolation is to be conducted, there is no way of verifying that these assumptions are well founded. The uncertainty represented in calculations such as prediction intervals assume that the necessary assumptions are satisfied. Because these assumptions cannot be verified, actual uncertainty may be greater but cannot be quantified.

If the model based on 30-Pa AZ-101 simulant with AFA were to be extrapolated to a gas-generation superficial velocity of $0.0001 \mathrm{~mm} / \mathrm{s}$, a typical value during plant operations, the $x$-value to use would be $\ln (0.0001)=-9.21$. The corresponding predicted $y$-value is $\hat{y}=-7.85$. The resulting $95 \%$ prediction interval lower and upper limits are -8.99 and -6.71 , respectively. Exponentiation produces predicted values for the retained gas volume fraction associated with a superficial velocity of $0.0001 \mathrm{~mm} / \mathrm{s}$, and corresponding prediction interval limits in the original units of gas volume fraction. The resulting values are $\hat{\alpha}_{G}=0.0004$, with lower and upper $95 \%$ prediction interval limits of 0.0001 and 0.0012 , respectively.

\section{E.4 References}

Bain LJ and M Engelhardt. 1992. Introduction to Probability and Mathematical Statistics. PWS-Kent, Boston.

Gibbons JD. 1985. Nonparametric Methods for Quantitative Analysis, $2^{\text {nd }}$ Edition. American Sciences Press, Inc., Columbus, Ohio.

Hines WW and DC Montgomery. 1990. Probability and Statistics in Engineering and Management Science. John Wiley \& Sons, New York.

Rencher AC. 2000. Linear Models in Statistics. John Wiley \& Sons, New York. 
PNNL-17170

WTP-RPT-156, Rev 0

\section{Distribution}

No. of

Copies

OFFSITE

1 Savannah River National Laboratory

Richard Edwards

Savannah River National Laboratory

Westinghouse SA

Aiken, SC 29808-0001
No. of

Copies

ONSITE

4 Pacific Northwest National Laboratory

C. E. Guzman-Leong K5-22

D. E. Kurath P7-28

Project Office (2) P7-28

2 Bechtel National, Inc.

V. J. Guynes (2) H4-02

Distr. 1 